\title{
VV.AA.
}

\section{Comunicación y Música: mensajes, manifestaciones y negocios}

Javier Herrero, Milena Trenta (Coords.)

Editores: Vanessa Rodríguez Breijo, Samuel Toledano Buendía, Ciro Hernández, Alberto Ardèvol Abreu

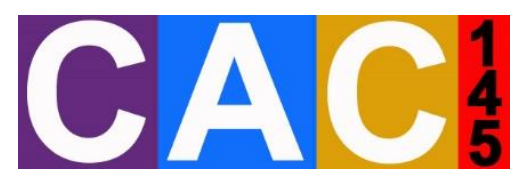

Cuadernos Artesanos de Comunicación / 145

ULL

Universidad de La Laguna

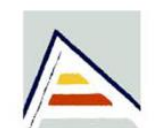

Universitat d'Alacant Universidad de Alicante

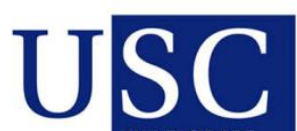

UNIVERSIDADE

DE SANTIAGO DE COMPOSTELA

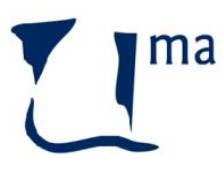

UNIVERSIDAD $D E M A L A G A$

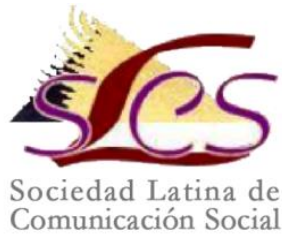




\section{CAC 128 - Comunicación y Música: mensajes, manifestaciones y negocios}

Javier Herrero, Milena Trenta (Coords.)

VV.AA.

Editores: Vanessa Rodríguez Breijo, Samuel Toledano Buendía, Ciro Hernández, Alberto Ardèvol Abreu

Diseño: F. Drago

Ilustración de portada: Fragmento del cuadro "Mujer de Fuenteventura", de Vale (Bolonia).

Imprime y distribuye: F. Drago. Andocopias S.L.

c/ La Hornera, 41. La Laguna. Tenerife.

Teléfono: 922250554 | fotocopiasdrago@telefonica.net

Edita: Sociedad Latina de Comunicación Social - edición no venal La Laguna (Tenerife), 2018 - Creative Commons * (http://www.revistalatinacs.org/09/Sociedad/estatutos.html)

Catálogo $=\underline{\text { http: } / / \text { www.cuadernosartesanos.org }}$

Protocolo de envío de manuscritos con destino a CAC:

http://www.cuadernosartesanos/protocolo.html

Descargar el $p d f$ :

http://www.cuadernosartesanos.org/\#145

ISBN: 978-84-16458-94-3

D.L.: TF- 800-2018

DOI: $10.4185 / \mathrm{CAC} 145$ 


\title{
VV. AA. \\ Cuadernos Artesanos de Comunicación \\ Coordinador editorial: José Manuel de Pablos - jpablos@,ull.edu.es \\ Comité Científico \\ Presidencia: José Luis Piñuel Raigada (UCM) \\ Secretaría: Milena Trenta (ULL)
}

- Octavio Islas (Unversidad de los Hemisferios, Ecuador)

- Ramón Zallo (Universidad del País Vasco, UPV-EHU)

- Núria Almiron (Universidad Pompeu Fabra, UPF)

- Francisco Campos Freire (Unioversidad de Santoiago de Compostela)

- José Cisneros (Benemérita Universidad Autónoma de Puebla, BUAP)

- Bernardo Díaz Nosty (Universidad de Málaga, UMA)

- Carlos Elías (Universidad Carlos III de Madrid, UC3M)

- Paulina B. Emanuelli (Universidad Nacional de Córdoba, UNC)

- José Luis González Esteban (Universitas Miguel Hernández de Elche, UMH)

- Marisa Humanes (Universidad Rey Juan Carlos, URJC)

- Juan José Igartua (Universidad de Salamanca, USAL)

- Xosé López (Universidad de Santiago de Compostela)

- Maricela López-Ornelas (Universidad Autónoma de Baja California, AUBC)

- Javier Marzal (Universidad Jaume I, UJI)

- José Antonio Meyer (Benemérita Universidad Autónoma de Puebla, BUAP)

- Ramón Reig (Universidad de Sevilla, US)

- Miquel Rodrigo Alsina (Universidad Pompeu Fabra, UPF)

- Xosé Soengas (Universidad de Santiago de Compostela)

- José Luis Terrón (Universidad Autónoma de Barcelona, UAB)

- José Miguel Túñez (Universidad de Santiago, USC)

- Victoria Tur (Universidad de Alicante, UA)

- Miguel Vicente (Universidad de Valladolid, UVA)

\begin{abstract}
* Queda expresamente autorizada la reproducción total o parcial de los textos publicados en este libro, en cualquier formato o soporte imaginables, salvo por explícita voluntad en contra del autor o autora o en caso de ediciones con ánimo de lucro. Las publicaciones donde se incluyan textos de esta publicación serán ediciones no comerciales y han de estar igualmente acogidas a Creative Commons. Harán constar esta licencia y el carácter no venal de la

publicación.

(c) (†) $\circledast$ Este libro y cada uno de los capítulos que contiene, así como las (CY NO No imágenes incluidas, si no se indica lo contrario, se encuentran bajo una Licencia Creative Commons Atribución-No Comercial-Sin Derivadas 3.0 Unported. Puede ver una copia de esta licencia en http://creativecommons.org/licenses/by-nc-nd/3.0/ Esto significa que Ud. es libre de reproducir y distribuir esta obra, siempre que cite la autoría, que no se use con fines comerciales o lucrativos y que no haga ninguna obra derivada. Si quiere hacer alguna de las cosas que aparecen como no permitidas, contacte con los coordinadores del libro o con el autor del capítulo correspondiente.
\end{abstract}

* La responsabilidad de cada texto es de su autor o autora. 


\title{
Comunicación y Música: mensajes, manifestaciones y negocios
}

\begin{abstract}
Los acontecimientos políticos y electorales acontecidos durante los meses que preceden a este IX Congreso Internacional Latina de Comunicación Social nos permiten reflexionar sobre las transformaciones surgidas en las formas de hacer política y los discursos que la acompañan.
\end{abstract}

El desplazamiento, las apropiaciones de los presupuestos y de los valores tradicionales presentes en el discurso del "otro político", y las diferentes maneras de construir el propio sobre ese postulado, son objeto de esta intervención.

Los enunciados y acciones derivados son tomados en consideración con la pretensión de evidenciar los medios utilizados, las estrategias presentes en dichas apropiaciones, así como, los valores usurpados para mostrar las fortalezas y debilidades presentes en el contemporáneo arte de hacer política y sus mediatizaciones, la cuales posibilitan una respuesta inmediata gracias, entre otros elementos, a las redes sociales en las que los políticos han asentado su vinculación y enlace con sus seguidores, o sus oponentes, en ese nuevo espacio público que es la Sociedad del Conocimiento o Sociedad Red y los instrumentos de comunicación que ésta provee para la difusión y la circulación de las ideas que desemboquen en construcciones simbólicas que se quieren compartir o imponer para, en definitiva, persuadir, convencer $\mathrm{O}$ conquistar.

\section{Keywords}

periodismo, comunicación audiovisual, política, elecciones, discursos, valores, medio, estrategias, mediatizaciones, redes sociales, sociedad del conocimiento, sociedad red, construcciones simbólicas.

\section{Forma de citar este libro}

Autor capítulo (2018): Comunicación y Música: mensajes, manifestaciones y negocios. VV. AA. Cuadernos Artesanos de Comunicación, 145. La Laguna (Tenerife): Latina. 


\section{Comunicación y Música: mensajes, manifestaciones y negocios}

001 - El paisaje: creación y contemplación - Francisco

Covarrubias Villa - Instituto Politécnico Nacional pancheco@prodigy.net.mx y Ma. Guadalupe Cruz Navarro Instituto Politécnico Nacional - lupitacruz63@hotmail.com

El paisaje es un constructo subjetivo territorial constituido con referentes artísticos y es un objeto de arte en el que se alude un territorio. La percepción de lo bello es una facultad humana desplegada por la incorporación de referentes a la conciencia, los cuales provienen de la sociedad en la que el sujeto se constituye, de ahí que la apropiación del territorio y el eventual establecimiento de una experiencia estética con él, estén determinados por la estructura de la conciencia del sujeto. La obra de arte es la realización de la idea de lo bello en lo concreto y la expresión máxima de la experiencia estética lograda por la forma artística de la conciencia, en tanto que la experiencia paisajística contemplativa es posible en las formas de conciencia empírica, mágicoreligiosa y teórica, pero sin alcanzar su plenitud como arte. La apropiación paisajística contemplativa está siendo envilecida por la conversión de los territorios bellos en mercancía, preestableciendo de manera estandarizada los sentimientos y las emociones generadas por el consumo del producto.

002 - Deporte, comunicación y nacionalismo: estado de la cuestión y propuesta metodológica para examinar grandes eventos deportivos - Victor Hasbani Kermanchahi Universitat Pompeu Fabra - victor.hasbani@upf.edu

El periodismo deportivo se ha visto implicado en los últimos 50 años con la construcción de discursos que trascienden el ámbito del deporte. En ellos se involucran aspectos de primer orden como el género, la raza y la formación de la identidad nacional. 
Una parte fundamental del nacionalismo aplicado a la comunicación deportiva ha sido la construcción, a través de la cobertura mediática, de héroes o iconos deportivos nacionales que tienen la capacidad de arrastrar la afición. La historia nos brinda múltiples casos significativos: el triunfo estadounidense en Lake Placid contra la URSS en hockey sobre hielo en plena Guerra Fría; los enfrentamientos sobre el tablero de ajedrez entre Spassky y Fischer; o la hazaña en las barras paralelas de Nadia Comaneci usada por Ceausescu para legitimar la causa rumana. También cabe destacar el tratamiento mediático de eventos que han servido como escaparate a un determinado país, como "El rugido en la selva", el combate entre Foreman y Ali que albergó Zaire en 1974 bajo los deseos de Mobutu.

Con el objetivo de ahondar en este ámbito, esta comunicación (1) ofrece una revisión sistemática de la literatura sobre la intersección entre deporte, comunicación y nacionalismo; y (2) propone un diseño metodológico (sistema de categorías y base de datos) para realizar un análisis del contenido sobre la cuestión en medios de comunicación de múltiples soportes (prensa escrita, medios online y televisión). Esta herramienta puede ser de gran utilidad para investigaciones presentes y futuras sobre la cobertura de grandes eventos deportivos. Se señala la aplicación específica de esta propuesta para el trabajo La representación de los éxitos del deporte cubano en la prensa de referencia de España, Estados Unidos y Cuba, un proyecto que aborda el tratamiento mediático de esta cuestión desde los Juegos Olímpicos de Montreal 1976 hasta Rio 2016.

003 - Ideología lingüística en artículos de opinión: el caso de la identidad y el género - M. Belén Alvarado Ortega - Grupo GRIALE - Universidad de Alicante - belen.alvarado@ua.es

El trabajo que presentamos pretende analizar diferentes artículos de opinión, publicados en la prensa española actual, que contienen procedimientos lingüísticos concretos que sirven para definir la identidad y la ideología del autor. Este hecho va a permitir realizar un estudio de las estrategias argumentativas que utilizan los autores para mostrar su ideología lingüística, a la vez que definen su identidad de género, a través de sus textos de opinión. 
Para llevar a cabo nuestro objetivo utilizaremos textos extraídos de la prensa escrita española en los que se debate el sexismo lingǘstico, a los que les aplicaremos procedimientos pragmáticos como la Teoría de la Argumentación de Anscombre y Ducrot ([1983] 1998), que se basa en el estudio de los medios formales de los que dispone la lengua para organizar de forma argumentativa sus enunciados y para que estos sean interpretados del mismo modo por el lector. Con este análisis intentamos demostrar que los encadenamientos argumentativos que introducen una conclusión dependen de la estructura lingüística de los enunciados y de la identidad de género de los autores que se manifiesta en ellos.

Sobre la identidad de género nos basamos en los trabajos de Hay (2000), Santaemilla (2002), Mills (2005), Kotthoff (2006), y Suderland y Litosseliti (2002), que desarrollan la identidad de género en el análisis del discurso.

04 - Viejitos en Red: la interacción en el ciberespacio de los adultos mayores a través de WhatsApp - Gonzalo Ordóñez Revelo -Universidad Andina Simón Bolivar Sede Ecuador-, okemampa@yahoo.es.

El concepto de nativos digitales perdió actualidad. Se puede decir que la migración digital culminó, ahora todos somos ciudadanos de la Sociedad de la Información, lo cual es particularmente visible en el caso de los adultos mayores cada vez más integrados al ciberespacio. El uso del chat con los cercanos: hijos, nietos, amigos, parejas parece extenderse e incorporarse como parte de sus modos de interacción. La renovación constante de los celulares por las nuevas generaciones creó una práctica que podría ser generalizada: la herencia de los teléfonos, a las viejas generaciones.

¿Cómo se articula el uso del chat en los modos de interacción en los adultos mayores? ¿Cómo influye el uso del celular inteligente en el grado de comunicación con sus personas cercanas, particularmente a través del WhatsApp? 
No sabemos suficiente de cómo y cuándo "los viejitos" se integraron a los nuevos medios, cuál es el nivel de uso de los dispositivos móviles y con qué fines.

Tampoco sabemos acerca de si la interacción en el ciberespacio incrementó el nivel de relación y encuentro cara a cara con sus familiares y con sus amigos. Mucho menos acerca de si estas tecnologías estimulan relaciones emocionales o modificaron su intimidad.

En cualquier caso, un eje importante de comunicación parece ser el Chat, por lo que nos enfocamos en este medio, con el fin de conocer como se integra el uso del Chat, a través de WhatsApp, en la interacción cara a cara.

Se efectuó una investigación descriptiva con adultos de Quito, ligados a programas del Instituto Ecuatoriano de Seguridad Social (IESS) y del grupo "60 y piquito del Centro del Adulto Mayor (CEAM) del sur de Quito".

005 - Evolución de la narrativa audiovisual en la serie de documentales Héroes Invisibles - Víctor Cerdán Martínez Universidad Camilo José Cela - vcerdan@ucjc.edu y Daniel Villa Gracia - Universidad Complutense de Madrid daniel.villa@ccinfucm.es

Víctor Cerdán y Daniel Villa, director y jefe de postproducción de Héroes Invisibles, describen el proceso creativo de un formato televisivo para la televisión pública española. Esta serie de documentales, producida por RTVE en colaboración con Taifas Comunicación, retrata la vida de un español expatriado en el extranjero que trabaja en proyectos de ayuda humanitaria. Todos los episodios reflejan diferentes conflictos sociales, como la malnutrición infantil en África, las consecuencias de la guerra en Siria, los inmigrantes irregulares en Estados Unidos, o los rescates en el Mediterráneo Central. En este artículo, los autores analizan la evolución de un formato televisivo desde la idea original, plasmada sobre un dosier, a la 
Comunicación y Música: mensajes, manifestaciones y negocios

producción y grabación de los primeros capítulos en comparación con los de la segunda temporada. El objetivo principal es reflexionar sobre la evolución de la narrativa audiovisual de Héroes Invisibles a lo largo de casi tres años.

Para este cometido, los autores emplearán fragmentos de los 16 capítulos de la serie, para analizar los perfiles de los personajes escogidos por la productora, los tipos de encuadres, la estructura del guión, el montaje, la postproducción de sonido y color, y la selección de localizaciones. También aportarán documentos sobre el proceso de producción, grabación y postproducción para valorar los aspectos más significantes de la evolución de este formato televisivo que han seguido miles de personas desde su estreno en la 2 de TVE.

006 - Narrativa documental en The act of killing y The look of silence - Víctor Cerdán Martínez - Universidad Camilo José Cela - vcerdan@ucjc.edu

Tras el golpe militar de 1965, el general Suharto ocupó el poder en Indonesia. A partir de ahí empezaron los asesinatos de miles de comunistas por los escuadrones de la muerte. Joshua Oppenheimer y Christine Cynn les proponen a los responsables de estos crímenes que recreen sus horribles fechorías en una película protagonizada por ellos mismos: The act of Killing. Mientras Joshua Oppenheimer rodaba la citada película conoció a una familia de supervivientes que descubre, gracias a los cineastas, cómo fue asesinado su hijo y decide enfrentarse a los asesinos en un país donde estos siguen en el poder. Este es el argumento de

The look of silence, la segunda película de Oppenheimer, rodada esta vez desde el punto de vista opuesto. El objetivo principal de este artículo es realizar un análisis de la narrativa audiovisual de ambas películas desde las teorías de David Bordwell, Noel Burch y Robert McKee. Asimismo, resaltar los límites entre la ficción y el documental en estos dos filmes de culto del siglo XXI. 
007 - La movilización feminista del 8 de marzo, a través del lenguaje metafórico de los discursos mediáticos - José Luis Martín Sáez - Universidad Rey Juan Carlos joseluis.martin.saez@urjc.es, Yolanda Ortiz de Guinea Ayala Universidad Rey Juan Carlos yolanda.ortizdeguinea.ayala@urjc.es

El pasado 8 de marzo, Día Internacional de la Mujer, la tradicional manifestación que conmemora dicha fecha sirvió de colofón a una jornada de huelga. La primera huelga feminista que ha tenido lugar en España. Una jornada que, ya desde días antes de su celebración, acaparó, podríamos decir que cuasi por sorpresa, tiempo y espacio en los distintos medios de comunicación. Y no solo de nuestro país sino también más allá de nuestras fronteras. Porque de las manifestaciones celebradas ese día en España se hicieron eco importantes y reputados medios extranjeros.

Por esta razón, en este trabajo, queremos investigar cómo contaron dicho acontecimiento los medios españoles escritos más importantes, haciendo un análisis socio-metafórico del lenguaje utilizado por los mismos. $\mathrm{Y}$ es que las metáforas no son simplemente un recurso retórico del discurso, que sirven para embellecer un relato. Porque las metáforas, más allá de lo que acabamos de comentar, organizan, estructuran, conforman los relatos (Lizcano, 1999). Unas metáforas que serían reflejo de cómo los medios de comunicación utilizan el lenguaje como generador de realidad.

Un lenguaje impregnado de ideología, en este caso, a través de la elaboración metafórica (Millán y Narotzky, 2012), que generaría una realidad, la de la jornada feminista del 8 de marzo, a partir de las metáforas empleadas por los diferentes medios en sus respectivos discursos. Discursos que implican la selección de unas metáforas y el descarte de otras. Discursos que generan una determinada realidad de género, en detrimento de otras. Sobre la metáfora nos basaremos fundamentalmente en los trabajos de Lizcano (1999) y Bustos (2014). 
Comunicación y Música: mensajes, manifestaciones y negocios

008 - La importancia de las redes profesionales ante el nuevo perfil académico digital del investigador en la Universidad Autónoma de Baja California - Maricela López Ornelasornelas@uabc.edu.mx; Javier Organista Sandoval javor@uabc.edu.mx y Katiuska Fernández Morales, Instituto de Investigación y Desarrollo Educativo, Universidad Autónoma de Baja California, México- katiuska.fernandez@uabc.edu.mx

Con la creciente llegada, incorporación y posicionamiento del movimiento de acceso abierto, los investigadores de diversas disciplinas se han visto en la necesidad, no solo de sumarse a esta iniciativa al preferir revistas que además de estar indexadas en importantes bases de datos, ofrezcan de manera libre su conocimiento a la comunidad en general, sino que paralelamente, han necesitado desarrollar competencias digitales para abrir sus perfiles académicos en bases de datos, índices, repositorios, e incluso catálogos de bibliotecas con la finalidad de obtener mayor visibilidad y difusión de sus textos científicos, pues descubren en estas prácticas, una forma de posicionarse y ser reconocidos por sus pares a nivel internacional.

En este sentido, el ser proactivo en la difusión y visibilidad de sus trabajos, incrementa la importancia de generar su identidad académica digital mediante las redes sociales, —también llamadas redes profesionales-, como Academia.edu, Google Scholar, ORCID y ResearchGate.

Para esta investigación, se optó por un diseño de corte cuantitativodescriptivo, debido a que el propósito fundamental de este método, provee de una aproximación detallada del objeto de estudio mediante la búsqueda, clasificación y análisis de los datos, determinante para "identificar el perfil académico digital de los investigadores de la Universidad Autónoma de Baja California (UABC). Entre los primeros resultados se observa que los investigadores de la UABC que promueven su identidad digital a través de la gestión en redes profesionales como las ya mencionadas, paralelamente construyen su perfil académico digital y contribuyen a elevar la visibilidad de su producción científica. 
009 - Mediatización de los debates parlamentarios en torno a los roles de la mujer y la violencia sexual - Eva Luisa Gómez, evaluisa.gomez@urjc.es; Raquel Vinader, raquel.vinader@urjc.es; Jorge Toirac,jorge.toirac@urjc.es; Beatriz Herrero-Jiménez, beatriz.herrero@urjc.es y Juana Anguita, Universidad Rey Juan Carlos, juana.anguita@urjc.es

Los temas que componen la agenda simbólica de los parlamentos pueden repercutir en la preocupación o el interés que se le da a una determinada cuestión. El fenómeno de mediatización explica que la lógica mediática haya desplazado a la política y, por tanto, que los representantes públicos busquen con su comunicación responder a las necesidades y a las reglas de los medios (Davis, 2007; Strömbäck, 2011).

No todos los temas son tan vulnerables de ser introducidos en la esfera política tras adquirir relevancia en la cobertura periodística. Por ello, esta investigación pretende revelar la presencia de los medios tradicionales y sociales como fuentes informativas en la agenda simbólica cuando se habla de la mujer y los roles que ejercen durante periodos de postconflicto, así como la presencia de la violencia sexual en los debates parlamentarios en el caso de la República Democrática del Congo - de enero 2012 a junio del 2015 -, y Burundi - de enero 2010 a junio del 2015 - . El estudio se ha llevado a cabo a través de un análisis de contenido cuantitativo automatizado de actas de debates sobre ambos postconflictos obtenidas del Parlamento europeo, británico, alemán, francés y español. Los resultados muestran que hay una presencia más baja de medios en los debates de la RDC que en Burundi, que puede ser debido a la censura y cierre de medios en el país. Por tanto, la presencia de la mujer en los debates parlamentarios, a las que se les asigna el rol de víctimas, está en relación con las ONGs como fuentes informativas, y no con los medios de comunicación. La violencia sexual como arma de guerra se debate en ambos postconflictos, destacando el Parlamento Europeo entre los otros cuatro.

Referencias Davis, A. (2007). Investigating Journalist Influences on Political Issue Agendas at Westminster. Political Communication 24(2), 181-199. 
Strömbäck, J. (2011). Mediatization of Politics: Towards a Conceptual Framework for Comparative Research. In E. P. Bucy, R. Lance Holbert (Eds.), Sourcebook for political communication research: Methods, measures, and analytical techniques (pp. 367-382). New York: Routledge.

010 - Lenguaje millennial: Uso de recursos comunicacionales en Twitter a través de una experiencia docente en la universidad española - Sergio Mena Muñoz - Universidad Complutense de Madrid - smenamun@ucm.es - Universidad Europea Miguel de Cervantes-smena@uemc.es

La red de microblog Twitter se ha convertido en un recurso de comunicación muy extendido entre usuarios, instituciones, medios de comunicación y demás actores para hacer llegar sus mensajes y para influir en la audiencia. Como tal, esa herramienta ya se enseña en la universidad desde el punto de vista comunicacional con todas sus posibilidades y limitaciones. En una iniciativa de experiencia docente en diferentes asignaturas y universidades españolas se ha visto que más allá del uso habitual que se hace de Twitter, los emisores de mensajes (en este caso, los alumnos de cada grupo) tienden a usar un conjunto de recursos específicos muy utilizados por su generación en esta y en otras redes sociales. Esta comunicación recoge de forma cuantitativa y cualitativa esos recursos comunicacionales (vídeos, memes, gifs animados, hilos, etc.) utilizados durante las diferentes experiencias realizadas, los analiza y evalúa su importancia dentro del discurso grupal narrativo en cada caso.

011 - Las redes sociales como medio para la comunicación social de la ciencia de excelencia en España - Lourdes LópezPérez - Universidad de Granada - lourdes.lpez@gmail.com, María-Dolores Olvera-Lobo y Elena Moya Molina

La implicación de los ciudadanos en el proceso científico es uno de los pilares de la nueva gobernanza de la ciencia establecida en Europa al amparo del programa Horizon 2020 (Comisión Europea, 2014) y bajo el concepto de investigación e innovación responsables (RRI, por sus 
siglas en inglés). La dimensión deliberativa y participativa de Internet facilita el desarrollo de una ciencia desarrollada con y para la sociedad.

El objetivo de la investigación que se presenta es analizar cómo la ciencia excelente usa las herramientas Web 2.0 para fomentar la participación del público en el proceso de investigación. En este contexto se entiende la participación desde la perspectiva de la investigación e innovación responsables, no sólo como la comunicación de los resultados científicos, sino también como la implicación de la sociedad en el proceso de investigación. Para llevar a cabo el análisis se ha desarrollado una herramienta adhoc validada científicamente y basada en el método Delphi. La muestra de estudio está constituida por los proyectos españoles financiados por el ERC (European Research Council) en 2015. Entre los resultados obtenidos destaca el bajo uso de las herramientas digitales. De hecho, únicamente el $23,9 \%$ de los proyectos cuenta con página web y menos de un 15\% con perfiles en redes sociales. Además, la comunicación se realiza de forma unidireccional en el $97 \%$ de los casos y se produce de arriba abajo, es decir desde la institución-responsable del proyecto hacia la sociedad. Por otro lado, esta comunicación presenta un alto nivel de especialización, de manera que en más del $80 \%$ de los casos se utiliza un lenguaje técnico y los mensajes publicados están dirigidos a los expertos.

012 - La humanización de los discursos digitales - Carlos Alberto Esparza Hernández y Adriana Padierna Beltrán Instituto Tecnológico y de Estudios Superiores de Monterrey, Campus Querétaro

La tecnología se ha vuelto parte esencial de nuestra realidad, es natural que su uso se adapte a las necesidades sociales, particularmente desde la comunicación. Los discursos contemporáneos se construyen desde una perspectiva correspondiente a una nueva necesidad de contrarrestar el decrecimiento de contacto humano. Dicha necesidad ha derivado en soluciones o tendencias en el lenguaje digital que confluyen hacia la búsqueda de humanización de las interacciones virtuales, es decir, la humanización de la comunicación digital. El presente texto pretende analizar tres fenómenos particulares. En 
Comunicación y Música: mensajes, manifestaciones y negocios

primer lugar, la deconstrucción de la escritura para dar paso a lo que se ha denominado 'texteo' ('texting') no implica un retroceso en la comunicación, sino una gramática particular para eficientar el proceso comunicativo. En segundo lugar, la tendencia parece fluir hacia una comunicación más visual, donde las imágenes y no las palabras son los elementos primordiales de la conversación. Finalmente, los discursos contemporáneos en la esfera digital tienden a la homogeneización, es decir, a la búsqueda de crear mensajes universales con un mismo símbolo. Esto luce particularmente con los llamados 'memes'.

Algunos autores han abordado estas modificaciones en el proceso comunicativo como una pérdida de riqueza en el lenguaje; sin embargo, existen otras posturas, como las de John McWorther y David Crystal que explican cómo estos cambios corresponden a una evolución del lenguaje, cuya función principal es comunicar de manera efectiva y humana. En este sentido, las nuevas tendencias de comunicación en el panorama digital únicamente son un reflejo de la búsqueda del regreso de la humanización a la esfera virtual, con el énfasis de llevar lo humano a la comunicación digital.

013 - Sentir Canario GobCan.es, un espacio de encuentro para la comunidad canaria residente en el exterior - Araceli Alvarez Díaz- Universidad de La Laguna aalvdiaw@gobiernodecanarias.org

Este trabajo pretende analizar los contenidos y el nivel de audiencia con que cuenta un proyecto de comunicación institucional que inició su andadura en el mes de julio de 2017 de la mano de la Dirección General de Emigración del Gobierno de Canarias con el objetivo de crear comunidad. Dicho proyecto denominado "Sentir Canario GobCan.es", que consta de una página de Facebook de actualización diaria y un programa de radio semanal, está dirigido principalmente a la comunidad canaria y sus descendientes que se encuentran viviendo fuera del Archipiélago. Se trata de un canal participativo en el que se da voz a los colectivos canarios que residen en el exterior a través de la publicación de contenidos relacionados con las actividades que desarrollan, tanto colectiva como individualmente. Los objetivos del estudio son analizar, por un lado, los contenidos del sitio web de 
Facebook, de actualización diaria, aunque con distintos ritmos los fines de semana; determinar cuáles son los criterios de selección de dichos contenidos, así como las fuentes; y, por otro, conocer y analizar los contenidos del programa semanal de radio, así como los niveles de audiencia.

014 - Un decálogo para investigadoras comprometidas con el acceso abierto al conocimiento - Sara Mandiá Rubal Universidade de Santiago de Compostela, USC sara.mandia.rubal@gmail.com

Unos por alcanzar mayor visibilidad y citas, y otros por un real compromiso con las formulas Open Access (OA), cada vez son más los investigadores e investigadoras que se animan a publicar en abierto. Definidos los modelos de negocio Green Route, o "vía verde", y Gold Route, o "camino de oro", el objetivo de este trabajo es proveer, a través del método descriptivo, un decálogo de cinco puntos con los que asegurar la publicación bajo las perspectivas y condicionantes del movimiento OA: "vía platino" o la situación ideal, se mantienen los controles de calidad sin condicionar el acceso a terceros; la importancia de la pre-publicación, o cómo evitar la ralentización de los procesos de investigación por la subordinación a intereses económicos de producción y promoción; publicar en cabeceras con presencia en bases de datos de divulgación en abierto -caso de Latidex o RedAlyc-, y por supuesto, en las nacionales del país en que se divulgue; la accesibilidad reflejada en diferentes puntos, y es que a menudo las desigualdades de acceso a la información no radican sólo en lo económico -a lo que ataca frontalmente el Open Access-, es importante por ejemplo la existencia de una red telefónica que permita el acceso a Internet y un ancho de banda capaz de descargar contenidos -PDF frente a HTML-, así como los dispositivos hardware de los que disponen en posibilidades diversas los distintos colectivos -siendo el smartphone el más democratizado, seguido de la tableta, y el PC-, y finalmente el grado de "alfabetización informacional" que manifieste la población que busca -a lo que el XTML responde con la descripción metadatada de los documentos, facilitando su recuperación y acceso-; y un último punto, que encierra a los anteriores, y es la presencia en SciELO de una cabecera, un 
Comunicación y Música: mensajes, manifestaciones y negocios

sistema digital que se autodefine como un modelo de publicación electrónica para países en desarrollo.

015 - Marchas de la diversidad sexual y de género en Bogotá: representaciones mediáticas y memoria - Doria Constanza Lizcano Rivera-dorialiscano@usantotomas.edu.co y Álvaro Lizarralde Díaz - Universidad Santo Tomás, Colombia alvarolizarralde@usantotomas.edu.co

El artículo tiene como objeto presentar los resultados de investigación en torno al análisis de las representaciones mediáticas en impresos bogotanos frente a las marchas de la Diversidad Sexual y de Género entre 1982 y 2017. Se trata de ejercicio de recuperación de memoria, de verificación e identificación en estas formas de movilización y accionar que, evidencian la ampliación de la democracia, el ejercicio de la ciudadanía, la instalación de acciones y discursos en torno a la exigibilidad de derechos en sectores históricamente vulnerados. El análisis de esos registros mediáticos permitió reconocer los errores de una concepción limitada de ciudadano, pero también documentar la historia de un movimiento que ha logrado ampliar la noción de ciudadano y, con ello, aplicar principios básicos de la democracia, como la igualdad de todos ante la ley y la celebración de la diferencia y la diversidad.

Desde un estudio cuantitativo, se analizaron 94 textos presentes en nueve medios que permitieron verificar asimetrías de poder, folklorización del lenguaje, generación de espacios de actuación y algunas desmitificaciones de los sectores LGBTI en esferas públicas. Así mismo, desde la etnografía se realizaron entrevistas a 17 líderes y activistas de este sector. Como parte de las conclusiones más relevantes, se puede afirmar que existe un interés y preocupación por respetar y reconocer las identidades sexuales, informar y reconocer a cada uno de los actores sociales (con marcada presencia y protagonismo de personas gay). En ese sentido, los medios siguen determinando el enfoque, sentido y lugar que dan a las personas de los sectores LGBTI. 
016 - Ideología de género y triunfo del No en el plebiscito sobre los acuerdos de La Habana, posverdad y banalización de la política - Sandra Marcela Lobo-Universidad Santo Tomás sandralobo@usantotomas.edu.co; Alexander Torres San Miguel-Universidad Santo Tomás alexandertorres@usantotomas.edu.co; Juan Carlos Córdoba Universidad Jorge Tadeo Lozano juan.cordoba@utadeo.edu.co y Virginia Canevá - Universidad de La Plata - virginia.caneva@perio.unlp.edu.ar

El artículo tiene como objetivos presentar los resultados de la investigación con respecto al manejo de la información en torno al concepto de ideología de género en los acuerdos de La Habana. Varios de estos, especialmente el punto relativo a las víctimas, incorporaron el enfoque de género, ante la realidad constatada que los conflictos armados no afectan por igual a hombres y mujeres. Desde la Segunda Guerra Mundial, hasta conflictos más recientes, como los del Congo, Ruanda, los Balcanes y el mismo conflicto colombiano, se ha hecho evidente que la guerra afecta en forma diferencial a los géneros.

La investigación se propone establecer de qué forma la ciudadanía estableció una diferencia entre lo enunciado en los acuerdos y lo difundido por los sectores opositores (mayoritariamente conservadores) a los acuerdos. En el marco de la convocatoria a plebiscito, entre agosto y octubre de 2016, para refrendar los acuerdos de La Habana entre el gobierno y las FARC, ciertos sectores de cuño político y religioso instalaron un debate en torno a la presencia de la llamada "ideología de género" en los textos de los acuerdos, cuando lo que se enunciaba en ellos era un "enfoque diferencial", orientado a reconocer y discriminar la vivencia del conflicto y la condición de víctima de la mujer, respecto de la del hombre. Es decir, buscaba visibilizar que el conflicto armado no afectaba del mismo modo a hombres y mujeres. Como colofón del proceso investigativo, se tendrán evidencias de si lo sucedido en Colombia ejemplificaría una nueva versión de la llamada posverdad, tal y como también sucedió con el Brexit en Inglaterra y el triunfo de Trump en Estados Unidos, entre otros, casos en los cuales se difundieron mentiras con categoría de verdad. 
Comunicación y Música: mensajes, manifestaciones y negocios

017 - Apropiación social del teléfono móvil en estudiantes de comunicación social - Ángel Páez - Universidad de Boyacá aepaez@uniboyaca.edu.co

La ponencia presenta un avance de una investigación en la que se analizarán los niveles de apropiación social del teléfono móvil de cara a las demandas y desafíos del mundo laboral de los comunicadores sociales de Boyacá (Colombia) en el contexto del proyecto "Análisis del impacto de la formación de comunicadores sociales de la universidad de Boyacá". El trabajo gira en torno a tres constructos teóricos: la apropiación social, el gobierno móvil y la generación APP. En éste trabajo se aborda la problemática del teléfono móvil desde la perspectiva de la participación ciudadana y las nuevas relaciones que se generan entre el Estado y la ciudadanía a través de la telefonía móvil. El hilo conductor del trabajo lo constituye el tema de la apropiación social de las TIC. Se estudian los niveles de apropiación, siguiendo las condiciones que propone Proulx (2004): a) El dominio técnico y cognitivo del artefacto; b) la integración significativa del objeto técnico en la práctica cotidiana del usuario; c) el uso repetido de esta tecnología que abre hacia posibilidades de creación (acciones que generan novedad en la práctica social); d) finalmente, a un nivel propiamente más colectivo, la apropiación social supone que los usuarios estén adecuadamente representados en el establecimiento de políticas públicas y al mismo tiempo sean tenidos en cuenta en los procesos de innovación (producción industrial y distribución comercial)".

018 - Análisis de los atributos tecnológicos y recursos didácticos del libro de texto digital en educación primaria en las asignaturas de español y matemáticas de México - Sandra Delia Faustino Cruz, delia.faustino@uabc.edu.mx, Maricela López Ornelas, ornelas@uabc.edu.mx y Javier Organista Sandoval, Instituto de Investigación y Desarrollo Educativo, Universidad Autónoma de Baja California, México- javor@uabc.edu.mx

La presente investigación tiene como propósito realizar el análisis de los atributos tecnológicos y de los recursos didácticos del libro de texto digitalizado en $5^{\circ}$ y $6^{\circ}$ de educación primaria de las asignaturas de español y matemáticas en México. Para realizar este trabajo, se 
desarrolló un proceso metodológico de corte cuantitativo-descriptivo diseñado en dos dimensiones: la tecnológica y la de recursos didácticos; posteriormente se acompañó de las fases: a) revisión de la literatura referente al libro de texto digital; b) identificación de coincidencias de conceptos y propiedades correspondientes al LTD; c) identificación de los atributos tecnológicos y de recursos didácticos del libro de texto digital; d) selección y tipificación de las características del libro de texto gratuito digitalizado de español y matemáticas; e) identificación de las características tecnológicas y didácticas de los libros de texto gratuitos digitalizados en educación primaria; f) diseño y validación por jueces de una ficha técnica sobre los atributos tecnológicos y los recursos didácticos de las asignaturas de español y matemáticas, y h) análisis y triangulación de los datos obtenidos mediante la ficha técnica, de acuerdo a lo identificado en la literatura y en los recursos provistos en los libros de texto gratuitos digitalizados.

019 - La Comunicación para el fomento de la actividad deportiva y social en los Clubes Náuticos - Paula González Redondo - Instituto Mediterráneo de Estudios de Protocolo paula.gonzalez@protocoloimep.com

Los clubes náuticos van buscando el fomento, la promoción, el desarrollo y la práctica del deporte en cualquiera de sus modalidades. Este tipo de organizaciones, sin ánimo de lucro, son conscientes de que en este siglo XXI tienen que impulsar sus actividades deportivas náuticas y sociales mediante una buena gestión de comunicación. En este sentido, las entidades deportivas náuticas del siglo XXI deben de incitar a sus socios o al público de interés a integrarse en este tipo de entidades ya sea por la práctica deportiva como por cualquier otra actividad social. Así mismo, a través de la comunicación trasladan su imagen a la sociedad, logran la explotación comercial de la entidad náutica y fidelizan a los seguidores vinculándolos con las actividades deportivas y sociales.

En esta contribución se presentan los principales resultados de una investigación sobre las funciones de comunicación dirigidas a los grupos de interés de los clubes náuticos. Para ello se realiza, en primer término, un análisis de las iniciativas que realiza la entidad para la masa 
Comunicación y Música: mensajes, manifestaciones y negocios

social que permite realizar, a posteriori, un estudio de las funciones de comunicación con los socios de este tipo de entidades.

020 - Estudio sobre las reacciones en Twitter ante el salto de 600 migrantes en la valla de Ceuta en julio de 2018 - Sergio Arce García - Universidad Internacional de La Rioja sergio.arce@unir.net

El salto de 600 personas migrantes subsaharianas sobre la valla de la frontera entre España y Marruecos en Ceuta el 26 de julio de 2018, y que desembocó en un enfrentamiento con los cuerpos de seguridad del Estado de España, fue noticia en los principales medios de comunicación. La situación de pobreza, pero también de peleas entre los asaltantes y la Guardia Civil, que se saldó con varios heridos, estuvo en la agenda de los medios, de los políticos y de la sociedad. En los días posteriores se realizaron diversas declaraciones y visitas por parte de diversos cargos institucionales y políticos a la zona.

En esta investigación se estudia la reacción en Twitter de los usuarios desde el día del salto y durante los 10 días posteriores a través de los comentarios que contenían las palabras "valla" y "Ceuta", recogiendo más de 21.000 intervenciones.

Para su estudio se realizó una descarga mediante el software estadístico $\mathrm{R}$ y se analizaron posteriormente con el mismo programa, y otros auxiliares, para recoger las relaciones entre usuarios. Se realizó, mediante el uso de léxicos prefijados, la asignación de aportaciones positivas y negativas, así como de emociones asociadas, procediendo a un estudio de lo obtenido.

De los resultados cabe destacar que existen dos grupos diferenciados de opinión y con poca relación entre si. Las emociones de miedo y enfado son las que más aparecen en los tweets de los participantes, coincidiendo sus máximos coincidiendo con las informaciones sobre el salto y enfrentamientos, así como con la intervención de diversos dirigentes políticos. 
021 - Perspectiva de género en la prensa ecuatoriana - Pablo Efraín Romero Guayasamín - promerog@ups.edu.ec y Nelly Valbuena - Universidad Politécnica Salesiana nellyvalbuena@gmail.com

La propuesta de ponencia recupera el resultado de un proceso de investigación realizado por el Grupo de Investigación en Comunicación de la Universidad Politécnica Salesiana, aplicado en 4 medios de comunicación escritos de Ecuador: El Comercio, El Universo, El Telégrafo y Extra, entre abril y junio del 2018, para determinar la representación de la mujer y la violencia de género en las notas interculturales de la prensa ecuatoriana.

Considerando que la Constitución ecuatoriana en su artículo 11, titulo 2, señala que: "nadie podrá ser discriminado por razones de etnia, lugar de nacimiento, edad, sexo, identidad de género (...), orientación sexual". Y que la Ley Orgánica de Comunicación establece en el art 61 la restricción de publicaciones con contenido discriminatorio entre otros por identidad de género, orientación sexual, sexo, portar VIH. Prohibiendo (art 62) cualquier práctica que "tenga por objeto o resultado menoscabar o anular el reconocimiento, goce o ejercicio de los derechos humanos reconocidos en la Constitución y en los instrumentos internacionales". Esta investigación devela las formas de presentación de la mujer, el cumplimiento y garantía de derechos enunciados, convirtiéndose en un aporte para la responsabilidad social de los medios de comunicación.

Se analizaron en total 1184 piezas periodísticas, entre ellas: notas cortas, noticias, reportajes, editoriales, etc. La aplicación de la metodología permite observar la presencia de la mujer en las notas interculturales y la relación entre imagen y contenido en las piezas periodísticas.

022 - El tratamiento de las elecciones legislativas en los principales cibermedios colombianos en Facebook y Twitter (2018) - Daniel Barredo Ibáñez - Universidad del Rosario (Colombia)-daniel.barredo@urosario.edu.co y Sandra Lucía Ruiz Moreno - Universidad Panamericana (Colombia) slruizm@unipanamericana.edu.co 
A través de las redes sociales, los medios en línea o cibermedios tienen la oportunidad no solo de distribuir los contenidos que originan, sino también de interactuar con sus audiencias y fomentar, con ello, un mayor diálogo social. Esto es especialmente relevante en las rutinas electorales, en que la activación de la ciudadanía resulta esencial para generar una menor afectación del abstencionismo, así como la posibilidad de un electorado más informado e involucrado. En esta ponencia, mediante un análisis de contenido, hemos evaluado 1272 mensajes difundidos a través de las cuentas de Twitter y Facebook de 8 cibermedios colombianos de orientación nacional durante las elecciones legislativas de ese país entre los meses de febrero y marzo de 2018. Entre los resultados principales, mostraremos aspectos relacionados con la calidad de las coberturas; el protagonismo político concedido y su favorabilidad; o los temas de los mensajes, entre otros, que son algunas de las claves que nos permiten trazar un diagnóstico sobre la participación e inclusión ciudadanas en algunos de los cibermedios más importantes de Colombia.

023 - La gestión de la interactividad según los periodistas: un análisis comparativo de los profesionales de Colombia, Perú y Ecuador - Daniel Barredo Ibáñez - Universidad del Rosario (Colombia) - daniel.barredo@urosario.edu.co; Úrsula Freundt Thurne - Universidad Peruana de Ciencias Aplicadas (Perú) ursula.freundt@upc.pe; Narcisa Jessenia Medranda Universidad Politécnica Salesiana (Ecuador) nmedranda@ups.edu.ec y Karen Tatiana Pinto Garzón Universidad del Rosario (Colombia) - karen.pinto@outlook.es

A través de la interactividad, los medios en línea definen aspectos como las posibilidades de comunicación del usuario con el medio; la participación de los usuarios con la comunidad que se establece alrededor de la cabecera; o bien la difusión de los contenidos originados por los propios usuarios, entre otros. Por ello, los medios están cambiando las rutinas de producción de los contenidos periodísticos, en aras de activar un mayor involucramiento de las audiencias dentro de las coberturas. En esta ponencia, mediante entrevistas en profundidad realizadas a más de una treintena de 
periodistas de algunos de los medios de alcance nacional más importantes de Colombia, Perú y Ecuador, evaluamos el concepto de interacción de estos profesionales. En ese sentido, describimos la importancia que conceden los periodistas colombianos, peruanos y ecuatorianos, al uso estratégico de las redes sociales como vías de contacto con los usuarios y como fuentes informativas. Asimismo, a partir de las respuestas dadas por el universo escogido, proponemos algunas pautas que podrían ayudar a fomentar una mayor innovación en las organizaciones periodísticas en línea de estos tres países.

024 - Pautas generales de seguridad a implementar en los eventos en los que concurren personas que debido al cargo que ocupan pueden generar expectativas de riesgo - José Ignacio Andrés Prieto- Universidad de Alicante- jiapriet@gmail.comBegoña Bueno Fernández- Universidad Pontificia de Salamanca-bbuenofe.chs@upsa.es-

Cuando hablamos de eventos hablamos de acciones de relaciones públicas organizacionales con gran capacidad de convocatoria y difusión. Los actos posibilitan el contacto directo de las organizaciones con sus públicos en un marco idóneo para consolidar las relaciones interpersonales. Sirven por tanto para crear puntos de encuentro entre la organización y sus públicos en los que poder confluir y compartir intereses comunes, al margen de que se produzca su difusión informativa.

Al mismo tiempo, el protocolo es un elemento rector de los actos que, además de definir las normas, usos, costumbres y tradiciones que los regulan, se ocupa de coordinar, ordenar y articular las diversas partes en que aquéllos se estructuran y de determinar el orden jerárquico de sus participantes.

La capacidad estratégica de las anteriores herramientas comunicativas no podrá desarrollarse exitosamente si no existen pautas generales de seguridad a implementar en los eventos en los que concurren personas que debido al cargo que ocupan generan expectativas de riesgo. 
Comunicación y Música: mensajes, manifestaciones y negocios

En esta comunicación se pretenden pautar medidas generales de actuación y comportamiento en materia de seguridad, para poder llevar a buen término un evento donde asisten personalidades que confluyen con un grupo abierto de individuos que interactúan en un acto social.

Los procedimientos a tener presente se desarrollan desde la fase previa con una correcta elaboración de inteligencia corporativa hasta la conclusión del acto. Siempre con la única pretensión de que los eventos programados se desarrollen dentro de una normalidad aceptable, ocasionando las menores de las injerencias en el desarrollo de los actos.

025 - Comunicación política en red en Colombia: la transición de la Presidencia de Juan Manuel Santos a Iván Duque - Fátima Martínez Gutiérrez - Profesora Universidad del Rosario (Colombia) - fatima.martinez@urosario.edu.co

La propuesta de este trabajo consiste en realizar un análisis de la Comunicación Política digital realizada por quien dejó de ser el Presidente de Colombia desde el 7 de agosto de 2018 en Colombia, Juan Manuel Santos, cuyo trabajo digital ha sido excelente en el uso de redes sociales como Facebook, Twitter e Instagram, para comenzar a observar el uso de Iván Duque, que es ya el nuevo presidente de la República en Colombia y que se estrena en términos digitales a partir de ahora, teniendo en cuenta que el presidente Juan Manuel Santos ha dejado el listón bien alto desde el punto de vista de la comunicación digital.

Se pretende realizar un estudio del trabajo digital en términos de comunicación política de los dos perfiles; tanto de Juan Manuel Santos como de Iván Duque, que ha llegado al poder como Presidente de la República en las últimas elecciones colombianas, con el fin de realizar una comparativa entre los dos. Aunque también resulta interesante observar y analizar la cuenta oficial de la Presidencia en Colombia, que tiene como nombre en redes sociales el nombre de Infopresidencia, desde las redes como Twitter, Facebook e Instagram con el fin de realizar un análisis de contenido de los posts publicados y su impacto digital en audiencias de Internet, dentro de las dos presidencias. Sin duda, Colombia se encuentra ahora en un contexto fundamental desde 
el punto de visto político y social, encaminado hacia el posconflicto y la implementación de la paz.

026 - Laboratorios Universitarios: Experimentación e Innovación. Caso MediaLab UTPL - Juan Carlos Maldonado jcmaldonado2@utpl.edu.ec; Andrea Victoria Velásquez Benavides - avvelasquez@utpl.edu.ec; Carlos Ortiz León ccortiz@utpl.edu.ec; Ana María B-Flandoli-Universidad Técnica Particular de Loja - ambeltran@utpl.edu.ec

Las universidades en América Latina necesitan una reestructuración tecnológica importante, para enfrentar el reto que hoy en día plantea la utilización de laboratorios como herramientas tecnológicas para la enseñanza aprendizaje de sus alumnos. Estos cambios deben estar orientados a proponer una opción educativa que se ajuste a las necesidades de la sociedad presente y futura, lo cual implica tener una educación de calidad, con equidad y pertinencia sociocultural en el contexto de un sistema de educación permanente a través de las prácticas pre-profesionales. Los laboratorios como espacios de experimentación se han convertido en uno de los principales centros de innovación.

El Medialab UTPL es un espacio ciudadano de producción, destinado a la investigación, generación y difusión de proyectos multidisciplinarios, donde investigadores, estudiantes, docentes, y público en general pueden proponer, crear, y explorar las distintas formas de experimentación y aprendizaje colaborativo, haciendo uso de las herramientas y tecnología con las que se cuenta. La presente investigación analiza el origen y desarrollo de este espacio y se centra en recopilar la opinión de los estudiantes sobre su experiencia de aprendizaje. Las conclusiones de esta investigación son de gran importancia para las comunidades educativas y para la sociedad en sí, ya que a partir de estas se pueden generar criterios de calidad que aportarán a mejorar las competencias mediáticas que contribuyan con dimensiones e indicadores para mejorar los laboratorios de comunicación en las universidades. 
Comunicación y Música: mensajes, manifestaciones y negocios

027 - Investigación sobre la gestión del protocolo universitario en las universidades españolas - Begoña Bueno FernándezUniversidad Pontificia de Salamanca-bbuenofe.chs@upsa.es

La gestión de la comunicación institucional universitaria va a permitir influir positivamente en los destinatarios de la misma, permitiendo con ello lograr objetivos como alcanzar credibilidad, relevancia o diferenciación.

Para llevar a cabo la gestión eficiente de esta comunicación, canalizada en muchas ocasiones por medio de eventos, que además permiten hacer partícipe al ciudadano, las instituciones universitarias recurren a disciplinas como el protocolo universitario, que nos permitirá desarrollar acciones comunicativas, dentro del amparo de sus normativas y costumbres. El protocolo, además, coadyuva en la consecución de los objetivos anteriormente expuestos puesto que, entre otros, posibilita la proyección de una imagen adecuada de la institución.

En la presente comunicación se muestran los principales resultados de la investigación realizada sobre cómo se gestiona el protocolo universitario en las universidades españolas. En primer lugar, encontraremos un mapa de las universidades existentes. En base al anterior, se hallan los resultados, alcanzados siguiendo una estrategia de investigación y metodología científica.

028 - Internet radio and podcasting. Radio 4.0: New business models, prospects and challenges for the radio industry - Rafael Galán Arribas - Universidad de Salamanca - rgalan@usal.es

Some authors consider that radio has not been researched enough and that it has been treated as an invisible medium, not only by cultural industry researchers, but also by other media, governments, politicians, and even radio producers and consumers (Lewis and Booth, 1989). However, the consolidation of the Internet in Spain is leading to the emergence of new technologies and the development of new forms of communication. 
This research follows the research line of two recently published journal articles (Galán, 2015; and Galán and Herrero, 2017). We aim to rigorously explore and analyse to what extent podcasting and ondemand audio-based programming are influencing the consumption of radio as a medium. At the same time, we aim to measure the use of smart devices and determine how the new generations influence these new business models.

Therefore, the scope of the study will be marked by new economic models and new distribution platforms for audio-based content; social networks as a model for participation, promotion and exchange of podcasts and internet radio; as well as the incorporation of young listeners thanks to new communication and information technologies.

The study will combine quantitative and qualitative methods and techniques. The first stage of the research will approach podcast and internet radio users to identify their relevant aspects and features. The second stage will use statistical inference to try to predict future behaviours of the selected population, anticipate the demands of the whole society, and identify the advantages and disadvantages in terms of usability and consumption of audio-based content. Finally, the results will bring us closer to the design and planning of services according to the features demanded by users.

029 - Abordaje de la interculturalidad en la prensa ecuatoriana Emilia Lucía Ramírez Paguay - Universidad Politécnica

Salesiana - emilialrp@gmail.com y Patricia Sofía Villagómez

Rodríguez - Universidad Politécnica Salesiana -

pvillagomez@ups.edu.ec

La propuesta de ponencia recupera el resultado de un proceso de investigación realizado por el Grupo de Investigación en Comunicación de la Universidad Politécnica Salesiana, aplicado en 4 medios de comunicación escritos de Ecuador: El Comercio, El Universo, El Telégrafo y Extra, entre abril y junio del 2018, para determinar el alcance y entendimiento que la prensa ecuatoriana tiene sobre lo intercultural y su representación a través de los géneros periodísticos. 
Comunicación y Música: mensajes, manifestaciones y negocios

Partimos de que Ecuador se reconoce en los principios fundamentales de la Constitución como un país intercultural y plurinacional y que la Ley Orgánica de Comunicación, vigente desde el año 2013, establece en su Artículo 36 el "derecho a la comunicación intercultural y plurinacional.- Los pueblos y nacionalidades indígenas, afro ecuatorianas y montubias tienen derecho a producir y difundir en su propia lengua, contenidos que expresen y reflejen su cosmovisión, cultura, tradiciones, conocimientos y saberes. Además, en la disposición transitoria décima quinta decreta que "los medios de comunicación incluirán en su programación o ediciones, contenidos en las lenguas de relación intercultural, en un porcentaje de al menos el $5 \%$ de su programación". Sin embargo, esta propuesta se interesa en conocer el abordaje de lo intercultural a través de un acercamiento teórico y educativo no así de carácter punitivo.

Se analizaron en total 1184 piezas periodísticas, entre ellas: notas cortas, noticias, reportajes, editoriales, etc. La aplicación de la metodología permite observar cuáles son los géneros periodísticos más utilizados en la cobertura de temas interculturales, así como identificar qué grupo humano se encuentra presente en la pieza periodística, la frecuencia de su tratamiento y el rol que cumple en la historia. Para finalmente determinar las temáticas y las locaciones que principalmente se asocian con lo intercultural. Sobre los resultados cuantitativos que se obtuvieron se realizó un análisis cualitativo para comprender no solo la frecuencia con que aparecen los datos sino entender a profundidad la relación con el contexto en el que se desarrolla.

030 - El documental de naturaleza ante la realidad virtual: una aproximación a su utilización en el panorama internacional Adriana Paíno Ambrosio - Universidad de Salamanca adriana.paino@usal.es, Ma Isabel Rodríguez Fidalgo Universidad de Salamanca - mrfidalgo@usal.es y Javier Herrero Gutiérrez - Universidad de Salamanca - javiherrero82@usal.es

La aparición del periodismo inmersivo hace posible que los espectadores puedan ser partícipes de la historia narrada asistiendo en primera persona a los hechos de los que informan los medios de comunicación; esto abre una línea de innovación narrativa dentro del 
ámbito comunicacional. Entre los años 2014 y 2015 comenzaban a aparecer, tímidamente, en los medios de comunicación algunos proyectos experimentales donde ya se podía apreciar el potencial que ofrece la tecnología de la realidad virtual como una potente herramienta para crear contenidos informativos. A partir de 2016 se ha producido un notable incremento de este tipo de producciones inmersivas, siendo Estados Unidos el país que acumula la mayor parte de dicha producción. Por otra parte, existe una gran amplitud temática en cuanto a las cuestiones abordadas en este tipo de proyectos periodísticos inmersivos, que van desde los conflictos armados, la cultura o la violencia de género, pasando por la educación o la ciencia y la tecnología. Pero uno de los temas que cuenta con mayor producción en el panorama internacional es el relacionado con "la naturaleza y el medioambiente", tratando aspectos vinculados tanto a la vida natural y animal en general, como a la contaminación y los efectos negativos de la mano del ser humano en los ecosistemas, o las catástrofes naturales y sus consecuencias devastadoras. En este estudio, a través de la utilización de una metodología de análisis cualitativa y cuantitativa, se analiza una muestra formada por 259 piezas realizadas por medios de comunicación de todo el mundo relacionadas con esta temática, con el objetivo de abordar la construcción narrativa de dichos productos periodísticos inmersivos realizados en realidad virtual. Los resultados muestran cómo este tipo de proyectos presentan unas características comunes y muy definidas, con una preferencia por la presencia de la fuente frente a la figura del periodista, y por la utilización de planos medios y cortos, así como aéreos, especialmente al inicio de las piezas; aspectos que abren dentro del periodismo, sin duda, nuevas formas de contar la realidad.

031 - El neuromarketing como herramienta efectiva para la Educación en las ventas y la publicidad - Guillermo Noel Gutiérrez Cárdenas - acreditacionfen2018@uft.clUniversidad Finis Terrae

Cuando hablamos de la forma en que nos comunicamos con nuestros clientes tanto para las ventas, como para la publicidad, la herramienta comercial más enseñada es la del Marketing. Desde su surgimiento a variado y se ha perfeccionado. Pero de forma irruptiva ha aparecido el 
Comunicación y Música: mensajes, manifestaciones y negocios

Neuromarketing entendiéndose que esta es y será la comunicación ideal en el mundo de los negocios. Grandes compañías ya la usan y los estudiantes universitarios de carreras de negocios y de la más importante de ellas en Chile Ingeniería Comercial, desconocen totalmente, su forma y uso, desconocen su implicancia, debiendo aprender de ella tarde, bajo el yugo de las empresas, su concepción e intencionalidad propia. Hoy en Chile no existen programas de pregrado y menos aún de posgrado que ayuden a entender desde un enfoque científico y ético, lo que es y que nos depara el Neuromarketing, para que los alumnos puedan tener una concepción cabal de la temática y de su estudio como fenómeno social. Es así que a contar de este año el profesor que suscribe, ha diseñado el primer programa (asignatura y cátedra) de "Neuromarketing y Publicidad", que hoy, ya se imparte en la Universidad Finis Terrae - Facultad de Economía y Negocios: en la Carrera de Ingeniería Comercial; para alumnos que han superado ya las cátedras de Marketing, Marketing Estratégico e Investigación de Mercados, al menos. Con gran acogida entre los alumnos y conforme a su éxito, la idea es que, a contar del 2019, esta, sea impartida como asignatura en la Maestría de Continuidad en Marketing (especialización) de la misma carrera. Siendo primera vez en Chile y en Latinoamérica que se imparte esta cátedra como parte de la enseñanza universitaria dentro de una carrera del área. Para ello se ha trabajado, en su historia, disciplinas que la hicieron nacer, el estado del arte actual, como sus implicancias, como forma de comunicación para las ventas y la publicidad, usando herramientas como vídeo, imágenes de campañas, paper y redes sociales, que facilitan la comprensión de la temática.

032 - Representación de estereotipos de la familia americana frente a la familia latinoamericana en la serie televisiva "los Simpson” de la Temporada 29 - Narcisa Jessenia Medranda Morales - Universidad Politécnica Salesiana nmedranda@ups.edu.ec y Palacios Mieles Victoria Dalila Pontificia Universidad Católica del Ecuador vdpalacios@puce.edu.ec

La serie norteamericana "Los Simpson" ha sido transmitida a nivel mundial. Esta serie presenta varios imaginarios colectivos respecto de 
la sociedad norteamericana, imaginarios que son propagados a las diferentes culturas a las que llega. Latinoamérica no ha estado exenta de estos estereotipos. En este sentido, este artículo busca visibilizar dichos estereotipos, de manera particular aquellos estereotipos presentes en la temporada 29. Se trata de mostrar como en las familias latinas ésos estereotipos aparecen como algo adquirido. En este sentido, para lograr visibilizar los estereotipos adquiridos por las familias latinas en la serie se aplicó la metodología mixta: Cuantitativa y cualitativa. En cuanto a la metodología cuantitativa, se aplicaron encuestas a 100 familias de Ecuador, Colombia, Brasil, Perú y México, mientras que para la metodología cualitativa se realizó el análisis de contenido de los 11 episodios de la serie "Los Simpson" temporada 29. Que han sido transmitidos en América Latina.

033 - El uso de insights en la narrativa audiovisual ejemplificado a través de la serie Black Mirror - Irene Martín Soladana Universidad Complutense de Madrid - Irenem14@ucm.es y Ana Sebastián Morillas-Universidad de Valladolid. Facultad de Ciencias Sociales Jurídicas y de la Comunicaciónanaseb@hmca.uva.es

La comunicación que se presenta tiene como objetivo poner en relación los insights (explicados desde el punto de vista de la publicidad), con la serie Black Mirror, con la intención de mostrar cómo se pueden utilizar los insights en el discurso de la narrativa audiovisual para conseguir conectar con los espectadores. Se pretende mostrar cómo, en este caso, el audiovisual no influye en la cultura si no que, al contrario, se fija en ella, analiza la sociedad y consigue crear un contenido especialmente atractivo relacionado con los problemas y preocupaciones del propio entorno social.

Este breve estudio se centra solo en esa relación de los insight con la serie mencionada, pero no pretende entrar más allá de los muchos factores que la componen ni entrar a juzgar el contenido de esta.

En esta comunicación, se explicará qué son los insight entendidos desde la perspectiva publicitaria a través de algunos ejemplos. Posteriormente, se expondrán los tráilers de los seis capítulos 
Comunicación y Música: mensajes, manifestaciones y negocios

seleccionados y se comentarán los insight que se han observado en cada uno de los capítulos. Se abrirá una pequeña discusión sobre los insight detectados y la relevancia de los mismos en la sociedad.

La metodología que se ha seguido para realizar este estudio es una metodología cualitativa. Para conocer el uso y relevancia de los insight en publicidad, se ha hecho una revisión bibliográfica, se han revisado estudios de casos y se ha realizado un panel de expertos. Para el estudio del caso, se han elegido seis capítulos de la serie Black Mirror en base a rankings relevantes sobre los episodios mejor valorados de la serie.

El resultado que se busca obtener con este estudio es mostrar la relevancia de los insight para conocer, no solo a los consumidores cuando se habla de publicidad, si no que también se podría abrir la puerta a trasladar la importancia de su uso a otros campos como el de la narrativa audiovisual, estrechamente vinculado en algunos aspectos a la publicidad.

034 - Planificación estratégica del marketing y la comunicación en la nueva economía - Patricia Coll y Josep Lluís Micó Universitat Oberta de Catalunya (España) y Universitat Ramon Llull (España)

El estudio analiza el modelo de planificación estratégica de la comunicación y el marketing que se desarrolla en el contexto interconectado de la nueva economía partiendo de la hipótesis de la existencia de un planteamiento $360^{\circ}$, heredero de la comunicación integrada de marketing, con un enfoque growth hacker centrado en lograr el máximo crecimiento a través de tácticas creativas y analíticas, mediante acciones sinérgicas de publicidad, marketing de contenidos, influencer marketing y relaciones públicas.

Los resultados de esta investigación provienen de los casos de estudio de tres marcas nativas digitales (Wallapop, de compraventa de segunda mano; Westwing, de decoración; y Fotocasa, de alquiler y compraventa inmobiliaria), de referencia en Barccelona, quinto hub europeo en volumen de startups y sede del Mobile World Congress. 
Las conclusiones del estudio muestran que su planificación estratégica consta de las cuatro fases del modelo RACE elaborado por Marston en 1963, aunque con las particularidades derivadas del nuevo contexto digital en el que se desarrolla la sociedad red. Así, las acciones de marketing, publicidad, relaciones públicas se plantean de forma nativa digital, combinando canales on y off line, con una visión centrada en el usuario, una calendarización a corto plazo, una toma de decisiones está basada en datos y una medición de resultados casi a tiempo real.

035 - Producción, distribución y exhibición del cine desde una nueva mirada: la web social - Yasmín Sayán Casquino Universidad Peruana de Ciencias Aplicadas cronopersona@gmail.com

El cine en Latinoamérica enfrenta problemas con respecto al financiamiento y a la difusión de proyectos desde el sistema tradicional. Sin embargo, hoy, la influencia del internet, la pantalla global, la web social y la participación colectiva han cambiado los hábitos de consumo dando herramientas para poder terminar el proceso de una película. La audiencia no solo consume, también produce. Los nuevos realizadores han aprovechado este cambio para replantear el modelo de negocio y la cadena de producción a la hora de contar historias. Nacen nuevos conceptos que ayudan a esta modificación de la cadena productiva, como el crowdfunding, que modifica la forma de financiar proyectos, experiencias como la wikipeli demuestran que se puede generar una nueva forma de producción y realización, eliminando intermediario en la etapa de distribución, y por último, la transmedia y el storydoing que no solo modifican la narración sino que generan la creación de una marca que reviste al producto. Se tratará demostrar el rol de plataformas digitales vinculadas a la web social como un sistema alternativo en la cadena de producción audiovisual mediante una metodología de análisis descriptivo-cualitativo de casos de éxito, entrevistas y plataformas.

036 - Rutas del Conflicto: un estudio de caso de Periodismo de Datos y Nuevas Narrativas sobre el Conflicto Armado en Colombia - Fátima Martínez Gutiérrez - Profesora Universidad del Rosario (Colombia) -fatima.martinez@urosario.edu.co, 
Comunicación y Música: mensajes, manifestaciones y negocios
Óscar Parra - Profesor Universidad del Rosario (Colombia) - oscar.parrac@urosario.edu.co y Juan Gómez - Profesor
Universidad del Rosario (Colombia)- juanp.gomez@urosario.edu.co

Rutas del Conflicto es un proyecto digital periodístico, pionero en el periodismo de datos y en las nuevas narrativas en América Latina, cuya misión es facilitar el acceso a la información, organizada y confiable, sobre el conflicto armado en Colombia. Este medio digital es aliado de la Universidad del Rosario. Sus principales impulsores son dos profesores de cátedra de la mencionada Universidad: Óscar Parra, el director de este proyecto digital, y Juan Gómez, el subdirector del medio, de una redacción donde trabajan alumnos e investigadores de la Universidad del Rosario con el fin de mapear información relacionada con violaciones a los Derechos Humanos, como masacres, desapariciones forzadas y casos de despojo de tierras, además de corregir y agregar datos con la ayuda de testimonios de sus sobrevivientes en Colombia.

Rutas del Conflicto es un laboratorio de Periodismo que se ha convertido también en un semillero de investigación interesante para los alumnos de Periodismo. Dentro de este proyecto han nacido numerosos proyectos como Yo Sobreviví, con testimonios de víctimas de conflicto armado en Colombia, La Paz en el Terreno, que documenta historias de agresiones contra líderes sociales y el proceso de reincorporación de exguerrilleros de las FARC; Ríos de Vida y Muerte, referido a las desapariciones forzadas perpetradas en los ríos de Colombia, entre otros proyectos. La idea de este artículo es la de hablar de Rutas del Conflicto, desde su nacimiento hasta su desarrollo en el último año. Además de hablar de la temática que aborda del conflicto en Colombia, conocer cuáles son sus herramientas principales de trabajo para contar historias con los datos y con los reportajes sobre terreno, al mismo tiempo. Este artículo profundizará en la pregunta qué es Rutas del Conflicto como medio digital independiente de reportería y de periodismo de datos, que ha recibido varios premios internacionales de periodismo, e identificar dónde reside su importancia en la memoria en cuanto al relato que concierne 
al conflicto armado en Colombia para contar masacres perpetradas desde 1982.

037 - La importancia de la estrategia de comunicación y su relación con el insight para conseguir la eficacia publicitaria Ana Sebastián Morillas-Universidad de Valladolid. Facultad de Ciencias Sociales Jurídicas y de la Comunicaciónanaseb@hmca.uva.es, Daniel Muñoz Sastre- Universidad de Valladolid. Facultad de Ciencias Sociales Jurídicas y de la Comunicación-daniel.munoz.sastre@uva.es y Marian Núñez Cansado- Universidad de Valladolid. Facultad de Ciencias Sociales Jurídicas y de la Comunicación-mariannc11@yahoo.es

Este trabajo plantea un análisis de las campañas ganadoras de los premios Eficacia en Comunicación Comercial de los últimos diez años. Tiene como objetivo, examinar qué papel han jugado las estrategias de comunicación utilizadas por las marcas para conseguir diferenciarse en el mercado de su competencia y alcanzar la eficacia publicitaria. Asimismo, se han analizado qué otros elementos son importantes para conseguir conectar la marca con el consumidor, uno de ellos es el insight pero, ¿se ha utilizado siempre?, ¿qué papel juega en el proceso de la campaña?, ¿es relevante? Para dar respuesta a estas y otras cuestiones, se ha utilizado una metodología cualitativa basada en el análisis de los casos de estudio de las campañas premiadas en la categoría oro (unas 40 campañas) en los últimos diez años, y se han realizado entrevistas a expertos del sector en el que se les pidió opinión, sobre temas relacionados con el ámbito publicitario.

Este estudio se centra solo en el análisis de las campañas publicitarias premiadas en la categoría Oro de los premios Eficacia en Comunicación Comercial de los últimos diez años. Se pretende mostrar qué evolución e importancia se les ha dado a las decisiones estratégicas en el peso de una campaña, detectar desde cuándo el termino insight se ha utilizado para conectar la marca con el consumidor, y conocer qué elementos son importantes a la hora de conseguir los objetivos propuestos por los anunciantes. 
Comunicación y Música: mensajes, manifestaciones y negocios

El resultado que se busca obtener con este estudio es mostrar la relevancia de las estrategias de comunicación en el proceso de desarrollo de una campaña publicitaria y en qué medida los insihgts junto con otros elementos de la comunicación son necesarios para conseguir conectar la marca con el consumidor y, por la tanto, acercarse a ellos de forma más eficaz.

038 - Etsa-Nantu/Cámara Shuar: comunicación en defensa de la vida, meta-ciudadanías ecológicas e interculturalidad en la Amazonía ecuatoriana - Yadis Vanessa Vanegas Toala Universidad Pompeu Fabra y Universidad Politécnica Salesiana - Sede Quito, Ecuador. yvanegast@ups.edu.ec vvanegast@gmail.com

Esta investigación reflexiona sobre la experiencia de EtsaNantu/Cámara Shuar, un laboratorio de creación audiovisual en defensa del territorio que, desde el 2013, genera procesos de comunicación con prácticas organizativas de carácter intercultural y comunitario. Este proyecto es emblemático porque constituye una respuesta a la política extractivista del Estado ecuatoriano, las concesiones de territorio sin consulta previa libre e informada, la violación de los derechos humanos, la criminalización de la protesta social y a la campaña mediática gubernamental pro "minería responsable".

Este artículo contempla un análisis sobre la acción política que se agencia desde la comunicación, a través del reconocimiento de unas "meta-ciudadanías ecológicas" propuestas por Eduardo Gudynas (2009), que incorporan ontologías relacionales, no jerárquicas, y otras formas interacciones ecológicas. En este contexto, se interpela a la dimensión intercultural crítica como lo propone Catherine Walsh (2009). Desde esta perspectiva, se tomará como base las categorías de "medios radicales" (Dowing, 2011) y "medios ciudadanos" (Rodríguez, 2008) que basados en la noción de "democracia radical" de Chantal Mouffle (1988), sostiene que la condición de sujeto debe superar una visión universalista por una pluralista; de modo, que la condición de sujetos reivindique una diversidad de racionalidades propias que efectivizan su ciudadanía de múltiples formas y demandan la 
amplificación del espacio de acción política. Así surge la pregunta de investigación central: ¿Qué papel juega la comunicación contra hegemónica, gestada por Etsa-Nantu/Cámara Shuar, en la generación de nuevas formas de agenciamiento que reivindican las "metaciudadanías ecológicas" en el marco de la interculturalidad?

039 - Prácticas audiovisuales indígenas y luchas interculturales en el Ecuador - Christian León - Universidad Andina Simón Bolívar - christian.leon@uasb.edu.ec

La ponencia revisa críticamente los debates que se han realizado sobre el video indígena y los conceptos fundamentales que se han desarrollado para pensar su complejidad en miras a construir la noción de "prácticas audiovisuales indígenas" por fuera de las meta-narrativas de emancipación, concepciones binarias y esencialismos étnicos dentro del contexto de las luchas interculturales contemporáneas. A través de historias de vida, etnografías multilocales y análisis de imagen, plantea un estudio de la obra y el pensamiento Alberto Muenala y Amaru Cholango, dos artistas indígenas precursores en el uso del video en Ecuador que han influenciado a las nuevas generaciones. Se plantea una serie de críticas a las conceptualizaciones establecidas sobre video indígena y finalmente se establecen un conjunto de elementos para la reconceptualización de las prácticas audiovisuales indígenas.

040 - Comunicación, ciudadanía y democracia - José Luis Calero Mieles - Universidad Católica del Ecuador jcalerom@puce.edu.ec

Este es un artículo analizado desde la visión ciudadana. La idea principal del estudio es colocar al ciudadano como ente vital del desarrollo de la sociedad, examinando el carácter empresarial de los medios de comunicación, la intención de sus mensajes y el enfoque que le dan al tema sus protagonistas, tanto internacionales como locales; además propone, que en el sistema democrático, el ciudadano común deje de ser un simple receptor y se convierta en perceptor con criterio de la información que recibe, entendiendo que la información es portadora de ideología. 
Comunicación y Música: mensajes, manifestaciones y negocios

Se busca establecer el impacto de la comunicación en la sociedad, la utilización de los medios masivos, el poderío mediático en la era de la globalización, cuyo proceso no ha sido un fenómeno equilibrado, pero influye íntegramente en el planeta. Nadie puede negar la existencia de vínculos políticos, económicos e ideológicos en los medios de comunicación, pero en democracia, la ciudadanía debe ser sensata y exigir sus derechos.

Se examina la influencia de los medios masivos de comunicación en la formación de la opinión pública, haciendo énfasis en el enfoque de expertos investigadores, que cuestionan la credibilidad y confianza de la sociedad respecto a tales empresas. Se concluye que, desde los medios masivos de comunicación, su dominio, facilita mantener a la sociedad dispersa, sin organización, sin capacidad comunitaria. Esa debilidad impide democracia y construcción de ciudadanía.

041 - Del "engaño de masas" de la Teoría Crítica al "vecindario indefinido" de Bauman - Luis Núñez Ladevéze- Universidad San Pablo CEU - ladeveze@telefonica.net, Teresa Torrecillas Universidad San Pablo CEU - teresat@ceu.es e Ignacio Álvarez de Mon - Instituto de Empresa -

Ignacio.AlvarezdeMon@ie.edu

Tomando como referencia teórica la noción de "vecindario indefinido" propuesta por Bauman en su póstuma Retrotopía, se aborda un análisis fenomenológico del concepto de "vecindario" en la Teoría Crítica de la Sociedad. La revisión tiene por objeto dilucidar si, desde la perspectiva conceptual que ofrece la noción propuesta por Bauman, las tendencias que se muestran en el uso de la red pueden interpretarse como discriminatorias o como imperativamente democratizadoras.

Según Bauman, la red, es un instrumento tecnológico de comunicación "ecuménica" interindividual que generaliza una "servidumbre voluntaria» global. El estudio se encamina a mostrar los precedentes de la noción de "servidumbre voluntaria" en la Teoría Crítica de la Sociedad, que se remontan a la Dialéctica de la Ilustración. Los teóricos críticos describieron la industria cultural como un proceso del capitalismo para el "engaño de masas". La revisión aplica la crítica 
fenomenológica para ilustrar las correcciones y adaptaciones sucesivas que van modificando la originaria tesis del "engaño" para ir adecuándola a los cambios sociales producidos por el progreso tecnológico de los medios comunicativos.

Desde este punto de vista fenomenológico, el concepto de "servidumbre voluntaria" es el desenlace conceptual de la última fase de la Teoría Critica representada por la noción de "posmodernidad líquida" que usa Bauman para describir la etapa actual de un mundo compuesto por individuos hiperconectados en red, cuyo rasgo principal es la "autoreproducción del consumo" para la autorreproducción de los flujos comunicativos. Los autores proponen adoptar el concepto de "servidumbre voluntaria" como una hipótesis teórica cuya congruencia descriptiva merecerá ser empíricamente contrastada en proyectos de investigación.

042 - La comunicación intercultural una mediación pedagógica y social para el ejercicio de la ciudadanía - María del Carmen Ramírez Soasti - Universidad Politécnica Salesiana mramirezs@ups.edu.ec

La ponencia es el resultado de la investigación sobre la experiencia de la producción de programas y construcción de narrativas sonoras que se realizan en un medio de comunicación comunitario que es gestionado por la Carrera de Comunicación de la Universidad Politécnica Salesiana en Ecuador, como es Radio Mensaje, ubicada en el cantón Cayambe, provincia de Pichincha, como un laboratorio de prácticas preprofesionales, que se constituye en un espacio de mediación para el ejercicio de ciudadanía. Analiza los cambios que, desde un proceso de innovación educativa, han incidido en la formación de comunicadores sociales y su vinculación con la sociedad, precisando no solo el uso de tecnologías de información y comunicación como herramientas para la producción y difusión de contenidos, sino la importancia de comprender a la comunicación intercultural como mediación para el diálogo intercultural y el ejercicio de ciudadanía. 
Comunicación y Música: mensajes, manifestaciones y negocios

Es una investigación de carácter cualitativo que vincula la programación con las audiencias para incidir justamente en la construcción de ciudadanía a través de su programación y producción radiofónica con enfoque intercultural en cuyo proceso se realiza una mediación pedagógica y social que, procura en los estudiantes una comprensión de lo intercultural y en la audiencia un constructo sociocultural para el ejercicio de su ciudadanía.

Se reflexiona sobre la producción radial intercultural incluida en la programación realizada por docentes y estudiantes de la carrera de Comunicación como es el caso de las cápsulas informativas interculturales inclusivas con las que se da cumplimiento a lo que establece el Reglamento para la Aplicación del Art. 36 de la Ley Orgánica de Comunicación en el Ecuador, sobre difusión de contenidos interculturales.

043 - Arquitectura de la información y usabilidad en un medio de comunicación universitario - Armando Cuichán Universidad Politécnica Salesiana, Sede Quito acuichan@ups.edu.ec y Esteban Plaza - Universidad Politécnica Salesiana - Sede Quito - mplaza@ups.edu.ec

El desarrollo de las tecnologías de información y la conectividad han diezmado el modelo de negocio de los medios de comunicación y por ello los mecanismos de generación y consumo de contenidos periodísticos han debido ser readaptados continuamente. En este contexto, las instituciones educativas, buscan mecanismos que les permitan transmitir a los comunicadores y periodistas en formación, los conocimientos teóricos, textuales, contextuales, habilidades y destrezas para la elección de temáticas coherentes, desarrollo de investigaciones periodísticas y sistematización de piezas informativas.

La Carrera de Comunicación de la Universidad Politécnica Salesiana sede Quito, para la formación de comunicadores, contemplando los procesos teóricos y prácticos para la generación de contenido y los flujos de comunicación ha implementado un laboratorio $\mathrm{I}+\mathrm{D}+\mathrm{I}$, de simulación, experimentación y práctica preprofesional, en el que en flujos de trabajo responden a las características y condiciones de una 
medio de comunicación digital, en el cual la producción periodística se adapta a los géneros y formatos emergentes.

A partir del análisis cuantitativo de contenidos publicados en el medio universitario, su distribución y visualización, se reflexiona sobre esta experiencia fundamentada en la investigación-acción; se incluyen criterios relevantes para el trabajo interdisciplinar como la arquitectura de la información, la usabilidad, la interactividad, las redes sociales asociadas, entre otros aspectos vitales durante el proceso de formación de los comunicadores.

044 - Academia y fútbol: el rol del periodismo deportivo en la era digital - Vladimir Stoitchkov, Gabriela Coronel-Salas, Ana María B-Flandoli y Diana Rivera-Rogel - derivera@utpl.edu.ec Universidad Técnica Particular de Loja

El fútbol es el deporte más popular del planeta, y los mundiales son su carnaval. En cuestiones de calidad el campeonato del planeta, quizá, no es el mejor espectáculo conocido por la humanidad, pero con toda seguridad es el más visto y eso lo convierte en uno de los temas fundamentales del periodismo contemporáneo.

Más allá de las canchas, los mundiales se juegan en el escenario del periodismo deportivo. Una innumerable lista de medios de todos los continentes y países compiten entre sí, sobre todo, en tres categorías: exclusividad, originalidad y conocimiento. En ello también se involucran otros aspectos relacionados con los códigos específicos de cada lugar, la cultura deportiva (futbolera, concretamente) y las características de la identidad nacional.

Con el objetivo de abandonar el territorio de los simulacros y trabajar en condiciones reales (tiempo, mercado, competencia, derechos de autor, etc.), dentro de la clase de Comunicación Deportiva de la carrera de Comunicación de la Universidad Técnica Particular de Loja, se realizó el proyecto de innovación docente denominado: "Almanaque Mundial Rusia 2018". En el periodo abril-agosto de 2018, la clase se convirtió en una aula-redacción, donde cada uno de los 37 participantes cumplió funciones específicas del ámbito periodístico. 
El objetivo principal fue la creación de un almanaque dedicado al Mundial de Rusia 2018, que ofrece al público un producto estético, original y alimenta el conocimiento de los estudiantes en este tema. Y para expandir y concluir, luego se realizaron coberturas radiales y digitales del mismo campeonato. Por esta razón, el almanaque fue dividido en dos secciones principales: actualidad (enfocada en la corriente informativa del último mundial) e histórica (enfocada en la cronología, las anécdotas y las estadísticas de los campeonatos anteriores). Respectivamente, se aplicaron las herramientas del periodismo de datos y periodismo de investigación que, a través de géneros clásicos como nota informativa, entrevista, reportaje y análisis, sirvieron como base para un producto innovador en el mercado informativo de Ecuador.

045 - La audiencia en diferido (timeshift) de los partidos de España en el Mundial de Rusia 2018 - Eva Lavín - Universidad Rey Juan Carlos - eva.lavin@urjc.es, Jorge Gallardo-Camacho Universidad Camilo José Cela - jgallardo@ucjc.edu y Marcos Mayo Cubero - Universidad Rey Juan Carlos marcos.mayo@urjc.es

La penetración de la televisión conectada a Internet ha cambiado radicalmente los hábitos de consumo televisivo. Ahora, los productos televisivos se consumen en cualquier momento, en cualquier lugar y en cualquier dispositivo. Por tanto, en el marco de la medición de la audimetría, adquiere especial relevancia el registro de la audiencia en diferido o timeshift. Para el estudio de la audiencia hemos escogido el reciente Mundial de Rusia 2018 por su relevancia como uno de los eventos televisivos con mayor audiencia global, acotando nuestra muestra representativa a los partidos jugados por la selección española. Los resultados demuestran que a pesar de que la aportación de la audiencia en diferido a la audiencia global en Rusia 2018 es aún residual (inferior al 1\%), se aprecia que el mayor consumo en diferido se realiza el mismo día del partido (VOSDAL). A pesar de esto, los resultados alcanzados revelan que los cuatro partidos de España en el mundial han conseguido situarse entre los 30 programas más visionados en diferido durante su periodo. 
046 - Ciudadanía Digital: una oportunidad de formación e innovación -Victoria Dalila Palacios Mieles, Pontificia

Universidad Católica del Ecuador, vdpalacios@puce.edu.ec Narcisa Jessenia Medranda Morales, Universidad Politécnica Salesiana,nmedranda@ups.edu.ec-María Teresa Bravo Paredes, Corporación para la Educación Audiovisual Francisco Xavier, mayte.bravo@gmail.com

Las redes sociales no solo son espacios casi omnipresentes en la sociedad digital, también representan una oportunidad para educar en ciudadanía, seguridad y derechos humanos. Esta ponencia busca reflexionar sobre cómo la educación en nuevas tecnologías necesita ir más allá de lo estrictamente funcional sino ir hacia una comprensión más profunda de sus riesgos, sí, pero también de cómo las presencias virtuales son espacios para la expresión de valores, deberes y derechos.

Con este fin se va a explicar el concepto de Ciudadanía Digital y explorar propuestas educativas innovadoras acerca del tema y, a través de estas experiencias, evidenciar cómo el mayor involucramiento de padres y profesores permite fomentar en los estudiantes una actitud crítica frente a los contenidos de estos nuevos medios, un comportamiento ético en los espacios del internet y un uso responsable que no vulnere su seguridad y respete la privacidad propia y de los demás.

Se estudiarán los recursos de Common Sense Education, una guía en línea para educar en Ciudadanía Digital en todos los niveles escolares, creada con el apoyo del Project Zero de Hardvard, y su página relacionada, Common Sense Media, que hace reseñas de productos audiovisuales (películas y series de televisión), libros, apps, páginas web y videojuegos con pautas para padres sobre la recomendación de edad, criterios de contenidos e incluso recomendaciones de temas de conversación después de su consumo.

047 - Las prácticas comunicativas de los jóvenes universitarios de Ecuador, la influencia que ejerce la cultura de masas y los factores que determinan sus narrativas transmedias - Phd. 
Comunicación y Música: mensajes, manifestaciones y negocios

Lourdes Paola Ulloa López - Escuela Superior Politécnica del Litoral-lulloa@espol.edu.ec

En este trabajo el objetivo es demostrar el resultado de una investigación que determina cuáles son las prácticas comunicativas de jóvenes universitarios en Ecuador. Los jóvenes ecuatorianos han dinamizado la forma en que transmiten su mensaje a través de las redes sociales y sus publicaciones se desarrollan en narrativas transmedias que reflejan sus hibridaciones culturales propias del contexto polisémico de la cultura digital en la que se desenvuelven. En esta investigación se incluyó una encuesta a una muestra de 656 universitarios de la ciudad de Guayaquil, que es la ciudad con la mayor población universitaria del país y además se realizó una etnografía virtual cultural con 8 jóvenes ecuatorianos que estudian en Guayaquil. Entre los resultados más notorios se reflejan la influencia de la cultura de masas en los jóvenes que cumplen el rol de prosumidores en los medios sociales; también se explicará como el capital social juega un papel determinante en las redes sociales. Asimismo, se analizará la transmedialidad del mensaje y de qué manera influye en capital social en el momento construir las narrativas transmedias.

048 - Las redes sociales y la desinformación en las campañas políticas - Fernando Esquivel Lozano - Catedrático de la Facultad de Ciencias de la Comunicación, Universidad Autónoma de Nuevo León (UANL) - feresquivel@hotmail.com

Con la llegada de las nuevas tecnologías y especialmente de las Redes Sociales, la comunicación y el marketing político recibieron con esperanza la posibilidad de que a través de estos nuevos medios los electores pudiesen recibir más y mejor información sobre los procesos electorales y sobre los candidatos participantes. La esperanza se centraba en que, con este flujo de información directa, específica y casi hasta personalizada, los votantes contaran con las armas suficientes para poder tomar una decisión de voto razonada y dejar atrás al llamado voto emocional que comúnmente se da en países en vías de desarrollo.

Sin embargo, resultó exactamente lo contrario y lo que sería una gran red de información y de empoderamiento ciudadano, se convirtió en 
una gran oleada de desinformación y de confusión para los votantes, dado que la gran mayoría de las informaciones que recibieron o eran falsas o eran parte de las campañas negativas que encontraron un importante caldo de cultivo en las redes sociales. Así sucedió en los pasados comicios federales en México de julio del presente año, donde se eligió al nuevo Presidente de la República y se renovaron los integrantes del Congreso de la Unión y del Senado, además de ocho gubernaturas.

La proliferación de las llamadas fake news, memes y videos virales fue la constante, tanto en las campañas federales como locales donde también se renovaron una gran cantidad de alcaldías de los municipios mexicanos. Con ese intenso flujo de desinformación, el voto razonado fue superado ampliamente por el voto emocional, en unos comicios marcados por los

049 - El Canto Coral infantil como herramienta para mejorar la comunicación en niños y jóvenes: un estado de la cuestión Cristina Llabrés González - Universitat de les Illes Balears crisllabres@gmail.com

La música es una actividad lúdica que permite el desarrollo de los dos hemisferios del cerebro a la vez (Despins: 2009), a la vez que promueve la socialización de todos los que la practican. El canto coral por su parte, fomenta algunas de las habilidades necesarias más importantes para una buena comunicación. Teniendo en cuenta las ventajas que aporta el canto coral en las primeras etapas del aprendizaje, se hace indispensable, entonces, promoverlo desde las escuelas, institutos o entidades para llegar y ayudar en este aspecto a todos los rincones de la sociedad.

El presente trabajo recaba información alrededor del canto coral infantil con el objetivo de plasmar un estado de la cuestión sobre la importancia del canto coral en el aprendizaje inicial y sus ventajas como herramienta comunicativa en esta etapa del desarrollo educativo. Los resultados ofrecen un estado de la cuestión y una reflexión bibliográfica alrededor de la herramienta como generadora de competencias 
Comunicación y Música: mensajes, manifestaciones y negocios

generales y específicamente comunicativas indispensables en la etapa inicial del aprendizaje.

050 - Comunicación y turismo sostenible: construyendo identidades a partir de la marca territorio - Francisco Javier Delgado Polo - Intellectio - Investigación \& Estrategia (Ecuador) y Universidad Politécnica Salesiana (Ecuador) fdelgado@intellectioec.com y María Cristina Toledo Romero Intellectio - Investigación \& Estrategia (Ecuador) y Universidad de las Américas (Ecuador) - ctoledo@intellectioec.com

En el desarrollo contemporáneo de las ciencias sociales, la búsqueda de nuevos cánones y parámetros sustentados en los cambios vertiginosos de la sociedad, se alejan de su sola comprensión y buscan, por su parte, una interpretación integral a partir de la multidisciplinariedad y la transdisciplinariedad. Uno de los cambios sustanciales en términos de construcción colaborativa de la sociedad, supone la sostenibilidad de las economías, entendidas como un patrón de desarrollo de los territorios, de forma conciliadora, equitativa y armónica entre quienes lo habitan, su entorno, sus recursos y sus potencialidades.

En este proceso, la investigación y la comunicación juegan un rol fundamental, tanto en la obtención de datos sustentados en el rigor científico, como en la forma en cómo estos datos se decodifican para construir mensajes que permitan, a través de nuevos soportes, plataformas y tecnologías, la circulación de saberes y la consolidación identitaria de un pueblo, de tal forma que su desarrollo en términos económicos, obedezca a una lógica sostenible y coherente.

En la actualidad, países, ciudades y territorios se encuentran repensando la manera de desarrollar alternativas sostenibles que permitan el crecimiento económico de sus países de forma sostenible, a partir del turismo. Mientras países como España (segundo receptor de turismo en 2017, de acuerdo con cifras de la OMT), están pensando en reorientar su política de turismo; otras economías emergentes buscan captar nuevos visitantes, con una política que se aleje de las formas depredadoras de turismo sustentadas en el libre mercado y 
atiendan a una forma equilibrada de promocionar un destino en función de su identidad, su cultura y su gente. En este sentido, la construcción de una marca de destino resulta de particular interés para que territorios que buscan conservar sus rasgos identitarios, y a su vez el bienestar de sus habitantes, puedan posicionarse como destinos sostenibles que mejoren sustancialmente su calidad de vida.

A partir de nuevas herramientas de comunicación como el place branding, o el citybranding, los gobernantes de los territorios y sus ciudadanos tienen una posibilidad importante de complementar, desarrollar y dinamizar sus economías desde la promoción y captación de turismo sostenible y que a su vez agregue valor a todos los encadenamientos productivos que existen en las distintas localidades. En este sentido, es vital conocer cómo se proyecta la gente del territorio, descubrir, a partir de la investigación y la comunicación su esencia; y ayudarlos a identificar su potencialidad turística sin vulnerar su identidad o su cultura; asimismo. Solo de esta manera, la marca territorio logra legitimarse, y pasa de ser un aspecto superficial de forma, a consolidarse como parte identitaria y herramienta de desarrollo sostenible de una localidad.

051 - Gestión de la comunicación digital interna, un reto para las organizaciones - Karen Cesibel Valdiviezo Abad y Janeth Ivanova Solórzano Vidal - Universidad Técnica Particular de Loja - kcvaldiviezo@utpl.edu.ec jisolorzano@utpl.edu.ec

Muchas de las organizaciones que surgieron hace varios años empiezan y algunas continúan el proceso de adaptación al mundo digital. Esta misma tendencia ha llevado a los públicos a presentar nuevas necesidades comunicacionales, donde las empresas se han visto obligadas a responder con acciones innovadoras, digitales y oportunas. El principal público al que deben prestar atención las organizaciones es el interno, pues de él depende el éxito de cada empresa.

El objetivo de este trabajo investigativo, es conocer las acciones de comunicación digital que se ejecutan en el marco de la comunicación interna, su aplicación y uso, a fin de determinar la eficacia y eficiencia de las mismas dentro de las empresas privadas del Ecuador. Para dar 
Comunicación y Música: mensajes, manifestaciones y negocios

cumplimiento a este objetivo, se seleccionó como muestra 112 empresas de todo el país de un ranking que evalúa las empresas más productivas a nivel nacional y de ellas, fueron 43 las que finalmente participaron a través de una encuesta digital.

Con los resultados obtenidos se hizo un análisis profundo de las tres escuelas de conducta organizativa: Clásica, Relaciones Humanas y Sistémica y entre una de las conclusiones evidenciadas es que las empresas ecuatorianas utilizan las herramientas digitales como una forma de apoyo a la difusión de información interna, siendo uno de los tres un modelo el predominante y sin que ello garantice una comunicación eficiente.

052 - La independencia de los periodistas frente a los regalos e interferencias económicas; una perspectiva comparada entre periodistas y ciudadanía - Juan Carlos Suárez Villegas Universidad de Sevilla, Jesús Díaz del Campo - Universidad Internacional de La Rioja y Ruth Rodríguez - Universidad Pompeu Fabra

Dentro del proyecto de I+D+I, "MediaACES. Accountability y Culturas Periodísticas en España. Impacto y propuesta de buenas prácticas en los medios de comunicación españoles", financiado por el Ministerio de Economía y Competividad de España, se ha llevado a cabo un trabajo de campo entre periodistas y ciudadanos sobre las buenas prácticas periodísticas y los sistemas de rendición de cuenta. Entre las cuestiones formuladas se ha planteado de qué manera los periodistas podría ver comprometida su independencia informativa ante relaciones más o menos estrechas con poderes políticos y económicos, así como cuando puedan mediar regalos que puedan ir desde un simple gesto de cortesia institucional a ciertas formas de compensación por un tratamiento informativo favorable. En esta comunicación se analiza la posición de los profesionales y de los ciudadanos. Se ha tenido también en cuenta la evolución de la profesión en este punto en relación con estudio de similares caractícas realizado en el año 2012. 
053 - Ciudadanías plurales para los Estados Plurinacionales David Moromenacho - Universidad FLACSO intipakchuri@gmail.com

En el siglo XXI, Bolivia y Ecuador se asumieron mediante mandado constitucional como estados plurinacionales. Esta denominación buscaba dar una salida a las históricas demandas de los pueblos indígenas por el reconocimiento de sus especificidades étnicas, culturales y políticas. La idea de plurinacionalidad implica una ruptura de la construcción histórica de las naciones latinoamericanas que han sido imaginadas como entes homogéneos y administradas principalmente por las élites criollas y mestizas. Este modelo de Estado aparece como la posibilidad de imaginar y construir la nación bajo criterios reales de reconocimiento y participación de los diversos pueblos y nacionalidades presentes en los territorios. De la mano del cambio en el modelo de Estado, es necesario repensar el concepto de ciudadanía; pues, históricamente, ésta ha estado concebida y ejercida dentro del modelo tradicional de Estado nacional homogéneo y vertical en donde la participación ciudadana se ha limitado a los eventos de una democracia representativa. En un Estado Plurinacional, es necesario reconocer ciudadanías plurales, reconocer nuevos sujetos de derechos y nuevas maneras de ejercerlos. La ciudadanía plural implica la posibilidad de que cada persona pueda reconocerse y asumirse como ciudadana y que pueda hacerlo desde su propia historia, lengua, cultura, forma de organización... Es aquí cuando conceptos como la interculturalidad aparecen como un camino para garantizar el ejercicio de derechos para una ciudadanía plural en un contexto plurinacional. El Estado Plurinacional está llamado poner en marcha políticas públicas interculturales en temas como salud, educación, justicia, democracia, participación. Es de esa manera que las personas podrán ser plenamente quienes son y, a la vez, plenamente ciudadanas.

054 - La acción comunicativa en los pueblos indígenas de Chimborazo como herramienta para el cambio social - Julio Bravo Mancero - jbravo@unach.edu.ec, Carlos Larrea Naranjo -carloslarrea@unach.edu.ec y Ramiro Ruales Parreño Universidad Nacional de Chimborazo, Ecuador rruales@unach.edu.ec 
Este artículo tiene como objetivo establecer la relación del método de acción católica: ver, juzgar y actuar con la investigación, acción, participación desarrollado para los procesos de comunicación, toma de conciencia y cambio de actitud en las comunidades indígenas de la provincia de Chimborazo, Ecuador. Se definió como pregunta de investigación ¿Qué elementos comunicativos se emplearon para generar la transformación?

La metodología de tipo cualitativa permitió descubrir la coincidencia que existe entre las dos propuestas que transformaron las condiciones de vida de los habitantes de estas poblaciones. Se utilizó como herramienta el análisis de contenido a: revista Mensaje, periódico Jatari Campesino, guiones del programa radiofónico Hoy y mañana, y a discursos y homilías pronunciados por el exobispo Leonidas Proaño. Los resultados tienen categoría de relevantes porque permitieron conocer cómo la información obtenida mediante el diálogo durante las visitas a los poblados, se empleó para impulsar actividades de socialización tendientes a modificar la realidad en la que se desenvolvía el grupo humano, objeto del estudio. En conclusión, puede decirse que la intervención formal en territorio permitió conocer las categorías de inter-acción e inter-relación.

055 - Cali y música en la serie Narcos - Antonio David Palma Crespo - Doctor en Patrimonio por la Universidad de Córdoba - teatinos@alu.uma.es

La tercera temporada de Narcos trata en profundidad el Cártel de Cali. La capital del Valle del Cauca se convierte en el escenario donde se desarrolla la trama principal. Durante los capítulos veremos el funcionamiento de la banda criminal, sus actores principales, sus relaciones con las estructuras del poder, el trabajo policial destinado a detener a los principales dirigentes del Cártel, pero también se describirá la ciudad. Y uno de los recursos para mostrarnos Cali, será la banda sonora utilizada a lo largo de los diez capítulos que conforman la tercera temporada. La música es un componente más de la ciudad y por eso se refleja en la trama. Las canciones elegidas servirán para 
enseñarnos la ciudad colombiana, para entender su idiosincrasia, para valorar el factor cultural de Cali.

056 - De la marginalidad al "blockbuster". Cuando el cine contemporáneo aceptó algunos himnos del "hard rock" David Fuentefría Rodríguez - Universidad de La Laguna dfuentef@ull.es

Después de varias décadas de tránsito sociológico y vital, las vertientes de la música rock reconocidas como "duras" en los años 80 y 90 parecen haber completado su integración definitiva en la cultura contemporánea. Fenómenos como la globalización, el "revival" y la revolución de internet, han llegado a situar a algunas de aquellas bandas, otrora relegadas a circuitos mediáticos marginales, al nivel de iconos de culto tras años de polémicas históricas, ejercicios de censura en regímenes de todo signo político, y acusaciones de influencia perniciosa en la juventud finisecular. Este artículo estudia los principales hitos del "hard rock" que, habiendo sido objeto de rechazo su tiempo, han pasado a formar parte indisoluble de las bandas sonoras de algunos de los productos cinematográficos estadounidenses más exitosos y conocidos de nuestra era, tanto desde una perspectiva panorámica como a partir de su relación con determinados géneros, e incluso como apoyo para la caracterización de sus complejos personajes.

057 - Interactividad en la prensa digital: análisis comparativo en diarios de Cataluña - J.-F. Fondevila-Gascón - Universitat Ramon Llull, EAE Business School, UPF, EUM-UdG, Cesine, Euncet-UPC, UOC y CECABLE, Barcelona y Terrassa (España) - joanfrancesc.fondevilag@upf.edu, S. LiberalOrmaechea - Universidad Francisco de Vitoria. Madrid (España) - s.liberal.prof@ufv.es y F. Vila - EAE Business School - fvila.marquez@campus.eae.es

Introducción: En el mundo interconectado y always on, los medios de comunicación y sus lectores se enfrentan a una continua transformación de sus relaciones. El multimedia, el hipertexto y la interactividad, como aspectos diferenciadores y disruptivos en la 
Comunicación y Música: mensajes, manifestaciones y negocios

relación entre medios online y usuarios, han sido objeto de estudio desde muy diversas perspectivas y concentran hoy gran parte de la investigación del marketing en torno a los efectos y posibilidades de las estrategias de difusión de los medios de comunicación digitales. Metodología: A partir del análisis comparativo de cuatro de los portales de referencia en la prensa online regional de Catalunya -Diari del Maresme, Vilaweb, Diari Ara y La Vanguardia-, esta investigación analiza la percepción (de una muestra de estudiantes $n=110$ ) en torno a los parámetros de interactividad y la naturaleza y penetración de los mismos, así como las principales dinámicas que tienen que ver con las relaciones online entre medios y lectores. Resultados y conclusiones: La valoración de la interactividad y sus componentes necesarios (banda ancha, conversación, engagement, calidad de experiencia, always on, recomendación y creación de comunidad) es positiva, aunque la escucha a la iniciativa del lector en la agenda setting es mejorable.

058 - Construcción de marca Club Atlético de Madrid: análisis de sus anuncios promocionales 2000-2008 - Santiago Mayorga Escalada - Universidad Pontificia de Salamanca / Universidad Europea Miguel de Cervantes - smayorgaes.com@upsa.es / smayorga@uemc.es

El final del siglo XX y los comienzos del siglo XXI suponen una transición disruptiva entre un paradigma de la comunicación clásico donde todo estaba controlado y cada agente tenía su lugar por uno nuevo donde todo es líquido, dinámico y no hay un patrón establecido. Dentro de esta situación novedosa se producen notables cambios tecnológicos y sociales. La globalización y la inmediatez en las formas de comunicación se trasladan al ámbito comercial y de consumo. De igual forma los usuarios pasan a ostentar el poder a la hora de consumir medios, contenidos o informarse de aquello que quieren, en el momento que quieren y a través de diferentes dispositivos. Con el fin de adecuarse a los cambios, las organizaciones le dan todo el protagonismo a las marcas, que se convierten en el agente principal que conecta con los nuevos usuarios a través de la construcción de experiencias únicas y el desarrollo de un proceso que acaba con una promesa cumplida. 
En el ámbito del fútbol profesional, como parte de la industria del entretenimiento, se tiende a profesionalizar la actividad de los clubes con el fin de adecuarse a las exigencias del mercado por un lado y obtener nuevas vías de financiación por otro. Los clubes pasan a convertirse en potentes empresas, muchas de ellas de ámbito global, lo que les obliga a establecer procesos estratégicos de gestión de marca. El Club Atlético de Madrid fue uno de los clubes pioneros en La Liga española que entendió esta nueva coyuntura. Junto con la agencia de publicidad madrileña Sra. Rushmore desarrolló toda una estrategia encaminada a construir su marca a través de una serie de promociones en forma de anuncios clásicos que lograron transmitir la identidad del club, conectando con sus públicos y posicionando la marca dentro del sector.

059 - La generación de nuevos contenidos comunicacionales, utilizando el patrimonio audiovisual - Jessica Ordóñezjessikordole@gmail.com, Milenny Suquilandamgsuquilanda1@utpl.edu.ec y Juan Carlos Maldonadojcmaldonado2@utpl.edu.ec Universidad Técnica Particular de Loja.

El término patrimonio es considerado como la recolección de material o bienes, cuyo valor puede ser histórico, económico, social o cultural. La UNESCO dentro de su programa memoria del mundo, tiene como objetivo primordial la recuperación del patrimonio audiovisual. En este contexto, los ciudadanos o custodios del patrimonio audiovisual, tienen la obligación de cuidarlo y preservarlo. Desde el Laboratorio de innovación y experimentación MediaLab de la Universidad Técnica Particular de Loja, se plantea la importancia de difundir este material, a través de la creación de nuevos contenidos.

Con el soporte y apoyo de docentes y estudiantes de la carrera de Comunicación se plantea el proyecto audiovisual: "Loja, ayer y hoy", en este se pretende rescatar la identidad cultural e historia de la provincia de Loja, utilizando como principal recurso el Patrimonio Audiovisual de la UTPL (video, fotografía, audios). La metodología que se aplica es experimental, el proyecto contrasta escenarios antiguos y actuales de la ciudad, creando una nueva producción de contenidos 
Comunicación y Música: mensajes, manifestaciones y negocios

audiovisuales. Las temáticas giran en torno a lugares, personajes, tradiciones y costumbres.

En el marco de la experimentación e innovación, se propone la generación de estos nuevos formatos que posteriormente pueden ser aplicados en los medios de comunicación y otras estancias involucradas en el ámbito cultural. En este caso se utiliza el archivo audiovisual que sirve como base para la creación de nuevos contenidos y narrativas. De esta manera el patrimonio audiovisual que posee la UTPL se convierte en un aporte para la sociedad, al utilizar ese material se puede recrear la historia y darla a conocer a las actuales y futuras generaciones.

060 - Hombres que escriben para mujeres: el Periódico de las Damas (1822) - Patricia Navas Romero del Hombrebueno patricianavas73100@gmail.com y José Bernardo San Juan Departamento de Ciencias de la Educación, Lenguaje, Cultura y Artes, Ciencias Histórica-Jurídicas y Humanísticas y Lenguas Modernas. Universidad Rey Juan Carlos jose.bernardo@urjc.es

Aunque la prensa fue en sus comienzos intrínsecamente masculina hecha por hombres y para hombres- a partir del siglo XIX comienza a percibirse -a través, por ejemplo, de la publicación de ciertos folletines o de algunas publicidades - la existencia de un público lector femenino. En ese "contexto iniciático" se encuentra el Periódico de las Damas (1822), una de las primeras publicaciones españolas escrita netamente para mujeres. En este trabajo se realiza un análisis de contenido de los contenidos de ese diario para mostrar qué modelo de mujer se trasparenta en sus páginas.

061 - Fact-Checking y debates electorales televisados: las elecciones generales de 2015 y 2016 - José Rúas-Araújo joseruas@uvigo.es, Andrés Mazaira-Castro amazaira@uvigo.es e Iván Puentes-Rivera ivanpuentes@uvigo.es - Universidad de Vigo

El tradicional control y verificación de hechos llevado a cabo con motivo de cada convocatoria electoral norteamericana (Wintersieck, 
2017) y que cuenta también con experiencias en varios países europeos (Graves y Cherubini, 2016) y con una metodología precisa de análisis (Lowrey, 2017), cobra cada vez un mayor interés, hasta el punto de convertirse en un reclamo y servicio (López, Rodríguez-Vázquez, Álvarez-Gromaz, 2016) en cada proceso electoral. Durante las últimas presidenciales celebradas en los EE.UU. se detectó -a través de la aplicación de herramientas de fact-checking, como "Truth-O-Meter", de PolitiFact (www.politifact.com)- que tanto el candidato republicano, Donald Trump, como la demócrata Hillary Clinton, realizaron declaraciones falsas en los tres debates electorales celebrados. En concreto, 104 afirmaciones falsas realizadas por Trump y 13 por Hillary Clinton (Dale y Talaga, 2016). Esta propuesta propone la realización de un análisis y fact-ckecking de los últimos debates electorales televisados celebrados en España, comparando el cara a cara entre los candidatos Mariano Rajoy (PP) y Pedro Sánchez (PSOE), de 2015, con el debate a cuatro entre los dos anteriores, Pablo Iglesias (Podemos) y Albert Rivera (Ciudadanos), de 2016. El objetivo es comprobar la veracidad de los datos indicados en cada debate por los protagonistas del mismo y observar si la introducción de nuevos actores en el escenario supuso una mayor riqueza y rigor, en cuanto a las aportaciones de cada uno de los intervinientes, comparando ambos eventos.

062 - Comunicación en contextos de crisis reputacional. Estudio de caso sobre la Universidad Rey Juan Carlos - Pablo Vázquez Sande - Universidad de Santiago de Compostela pablo.vazquez.sande@usc.es y Lito García Abad - Centro de Estudios Superiores Universitarios de Galicia - jlgarcia@usj.es

La Universidad Rey Juan Carlos (URJC) se ha visto sacudida en los últimos meses por varios escándalos de corrupción que trascendieron a la opinión pública debido a la amplia cobertura que realizaron al respecto la mayoría de medios de comunicación españoles.

En este contexto de crisis declarada, se analizan los mensajes que en los últimos dos años (noviembre 2016 - octubre 2018) recibieron los estudiantes actuales de la institución por parte del rectorado de la URJC a través del correo electrónico corporativo. Se plantea, por tanto, una 
Comunicación y Música: mensajes, manifestaciones y negocios

investigación que emplea como técnica el análisis de contenido y que se centra en un stakeholder especialmente sensible desde el punto de vista de la comunicación interna, como son los alumnos.

Los resultados obtenidos reflejan tres tendencias: un comportamiento mayoritariamente reactivo y no proactivo; una demora considerable en la gestión de los diferentes conflictos que se sucedieron; y la preferencia por la estrategia de la transferencia de responsabilidades.

063 - Mediatización de los debates parlamentarios en torno a los roles de la mujer y la violencia sexual - Rosa Berganza rosa.berganza@urjc.es, Eva Gómez, Raquel Vinader, Jorge Toirac, Beatriz Herrero y Juana Anguita - Universidad Rey Juan Carlos

Los temas que componen la agenda simbólica de los parlamentos pueden repercutir en la preocupación o el interés que se le da a una determinada cuestión. El fenómeno de mediatización explica que la lógica mediática haya desplazado a la política y, por tanto, que los representantes públicos busquen con su comunicación responder a las necesidades y a las reglas de los medios (Davis, 2007; Strömbäck, 2011).

No todos los temas son tan vulnerables de ser introducidos en la esfera política tras adquirir relevancia en la cobertura periodística. Por ello, esta investigación pretende revelar la presencia de los medios tradicionales y sociales como fuentes informativas en la agenda simbólica cuando se habla de la mujer y los roles que ejercen durante periodos de postconflicto, así como la presencia de la violencia sexual en los debates parlamentarios en el caso de la República Democrática del Congo - de enero 2012 a junio del 2015 -, y Burundi - de enero 2010 a junio del 2015 -. El estudio se ha llevado a cabo a través de un análisis de contenido cuantitativo automatizado de actas de debates sobre ambos postconflictos obtenidas del Parlamento europeo, británico, alemán, francés y español. Los resultados muestran que hay una presencia más baja de medios en los debates de la RDC que en Burundi, que puede ser debido a la censura y cierre de medios en el país. Por tanto, la presencia de la mujer en los debates parlamentarios, a las que se les asigna el rol de víctimas, está en relación con las ONGs 
como fuentes informativas, y no con los medios de comunicación. La violencia sexual como arma de guerra se debate en ambos postconflictos, destacando el Parlamento Europeo entre los otros cuatro.

064 - La Importancia de Laclau en los Estudios de la Comunicación - Nina Lulushca Aguiar Mariño y Roberto Miguel Sánchez Montoya- Universidad Politécnica Salesiana, Sede Quito- Ecuador - naguiar@ups.edu.ec

El primer desafío teórico que afrontaremos es la definición de qué es discurso. En la academia el discurso ha sido abordado por diferentes disciplinas de las humanidades y las ciencias sociales que buscan analizar la construcción social de sentido. Nuestra intención no es hacer un recuento de la extensa literatura que se ha generado sobre el tema, desde diferentes escuelas teóricas, sino más bien, buscaremos centrarnos en los argumentos de la corriente postestructuralista que sostiene Ernesto Laclau. Para lograr establecer la importancia de Laclau en los estudios de la comunicación, es necesario explorar las raíces de las que se alimenta su edificio teórico. Para ello, presentaremos los más importantes ejes del estructuralismo clásico y las críticas posteriores de las que se desprende una serie de reformulaciones teóricas.

En materia discursiva, Laclau pertenece a la corriente postestructuralista que cuestiona el racionalismo, el cierre total de sentido; y más bien; sostiene el desplazamiento del sentido en una compleja heterogeneidad social. Asimismo, un aspecto fundamental en su obra, es que considera que lo discursivo no se queda en el habla o lo escrito, sino que es visto como sinónimo de articulación social. "Rechaza la distinción entre prácticas discursivas y no discursivas y afirma (...) que todo objeto se constituye como objeto de discurso" (Laclau y Mouffe, 1987:144). Esta totalidad discursiva, lejos de ser homogénea y cerrada, está sujeta a una serie de tensiones. Cuando hablamos de una situación de tensión nos estamos refiriendo a una relación contingente que no puede resolverse a priori, sino que es intrínseca a su constitución y sujeta a desplazamientos de sentido según diversas circunstancias. Para comprender esta situación, debemos tener 
Comunicación y Música: mensajes, manifestaciones y negocios

en cuenta que, en la práctica, varios elementos buscan constituirse simultáneamente como totales, lo que implica una lucha de distintas particularidades por fijar significantes.

Las relaciones diferenciales y equivalenciales presentes en la construcción de sentido son fundamentales para comprender la construcción de relaciones sociales. La forma en que se genera sentido es equiparada a la construcción de una identidad social, que a fin de cuentas es una formación discursiva. Comprender los fundamentos teóricos de Laclau desde la comunicación, es abrir una discusión en torno a la participación activa que los actores políticos y sociales logran- a través de sus prácticas discursivas. Entender las claves del discurso político tiene una especial relevancia, ya que lejos de ser una actividad desinteresada, la producción discursiva sería pues, la posibilidad para el ejercicio de la ciudadanía.

065 - Desinformación y comunicación organizacional - Leticia Rodríguez-Fernández - Universidad Nebrija lrodrigu@nebrija.es

Las fake news son protagonistas de la actualidad y han abierto el debate público sobre su impacto y consecuencias. Las organizaciones se enfrentan a nuevos retos para preservar su reputación y evitar que este tipo de bulos dañe la relación con sus públicos.

El presente trabajo aborda el estudio de la desinformación y su injerencia en la comunicación corporativa e institucional. Para ello, se ha realizado una revisión bibliográfica de la literatura académica relacionada y un seguimiento de las verificaciones realizadas por el factchecker Maldito Bulo, publicadas en su página web entre el 1 de julio y el 30 de septiembre de 2018. A través del análisis de contenido se han identificado los tipos de organizaciones más afectadas por la desinformación y los bulos más comunes. El objetivo final es detectar cuáles son las informaciones falsas más generalizadas y establecer potenciales acciones de anticipación que puedan contrarrestar su impacto.

Cerca del 60\% de las verificaciones analizadas en la muestra están relacionadas con alguna organización y se identifican, entre los bulos, 
contenidos sobre ofertas falsas de trabajo, supuestas promociones y regalos de producto, así como declaraciones nunca emitidas de sus representantes.

066 - Los discursos pseudocientíficos en las redes sociales: un análisis a través de canales temáticos - Yolanda Cabrera GarcíaOchoa - Universidad de Valencia- yolanda.cabrera@uv.es y Vanessa Roger-Monzó - ESIC Business\&Marketing School vanessa.roger@esic.edu

El objetivo de esta investigación consiste en analizar cómo se construye el imaginario social de las terapias naturales, complementarias y alternativas a través de redes sociales. Para ello, se ha llevado a cabo un análisis de contenido del canal temático "Terapias alternativas y remedios naturales" de la plataforma Youtube y de la FanPage de Facebook asociada a este canal, examinando su evolución de julio de 2017 a julio de 2018. El seguimiento en Youtube se ha realizado tomando como muestra los 20 vídeos más visionados y los 20 menos visionados en el período indicado. Del mismo modo, se ha estudiado el contenido de la página de Facebook, especialmente, de las publicaciones de carácter audiovisual y sus comentarios asociados. Los resultados obtenidos revelan un elevado interés por las terapias alternativas y complementarias y confirman la utilización de este canal como plataforma para difundir marketing de contenidos y captar tráfico a la FanPage vinculada, la cual posee fines comerciales y busca, de este modo, incrementar sus ventas. Asimismo, se constata que el canal de Youtube está asociado a una página web integrada por una tienda online y un blog, a la que también redirige las visitas, si bien en menor medida, aunque igualmente con evidente objetivo lucrativo. Además, se constata que los contenidos publicados tanto en las redes sociales de Youtube y Facebook, como en el blog de la página web contribuyen a la difusión de temas de carácter pseudocientífico, con los riesgos que conlleva para la sociedad.

067 - El branded content en la comunicación política: reforzar la identidad a través de la emoción. El caso de la publicidad institucional del Govern balear - Dra. Ángeles Durán Mañes Centro de Enseñanza Superior Alberta Giménez-Universidad 
Comunicación y Música: mensajes, manifestaciones y negocios

Pontificia de Comillas, España. -aduran@cesag.org, Dr. Francisco Fernández Beltrán - Universitat Jaume I, España fbeltran@uji.es y Antonio Marín - Universidad de Granada, España - amarin@ugr.es

Las organizaciones han asumido la importancia de consolidar su imagen corporativa y proyectar de forma eficiente los rasgos de su identidad. En el ámbito político, entendido como uno de los elementos esenciales de la esfera pública, la comunicación y transparencia de las instituciones debería ser una obligación ineludible. Pero más allá de la información, las administraciones necesitan posicionarse con otras formas de comunicación más emocionales, que impacten más en la opinión pública y garanticen una adhesión de la ciudadanía, especialmente en aquellos temas de responsabilidad social. Frente a la publicidad tradicional, el branded content, entre ellos el storytelling y el storybuilding, abren posibilidades para la comunicación política, que puede encontrar en la viralización espontánea, gracias a las redes sociales y a la participación ciudadana, una alta rentabilidad.

En esta comunicación argumentamos la eficacia potencial de estas nuevas formas de comunicación, que ejemplificamos con el análisis de varias campañas audiovisuales del Gobierno balear. La participación de la propia audiencia en la producción, en la que los ciudadanos intervienen como sujetos protagonistas de las historias, puede generar una empatía que anime a su consumo y proporcione una mayor aceptación del mensaje.

068 - Fake news y elecciones: una revisión teórico-metodológica - Leonardo Magalhães Firmino, Pontifícia Universidad Católica de Rio de Janeiro (Brasil) y Juliana Colussi, Universidad del Rosario (Colombia) - juliana.colussi@urosario.edu.co

Desde la primera campaña de Barak Obama llevada a cabo en 2008 el marketing político se aprovecha de las redes sociales para divulgar los contenidos que convienen a sus candidatos. Entre estos contenidos que viralizan a través de cuentas de usuarios de Facebook y Twitter, se encuentran las fake news, que empezaron a ganar protagonismo en la campaña electoral del presidente estadounidense Donald Trump. Ante 
este escenario, y teniendo en cuenta los procesos electorales recientes que se ha llevado a cabo en diferentes países de América Latina, como México, Colombia y Brasil, el presente trabajo se propone a realizar una revisión teórico-metodológica sobre fake news en ambientes electorales. Más que plantear una discusión con base en las investigaciones desarrolladas sobre noticias falsas y posverdad, este artículo busca verificar los procedimientos metodológicos probados por otros investigadores para identificar las fake news para mejorarlos y aplicarlos en futuros estudios con las campañas políticas en países latinoamericanos.

069 - Viagem virtual aos Paradores de Espanha e às Pousadas de Portugal: os aspetos informacionais e interacionais dos seus websites. - Andreia Galhardo e Ana Nogueira - Universidade Fernando Pessoa, Porto, Portugal

No quadro da atual economia digital, que se impôs mais acentuadamente com a $4^{a}$ Revolução Industrial sentida em grande parte do mundo, o setor do turismo, altamente dependente da circulação de um elevado número de informações, beneficia, ao mesmo tempo que depende, para o seu desenvolvimento, das ferramentas e plataformas que a Internet disponibiliza. Entre essas ferramentas conta-se o website ao serviço da comunicação e do setor de distribuição das empresas. A criação, manutenção e gestão de um website já não é considerada uma moda do marketing, mas antes uma das principais preocupações das empresas que pretendam ter visibilidade, seja a uma escala regional seja a um nível global.

No setor do turismo a realidade não é diferente e hoje fala-se, inclusivamente num turismo 2.0 que se desenvolveu paralelamente à web 2.0. O website figura para os players deste setor como um meio de difundir informações acerca dos seus serviços e de interagir com os seus distintos públicos. Tal realiza-se independentemente da natureza dos estabelecimentos hoteleiros pelo que é aplicado pelos modernos hostels e boutique hóteis como pelas seculares Pousadas de Portugal e Paradores de Espanha, verdadeiras instituições turísticas com valores patrimoniais, históricos e culturais incomensuráveis e que constituem o objeto de interesse do trabalho. 
Centrando-nos no campo da comunicação, pretendemos, neste estudo, descrever, através de uma análise de conteúdo de tipo quantitativa, as caraterísticas dos websites oficiais dos Paradores de Espanha e das Pousadas de Portugal, ao nível dos seus traços informativos e interativos, e, por esta via, perceber, numa análise comparativa, o seu desempenho ao nível da comunicação e da distribuição. A análise da dimensão interacional destas plataformas leva-nos, ainda, à pesquisa e observação da eventual inclusão de ligações para os media sociais nos websites destes estabelecimentos.

070 - Los debates electorales en las elecciones primarias:

Análisis de caso de las primarias socialistas - Erica, Conde

Vázquez- Universidade de Vigo-

erika.condevazquez@gmail.com

Los procesos de elecciones primarias son herramientas de desgaste de los partidos (Boix, 1998)

motivado, especialmente, por la realización de debates entre los diferentes candidatos permitiendo que se expongan públicamente diatribas internas. También es una realidad que, en la actualidad, los debates electorales se encuentran en una búsqueda continua de nuevos formatos y medios de difusión (Padilla, 2014). Por ello, con el objetivo de profundizar en la influencia de la prensa en dichos instrumentos se propone analizar el debate electoral de las elecciones primarias del PSOE celebrado el 15 de mayo de 2017 entre los tres candidatos: Pedro Sánchez, Patxi López y Susana Díaz. Así como, su repercusión en medios para ver como se ha visto afectada la imagen del partido mediáticamente y la repercusión que ha tenido en los ciudadanos comunicativamente.

La propuesta se realizaría mediante un estudio de caso analizando la repercusión del debate en dos medios nacionales con líneas editoriales opuestas (El País y El Mundo). Se recoge el estudio de los perfiles de Twitter de los citados medios durante los debates: observando el seguimiento del evento y la creación de contenido: número de tweets de cada publicación, producción de contenido audiovisual, seguimiento en directo, número de tweets por candidato, hastags, memes, 
menciones a los candidatos, comentarios de los seguidores, me gusta y retweets. Así mismo, la revisión de su hemeroteca digital durante el mismo periodo de tiempo observando los titulares y realizando un análisis comparativo del seguimiento en el medio digital y en la red social.

071 - México visto por los corresponsales españoles - José Ramón Santillán Buelna - Observatorio de México en España joserrabuelna@hotmail.com

Se examina la cobertura informativa que los corresponsales de dos diarios españoles realizaron de México durante los años de 2013 a 2016. Para ello se ha realizado un análisis de contenido a 139 noticias producidas por los corresponsales de El Periódico y La Vanguardia con el fin de identificar producción informativa, temáticas tratadas, fuentes y valoración de las noticias. Entre los principales resultados destacan que los corresponsales firman una noticia a la semana en cada diario. Por lo general no escriben del día a día informativo, sino que profundizan en los acontecimientos o incorporan temas nuevos. Predomina la cobertura de temas relacionados con la inseguridad y el narcotráfico sobre asuntos económicos o culturales. Resalta el uso de fuentes oficiales y de testigos, y un tratamiento informativo negativo que relaciona la imagen de México con la idea de país peligroso.

072 - Storytelling y relato transmedia en la comunicación de las empresas - María Merino Bobillo - Universidad de Valladolid maria.merino@hmca.uva.es

Compaginar lo local y lo global es una de las preocupaciones de las organizaciones en el mundo actual. Pisar firme en el territorio en el que están implantados y volar fuera de sus límites. Sucede a nivel empresarial y comunicativo. Nos interesa fijarnos en este último, observar cómo desde una empresa dedicada a la moda se combinan ambas cosas. Por un lado su raigambre con la tradición cultural de su territorio, y por otra estar en voga las tendencias

Nos interesa fijarnos en este último, observar cómo desde una empresa dedicada a la moda combinan su raigambre con la tradición cultural de 
Comunicación y Música: mensajes, manifestaciones y negocios

su territorio, con las últimas tendencias en comunicación. Colombia y el realismo mágico sirven de inspiración para la creación de un universo visual que Lafayette transforma en imágenes textiles. Estas, a su vez, ejercen de protagonistas de un storytelling que la empresa utiliza en diferentes formatos, como una influencia del relato transmedia.

073 - Digital Influencers e a Comunicação das Marcas: Atuação nos Blogs e no Instagram - Andreia Pinto, Andreia Galhardo galhardo@ufp.edu.pt - University Fernando Pessoa, Álvaro Cairão

O crescimento exponencial que se observou nos media sociais originou o aparecimento de novos líderes de opinião, influenciadores, portanto, que desenvolvem um inesperado nível de proximidade junto da sua rede de contactos. Já as marcas, procuram no marketing de influência o contributo destes novos influenciadores para se aproximarem dos seus alvos. O presente artigo debruça-se sobre a comunicação das marcas pelos digital influencers e a atuação destes em plataformas digitais, designadamente em Blogs e no Instagram. Desenvolveu-se um estudo exploratório, que teve por base uma análise de conteúdo de todos os posts, em Blog e Instagram, de 4 digital influencers portugueses da área da moda.

Inicialmente desenvolveram-se duas grelhas de análise, estruturadas em diversas categorias e variáveis, que serviram de linhas orientadoras da leitura e posteriormente procedeu-se à análise quantitativa dos resultados. Os dados obtidos dizem respeito ao primeiro trimestre de 2018 e respeitam a 266 publicações em Blogs e 440 posts em Instagram.

Apesar de as marcas apostarem cada vez mais nesta estratégia, aparentemente inócua, começam a aparecer sinais de que o ciclo de consumo está a ser quebrado pela falta de confiança nos influencers, fato que merece atenção no espaço deste trabalho. Consideramos, ainda assim, que esta é uma área de comunicação e de estratégia de marketing que vai continuar, não só em crescimento, mas também em constante transformação, uma vez que as empresas já começam a ter o impacto esperado no digital e que os públicos continuam a confiar mais 
em pessoas que estão, pelo menos num nível aparente, mais distanciadas das insígnias comerciais e mais próximas da realidade dos consumidores.

074 - Televisiones autonómicas y debate político en las redes sociales - Julia, Fontenla -Universidad de Vigojulia.fontenla@gmail.com

Las redes sociales han irrumpido en el panorama mediático provocando un cambio en el consumo de contenidos por parte de las audiencias, así como en la generación de opiniones, diálogo e incluso actitudes relacionadas con el ámbito político, especialmente en el público joven. Las televisiones públicas y privadas deben adaptarse a estas nuevas plataformas, generadoras de debate público y político.

En esta propuesta se analiza la presencia en las redes sociales YouTube e Instagram de los 12 canales de TV autonómicas que forman parte de la Federación de Organismos de Radio y Televisión Autonómicos (FORTA): Canal Sur, TV3, TeleMadrid, À punt media, TVG, ETB, TV Canaria, CMM, 7 Región de Murcia, Aragón TV, TPA, IB3 Televisió). Se realiza un análisis de contenido teniendo en cuenta los siguientes parámetros: suscriptores, vídeos, canales, visualizaciones (en el caso de YouTube); post, seguidores, presencia/ausencia de comentarios en abierto (Instagram). Por otro lado, se estudiará el modo en el que cada una de estos canales retransmitió a través de redes sociales los correspondientes debates electorales de los procesos electores autonómicos y municipales de 2015, así como de 2016 (Galicia y País Vasco).

Los resultados establecerán una visión general de cómo las televisiones autonómicas emplean estas redes sociales, más visuales, a la hora de generar opinión entre su audiencia. Además, el estudio de las emisiones de los procesos electorales pondrá de manifiesto si las cadenas de servicio público aprovechan los recursos de Youtube e Instagram para suscitar debate o si se mantienen como un canal de comunicación meramente unidireccional. 
Comunicación y Música: mensajes, manifestaciones y negocios

075 - ¿Hay modelos periodísticos en el tratamiento de noticias sobre la muerte de mujeres por violencia de género? Más allá de los decálogos - Ainhoa Novo Arbona - UPV/EHU ainhoa.novo@ehu.eus y Simón Peña Fernández - UPV/EHU

La presente comunicación tiene como objetivo detectar y dar respuesta a tres cuestiones:

1. ¿Cuáles son los elementos que incluyen las investigaciones sobre la violencia contra las mujeres en la prensa? ¿Miden la conceptualización del fenómeno, la relación entre el homicida y la víctima, el perfil del homicida y la víctima, los detalles en la narración de los hechos, las fuentes consultadas, la inclusión de estadísticas o de valoraciones, el género de la noticia?

2. ¿Cuáles son las variantes o categorías de las que disponen los medios dentro de cada uno de los citados elementos a la hora de redactar la noticia? ¿Existe una correlación entre las decisiones adoptadas en el tratamiento de uno de estos elementos y otros? ¿Existen modelos? Por ejemplo, ¿hay correlación entre el detalle de la información sobre el homicida y la víctima?

3. ¿Se pueden establecer modelos de noticias sobre la muerte de mujeres por violencia de género? Por supuesto, las investigaciones diacrónicas ya nos hablan de la evolución del tratamiento de la violencia de género en los medios de comunicación. Sin embargo, en la actualidad ¿se podría concluir que unos modelos son más educativos y que otros generan más sensibilización según el peso y la forma que adquieren cada uno de los elementos relevantes señalados?

Para abordar estas preguntas se han revisado las investigaciones con impacto sobre el tratamiento de la prensa de la violencia contra las mujeres en general, y sobre la muerte de la víctima en particular, en los medios de comunicación desde el 2000 hasta la actualidad. Las bases de datos para la selección de las publicaciones han sido Scopus, Web of Science y Dialnet, y el impacto se ha medido teniendo en cuenta el número de citas en relación con el año de publicación. Esta revisión, 
además de dar una visión evolutiva de la caracterización de las citadas informaciones, nos ha permitido determinar en la actualidad las diferentes formas a través de las cuales se aborda la violencia contra las mujeres. Se trata de un paso previo encaminado a la creación de una herramienta que no solo establezca los parámetros de medición, sino que permita una interpretación en clave de modelos de noticias.

076 - Análisis de los atributos comunicacionales para la construcción de una personalidad de marca socialmente responsable - Dr. Javier Mayorga Gordillo - Profesor Especial Doctor - Universidad Autónoma de Occidente - Colombia jmayorga@uao.edu.co y Dra. Elena Añaños Carrasco Profesora Titular de Universidad - Universidad Autónoma de Barcelona - España - elena.ananos@uab.cat

En el contexto actual donde los gobiernos, las empresas y en general la sociedad están en búsqueda de poner fin a la pobreza, proteger el planeta y garantizar que las personas gocen de paz y prosperidad, las acciones de tipo social gestionadas por las organizaciones se han convertido en un elemento que puede influir en la percepción positiva que tienen los públicos de las mismas. Es por este motivo que diversos estudios (Becker-Olsen, Cudmore, y Hill, 2006; Du, Bhattacharya, y Sen, 2007; Hildebrand, Demotta, Sen, y Valenzuela, 2017; Hoeffler y Keller, 2002; Madden, Roth, y Dillon, 2012; Manzano, Simó, y Pérez, 2013; Rivera, Bigne, y Curras-Perez, 2016; Sen y Bhattacharya, 2001, entre otros) se han centrado en analizar los efectos de las acciones de responsabilidad social corporativa (RSC), llegando a concluir que pueden ser un factor que modifica positivamente las percepciones de los consumidores sobre una empresa en su conjunto y de su rol en la sociedad, logrando afectar significativamente la solidez y el valor de una marca. En esta línea, este trabajo analiza los atributos comunicacionales que son percibidos como rasgos determinantes de una personalidad de marca socialmente responsable. Dichos rasgos son valorados por 385 sujetos de diferentes nacionalidades con el objetivo de identificar las asociaciones y las agrupaciones de atributos que permiten la construcción de la personalidad de las marcas socialmente responsables. Los resultados obtenidos muestran la existencia de diversos factores que influyen en la valoración de los atributos 
Comunicación y Música: mensajes, manifestaciones y negocios

estudiados y permiten concluir que existe una estructura relacional de atributos que pueden conformar una nueva dimensión de las marcas dotándolas de una de personalidad socialmente responsable que complemente y engrandezca los propios de la organización en su conjunto.

077 - El epicentro de la planificación en los debates electorales: estudio de la escenografía en los debates presidenciales en Espapa con la herramienta eyetracking - Ana Belén, Fernández Souto - abfsouto@uvigo.es, Montserrat, Vázquez Gestal mvgestal@uvigo.es y Beatriz, Legerén- Universidade de Vigoblegeren@uvigo.es

Los debates electorales en televisión siguen contando con un gran peso dentro de la planificación estratégica de las campañas electorales. Existe bastante literatura sobre la propia organización de este tipo de eventos y su adaptación a las necesidades sociales con el paso del tiempo. Es evidente que las nuevas tecnologías afectan de forma directa a la propia organización del acto, así como a su desarrollo. Sin embargo, existen otros factores, que podemos denominar "clásicos" que, desde su inicio han preocupado de forma especial a los organizadores de los debates. Nos referimos a la propia puesta en escena del evento, donde se procura una cierta neutralidad en la que todos los participantes se sientan cómodos.

Esta intervención se centrará en el análisis de la puesta en escena de los debates electorales que se han celebrado con respecto a las elecciones generales españolas, haciendo un recorrido histórico. Basándonos en el uso de técnicas propias de las neurociencias a través de Eyetracking, recopilaremos datos que nos permitirán verificar qué aspectos de la puesta en escena de los debates electorales son más importantes y valoradas para los televidentes.

079 - Dos décadas de investigación sobre periodismo en Iberoamérica. Un estudio sobre la generación, la apropiación y la divulgación del conocimiento científico - académico en las revistas científicas de comunicación - Dolores Aragón Robles- 


\section{Linares - lolita.aragonrl@gmail.com y Gustavo Adolfo León \\ Duarte-gustavo.leon@unison.mx - Universidad de Sonora}

En el ámbito de estudio de la investigación sobre periodismo en Iberoamérica, el artículo aspira a conocer e identificar las características estructurales que definen a la producción de conocimiento generada durante el periodo 1998-2017 en tres destacadas revistas científicas de la comunicación en el plano iberoamericano: Revista Latina de Comunicación Social, Communication and Society y Sociedad y Conocimiento. Utilizando una perspectiva teórica interdisciplinar y una metodología mixta integrada, la presente contribución centra su interés en lograr una aproximación a la definición del tipo de conocimiento periodístico generado (epistemológico y, por tanto, teóricometodológico) como al tipo de proyecto ético-político al cual nos referimos cuando aludimos a la investigación sobre periodismo en Iberoamérica. Así, el texto expone, por un lado, los resultados cuantitativos referentes al nivel de producción científico-académica que presentan los países e instituciones en Iberoamérica (España, Portugal y América Latina). Por otro, el análisis cualitativo del contenido discursivo asociado a la evolución teórica-metodológica y ética-política de las producciones analizadas. El texto discute también las diferencias y similitudes entre el Pensamiento Latinoamericano de la Comunicación (PLC) y su marcada influencia en la investigación periodística de las revistas analizadas. Se advierte, además, que la investigación sobre periodismo en Iberoamérica es un espacio de interés predominante para la investigación en comunicación, adquiriendo acentuaciones relacionadas al estudio de la éticadeontología y las necesidades de formación asociadas fuertemente con la innovación tecnológica en torno a la generación, la apropiación y la divulgación del conocimiento científico - académico.

080 - Hasta ahí hemos llegado: análisis lingüístico y pragmático del debate cara a cara 2015 entre Mariano Rajoy y Pedro Sánchez - Inmaculada, Anaya - Universidade de Vigo ianaya@uvigo.es-y Miljana, Micovic-Centro de Educación Superior Next-m.micovic@nextibs.com- 
Comunicación y Música: mensajes, manifestaciones y negocios

Esta comunicación analiza el debate celebrado entre Mariano Rajoy y Pedro Sánchez, con motivo de las elecciones del 20 de diciembre de 2015, más conocido como el "cara a cara", desde una perspectiva lingüística, pragmática y funcional. Los debates electorales constituyen una oportunidad única para que los candidatos puedan transmitir su mensaje y otras informaciones que se deducen de su interacción; "única", porque cada debate es irrepetible y los políticos deben esforzarse en que sus ideas lleguen a los electores con claridad y en cumplir sus expectativas.

Anaya (2014:27) afirma que el análisis de las estrategias discursivas corrobora la relación existente entre el uso adecuado de algunos recursos lingüísticos y la recepción positiva que conlleva en el receptor del mensaje. Por otro lado, Micovic (2014), a través del análisis argumentativo basado en la Teoría de la argumentación de Perelman y en estudios lingüísticos sobre debates en español, demuestra que los políticos usan un gran abanico de estrategias y mecanismos lingüísticos y pragmáticos para convencer a los ciudadanos de sus ideas en una lucha dialéctica.

De acuerdo con estos principios desarrollamos el análisis de este debate con el modelo propuesto por Cortés (2008:30), para el cual el Análisis del discurso comprende dos aspectos: el de los condicionantes externos y el de los condicionantes internos. Asimismo, realizamos un análisis de las principales estrategias argumentativas de ambos candidatos, especialmente, el uso de la (des)cortesía lingüística.

El estudio de las estrategias discursivas y de la argumentación empleadas por ambos candidatos, así como el antagonismo exacerbado que impera en este debate ponen de relieve, por un lado, la estrecha relación que existe entre saber utilizar adecuadamente los recursos lingüísticos y la reacción del público, y, por otro, cómo el uso de determinadas estrategias de la (des)cortesía lingüística aumenta la agresividad en el debate político.

081 - Sistema de partidos y modelos organizativos en los debates electorales en España (1993-2016) - Antón R. Castromil - Universidad Complutense de Madrid - 
arcastromil@ccinf.ucm.es; Raquel Rodríguez Díaz -

Universidad Rey Juan Carlos de Madrid -

raquel.rodriguez@urjc.es y Jorge Juan Morante - Universidad

Complutense de Madrid - jorjejmo@ucm.es

Los debates electorales en España han constituido más la excepción que la norma. De las trece elecciones generales celebradas hasta el momento, sólo en cinco de ellas se ha debatido. Desde el momento pionero, 1993, hasta los comicios de 2016, los formatos han sido varios. Especialmente en las últimas dos elecciones generales.

La ponencia explorará los motivos de, por un lado, la concentración de debates en las últimas cinco elecciones (2008, 2011, 2015 y 2016), y, por otro, la conexión existente entre la posibilidad de organización de debates y la variación en el sistema de partidos español.

También se tendrá en cuenta otro elemento decisivo a la hora de hablar de debates electorales: los cálculos estratégicos de partidos y elites partidistas a la hora de acceder al debate.

Se argumentará que tanto la evolución del sistema de partidos como los cálculos estratégicos están detrás de la posibilidad de que los ciudadanos cuenten o no con la posibilidad de ver por televisión (u otros medios) un debate en tiempo electoral.

082 - The use of social networks by the media in the Scottish and Catalan processes - Casandra López Marcos - Centro de Educación Superior Next - casandra.lm@gmail.com

It is obvious that news corporation are interested in being where they can maintain their audience or even reach new users. This would explain why many academics agree that these platforms are gaining importance inside journalism (Carrera et al., 2012; Casero-Ripolle's, 2013; Farrel, 2013; Masip et al., 2010; Pe'rez-Latre, 2011). From 2008 media outlets discovered the importance of being on social networks in order to establish contact with their users (Emmett, 2009; Noguera, 2010). 
Comunicación y Música: mensajes, manifestaciones y negocios

However, these are not the only reasons. The social network is as important as it is for two main reasons: firstly, because the audience gives social media the power to create a type of audience sphere, where a lot of people look forward to receiving news and information about their worries or interests; and secondly, that journalists have noticed that sphere and have decided to take advantage of this situation. So, social media is not only seen as a way to keep in touch with the audience, but also as a technology that means transformations to journalistic routines (mainly in the way journalists do their reports), which means that journalists have to assume new roles (Campos, 2008; Cerezo, 2008; Lara, 2009; Flores, 2009; Noguera, 2010). These roles can be summed up in three: selector of content (journalists have to choose from huge amounts of information, which might be important to their audience), detective (journalists have to seek information through social media and also by contrasting, verifying and showing the reliability of the information found) and prescriber (this should be understood as the role that journalists take on when having to recommend a piece of information).

So, all these elements together created the greatest environment ever to 'shake' the journalism world which has resulted in a new sphere with a huge amount of users who seek breaking news. Moving these values into a journalism context, social networks enhance news corporations' brands as well as provide further disseminating news with the help of other citizens, increase their sales by raising users' interest in their news products and by creating new channels for obtaining feedback from their audience.

It is the aim of this research to show the results of the research carried out into the journalistic practices on social networks regarding two political processes, in two different social and political contexts, which also attracted enormous attention in the autumn of 2014: the Scottish Referendum in United Kingdom, and the Catalonia Sovereignty Consultation in Spain. The main goal of this study is to discover how the analysed media outlets have used social networks for these political processes. 
083 - Las condiciones técnicas para la realización de un debate televisivo: comparativa entre los debates los debates cara a cara $(2008,2011,2015)$ y los debates a cuatro (2016) en España María Gallego-Reguera, Centro de Educación Superior Next (Universitat de Lleida),m.gallego@cesnext.com

El debate electoral, como producto audiovisual, no escapa a las exigencias de producción y realización de cualquier programa televisivo. Es más, por su relevancia mediática y su importancia política su realización técnica forma parte importante del proceso de negociación. Al final, las decisiones que se toman en referencia a la realización del programa de televisión tienen tanta importancia porque se trata de establecer la propia puesta en escena de los candidatos en directo ante la audiencia. Esto incluye no solo la disposición de los candidatos, sino también el número de cámaras, la localización y los recorridos de las mismas, el tipo de planos y planos escucha, la iluminación, la música, etc. En este artículo se analizará la negociación de los aspectos técnicos, que va a tener dos momentos clave. El primero, el diseño del propio formato que quedará reflejado en el documento de acuerdo. El segundo, que se producirá el propio día del debate cuando los asesores inspeccionan y comprueban la puesta en escena y la propia realización técnica en directo del programa televisivo. El principal objetivo de esta investigación es realizar una comparativa entre las condiciones técnicas de los debates cara a cara, que se realizaron en España con motivo de las elecciones generales en 2008, 2011 y 2015, y el debate a cuatro que se realizó ante los comicios generales de 2016.

084 - La Feminización de la Política y su Influencia en las Estrategias de Comunicación en el Contexto de la Comunidad Autónoma Vasca - Ainara Larrondo Ureta ainara.larrondo@ehu.eus, Simón Peña Fernández simon.pena@ehu.eus y Julen Orbegozo Terradillos julen.orbegozo@ehu.eus - Universidad del País Vasco/Euskal Herriko Unibertsitatea.

La feminización de la política (Childs y Kittilson, 2016) es un fenómeno en alza que se ha considerado positivo, por su valor para 
Comunicación y Música: mensajes, manifestaciones y negocios

humanizar este ámbito y contribuir a acabar con su desprestigio social generalizado. Relacionado con ello, cabría recordar que las problemáticas vinculadas a la cuestión de género resultan de plena actualidad en la agenda pública, social y política (violencia sexista, feminización de la pobreza, etc.). Partiendo de ambas premisas, esta comunicación centra su interés en la feminización de la política vasca y en las posibles consecuencias de dicho fenómeno en las pautas comunicativas de los partidos políticos de la Comunidad Autónoma Vasca (CAV) en un contexto de campaña. La investigación tiene en cuenta específicamente la última cibercampaña de las elecciones al Parlamento de la CAV de la XI Legislatura (2016/2020). Por primera vez, estos comicios contaron con un mayor número de mujeres candidatas, sentando un precedente a nivel electoral en España, tanto en lo referido a las convocatorias de ámbito estatal, como autonómico. Siguiendo trabajos anteriores como el de Annesley y Gains (2017), la investigación se pregunta por la presencia del género en la agenda política en medios sociales, a través de un análisis de las cuentas de Twitter y Facebook de los principales candidatos y candidatas, a partir de su visión de las problemáticas de género como asuntos de campaña (campaing and political issues) o como asuntos políticos con un componente más personal (political issues). En línea con este análisis, se examina también el uso que algunas mujeres políticas hacen del storytelling transmedia, la personalización y la emotividad en el discurso. Las conclusiones reflexionan así sobre el papel de las lideresas vascas para desarrollar un know-how político diferente del fomentado tradicionalmente por sus compañeros líderes masculinos.

085 - El derecho al olvido en Internet bajo el prisma de la libertad información y prensa - Chicharro, Alicia - Profesora Contratada Doctora de la Universidad Pública de Navarra alicia.chicharro@unavarra.es

El derecho al olvido digital tiene en los medios de comunicación online su escenario más conflictivo al situarse entre la protección de los datos de carácter personal y las libertades de expresión, información y prensa.

La entrada en vigor del Reglamento General de Protección de Datos el pasado mes de mayo consolida un derecho, nacido de la doctrina 
jurisprudencial, que permite al individuo requerir la cancelación o limitación del uso de sus datos personales en un medio de comunicación, cuando su mantenimiento le causa algún tipo de perjuicio o lesión.

Parece que la colisión entre derecho al olvido y libertad de información es inevitable; sin embargo, estos dos derechos están llamados a coexistir en el ámbito de protección de la Unión, cuyo Tribunal de Justicia ha ido desvelando la senda de conciliación a través de sus decisiones judiciales.

Tanto la inclusión de datos personales en las reseñas actuales, como la indexación por los motores de búsqueda de información aparecida en su momento en papel, plantean una búsqueda de equilibrio entre los derechos afectados con el fin de minimizar el sacrificio de uno respecto del otro.

086 - Millenials y Fake News: Actitud de los estudiantes universitarios ante la difusión de noticias falsas - Terese Mendiguren - Universidad del País Vasco terese.mendiguren@ehu.eus, Jesús Ángel Pérez Dasilva y Koldo Meso

Hoy por hoy los jóvenes tienen acceso la información de actualidad a través de muy diversos medios. Además de los tradicionales medios de comunicación de masas, como pueden ser la televisión, la radio, o los periódicos; Internet y las redes sociales se han convertido en un recurso de información cada vez más atractivo y accesible. Según un estudio del Pew Research Center (Gottfried y Shearer, 2016) el 61\% de los millenials dependen más de Facebook que de cualquier otra fuente para informarse de política. Esta investigación examina las conductas de estudiantes universitarios ante las Fake news. La investigación se ha realizado en dos fases. En primer lugar, se han realizado encuestas abiertas a 123 alumnos y alumnas de periodismo de la Universidad del País Vasco, con el fin de conocer cómo se informan, cómo actúan ante una información dudosa o qué impresiones les causan las denominadas Fake news. Teniendo en cuenta los resultados de esta primera fase, se ha extendido el análisis a alumnos de Ciencias, Medicina y Ciencias 
Comunicación y Música: mensajes, manifestaciones y negocios

políticas, por ser estas áreas de conocimiento, según los resultados iniciales, las más susceptibles, según los estudiantes, de ser invadidas por las Fake News. Se pretende comparar las primeras conclusiones obtenidas, con las conductas y criterios de universitarios de áreas de conocimiento no relacionadas con el periodismo.

087 - Deconstruyendo la ciudad creativa: Una aproximación desde los sistemas de indicadores - Antonio Castro-Higueras Universidad de Málaga - acastro@uma.es

A partir de la eclosión de las industrias creativas en la última década del siglo pasado, numerosos investigadores, organismos e instituciones han abordado su evaluación con el fin de conocer el fenómeno y, de esta manera, servir de herramienta para el diseño y aplicación de políticas públicas que permitan el desarrollo de este sector estratégico de la nueva economía del conocimiento. Estos sistemas de indicadores que califican y clasifican la creatividad de los entornos urbanos analizados, suelen desembocar en rankings de ciudades creativas. En el presente texto se plantea un procedimiento inverso, a partir de los indicadores más comunes hallados en los distintos índices describimos la ciudad creativa ideal. De esta manera desharemos analíticamente los elementos nucleares que conforman el constructo de ciudad creativa. Para ello realizaremos una revisión de los índices existentes, agruparemos sus indicadores y dimensiones y definiremos el concepto de ciudad creativa ideal a partir de estos elementos. El resultado será un modelo o referente que permita a los policymakers orientar sus acciones a favor de la promoción de las industrias culturales y creativas.

088 - Análisis del primer debate electoral on-line en España. Hacia un nuevo paradigma - - José Ángel FernándezHolgado - Universidad de Vigo - xholgado@gmail.com, José Ángel Alén-Amil - Universidad de Vigo - alenamil@gmail.com

La generalización en el uso de nuevos canales de comunicación asociados a los avances tecnológicos, así como la fragmentación de las audiencias distribuidas en diferentes plataformas, obliga tanto a medios de comunicación como a partidos políticos a innovar en cuanto a sus estrategias de comunicación. 
El presente artículo analiza el primer debate transmitido a través de internet, organizado por el diario El País el 30 de noviembre de 2015. El debate fue entre candidatos a la presidencia del gobierno español del PSOE, Ciudadanos y Podemos. El Partido Popular decidió que asistiera la Vicepresidenta del gobierno Sáenz de Santamaría en lugar del candidato, medida que no fue aceptada por el periódico.

Durante años la Academia de Televisión viene organizando en España los debates de las elecciones generales. En ellos, dos partidos mayoritarios exigían condiciones blindadas haciendo los debates encorsetados y previsibles. En el año 2015 se celebraron es España los comicios con el mayor número de partidos políticos con posibilidades reales de ganar la votación. Esta situación abrió nuevos horizontes a los debates electorales. Una demanda histórica de las televisiones privadas integradas en UTECA, (Grupo Atresmedia, Mediaset, Nettv, veo, Ten, Trece, Realmadridtv, Dkiss), que representan el 85\% de la televisión en abierto, que se amplía hoy en día a la prensa digital por internet, en búsqueda constante de nuevos formatos que les permitan incrementar y renovar el interés informativo de las audiencias hacia la política, y por consiguiente darles la posibilidad de obtener nuevas fuentes de financiación.

089 - Pacientes (des)informados. Cómo una incorrecta transmisión de la información afectaría negativamente la relación médico-paciente - Dr. Marc Compte-Pujol marc.compte@uvic.cat, Dr. Guillem Marca-Francès guillem.marca@uvic.cat, Dra. Jesica Ana Menéndez jesicaana.menendez@uvic.cat y Dr. Joan Frigola-Reig joan.frigola@uvic.cat - Universitat de Vic-Central de Catalunya (UVic-UCC)

Los ciudadanos del s. XXI tenemos una creciente necesidad de información, en especial cuando adoptamos el rol de pacientes. Gracias a Internet, somos cada vez más proactivos y estamos mejor informados en cuestiones de salud, una realidad que suele contribuir a una mejor relación médico-paciente, en tanto que ambos actores pueden compartir conocimientos y mejorar su comunicación, facilitando que 
Comunicación y Música: mensajes, manifestaciones y negocios

el encuentro presencial sea más eficiente (Lupiáñez-Villanueva, 2011). Asimismo, los profesionales médicos de todo el mundo apuestan por informar al paciente de un modo cada vez más mesurado y ajustado, contemplando las complejidades del ser humano, las diferencias culturales y procurando equilibrar la difícil relación entre honestidad y esperanza (Núñez Olarte, 2012).

En esta investigación, hemos realizado un estudio cualitativo fenomenológico, analizando el contenido de experiencias subjetivas explicadas por pacientes crónicos recientemente hospitalizados en la ciudad de Vic (Barcelona), con el objetivo de identificar, desde la perspectiva del paciente, qué mensajes y temáticas son los más importantes para ellos a nivel de información y cómo prefieren que ésta les sea transmitida para evitar el ruido.

Para ello, desarrollamos dos focus groups con pacientes y familiares y 15 entrevistas en profundidad a pacientes ingresados en el hospital, de los cuales extrajimos que los temas más recurrentes fueron la necesidad de contenido informativo de calidad, la alfabetización en salud alrededor de las condiciones de los pacientes y el procedimiento de hospitalización. Asimismo, los pacientes mostraron su predilección por la información fácilmente entendible y preferiblemente escrita. A nivel de ruido y problemáticas de comunicación, los pacientes criticaron un exceso de comunicación exclusivamente oral e insuficiente por parte de los médicos, algo que les suele generar estrés y les hace sentirse más cercanos a las enfermeras, que resultan más accesibles y comunicativas. Los resultados también apuntan a la apuesta por la co-creación de la información entre profesionales de la salud y los propios pacientes para mejorar futuras relaciones.

090 - El sexismo vende en la televisión ecuatoriana. Análisis de la serie "Tres familias" - Pepe Cueva Yaguana ppcueva15@hotmail.com y Ana Dolores Verdú Delgado

En este trabajo presentamos un análisis de la serie "Tres familias", una de las producciones ecuatorianas de ficción con más alto rating del país, y la primera en ser exportada a nivel internacional a un grupo importante como TV Azteca de México en 2017. "Tres familias" se 
estrenó en 2014 como comedia televisiva formato serie y desde la segunda temporada se emite como telenovela con humor. Cuenta ya con cuatro temporadas con 242 capítulos. La trama se centra en cómo tres familias de diferentes clases sociales (baja, media y alta) enfrentan un tema o una situación determinada en cada capítulo, desde su estatus social, usando de forma constante del género y la discriminación como principales recursos cómicos. La rigidez de los estereotipos de género y de clase en esta serie, si bien puede adquirir una apariencia caricaturesca que busca la risa del telespectador, es también un modo de naturalizar y banalizar problemas sociales como el maltrato, la violencia sexual y la pobreza, presentes en esta comedia televisiva.

En este análisis nos centramos en tres capítulos que nos sirven para explorar tres aspectos esenciales de las relaciones de género implícitas en la serie: los celos masculinos, la cosificación sexual femenina y la lucha de sexos, planteada a través del tradicional antagonismo sexual de la ideología machista. Para concluir destacamos que el alto contenido sexista, así como la utilización de la desigualdad, la violencia y la discriminación como recursos para el entretenimiento de masas, no permiten cuestionar con firmeza los mecanismos culturales en los que estos problemas se asientan, particularmente en una sociedad como la ecuatoriana, con altos niveles de desigualdad y de violencia de género.

091 - Comunicación de crisis en el ámbito universitario. El caso de los altercados estudiantiles en la campaña de elecciones a rector de la Universidad del País Vasco - Leyre, Eguskiza Sesumaga -UPV/EHU - leyre.eguskiza@ehu.eus

La Universidad del País Vasco debe afrontar en su actividad diaria diferentes modalidades de crisis que pueden comprometer su imagen institucional y repercutir de forma negativa en su reputación. Esta propuesta ahonda en la gestión comunicativa de dichas situaciones por parte de la institución, centrando el análisis en una de sus tipologías de crisis más recurrentes: los altercados ocurridos en las instalaciones universitarias. El estudio de caso aborda los incidentes violentos registrados en los campus vascos durante la campaña electoral y al comienzo del mandato de la actual rectora Nekane Balluerka -entre noviembre de 2016 y marzo de 2017-, en los que se vio involucrado el colectivo estudiantil. 
La identificación de las herramientas, plataformas y acciones comunicativas utilizadas por la UPV/EHU para trasladar mensajes a sus públicos objetivos, junto a la medición del impacto mediático generado en la prensa vasca, permiten la elaboración de un exhaustivo diagnóstico. En él destacan una alta cobertura mediática, el posicionamiento de la institución como fuente informativa de referencia, la confrontación de la violencia con la imagen de unidad institucional y la aparición en los medios de una corriente pública de opinión en defensa de la universidad pública vasca.

Las entrevistas en profundidad mantenidas con los responsables del área de comunicación complementan esta panorámica a la que se aportan algunas consideraciones futuras. Entre ellas destacan la prevención y protocolización de la gestión de crisis, la centralización de las comunicaciones, la mejora en el manejo de las redes sociales y la implementación de la evaluación post-crisis. Igualmente, la significativa incidencia de los conflictos asociados a sus públicos internos refleja la necesidad de fortalecer la imagen institucional, situando a la comunidad universitaria como un objetivo prioritario durante las crisis y estableciendo con ella un continuo flujo informativo.

092 - Revistas Jot Down, Anfibia y Panenka: tres formas audaces de entender el periodismo narrativo digital en plena crisis del papel - Udane-Goikoetxea - Universidad del País Vasco UPV/EHU (grupo de investigación HGH) udane.goikoetxea@ehu.eus y Txema-Ramírez de la Piscina Universidad del País Vasco UPV/EHU (grupo de investigación HGH) txema.ramirezdelapiscina@ehu.eus

Las revistas Jot Down, Anfibia y Panenka tienen en común un amplio abanico de características. Las tres surgieron entre 2011 y 2012 en plena crisis económica y decadencia del papel. Las tres practican a diario un periodismo narrativo diferente y diferenciado. Las tres han mostrado una audacia en sus planteamientos poco habitual en época de cambios. Las tres han sabido adaptarse a las nuevas circunstancias apostando por la era digital sin renunciar a las estrategias analógicas. Todo ello las ha convertido en referentes de vanguardia dentro de sus respectivos 
ámbitos, ya sea el periodismo cultural (Jot Down), la realidad argentina (Anfibia) o la cultura futbolística (Panenka).

La presente comunicación se enmarca dentro de una amplia investigación sobre el periodismo narrativo digital en español. En este caso se han analizado estas tres revistas por considerarse exponentes del periodismo narrativo en España, Argentina y, en el caso de Panenka, del periodismo especializado. La metodología utilizada ha sido el estudio de caso de cada una de esas revistas: entrevistas en profundidad a sus máximos responsables y análisis de sus ofertas digitales e impresas durante el primer semestre de 2018. Los resultados obtenidos son claros: las tres revistas han sabido labrar su propia imagen de marca; exhiben orgullosas la hibridación en sus géneros; han conectado con una cuota de audiencia que se deleita con los textos atemporales, alcanzando una buena (aunque diferente) acogida en la red. Jot Down tiene 700.000 usuarios únicos al mes; Anfibia, 600.000 y Panenka, 86.000. A pesar de sus modestas plantillas, las tres revistas han demostrado que es posible sobrevivir y plantear alternativas en un contexto especialmente adverso. Podría decirse que la nueva era de la información está pariendo un corazón alternativo y osado que se rebela ante la monotonía y aburrimiento del mercado.

093 - Política y Ciudadanía Digital: los migrantes venezolanos y sus comunidades virtuales en México - Dr. Roberto Alejandro López Novelo - Universidad Anáhuac (México) robertoa.lopez@anahuac.mx, Mtro.José Luis Flores Torres Universidad Anáhuac (México) - jluisflorest@hotmail.com y Dr. Raúl Santos Morales - Universidad Anáhuac (México) raul.santos@anahuac.mx

La política, entendida desde una perspectiva amplia, se refiere a todo aquello que compete o resulta importante para la ciudad. Ésta disciplina se relaciona con los diferentes modos y/o formas de comunicación existentes en cada época; concebir a la política, solo en el marco de la gobernanza o desde la perspectiva de las instituciones formales hoy resulta insuficiente en un entorno sociotécnico en el que las nuevas herramientas digitales han nutrido la manera en la que la ciudadanía participa en los asuntos de la política y en donde incluso 
Comunicación y Música: mensajes, manifestaciones y negocios

fenómenos que no tienen nada de novedosos (como la migración y la actividad político electoral) se ven trastocados como consecuencia del nuevo paradigma tecnosocial derivado de Internet.

Un ejemplo de esto lo constituye el caso de los migrantes venezolanos, que ante la compleja situación política y económica por la que atraviesa Venezuela, han decidido salir de su país, buscando oportunidades de desarrollo en distintos países, entre ellos México. Resulta pertinente señalar que este fenómeno migratorio en concreto reviste características particulares pues forma parte de la diáspora venezolana que desde 2015 ha movilizado a más de 1 millón y medio de venezolanos fuera de su país debido ante todo a la crisis política por la que atraviesa dicha nación.

Así, fenómenos como la migración venezolana, son atractivos para la investigación en comunicación, ya que un número importante de miembros de esta colectividad, recurren a la conformación de comunidades virtuales para establecer, por una parte vínculos de contacto y ayuda mutua y por la otra informarse y opinar acerca de lo que sucede su país de origen. El caso de los migrantes venezolanos, constituye entonces un ejemplo de acción política comunitaria en red organizada de manera colectiva e inteligente a partir de las herramientas proporcionadas por las tecnologías digitales, para así constituirse como una comunidad de apoyo y de protesta política.

094 - Didácticas educativas para el aprendizaje de la crítica cinematográfica - Silvia Magro-Vela - Universidad Rey Juan Carlos - silvia.magro@urjc.es, Rainer Rubira-García Universidad Rey Juan Carlos - rainer.rubira@urjc.es y Belén Puebla-Martínez - Universidad Rey Juan Carlos belen.puebla@urjc.es

El lenguaje cinematográfico tiene sus propias características relacionadas con las rutinas productivas y las ideologías profesionales del sector. En esta propuesta se pretende estudiar el concepto de crítica de cine con un sentido histórico, profundiza en los distintos modos de concebir la crítica y analizar las funciones y tipologías de las escuelas más representativas del campo profesional, una manera práctica y 
amena en tanto que didácticas en una educación tanto para procesos formativos reglados como no reglados. Mediante actividades que integran lo lúdico y lo educativo se plantea un programa basado en tres ejes fundamentales: contenidos conceptuales, procedimentales y actitudinales. El primer eje debe ocuparse del cine y los textos críticos en torno a él, con énfasis en las cuestiones teóricas. El segundo eje se encarga de las metodologías para la elaboración de críticas cinematográficas usando distintas herramientas de análisis. Por último, el tercer eje, que complementa el ciclo del aprendizaje integra elementos motivacionales para que el espectador asuma la reflexión crítica sobre el cine como parte de su vida cotidiana. Esta propuesta se engloba en la línea de educación para la comunicación como un área especialmente fructífera en la disciplina objeto de estudio.

095 - La movilidad académica en las Facultades de Comunicación del Ecuador - Abel Suing, Grupo de Investigación en Comunicación y Cultura Digital, Universidad Técnica Particular de Loja, arsuing@utpl.edu.ec; Lilia Carpio, Grupo de Investigación en Comunicación y Cultura Digital, Universidad Técnica Particular de Loja, lkcarpio@utpl.edu.ec y Kruzkaya Ordóñez, Grupo de Investigación en Comunicación y Cultura Digital, Universidad Técnica Particular de Loja, kordonez@utpl.edu.ec

La relación con pares académicos y profesionales de otros países ya no es una opción, es una práctica diaria que dinamiza y proyecta el desarrollo. La relación entre personas de diferentes países se ha visto favorecida por las TIC. Este entorno de apertura puede ser el preludio de amplias vinculaciones que lleguen más allá de un primer contacto y un reconocimiento de aspiraciones comunes. La movilidad física, los intercambios, las estancias en otras ciudades, de a poco, se convierten en una realidad. El propósito de la investigación es determinar la tendencia y condiciones de la movilidad académica en las Escuelas y Facultades de Comunicación del Ecuador. La metodología es cualitativa a través de entrevistas semiestructuradas a representantes de los tres grupos de la Red Ecuatoriana de Facultades de Comunicación: Centro, Sur y Costa. Una de las críticas frecuentes en los procesos de integración es que para visitar otros países deben cumplirse procesos 
Comunicación y Música: mensajes, manifestaciones y negocios

internos y visados que frenan el interés en la movilidad. Pese a estos protocolos la internacionalización es frecuente, es una manera de insertar al país en las rutas culturales, educativas y de desarrollo del mundo.

096 - Las narrativas de paz en los discursos sobre CDCS: análisis desde la lingüística de corpus - Marta Sánchez-Saus Laserna - Universidad de Cádiz - marta.sanchezsaus@uca.es

La comunicación para el desarrollo y el cambio social (CDCS) ha experimentado en los últimos años un incremento de su protagonismo en el campo de la comunicación. La investigación que aquí presentamos forma parte de un proyecto interdisciplinar cuyo objetivo es la evaluación del campo de la CDCS en España, a partir del diseño de un dispositivo metodológico que, partiendo de distintos tipos de marcadores, permita mapear la presencia de la CDCS en la investigación sobre comunicación en España, tomando como referencia investigaciones similares impulsadas con éxito en países anglosajones. Consideramos que el hecho de que la expansión de la CDCS no haya estado lo suficientemente cimentada en la producción científica de calidad, en el avance institucional ni en el desarrollo epistemológico riguroso hace que sea una necesidad estratégica que este campo sea abordado a través de una investigación rigurosa y seria, que parta de la evaluación de lo realizado y que permita establecer indicadores que traduzcan a un nivel operativo los principios, valores y tradición reflexiva de la CDCS.

Con este contexto, en esta comunicación presentaremos los marcadores lingüísticos más significativos que caracterizan los discursos sobre CDCS y, en particular, analizaremos la importancia del concepto de "narración" y de los relatos de paz en los corpus que hemos manejado - uno con las aportaciones realizadas en Twitter con el hashtag \#comunicambio y otro con los artículos sobre CDCS publicados en las principales revistas españolas en los últimos quince años-. La metodología empleada será el análisis de contenidos a partir de palabras clave, técnica de la lingüística de corpus que permite determinar qué palabras son 
097 - Narrativas del proceso de paz en Twitter durante la campaña electoral en Colombia (2018) - Juan Sebastián López Universidad Santo Tomás sebastianlopez@usantotomas.edu.co, Joan Pedro-Carañana Saint Louis University, Madrid - joan.pedro@slu.edu, Sergio Alvarado - Uniminuto - salvarado@uniminuto.edu y David Rojas - Universidad Santo Tomás david.rojaso@usantotomas.edu.co

La campaña de 2018 para las elecciones presidenciales en Colombia será recordada como la primera tras la firma de los Acuerdos de Paz. Por tanto, se antojaba como un evento paradigmático que ofrecía el contexto idóneo para indagar qué tipo de discursos sobre paz y guerra iban generándose en la esfera pública. En principio, este trabajo pretendía investigar las narrativas que se construían en Twitter en torno al proceso de paz durante los tres meses que duró la campaña electoral. No obstante, los resultados obtenidos frente al proceso de paz obligaron a un análisis más complejo de la campaña, involucrando otros contenidos que rebasaban ese ámbito específico.

La muestra se configuró teniendo en cuenta los tiempos oficiales de la campaña, los Trending Topics que aludían específicamente a temas asociados a esta y un número limitado de trinos seleccionados en función de su relevancia. A continuación, se identificaron aquellos trinos que hacían alusión directa al proceso de paz. Tras un primer análisis se determinó la necesidad de volver sobre el total de la muestra para indagar por los emisores, orientaciones ideológicas, actores mencionados, temas y tonos dominantes de la campaña. Contrario a la hipótesis inicial, el debate público referente a la campaña presidencial se orientó hacia temas ajenos al proceso de paz y la polarización. Sin embargo, el tono, los participantes y los bloques discursivos predominantes indican que la campaña se configuró rehuyendo el conflicto frontal, en un intento por captar votantes indecisos, o agotados por la exposición de los avatares del Proceso.

098 - Representaciones de la mujer en el audiovisual contemporáneo español en plataformas digitales globales: el caso Netflix - Rainer Rubira-García - Universidad Rey Juan 
Comunicación y Música: mensajes, manifestaciones y negocios

Carlos - rainer.rubira@urjc.es, Silvia Magro-Vela - Universidad Rey Juan Carlos - silvia.magro@urjc.es y Belén Puebla-

Martínez - Universidad Rey Juan Carlos - belen.puebla@urjc.es

Las nuevas plataformas en línea como Netflix para la distribución y el consumo de productos culturales a escala global han atestiguado una mayor presencia del audiovisual generado en España en los últimos tiempos. Series como Vis a Vis; Las chicas del cable; Élite; La casa de papel; Paquita Salas...entre otras, han favorecido un amplio diapasón de representaciones femeninas a través de personajes en su mayor parte de carácter protagónico. Mediante estrategias de análisis del discurso crítico se estudian los rasgos propios de la representación audiovisual de la mujer a través de una comparación diacrónica, considerando la evolución histórica de dichos personajes entre los distintos programas elegidos como casos de estudio. A partir de la investigación llevada a cabo se ha determinado la existencia de patrones comunes de representación de la mujer en distintas series de ficción, desligados de sus contextos espacio-temporales dentro del marco narrativo. Lo anterior podría relacionarse con la tendencia actual en pos de aumentar la visibilidad de la mujer en el audiovisual ampliando el abanico de los clásicos roles que siempre se han asignado a las mismas hacia otros emergentes, en sintonía con el actual empoderamiento femenino que se aprecia en la industria cultural.

099 - Comunicación Interpersonal y Vih/sida - Leonardo

Moggia Narváez - INCOM -UAB - Estudiante Doctorado

Comunicación Audiovisual y Publicidad -1.moggia@gmail.com

La comunicación interpersonal en el ámbito de la salud se ha estudiado mayoritariamente en torno la relación profesional de la salud y paciente. Existe una vasta evidencia empírica que da cuenta de la comunicación profesional de la salud - paciente como elemento sustancial en el ámbito de la salud (Nayak, Pradhan, Reddy, Palmer Zhang y Bruera, 2005; Barnett, 2006; Domingo 2010); contribuyendo en el correcto diagnóstico de enfermedades, correcta ejecución de tratamientos, recuperación de enfermedades complejas, apoyo emocional en enfermedades terminales y satisfacción por parte de los pacientes. 
Sin embargo, si revisamos las publicaciones científicas realizadas en los últimos 10 años respecto a Comunicación Interpersonal y VIH/Sida podemos observar que existen otras áreas de la comunicación interpersonal que están siendo estudiadas también, particularmente en torno a esta enfermedad crónica. Desde el descubrimiento del VIH/Sida hace ya más de 30 años, la investigación sobre el virus no solo ha sido desde las ciencias biomédicas sino también desde las ciencias sociales.

El objetivo del presente estudio es identificar y describir de qué se habla en comunicación sobre salud cuando se habla de Comunicación Interpersonal y Vih/Sida, para ello se realizó una revisión sistemática de lo publicado en la base de datos Scopus desde el 1 de enero de 2008 hasta el 4 de junio de 2018, considerando aquello que respondiera a las palabras motores de búsqueda comunicación, comunicación Interpersonal, comunicación médico - paciente y red social. La metodología utilizada es el análisis de contenido y cabe señalar que los resultados responden a una investigación mayor denominada Comunicación y VIH/Sida: una revisión sistemática.

Los resultados arrojan que un $42 \%$ de los estudios se desarrollan en torno a la relación equipos sanitarios pacientes, sin embargo, existe un $58 \%$ restante que abordan temas respecto a la comunicación interpersonal entre parejas, comunicación entre pares, red de apoyo y comunicación con niños, jóvenes y adolescentes. Resulta interesante observar también como existen temáticas emergentes como la revelación del estado serológico a las parejas y su entorno con un 3\%.

100 - Economía Social y Solidaria y Periodismo para la Paz en la nueva prensa digital española: el caso de La Marea - Tamer Al Najjar Trujillo — Universitat Jaume I — alnajjar@uji.es

En los últimos años, se ha observado una proliferación de nuevos medios de comunicación, la mayoría de ellos nacidos en el ámbito de Internet, en gran parte debido a las consecuencias de la crisis económico-financiera que comenzó a finales de 2007 (Negreira y López, 2016: 327). Por un lado, esta crisis económica ha destruido miles de puestos de trabajo en el ámbito del Periodismo y la 
Comunicación y Música: mensajes, manifestaciones y negocios

Comunicación (Asociación de la Prensa de Madrid, 2015: 93). Por otro, esta situación económica ha abierto nuevos horizontes, todavía en desarrollo y por descubrir, dentro de la empresa periodística: nuevos medios de comunicación que se han constituido como proyectos periodísticos alternativos e independientes, a través de otros modelos de financiación y con el objetivo de realizar un periodismo riguroso, honesto y de calidad (Rius, 2014: 1473).

Como caso paradigmático destaca La Marea, fundada en 2012 como cooperativa tras los fallidos intentos por refundar el periódico Público, y que en 2014 recibió el sello de Xarxa d'Economia Solidària que identifica y diferencia a las organizaciones comprometidas con los principios de la Economía Social y Solidaria. El objetivo de esta ponencia es analizar de qué manera se relacionan los principios de este medio de comunicación con las alternativas al sistema económico neoliberal planteadas desde los movimientos sociales, como la Economía Social y Solidaria (Askunse, 2013: 108). Por otro lado, a nivel de contenido, se estudian los principios editoriales de La Marea en relación con las características del Periodismo para la Paz (Arévalo Salinas, 2014: 67).

Para ello se ha utilizado una metodología de tipo cualitativo al confrontar los principios editoriales, organizativos y de financiación de este medio de comunicación, presentes en su página web, con las características de la Economía Social y Solidaria y del Periodismo para la Paz.

101 - Las noticias y el interés por las mismas entre los usuarios de Menéame - Begoña Zalbidea Bengoa bego.zalbidea@ehu.eus; Santiago Urrutia Izaguirre santi.urrutia@ehu.eus; Jose Mari Pastor González josemari.pastorehu.eus e Idoia Camacho Markina - Universidad del País Vasco/Euskal Herriko Unibertsitateaidoia.camacho@ehu.eus

Relevancia. Las nuevas tecnologías ofrecen una magnífica oportunidad para que los ciudadanos participen directamente en los debates que se producen en la esfera pública sobre cuestiones diversas. En concreto, 
los usuarios de las redes sociales tienen a su disposición múltiples formas para expresar sus puntos de vista mediante los comentarios que pueden realizar.

Objetivos. Esta comunicación analiza la temática de las noticias, su origen, procedencia, y número de usuarios que participan en los debates en una muestra cualificada de noticias publicadas en la portada de Menéame, el agregador de noticias de mayor éxito en habla hispana. Los objetivos principales son: a) conocer qué categorías temáticas son las que han suscitado el máximo nivel de participación de los usuarios; b) cuál es el origen de esas noticias -estatal o internacional-; c) de dónde proceden las mismas (medios, blogs...); y d) cuantificar los usuarios que hacen comentarios en las discusiones que se suscitan. Método. Se trata de una investigación enmarcada en el proyecto ministerial CSO2014-59077-R, realizada sobre una muestra de las 100 noticias que han provocado mayor número de comentarios de un total de 151.060 publicadas en las portadas de Menéame a lo largo de sus 13 años de historia, desde su origen en diciembre de 2005 hasta finales de septiembre de 2018. La temática ha sido clasificada en 14 categorías, el origen en 2 y la procedencia en 9. Asimismo, se ha contabilizado los usuarios participantes en los debates de la categoría Política.

Resultados. Los datos preliminares indican que entre los usuarios de Menéame sobresalen los comentarios relacionados con temas vinculados a Política (61\%), seguidos por los de Sociedad (12\%), Justicia $(10 \%)$ y Deportes $(9 \%)$. La inmensa mayoría de las noticias tiene origen estatal (83\%), y gran parte de las mismas proceden de medios convencionales y online estatales (59\%).

102 - Noticias y formatos para móviles en redes sociales:

Twitter e Instagram - Ana Isabel Bernal Triviño - Universitat Oberta de Catalunya -abernalt@uoc.edu

Si la llegada de Internet incorporó notables modificaciones en las redacciones de los medios de comunicación, las redes sociales han producido otra revolución. En estos últimos años se ha experimentado con narrativas y formativos diferentes para mostrar contenidos, incluso con la creación de géneros periodísticos específicos. En ello ha tenido 
Comunicación y Música: mensajes, manifestaciones y negocios

una gran influencia la alta penetración del dispositivo móvil, que ha originado la adaptación de contenidos más accesibles y fáciles de leer o ver en este soporte. Twitter se definió como un espacio de microblogging que aportó una micronarrativa profesional, con una adaptación de géneros informativos y formatos marcados por la inmediatez. Por otra parte, Instagram permite un análisis más visual, selectivo y concreto de la actualidad de la jornada, aunque se introducen formatos de vídeo para las informaciones más extensas. Este trabajo muestra un recorrido exploratorio por algunas de las soluciones y adaptaciones en las dos redes sociales.

103 - Rutinas profesionales y nivel de satisfacción de los estudiantes de Periodismo en prácticas: la brecha entre medios y gabinetes - Manuel García-Borrego, Manuel - Universidad de Málaga-manoletus@uma.es y Bernardo Gómez-Calderón Universidad de Málaga - bjgomez@uma.es

Las prácticas en empresas representan una de las vías de acceso más fructíferas a la profesión periodística (cf. APM, 2017). En esta comunicación se analizan las rutinas prof

esionales de los estudiantes de Periodismo que realizan prácticas y se comparan las dos principales salidas laborales del grado: los medios informativos y los gabinetes de comunicación. La metodología seguida para recabar la información ha sido el cuestionario; se suministró una encuesta a los estudiantes de las tres últimas promociones de Periodismo de la Universidad de Málaga ( $\mathrm{n}=345)$, de los cuales eran algo menos de un tercio los que habían realizado prácticas, alcanzándose un nivel de respuestas superior al 50\% del universo. La remuneración media percibida por los estudiantes es de 382 euros, sin apenas variaciones según el tipo de empresa. Sin embargo, sí se observan divergencias en las rutinas: los alumnos que desarrollan sus prácticas en medios les dedican más horas al día que sus compañeros de gabinetes $(6,6$ de promedio frente a 5,1), elaboran más piezas $(4,6$ frente a 3,4 ) y disponen de menos tiempo para cada una de ellas (unos 45 minutos frente a 1 hora y 15 minutos). 
En los gabinetes los estudiantes parecen sufrir en menor medida las presiones de sus jefes o de las partes interesadas, la necesidad de ser productivos o de captar el interés de la audiencia, la falta de tiempo o recursos materiales para realizar su trabajo y el desconocimiento de los temas tratados. En consecuencia, su satisfacción es mayor en casi todos los aspectos contemplados en el cuestionario: remuneración, estabilidad, horario, carga de trabajo, política de la empresa y relación con los compañeros, los tutores o los superiores. Se da una única coincidencia, en lo relativo a las expectativas de promoción, que en ambos casos resultan bajas.

104 - Recursos audiovisuales en cursos MOOC como herramienta educativa, en universidades categoría A en Ecuador - Miguel Enrique Granda Cueva - Universidad Técnica Particular de Loja. miguelgrandac@gmail.com y Milenny Gabriela Suquilanda Ramírez - Universidad Técnica Particular de Loja.mgsuquilanda1@utpl.edu.ec

La educación a distancia nace de la necesidad de poder llegar a cuyos estudiantes que por diferentes motivos no pueden asistir a un centro de educación superior de manera permanente para poder obtener un título de tercer o cuarto nivel, o simplemente desarrollar competencias profesionales. Por ello se han creado diferentes herramientas tanto síncronas como asíncronas de comunicación, que permita acercar a los alumnos con la planta docente; una de estas formas de estudio son los Cursos Abiertos Masivos en Línea, (MOOC por sus siglas en inglés), evolucionan las nuevas formas de educación. Esta herramienta educativa se imparte en línea de manera gratuita y de corta duración; al ser de fácil acceso y brindar contenidos actualizados permite al participante, ampliar su conocimiento en áreas determinadas en un momento específico de su carrera profesional, mediante un método de aprendizaje virtual, dinámico e interactivo. La metodología se basa en las nuevas narrativas audiovisuales que utilizan las plataformas en las que se imparten los cursos MOOC, estos recursos educativos en línea forman parte de la innovación educativa, ya que el formato tiene como finalidad llegar al estudiante, a través de videos cortos, audio, infografías, animación, lecturas, enlaces, hipertextos, vínculos, etc. 
Comunicación y Música: mensajes, manifestaciones y negocios

La presente investigación analiza las universidades ecuatorianas de categoría "A", que utilizan recursos audiovisuales como herramienta de estudio, así como la aceptación e impacto que tiene este método de aprendizaje. La metodología que se aplica en la investigación es mixta: cuantitativa, por cuanto se pretende realizar una observación directa y tabulación de los cursos que ofertan estas instituciones; y es cualitativa, por la utilización de entrevistas a directivos de las plataformas que imparten estos cursos, finalmente se aplicará una encuesta a una muestra determinada de participantes para conocer el nivel de satisfacción. La hipótesis que se plantea en la investigación, es: ¿Los recursos audiovisuales, que se imparten como herramienta de estudio en los cursos MOOC, satisfacen las necesidades de aprendizaje del estudiante? Las personas quienes optan por este tipo de educación, tienen como limitantes el carecer de tiempo necesario para formar parte de una institución de carácter presencial, por ello optan por la educación a distancia para desarrollar destrezas en su plano profesional y personal.

105 - El concepto de Comunicación Comunitaria y su función educativa en los pueblos originarios - Dr. José Cisneros Espinosa ulises33@yahoo.com, Dr. José Antonio Cisneros Tirado joseantonio.cisneros@correo.buap.mx, Mtra. María Carolina Restrepo Gómez restrepocarolina91@gmail.com Benemérita Universidad Autónoma de Puebla- Instituto de Ciencias de Gobierno y Desarrollo Estratégico

El modelo de comunicación dominante surgido en los años 30 del siglo pasado, invisibiliza otras prácticas y concepciones de la comunicación, como es el caso de los procesos de comunicación en las prácticas comunitarias de los pueblos originarios y rurales en general. En este caso, los procesos de comunicación, siempre han estado ligados al entendimiento y al consenso entre los participantes, no se enfocan al éxito personal sino a la sobrevivencia y crecimiento sustentable del grupo social en su conjunto.

Por otra parte, la educación en nuestras sociedades capitalistas se ha convertido en un servicio-mercancía que ya no es controlada por el Estado ni por los padres de familia, sino dominada por las empresas 
educativas y los organismos internacionales, las cuales buscan homogeneizar el pensamiento de las nuevas generaciones en función de la producción y la ganancia, y para ello estimulan la competencia entre las personas por lograr éxitos en ese sentido, en detrimento de la convivencia solidaria y la conservación de la Naturaleza. Para ello emplean tanto el sistema escolar como los medios de difusión masiva enfocados al entretenimiento y la distracción para los educandos, junto con el lucro indiscriminado para las empresas. Por el contrario, en los pueblos originarios la educación se da en los procesos sociales comunitarios basados en la solidaridad y la equidad, y enfocados al Buen Vivir de la comunidad en su conjunto.

En el trabajo que se presenta en este congreso, se informa principalmente de algunos encuentros significativos sobre el tema de la Comunicación Comunitaria que un grupo de investigación del ICGDE ha venido desarrollando desde 2015 en el proyecto Comunicación política y democracia: Los procesos de comunicación en la toma de decisiones para la vida comunitaria. Estos resultados son considerados como elementos fundamentales en la construcción de un concepto de comunicación comunitaria, porque nos permita entender la complejidad de sus implicaciones culturales, sociales y, en este caso, educativas; entendiendo la educación en términos de Paulo Freire como "la reflexión y acción de los hombres sobre el mundo para transformarlo", y ubicando esta transformación dentro de la cosmovisión de los pueblos originarios.

106 - Nuevos discursos para nuevos tiempos: el cine digital Manuel Blanco Pérez - Universidad de Huelva manuel.blanco@dfilo.uhu.es

La primera película española rodada íntegramente en digital fue Caótica Ana, de Julio Medem, a finales de 2007. Tras ella la industria empezó a adaptarse a la digitalización de todo el proceso productivo. Innovaciones en el campo de la ingeniería informática, la robótica o la ciencia aeronáutica entre otros ámbitos, han propiciado que un film que hace apenas unos años fuera catalogado de "cine de bajo presupuesto" hoy tenga acabados tan dignos como la mayor de las superproducciones. Además, la reconversión que se ha producido 
Comunicación y Música: mensajes, manifestaciones y negocios

desde el cine del analógico a la digital es de tal magnitud que no hay ni un solo aspecto del sector audiovisual que no haya sufrido grandes cambios, incluso aspectos considerados antes menores como la relación con los espectadores -a través, fundamentalmente, de los social media- o la promoción de los films.

Para analizar técnicamente a qué se debe esa revolución, necesitamos vehicular el cine a sectores de mucho empuje, como la industria de los drones, que han empezado a usarse en el acabado de las películas low cost, consiguiendo una estética muy mainstream; los nuevos aparatos como os gimbals o estabilizadores, y, por último, la nueva tecnología $4 \mathrm{~K}$. En este contexto, nos proponemos analizar el papel de lo digital en el cine desde la perspectiva de la repercusión que estas innovaciones han tenido en la manera de narrar, particularmente en las tres últimas películas dirigidas por Alberto Rodríguez con guion de Rafael Cobos: Grupo 7 (2012), La isla mínima (2014) y El hombre de las mil caras (2016). Para ello seguiremos la metodología descrita por Marzal, basado en su teoría de análisis fílmico y su interpretación en clave semiótica propuesta por el catedrático Vázquez Medel en su teoría del emplazamiento/desplazamiento.

107 - Análisis supervisado de sentimientos políticos en Twitter en el periodo poselectoral en México 2018. - Dr. Roberto Alejandro López Novelo - Universidad Anáhuac MéxicoProfesor - Investigador del Centro de Investigación para la Comunicación Aplicada (CICA) de la Facultad de Comunicación - robertoa.lopez@anahuac.mx y Dr. Carlos E. Arcila Calderón - Universidad de Salamanca (USAL), España Profesor del departamento de Sociología y Comunicación. Miembro del Observatorio de los Contenidos Audiovisuales (OCA) - carcila@usal.es

Actualmente Internet ofrece una serie de entornos digitales que permiten a los usuarios crear contenidos de diversa índole y generar redes complejas, a través de las cuales expresan sus intereses en diversas áreas, entre ellas: la política. Asimismo, en los últimos años, la comunicación política se ha interesado en el estudio de la opinión política utilizando millones de datos acumulados en los diversos 
entornos tecnosociales, particularmente en Twitter. Entre las técnicas que permiten identificar patrones y obtener consecuencias significativas en el estudio de fenómenos políticos, se encuentra el Análisis Supervisado de Sentimientos Políticos

Por otro lado, el pasado 1 de julio de 2018 concluyó en México el proceso electoral para elegir al presidente constitucional para el periodo 2018-2024, en la que participaron 56, 611, 027 electores, con los siguientes resultados: coalición "Juntos haremos historia", con el candidato Andrés Manuel López Obrador (AMLO), 30,113,483 votos (53.19\%); coalición "Por México al Frente" con el candidato Ricardo Anaya 12, 610,120 votos (22.27\%); la coalición "Todos por México" con el candidato José Antonio Mead, 9,289,853 votos (16.40\%); y, el candidato independiente Jaime Rodríguez, 2,961,732 votos (5.23\%). Estos resultados son trascendentes, ya que, en la historia reciente de México, nunca antes un candidato había ganado una elección con un margen tan grande de diferencia y había generado un nivel de popularidad y expectativa tan alta de cambio. El Análisis supervisado de sentimientos políticos en Twitter en el periodo poselectoral en México 2018, permite analizar y comprender de forma significativa los factores que impactan en el proceso de pérdida o aumento en la popularidad, del presidente electo en el periodo que va del día de la elección a la toma de posesión, y, a los primeros 100 días de gobierno.

108 - Uso, actitudes, mediación parental y flujos de comunicación en el ecosistema digital por menores escolarizados de la Comunidad Madrid - T. Torrecillas-Lacave Profesora Adjunta. teresat@ceu.es; T. Vázquez-Barrio Profesora Contratada Doctora. Universidad San Pablo CEU (España)tamarav@ceu.es; R. Suárez-reb.suarez@ceindo.ceu.es y L.M Fernández Martínez - Investigador en formación de CEINDO. Universidad San Pablo CEU (España) lui.fernandez.ce@ceindo.ceu.es

La hiperconectividad frente a las multipantallas en la que viven los menores se produce cada vez a edades más tempranas al tiempo que se incrementa el tiempo que pasan conectados. Ante esta realidad, los progenitores deben convertirse en elementos dinamizadores y 
Comunicación y Música: mensajes, manifestaciones y negocios

referenciales para el desarrollo y crianza de los hijos, que se comunican con sus pares y, cada vez más con ellos, a través de Internet como canal de comunicación activo entre padres e hijos. La presente investigación aborda la realidad que viven los menores ante esta inmersión TIC así como la mediación que realizan sus padres y los flujos de comunicación que se suceden a través de las TIC. Para ello, se han realizado encuestas a 1.040 menores escolarizados de entre 5 a 17 años teniendo en cuenta los niveles de enseñanza y la tipología de centro educativo (privado/concertado o público) al que asisten. Se prepararon tres tipos de cuestionarios adaptados a las edades de los participantes: un cuestionario para menores de $3^{\circ}$ de infantil, otro para alumnos de $2^{\circ}$ de primaria y otro para estudiantes de $5^{\circ}$ de primaria, $2^{\circ}$ de la ESO y $1^{\circ}$ de bachillerato. Los resultados muestran los usos que realizan los menores de las tecnologías digitales y que, a pesar de que los padres de adolescentes muestran una mediación más dialogante, los progenitores de niños y niñas de 5 a 10 años no efectúan estrategias de mediación activas, poniendo de manifiesto que a edades más tempranas no perciben riesgo en la influencia que las TIC puede efectuar en el desarrollo de sus hijos.

109 - La independencia de los periodistas frente a los regalos e interferencias económicas; una perspectiva comparada entre periodistas y ciudadanía - Juan Carlos Suárez Villegas Universidad de Sevilla - jcsuarez@us.es, Jesús Díaz del Campo - Universidad Internacional de La Rioja y Ruth Rodríguez Universidad Pompeu Fabra

Dentro del proyecto de I+D+I, "MediaACES. Accountability y Culturas Periodísticas en España. Impacto y propuesta de buenas prácticas en los medios de comunicación españoles", financiado por el Ministerio de Economía y Competitividad de España, se ha llevado a cabo un trabajo de campo entre periodistas y ciudadanos sobre las buenas prácticas periodísticas y los sistemas de rendición de cuenta. Entre las cuestiones formuladas se ha planteado de qué manera los periodistas podría ver comprometida su independencia informativa ante relaciones más o menos estrechas con poderes políticos y económicos, así como cuando puedan mediar regalos que puedan ir desde un simple gesto de cortesía institucional a ciertas formas de 
compensación por un tratamiento informativo favorable. En esta comunicación se analiza la posición de los profesionales y de los ciudadanos.

110 - Influencia del consumo cultural en el uso de redes sociales entre los estudiantes universitarios - Conde Melguizo, Rafael Universidad Camilo José Cela - rconde@ucjc.edu

En este trabajo se presentan los resultados de una investigación realizada como actividad de innovación docente en la asignatura de Diseño y Sociedad del grado de Diseño de Producto de la Universidad Camilo José Cela, impartido en la Escuela Universitaria ESNE, durante el curso 2017/18.

Dentro de la actividad de innovación docente se incluyó la realización de un cuestionario distribuido entre la población universitaria donde se preguntaba sobre diferentes hábitos de consumo. Entre todos ellos, se ha analizado el consumo cultural y el consumo de redes sociales, haciendo hincapié en la posible relación entre ambos hábitos, considerando el consumo cultural como la variable independiente que puede influir en el consumo de diferentes redes sociales.

Entre los resultados obtenidos que se explican en este texto destacan la influencia negativa del consumo de cultura sobre el consumo de la red Instagram, la fuerte variabilidad de Twitter en función de algunos consumos culturales y la escasa influencia del consumo cultural en algunas de las redes más utilizadas como Facebook o Whatsapp. El estudio tiene a su vez limitaciones con respecto a algunos elementos importantes, como el consumo de videojuegos, que se apuntan como líneas futuras de investigación.

111 - Memorias lejanas; memorias cercanas. Narrativa, relatos y violencia en Nueva Venecia - Magdalena (Colombia) - Gabriel Ruiz Romero - Universidad de Medellín - gruiz@udem.edu.co

El 22 de abril del año 2000, un comando paramilitar de Bloque Norte de las Autodefensas Unidas de Colombia (AUC) asesinó a 38 personas en el poblado pesquero de Nueva Venecia (Magdalena - Colombia), 
Comunicación y Música: mensajes, manifestaciones y negocios

generando un desplazamiento forzado masivo. La masacre constituye el peor acto de violencia armada en la historia de ese poblado palafito, donde hoy viven unas 2000 personas. Posterior al retorno voluntario de la población, diversas instituciones del Estado, ONG e investigadores académicos han hecho allí presencia con trabajos de reparación individual y colectiva y/o con proyectos productivos. En este sentido, el Centro Nacional de Memoria Histórica, en desarrollo del deber de la memoria que le corresponde al Estado colombiano por ley, y como parte de los procesos centrales de reparación integral, publicó en el año 2015 el informe de memoria histórica "Ese día la violencia llegó en canoa", sobre la masacre paramilitar en Nueva Venecia. Así mismo, cada 22 de noviembre se reúnen en el pueblo representantes de distintas instituciones estatales para conmemorar el aniversario del hecho violento.

La ponencia analiza las áreas de tensión y complementariedad entre esos trabajos y eventos oficiales de memoria (informes $y$ conmemoraciones) y los espacios y prácticas locales de recuerdo sobre lo sucedido (la conversación cotidiana y las décimas de los poetas y cantores locales). Se propone entender los primeros como narrativas lejanas que buscan situar el hecho puntual dentro de unos marcos de interpretación nacional de la violencia colombiana, mientras los segundos se instalan localmente como relatos afectivos que contribuyen a la construcción de las tramas de convivencia y socialización cotidiana del palafito. Así, los trabajos oficiales de memoria se proyectan hacia el exterior del lugar donde ha tenido lugar la violencia, mientras el relato local se instala en tanto prolongación de una conversación que la violencia ha buscado interrumpir.

112 - La retroalimentación inmediata en el aprendizaje gramatical del inglés - Adriana Jeanyne Guanuche Albán Universidad Politécnica Salesiana - aguanuche@ups.edu.ec y adrianajga@yahoo.com

El presente trabajo tiene como objetivo mostrar los resultados de investigación sobre el impacto del uso de ejercicios autocorrectivos con retroalimentación inmediata en el aprendizaje de la gramática del idioma inglés; propuesta metodológica que consiste en un estudio cuasi 
experimental con tres grupos de estudiantes de primer nivel de distintas carreras de la Universidad Politécnica Salesiana de la Sede Quito, cuyos rangos de edad están entre 18 a 22 años. Para el estudio se les administró una pre prueba, tratamiento y posprueba de gramática del idioma inglés. Tanto en el pre prueba como en la posprueba se consideró una temática gramatical relacionada con los contenidos de una unidad del plan curricular de primer nivel; y, se utilizó un formato similar constituido por cuatro secciones de evaluación. Es necesario señalar que la propuesta metodológica incluyó un tratamiento diferenciado en el empleo de instrumentos para cada grupo. Se analiza la ventaja del uso de la plataforma gratuita Canvas, como un recurso de innovación educativa que facilita la retroalimentación en el proceso de aprendizaje de la segunda lengua de los estudiantes universitarios.

Es una investigación de carácter cualitativo y cuantitativo que analiza, por un lado, el impacto de la retroalimentación inmediata con explicaciones metalingüísticas en el aprendizaje del idioma inglés; y, por otro, los porcentajes del mejoramiento del aprendizaje gramatical de los estudiantes de los tres grupos estudiados.

Se reflexiona sobre los procesos de mejora en el aprendizaje de la segunda lengua por parte de los estudiantes y los procesos de retroalimentación inmediata realizados por los docentes, como estrategia para fortalecer los procesos de aprendizaje del idioma inglés. El estudio destaca la optimización del tiempo y brevedad de respuesta personalizada en base al proceso de retroalimentación positiva y negativa según el desempeño de cada estudiante.

113 - Las mujeres del dating show: presentadoras, productoras y concursantes - Tatiana Hidalgo-Marí - Universidad de Alicante - tatiana.hidalgo@ua.es

En el contexto del dating show, la representación y las variaciones de género juegan un papel clave, ya que, a lo largo de la historia del subgénero, se han venido representando escenarios desiguales en la representación de hombres y mujeres. 
Comunicación y Música: mensajes, manifestaciones y negocios

En los últimos años han proliferado los estudios destinados a analizar el subgénero televisivo del dating show, con el objetivo de detectar tanto sus contribuciones en la construcción social de hombres y mujeres como sus implicaciones desiguales y que refuerzan y perpetúan las diferencias entre géneros.

Esta comunicación pretende aportar datos que permitan reflexionar sobre el papel de las mujeres en el seno de los dating shows de producción española desde tres perspectivas, que se corresponden con los tres roles existentes alrededor del programa: en primer lugar, conociendo el papel que juegan las presentadoras; en segundo lugar, analizando la construcción de las concursantes y por último, teniendo en cuenta a las mujeres del back end, las productoras, directoras y ejecutivas que forman parte del desarrollo de estos programas.

- 114 - Recuerdos de una ficción: El caso de Canal 9 - Tatiana Hidalgo-Marí - Universidad de Alicante tatiana.hidalgo@ua.es

El año 89, coincidiendo con la creación de la FORTA (Federación de Organismos o Entidades de Radio y Televisión Autonómicos), empezaban las emisiones de Canal 9, la televisión pública de la Comunidad Valenciana. Tras catorce años de información, producción y difusión, el 5 de noviembre de 2013 se anunció el cierre del ente tras acumular hasta 1.200 millones de euros en deuda y la imposibilidad de recolocar a los casi 1.000 empleados despedidos en un ERE. A pesar de su desenlace, la cadena disfrutó de una trayectoria sólida y desarrollada desde un punto de vista comunicativo y se postuló como un referente en su zona de emisión, tanto a nivel de información como de entretenimiento. En ese sentido, resulta necesario destacar la importancia de la ficción televisiva en la consolidación de la cadena, llegando a producir y coproducir las ficciones a la valenciana más memorables desde los orígenes de la televisión.

Esta comunicación pretende presentar un estudio sobre géneros, formatos y contenidos alrededor de la ficción televisiva emitida en el canal valenciano desde su creación hasta el apagón definitivo, que acabo con catorce años de televisión autonómica. Los objetivos, 
fundamentalmente descriptivos, pretenden ofrecer una taxonomía que permita comprender cómo se articuló la emisión de ficción televisiva en los años de emisión de la cadena y proponer, además, unas líneas comunicativas, productivas y de difusión que puedan servir como declaración de intenciones a la nueva cadena autonómica valenciana À punt.

115 - Análisis sobre la musicología en series: el caso de The handmaid's tale - Paula, Díaz Revuelta - Universidade de Santiago de Compostela - paulada24@gmail.com

En pleno siglo XXI, la manera en que los ciudadanos disfrutamos de nuestro tiempo libre está íntimamente ligada al consumo de nuevas narrativas y productos digitales, bien sean de carácter estrictamente informativo o de entretenimiento. Dentro de este panorama, las series se han consolidado como la alternativa preferida por parte de los públicos gracias a su formato audiovisual, además de haberse perfilado como el gran modelo de negocio para las plataformas OT'T. Es por todo lo expuesto anteriormente por lo que esta investigación se centra en el análisis del papel que juega la música en la serie The handmaid's tale, una narrativa cuyo público objetivo se encuentra en las personas que rocen y/o estén en la treintena, atributo que permite reconocer gran cantidad de sonidos y ritmos empleados a lo largo de las secuencias de la serie, y por tanto permite establecer puntos de conexión entre determinados videoclips (formato de origen en la década de los 80) de las canciones empleadas y los planos de la propia producción. Esta distopía juega de manera inteligente con la música diegética y extradiegética, y es esta convivencia -compleja- entre música y personajes lo que garantiza un relato 100\% efectivo, y como consecuencia, la transmisión de una historia a través de lo audiovisual.

116 - Comunicación publicitaria e innovación tecnológica en el marco de las industrias creativas - Natalia Papí-Gálvez Universidad de Alicante-Natalia.p@ua.es y Marcial Murciano Martínez - Universitat Autónoma de Barcelona marcialmurciano@gmail.com 
Comunicación y Música: mensajes, manifestaciones y negocios

Las industrias culturales y creativas (ICC) abarcan varios sectores impulsores de economías de vanguardia que pudieran liderar los procesos necesarios para un crecimiento basado en la innovación. Entre todos ellos, este estudio se centra en el sector publicitario dado que los cambios tecnológicos y la generalización del uso de los medios digitales han transformado de forma significativa a esta industria. En consecuencia, se plantea un estudio descriptivo sobre el sector publicitario por comunidades autónomas; que analiza la evolución de los principales indicadores en siete años (2008-2014), de acuerdo con el modelo Localcom. Este análisis permite observar cómo la Publicidad se alía con las nuevas tecnologías y con los procesos de comunicación digital para hacer frente a la crisis económica en España, y se convierte, así, en un marco de observación apropiado para explorar las relaciones entre la innovación y la comunicación. Este estudio permite detectar hitos que respaldan abordar el impacto de la innovación tecnológica a través de la evolución del sector publicitario y conduce a comprender su papel como promotor de otras industrias culturales y creativas.

Esta comunicación forma parte del proyecto "La transformación de las industrias culturales y creativas (ICC) en España: cambio digital, competitividad, empleo y contribución al bienestar social en el horizonte 2020". Referencia: CSO2013-42822-R. Programa estatal de investigación, desarrollo e innovación orientada a los retos de la sociedad (Ministerio de Economía y Competitividad).

* 117 - Estrategias de medios de los casos "Eficacia" en la era digital: innovación, investigación y planificación en Publicidad Natalia Papí-Gálvez - Universidad de Alicante-Natalia.p@ua.es

La investigación y planificación de medios son dos ámbitos relevantes relacionados entre sí a través de los cuales se puede apreciar el impacto de la innovación en la tecnología y de la comunicación digital en Publicidad. Como apuntan investigaciones previas, la transformación digital en la función de medios publicitaria necesita nuevas mediciones y promueve nuevos modelos de negocio y cambios en las estrategias de medios. En particular, esta comunicación se sitúa en los últimos cinco años para, desde un planteamiento exploratorio, describir los principales rasgos de la investigación y planificación actuales que 
pueden ser detectados a través de los casos de éxito. Profundiza, así, en las estrategias de las campañas galardonadas en los premios a la eficacia en comunicación digital de la Asociación Española de Anunciantes, con especial atención en dos categorías: eficacia en medios y reconocimiento en investigación. A modo de cierre, plantea tanto rasgos potenciales de desarrollo del nuevo modelo en investigación y planificación como futuras líneas de trabajo que contribuyan a conocer, en mayor medida, los procesos de innovación que explican el nuevo paradigma en este campo. Este estudio se sitúa en una de las líneas de trabajo del grupo E-COM de la Universidad de Alicante.

118 - Propuesta metodológica para la enseñanza de la comunicación estratégica en redes sociales a través de las series de ficción - Mariché Navío-Navarro - Universidad CEU San pablo-mariajose.navionavarro@ceu.es

La ficción seriada televisiva cuenta con un gran consumo por parte de los segmentos jóvenes. Los alumnos universitarios, por tanto, son por lo general espectadores de estos productos de entretenimiento y participantes activos de las comunidades de fans que muchas de estas series concentran alrededor de sus canales digitales. El interés de los estudiantes al respecto resulta, de esta manera, un acicate perfecto para fomentar el aprendizaje dentro y fuera del aula en lo relativo a la educación mediática.

La propuesta metodológica que llevamos a cabo pretende la adquisición, por parte de los estudiantes de titulaciones del ámbito de la comunicación, de competencias específicas relacionadas con la comunicación en redes sociales. Para ello, presentamos un modelo de análisis mediante el cual el alumno puede acometer el proceso de estudio de las estrategias de social media empleadas por las series de ficción a través de un benchmark creado ad hoc.

Con él, el alumno aprenderá las herramientas y procesos para medir qué estrategias de creación y difusión de contenidos son las más exitosas, en redes sociales, en términos de engagement, reach o alcance y viralidad según los distintos segmentos de audiencia. Desde la elección del formato, lenguaje, tono, uso de hashtags y emojis hasta las 
Comunicación y Música: mensajes, manifestaciones y negocios

estrategias de periodicidad, esta metodología capacita al alumno, tanto desde un punto de vista profesional como investigado, para su futura empleabilidad en el canal de los social media.

La comunicación muestra, además, un caso práctico donde se ha implementado esta metodología a través de la creación de un Benchmark sobre las estrategias de redes sociales de las series de ficción en España para las plataformas de VoD: los casos de los originales de Netflix, HBO y Amazon Prime.

119 - La creación audiovisual como metodología de enseñanzaaprendizaje en la educación mediática - Mariché Navío-Navarro - Universidad CEU San Pablo - mariajose.navionavarro@ceu.es y Laura González-Díez - Universidad CEU San Pablo design@ceu.es

El alumnado de la universidad actual, como nativo digital, exige la implantación de metodologías formativas que se adapten a los lenguajes, canales y dispositivos que utiliza en su día a día. De entre todos los formatos disponibles, el audiovisual es el actual protagonista de las plataformas digitales, de manera que es el tipo de contenido con un mayor consumo por parte de la Generación Z. Su uso, dentro del aula, para el caso concreto de la educación mediática, se erige como la metodología de enseñanza-aprendizaje ideal para fomentar la adquisición, por parte de los estudiantes, de competencias básicas y específicas de las titulaciones del ámbito de la comunicación. Esta adquisición se incrementa exponencialmente cuando, además, es el propio alumno el encargado no solo de aprender sino de expresar y difundir, a través de la creación audiovisual, lo aprendido.

La experiencia docente que presentamos propone una metodología de enseñanza-aprendizaje basada en la creación de productos audiovisuales para plataformas digitales por parte del alumnado. En ella, se exponen, en primer lugar, los principios de marketing de contenidos para la concepción y optimización de vídeos para internet. Segundo, se presentan los métodos de creación e implementación de estrategias de publicación, posicionamiento SEO y analítica web de resultados de estos productos audiovisuales. Paso a paso, se muestra 
cómo el alumno ha de abordar el proceso de creación y difusión de estos contenidos para que tengan éxito en la red. Además, se analizan casos de estudio concretos en los que se ha empleado esta metodología.

120 - Fortalezas y debilidades de la formación especializada extrauniversitaria en dirección de arte - Blanca Miguélez-Juan Universidad del País Vasco/Euskal Herriko Unibertsitatea (UPV/EHU) - blanca.miguelez@ehu.eus

La formación en dirección de arte se imparte dentro y fuera del ámbito universitario. El análisis de la formación especializada, por su parte, supone hacer un análisis de una enseñanza que en su mayoría se imparte en centros extrauniversitarios. Es en este tipo de centros educativos donde los másteres, los cursos, los postgrados u otro tipo de enseñanza concentran su oferta formativa. Esta formación es muy heterogénea tanto en su denominación como en su duración, precio, etc. A pesar, en ocasiones, de la falta de oficialidad y de ser una oferta formativa poco estructurada, el bagaje y reconocimiento en el ámbito profesional de estos centros hacen que sea una formación cada vez más demandada por los egresados.

En este trabajo, se presenta un examen profundo que permite establecer las fortalezas y debilidades de esta formación desde las percepciones de los diferentes expertos cercanos a la misma. Se hace una puesta en común y se contrastan las visiones de docentes universitarios y profesionales publicitarios para conocer su origen y hacer un diagnóstico de la formación especializada en el ámbito de la Dirección de Arte.

121 - ¿Tendencia a la americanización en la ciber-política española? - Marta Gil Ramírez - Universidad de Málaga martagr@uma.es, Ruth Gómez de Travesedo Rojas Universidad de Málaga - ruthgtr@uma.es y Ana Almansa Martínez - Universidad de Málaga - anaalmansa@uma.es

Fenómenos como la espectacularización o la personalización, característicos de la comunicación política norteamericana, se han ido implantando en los últimos años en gran parte de las democracias 
Comunicación y Música: mensajes, manifestaciones y negocios

occidentales. Estos aspectos han sido ampliamente estudiados en el medio televisivo como el más propicio por sus códigos y lenguajes a acoger esta tendencia. Sin embargo, la política se enfrenta hoy a un nuevo escenario mediático digital que cada vez adquiere un peso mayor en la gestión de la comunicación. En el entorno de la ciber-política, YouTube se erige como la red social que guarda más similitudes con la televisión, al basar su actividad en la difusión de audiovisuales. Esta investigación se propone, mediante el análisis de contenido de ochenta vídeos sobre los cuatro partidos políticos españoles con mayor representación parlamentaria, corroborar si la tendencia a la americanización constatada en televisión es extrapolable a la plataforma de videos online.

Se evidencia una proporción equilibrada entre contenido de corte informativo y contenido correspondiente al género del infoentretenimiento. Igualmente encontramos que la distribución de la atención hacia los partidos y hacia los personajes políticos particulares esta nivelada. Estos datos apuntan a una considerable presencia de los fenómenos de espectacularización y personalización política en la red social You'Tube, una presencia que, de momento y en el caso español, no prevalece a los contenidos sobre comunicación política regidos por la información seria y argumentativa focalizada en el discurso de los partidos políticos.

* 122 - Blockchain y periodismo: un nuevo modelo de negocio para la empresa informativa - Gema Alcolea-Díaz Universidad Rey Juan Carlos, URJC, España gema.alcolea@urjc.es y José-Vicente García-Santamaría Universidad Carlos III, UC3M, España jvgsanta@hum.uc3m.es

El presente trabajo analiza la aplicación de la tecnología blockchain a la empresa informativa y detecta sus implicaciones en la configuración de un nuevo modelo de negocio, entendido este de una forma global. Se estudia el empleo de blockchain en proyectos periodísticos, en la medida en que transforma gran parte de los elementos fundamentales del modelo de negocio de un medio. Así, además de su efecto sobre las fuentes de financiación e ingresos (se considera que facilita el salto 
hacia el llamado "internet del valor"), puede repercutir sobre la propuesta de valor de la empresa, fundamentalmente por las posibilidades de trazabilidad del producto y su repercusión sobre el contenido (por ejemplo, al detectar fake news, identificar su procedencia y bloquearlas, e incentivar la calidad). El uso de esta tecnología afecta, igualmente, a la definición del segmento del mercado al que se dirige, así como a las relaciones con el cliente y la participación del mismo. Asimismo, las asociaciones con otros proyectos y empresas también se potencian, en cuanto que se hacen prácticamente imprescindibles para la optimización del modelo de negocio. Todo ello teniendo en cuenta que el uso de blockchain en proyectos periodísticos es aún incipiente, casi inexistente y lleno de incertidumbre, por lo que el objeto aplicado de estudio es reducido, obligando a compaginarlo con otros ámbitos e ir más allá del análisis de casos para inferir de un modo más teórico sus posibles implicaciones. No obstante, el interés es máximo puesto que, aunque todavía es una pequeña parte de la industria, y no solo periodística, junto a algunas instituciones, quienes caminan en este sentido, hacia la aplicación de la tecnología blockchain, esta se dibuja con fuerza en el horizonte no solo de las empresas sino de la sociedad en su conjunto.

123 - La enseñanza-aprendizaje de Diseño de la Información Periodística mediante el uso del vídeo educativo en el contexto de la formación universitaria semipresencial - Gema AlcoleaDíaz - Universidad Rey Juan Carlos, URJC, España gema.alcolea@urjc.es

El presente trabajo pone de relieve el valor del uso educativo en la formación universitaria en la modalidad semipresencial, a través del análisis de caso. Se describe y analiza una experiencia de enseñanzaaprendizaje en la asignatura Diseño de la Información Periodística, del Grado en Periodismo, de la Universidad Rey Juan Carlos, llevada a cabo en el curso académico 2018-2019. En concreto, el vídeo se ha utilizado como herramienta didáctica de forma equivalente al uso de los laboratorios en la formación presencial, con el objetivo de capacitar, con solvencia, en el uso de "las tecnologías y herramientas para el diseño de la información periodística impresa aplicado a la elaboración de textos y productos periodísticos integrales", una de las cuatro 
Comunicación y Música: mensajes, manifestaciones y negocios

competencias específicas que se busca alcanzar con esta materia, estando esta, además, en estrecha relación con las demás a las que sirve de base expresiva. Así, valorando la necesidad de saber usar un programa de diseño periodístico, se ha elaborado y puesto a disposición del alumnado un conjunto de vídeo-tutoriales que abarcan un curso completo de InDesign, utilizando YouTube (https://bit.ly/2xW9wvf) como plataforma de alojamiento y difusión, y enlazados a través del Aula Virtual de la Universidad. Asimismo, se aportan los resultados de evaluación de la experiencia, con los datos extraídos de la encuesta realizada a los alumnos y alumnas una vez finalizada aquella, y de la medición de su efecto sobre el aprendizaje, con resultados muy favorables en ambos casos.

124 - Twitter, una herramienta para la promoción turística de Iberoamérica - Dra. Verónica Altamirano-Benítez - Universidad Técnica Particular de Loja - vpaltamirano@utpl.edu.ec, Dr. Miguel Túñez-López - Universidad Santiago de Compostela miguel.tunez@usc.es y María Fabiana Altamirano-Benítez Universidad de Vigo - mariafabiana.ab@gmail.com

El Twitter es, probablemente, una de las redes sociales más influyentes en el ámbito comercial debido a la cantidad de mensajes y conversaciones que se producen entorno a las marcas, lo que interviene en la creación de la imagen de marca y las decisiones de compra. Desde otro ángulo es, también, una importante herramienta para recolectar las opiniones de los usuarios por la facilidad de monitoreo que brinda, permitiendo dar una atención personalizada e inmediata y generando una experiencia agradable con los clientes, que valoran la respuesta de las organizaciones, pero, sobre todo la inmediatez. "Los sitios de microblogging proporcionan una plataforma para conectar directamente, casi en tiempo real, con los clientes, lo que puede construir y mejorar las relaciones con clientes" (Jansen, Zhang, Sobel, \& Chowdury, 2009, p. 2186).

Por esta razón, se convierte en una herramienta de promoción turística para los 22 Gobiernos de Iberoamérica. En la presente investigación se analiza la red social a través de 6 indicadores claves de desempeño (KPI): presencia, crecimiento, participación, servicio, engagement para 
determinar el índice de la comunicación turística 2.0. Además se realiza un análisis comparativo entre el la temporada baja (marzo - mayo) y la temporada alta (junio - agosto) de los años 2015 y 2018, con la finalidad de determinar las tendencias y avances en la comunicación turística.

125 - "Esto yo lo dejo ahí, extiéndalo usted más allá, componiendo los errores lograremos la paz". La obra poética del Wilson Caicedo y la memoria histórica del corregimiento 8 de Buenaventura - Juan Sebastián López López sebastianlopez@usantotomas.edu.co, Juan Guillermo Miranda Corzo - juanmiranda@usantotomas.edu.co, Andrea Paola Buitrago Rojas- andreabuitrago@usantotomas.edu.co y Mayra Alejandra García Jurado - mayragarcia@usantotomas.edu.co Universidad Santo Tomás (Colombia)

Introducción. La ponencia aborda la memoria histórica de la comunidad afrodescendiente del corregimiento 8 de Buenaventura (Valle del Cauca, Colombia) a partir de las poesías de Wilson Caicedo, uno de sus miembros. El objetivo es evidenciar de qué modo el análisis de tejidos líricos contribuye al estudio y el trabajo con comunidades étnicas, particularmente aquellas en situación de vulnerabilidad. Metodología. Las poesías se analizaron desde la semiótica cultural, a partir de un eje sintagmático y un eje paradigmático. Los demás testimonios se utilizaron para componer una línea de tiempo y una red semántica. Resultados.

Las poesías presentan una síntesis original de hechos victimizantes, experiencias, exhortaciones y elaboraciones simbólicas. Estas últimas, en particular, no se registran en los otros testimonios analizados. Discusión y conclusiones: La obra poética de Wilson Caicedo compone una narrativa sobre los avatares del Corregimiento 8, por lo que su análisis permitió ensanchar el horizonte de comprensión tanto del daño cultural que ha padecido la comunidad como de sus procesos de resiliencia. Además, su carácter performativo refuerza los vínculos comunitarios, pues los poemas representan el sentir de la comunidad al tiempo que la retan a producir nuevos significados, narrativas y prácticas de resistencia. 
Comunicación y Música: mensajes, manifestaciones y negocios

126 - Incongruencia en comicios electorales y la izquierda mexicana en elecciones 2018 en Chiapas - Juliana Matus López, Jorge Gómez Velasco y Bertha Palacios López - Universidad Autónoma de Chiapas, México

Calificadas como las votaciones más disputadas en la historia de México, la jornada electoral del primero de julio del 2018, marcaría un cambio radical en el proyecto de gobierno. El más fuerte de los candidatos perteneciente al partido Morena, de izquierda: Andrés Manuel López Obrador; frente a otros cuatro aspirantes de derecha y extrema derecha.

Cuatro candidatos a ocupar la silla del ejecutivo de la nación y también, cuatro los candidatos a la gubernatura del estado de Chiapas, que por efecto dominó le confiere el triunfo también al mismo partido de la izquierda, representado por Rutilio Escandón y por efecto dio el triunfo al presidente municipal de la capital chiapaneca. Este trabajo parte de un problema observado en el proceso de las elecciones del 2018 en el entorno político chiapaneco. Existe una incongruencia en el discurso de los candidatos, frente a las plataformas políticas de los partidos a los que representan y los idearios políticos de los partidos.

En este sentido, la conformación de alianzas entre partidos y los candidatos ha sido un evento insólito que ha creado confusión entre el electorado, ya que candidatos de la izquierda se alían con candidatos de la derecha, pasando por alto los idearios políticos propios de cada instituto político.

A partir de este hecho, un equipo de universitarios revisó los contenidos de las plataformas políticas que se anunciaron en la página oficial del Instituto de Elecciones y Participación Ciudadana (IEPC) para analizar los temas que en estos proyectos se presentan contrastando con la realidad y necesidades de la sociedad chiapaneca. Los temas que son prioritarios y que deberían aparecer en las plataformas políticas de los candidatos. Son 5 temas temas ejes: seguridad, gobernabilidad, crecimiento económico, democracia y sociedad, sin embargo, ningún proyecto los aborda a cabalidad. 
127 - "El lobby del alcohol y sus campañas de prevención sobre el consumo en España" - Paloma López Villafranca Universidad de Málaga- pallopvil@uma.es, Emilia Smolak Lozano - Universidad de Málaga - smolak@uma.es y Antonio Castillo Esparcia - Universidad de Málaga - acastilloe@uma.es

Según la Organización Mundial de la Salud, OMS, el alcohol provoca más de 3 millones de muertes al año y es agravante para más de 200 enfermedades como el cáncer, la cirrosis hepática y algunos tipos de demencia. Recientes estudios sobre el consumo de alcohol como los de la revista The British Medical Journal, confiman que la ingesta moderada de alcohol puede afectar negativamente al cerebro. Otros informes publicados en The Economist y The Washington Post muestran que causa más daños que la heroína y la cocaína. Sin embargo, la industria del alcohol representada por el lobby FEBE, Federación Española de Bebidas Espirituosas, promueve campañas de prevención de esta droga legal. En la siguiente investigación analizamos las campañas de la Federación FEBE: "Disfruta de un consumo responsable" (2010), la campaña de conductor alternativo "Noc Turnos" (2011), la campaña que la federación realiza con la Fundación de Víctimas de Accidentes de Tráfico, Fundtrafic en 2014 y la campaña actual "Menores ni una gota" (fecha de inicio-2014). El objetivo de la investigación es comprobar la relación de estas campañas con el intento del lobby de reflejar una imagen positiva libre de responsabilidades en el consumo abusivo. Para llevar a cabo este estudio se realiza análisis de contenido teniendo en cuenta variables como tipo de mensaje, personajes y sus roles, público al que va dirigido y canales en los que se difunde.

Aunque dirigidas a públicos distintos el objetivo es común la prevención de un consumo abusivo, aunque sin advertir de efectos que ocasiona el consumo moderado en públicos en los que el consumo está permitido. En las campañas no se abunda en detalles que puedan propiciar el no consumo y se aprecia alianza con las administraciones, como el Ministerio de Sanidad en la campaña de prevención de alcohol en menores o la campaña sobre conductor alternativo que FEBE realiza con la cooperación de Tráfico. Con conclusión principal, podemos evidenciar a través del análisis de estos casos que la industria 
Comunicación y Música: mensajes, manifestaciones y negocios

del alcohol proyecta una imagen responsable positiva a lo que contribuye su alianza con las administraciones públicas y con expertos en salud que refutan y sustentan dichas campañas.

* 128 - La brecha política de género en las campañas internacionales en las redes sociales - Emilia Smolak Lozano Universidad de Málaga - smolak@uma.es, Paloma López Villafranca - Universidad de Málaga-pallopvil@uma.es y Ana Almansa Martínez- Universidad de Málaga anaalmansa@uma.es

El desarrollo de la "aldea global" (McLuhan, 1963) y la irrupción de la sociedad en red a la que se unió la galaxia de Internet (Castells, 1996, 2001 y 2006) han motivado que cualquier campaña política tenga consecuencias políticas globales. Con rasgos comunes, sin embargo, el tema de género de los candidatos políticos, a pesar de ser ilustrativo en el reciente caso de las elecciones estadounidenses en 2016, no es significativo. La brecha de género en la política se observó científicamente en 1996 (Clark \& Clark, 1999) e incluso antes de los 60 (Shapiro y Mahajan, 1986). McElroy y Marsh (2010) declaran que: "las mujeres están muy poco representadas en el cargo electo. La abundante literatura sobre este tema ha mejorado considerablemente nuestra comprensión de este fenómeno, pero muchas preguntas siguen sin respuesta".

Mediante el presente estudio se realiza un análisis sobre las publicaciones de revistas internacionales con mayor impacto para conocer el estado actual sobre género y uso de redes sociales en las campañas políticas. Mediante análisis de contenido examinamos las publicaciones sobre género y campañas políticas mediante la perspectiva de la comunicación política digital (marketing, publicidad, relaciones públicas, POPR, OPR); la implementación de redes sociales en campañas políticas (redes sociales, gestión de contenidos, narrativa, presentaciones audiovisuales, hashtags, sentimientos y opiniones de usuarios de redes sociales, etc.); métodos de investigación utilizados en estas publicaciones; el ámbito de interés (región del mundo, país) y, finalmente, el tipo de campaña (presidencial, local, etc.). 
Los resultados demuestran el creciente, pero limitado interés en la investigación sobre género y redes sociales en campañas políticas. La investigación, la encuesta y los datos secundarios son los métodos utilizados con una casi inexistencia de estudios multidisciplinarios.

129 - Evolución de la narrativa audiovisual en la serie de documentales Héroes Invisibles - Víctor Cerdán Martínez Universidad Camilo José Cela - vcerdan@ucjc.edu y Daniel Villa Gracia - Universidad Complutense de Madrid daniel.villa@ccinfucm.es

Víctor Cerdán y Daniel Villa, director y jefe de postproducción de Héroes Invisibles, describen el proceso creativo de un formato televisivo para la televisión pública española. Esta serie de documentales, producida por RTVE en colaboración con Taifas Comunicación, retrata la vida de un español expatriado en el extranjero que trabaja en proyectos de ayuda humanitaria. Todos los episodios reflejan diferentes conflictos sociales, como la malnutrición infantil en África, las consecuencias de la guerra en Siria, los inmigrantes irregulares en Estados Unidos, o los rescates en el Mediterráneo Central.

En este artículo, los autores analizan la evolución de un formato televisivo desde la idea original, plasmada sobre un dosier, a la producción y grabación de los primeros capítulos en comparación con los de la segunda temporada. El objetivo principal es reflexionar sobre la evolución de la narrativa audiovisual de Héroes Invisibles a lo largo de casi tres años.

Para este cometido, los autores emplearán fragmentos de los 16 capítulos de la serie, para analizar los perfiles de los personajes escogidos por la productora, los tipos de encuadres, la estructura del guión, el montaje, la postproducción de sonido y color, y la selección de localizaciones. También aportarán documentos sobre el proceso de producción, grabación y postproducción para valorar los aspectos más significantes de la evolución de este formato televisivo que han seguido miles de personas desde su estreno en la 2 de TVE. 
Comunicación y Música: mensajes, manifestaciones y negocios

130 - La animación como estilo narrativo en el cine documental contemporáneo - Alberto Daniel Villa Gracia - Universidad Complutense de Madrid - daniel.villa@ccinfucm.es

En las últimas décadas el cine documental ha estado asociado al uso de la cámara in situ, la grabación de los entornos y personajes y la mímesis que otorga el cine con el tema retratado. Sin embargo, desde principios del siglo xx autores como los hermanos Fleischer, Windsor McCay o Walt Disney emplearon la animación para la producción documental. En este artículo nos proponemos analizar algunos de los documentales animados de la última década, como Waltz with Bashir (2008), Is the Tall Man who is Happy (2013) o 25 April (2015) y como emplean las técnicas de animación. Emplearemos los conceptos de domesticación y extranjerización de Lawrence Venuti, asociados inicialmente a la traducción literaria, para valorar la cercanía de las obras seleccionadas en la muestra con la estética de los filmes acción real o el cine de animación.

131 - La información que se muestra en la publicidad de alimentos: una cuestión de salud - Cristina González-Díaz Departamento de Comunicación y Psicología Social. Facultad de Ciencias Económicas y Empresariales. Universidad de Alicante - Email: cristina.gdiaz@ua.es

El mercado de los alimentos funcionales va en aumento y este hecho se refleja en los mensajes sobre propiedades saludables que estos productos realizan a través de la publicidad. El objetivo de este trabajo fue estudiar qué y cómo se presenta la información sobre los beneficios saludables de los alimentos en la publicidad. Se realiza un análisis de contenido de 263 spots emitidos en televisión durante el 2013. Se estudiaron las siguientes variables: temática del mensaje publicitario, cómo se muestra, la existencia de información extra además del mensaje principal, qué y cómo se ofrecía esa información y terminología utilizada. De las 263 piezas publicitarias analizadas, el $40,30 \%$ utilizaron el reclamo "salud". De éstas, en solo el 63,20\% había información extra más allá del mensaje principal y un 94\% lo hacía con un texto cuyo tamaño dificultaba su legibilidad por el tamaño de la letra. Como conclusión principal se evidencia que existen carencias de 
forma y contenido a la hora de exponer la información relevante sobre los beneficios saludables que reporta el producto. Por este motivo, se elaboran una serie de propuestas encaminadas a mejorar el diseño y la información en las piezas publicitarias para ofrecer mensajes más completos y claros.

132 - Narrativa audiovisual performativa: ¿Auto representación en el documental E agora? Lembra-me - Félix Gómez-UrdaUniversidad Complutense de Madridfelixgomezurda@gmail.com

El cineasta portugués Joaquim Pinto filmó durante un año lo que él mismo denomina un "cuaderno de ensayos clínicos", un experimento científico al que se sometió en Madrid para tratar de paliar los efectos devastadores que el virus de la Hepatitis C estaba provocando en su organismo, cuyo proceso se aceleraba en co-infección con el VIH. En ese año de descanso forzado, tuvo tiempo de abrir cajas viejas, reciclar papeles y revisar su vida junto a su compañero, el también cineasta Nuno Leonel, ¿para finalmente ofrecer E agora? Lembra-me, (2013) un documental cinematográfico de cerca de tres horas de duración. Pinto ofrece intensas reflexiones sobre el lugar del individuo en la sociedad: sitúa al receptor frente al desmoronamiento del estado del bienestar en España debido a las durísimas medidas tomadas por el Gobierno Rajoy, que afectan también a las políticas de $\mathrm{I}+\mathrm{D}+\mathrm{I}$ y repercute en la financiación de los proyectos que investigan en nuevos tratamientos retrovirales.

Las imágenes muestran a un hombre cuya supervivencia está supeditada a los inciertos progresos de la ciencia médica, en un tiempo en el que las políticas neoliberales desarrolladas en Europa están dejando en barbecho la investigación, la sanidad, las conquistas sociales... El resultado es un texto fascinante, elaborado en primerísima persona, que da cuenta del ahora de un individuo que decide poner en juego su vida delante de un objetivo, en un ejercicio de performatividad narrativa, donde cuerpos y sexualidades adquieren una relevancia de primer orden como personajes que atraviesan el tiempo del relato, desde el pasado hasta el presente, y son, con Pinto, narradores de la lucha del protagonista por su supervivencia. 
133 - La percepción de los adolescentes sobre los videojuegos violentos - Júlia Vilasís Pamos - Universitat Pompeu Fabra julia.vilasis@upf.edu

Esta investigación trata sobre uno de los fenómenos de ocio cultural con más crecimiento de la última década: los videojuegos, que ya son consumidos por más de la mitad de la población de España y de los países desarrollados.

El debate abierto sobre esta cuestión difiere en cuando a la visión y posición de los jugadores respecto el medio, y viceversa. Siendo así, esta investigación cualitativa se posiciona a favor del jugador como sujeto activo, considerando sus opiniones y consideraciones para entender los resultados del estudio, que se encuentra entre la intersección de los estudios culturales, de juegos y de juventud.

El objetivo de la presente es analizar la percepción de los adolescentes, considerando las variables género y clase social, a cerca de sus diferencias de acceso, consumo y preferencias sobre los videojuegos, así como el papel de su identidad y la percepción que tienen sobre la violencia virtual. Jugadores, desarrolladores, familias, ciudadanos y políticos tenemos el deber de promocionar una cultura ética del juego, promoviendo el desarrollo de jugadores críticos y la madurez de los videojuegos, en tanto que medios expresivos.

Esta responsabilidad es parte fundamental de nuestro propio ser y de las obligaciones hacia el resto de la sociedad. En este contexto, el poder digital está creando nuevas posibilidades y demandas que son fundamentales para la construcción de la cultura gamer.

En definitiva, el desarrollo tecnológico, en tanto que fenómeno global, no puede ser tratado de forma aislada, es necesario situarlo entre la frontera de los cambios socioculturales, escuchando y entendiendo a la comunidad como parte fundamental de los mismos. 
134 - Redes sociales como fuentes de información, el fanpage de PlayGround en jóvenes universitarios - Msc. Juan Sebastián Gómez Navas - Facultad de Comunicación, Artes y Humanidades - Universidad UTE sebastian.gomez@ute.edu.ec y Lic. Pablo Andrés Benítez Guerrero - Pontificia Universidad Andina Simón Bolivar pablobenitezg4@gmail.com

El consumo de información a través de las redes sociales se ha disparado progresivamente en los últimos años. Plataformas digitales como Facebook, YouTube, Instagram y Twitter se han implantado en el estilo de vida de miles de personas, sentando un precedente en la manera cómo vemos, compartimos y accedemos a información en la red. PlayGround Magazine, que se define como una revista online de cultura digital, se ha posicionado con su Fan Page de Facebook en varios países como un referente de información. Una fuente informativa predilecta, que se ha convertido en un medio de comunicación alternativo de gran demanda, orientado a un público juvenil desde su diseño y concepto.

El presente estudio descriptivo cualitativo analiza la relación entre los jóvenes universitarios y el uso de la Fan Page de Facebook de la revista digital PlayGround; específicamente su sección PlayGround Noticias como medio informativo. Se recolectaron datos a través de grupos de discusión donde se expusieron los videos más virales de la sección con el fin de indagar en el consumo y opinión de estudiantes de una universidad privada de la ciudad de Quito, Ecuador.

Se realizó un análisis de contenido de los datos descriptivos obtenidos, que permitió conocer la afinidad de los jóvenes con el formato, la respuesta hacia la exposición de contenido novedoso, el tono y la crítica, y el discurso periodístico que subyace en la línea editorial del medio. 
Comunicación y Música: mensajes, manifestaciones y negocios

* 135 - La situación actual de la empresa saludable en Bizkaia Ana Mata Galíndez - Camarabilbao University Business School - ana.mata@camarabilbaoubs.com, Lázaro Echegaray

Eizaguirre - Camarabilbao University Business School -

Lazaro.echegaray@camarabilbaoubs.com, Carmen Peñafiel Saiz

- Universidad del País Vasco/ Euskal Herriko Unibertsitatea

(UPV/EHU) - carmen.penafiel@ehu.eus y Milagros Ronco

López - milagros.ronco@ehu.eus

La implantación de la Responsabilidad Social Empresarial es una de las asignaturas pendientes en el tejido empresarial vasco y español. Incluirlas dentro del sistema empresarial significa mejorar las condiciones laborales de las empresas en todos sus aspectos, pero principalmente en aquellos que tiene que ver con la calidad de vida de los trabajadores. El proceso evolutivo de esta implantación se ha ido desarrollando paulatinamente en España y en la actualidad, aparecen nuevas políticas y conceptos que complementan los anteriores. La empresa saludable es un término que recibe influencias de diferentes disciplinas y que busca la mejora de la calidad de vida de las plantillas laborales, desde la implantación de acciones y programas saludables. La preocupación por la salud de los trabajadores se convierte hoy en un objetivo a alcanzar. Objetivo. El objetivo de esta investigación es presentar la situación actual de las empresas saludables de Bizkaia, a partir del desarrollo de un proyecto de investigación que analizó la percepción que tienen los mandos directivos sobre este concepto y el grado de aceptación, por parte de las plantillas, de un programa e-Salud que, a modo de prueba piloto, se ha implantado en las empresas participantes en el proyecto de investigación. Método. Al tratarse de una investigación de tipo exploratorio, hemos desarrollado una investigación mixta, cuantitativa y cualitativa, con las aportaciones de 16 responsables de diferentes organizaciones de Bizkaia, a través de entrevistas en profundidad. La parte cuantitativa se realizaba mediante encuestas de satisfacción y percepción dirigidas a aquellos/as empleados/as que se habían prestado a seguir la prueba piloto mediante el uso del programa. Los resultados que se exponen en este trabajo son los que tienen que ver con la parte cualitativa. Resultados. Los resultados, los podemos agrupar según la tipología de empresa que ha quedado definida por su posición frente al concepto de empresa 
saludable. Conclusión. La principal conclusión.es que estas tres tipologías, marcan a su vez y más allá de la voluntad, la posibilidad que las acciones se pongan en marcha.

136 - Cuestión de marca ¿para qué vale el periodismo responsable? - Dra. Miren Gabantxo - Uriagereka Universidad del País Vasco/ Euskal Herriko Unibertsitatea UPV/EHU - miren.gabantxo@ehu.eus

El equipo del diario Público (www.publico.es), desde octubre de 2018, ha implementado en su editor de noticias una aplicación que cada periodista chequea con ocho indicadores de transparencia editorial. Como si fuera una Q de calidad empresarial, la herramienta "TJ Tool" es fácilmente identificable con un logo de color azul junto a cada noticia, donde cuando el público hace click, una calculadora gráfica puntúa el proceso de creación del trabajo periodístico, en cuanto a su trazabilidad. En un entorno de contaminación informativa constante, con emisores de mensajes robotizados, al servicio de intereses políticos y económicos, el proyecto "TJ Tool”, financiado parcialmente por la Fundación Google DNI, pone boca arriba las cartas de un negocio donde todas las reglas éticas saltaron hace tiempo.

No cabe duda que la marca Google está muy interesada en mejorar su reputación, y por ello, ha financiado este y otros proyectos de innovación periodística, con 150 millones de euros. La RSC -reputación social corporativa- del diario Público también mejora con este tipo de iniciativas que le dan relevancia profesional. Pero más allá de estas evidencias, ¿qué piensan los estudiantes de Periodismo, Comunicación Audiovisual y Publicidad y Relaciones Públicas de nuestra Facultad en el Campus de Bizkaia?

Esta investigación cuantitativa y cualitativa, recoge la experiencia de marca de un grupo de ochenta alumnos y alumnas de primer curso, que el 30 de octubre de 2018, en el Campus de Bizkaia, escucharon in situ una conferencia de las dos periodistas que lideran el proyecto y contestaron un formulario a posteriori. Todo ello, realizado en el contexto de una asignatura obligatoria denominada "Comunicación Comercial, Corporativa e Institucional". 
Comunicación y Música: mensajes, manifestaciones y negocios

137 - Los retos de la televisión pública en España ante el mercado único digital europea - Marcial Murciano marcialmurciano@gmail.com, Carmina Crusafon y Carlos González Saavedra, Carmina Crusafon y Carlos González Saavedra

Los canales de televisión de servicio público se esfuerzan por atraer y mantener a sus audiencias mediante nuevas plataformas y aplicaciones digitales, con la finalidad de fortalecer la interacción con los espectadores y diferenciarse de otras ofertas, mediante el conjunto de valores institucionales que le son propios. A falta de una política común europea, más allá del mantenimiento de la importancia del mandato de servicio público, la nueva realidad multipantalla plantea muchos interrogantes acerca de cómo mantener la vitalidad y la relevancia de la televisión pública en el nuevo ecosistema de medios digitales. En este escenario, la presente comunicación analiza las estrategias de innovación y adaptación de la televisión pública al nuevo ecosistema, donde confluyen distintos dispositivos de visualización e interacción, así como la necesidad de renovar el mandato de servicio público.

* 138 - La especialización del consumo informativo entre los jóvenes y su influencia en el uso de la prensa en el aula de secundaria - Morán López, Próspero Manuel; Universidad de Oviedo, moranprospero@gmail.com, moranprospero@uniovi.es

Los cambios en el consumo informativo producidos en las dos últimas décadas, tras la irrupción y posterior desarrollo de la prensa digital, han llevado a trastocar sensiblemente la forma en que los diferentes grupos de edad de nuestra población obtienen esa información. Los adolescentes han comenzado a abandonar de forma sistemática la televisión, en beneficio de las redes sociales y los medios digitales, tanto para llenar sus horas de ocio como para obtener información de forma cotidiana. Y esa tendencia se produce contrariamente a la que muestras sus progenitores, que siguen manifestando en toda Europa una preferencia inequívoca por la televisión y los medios de masas tradicionales y de propiedad pública como demuestran los estudios más recientes (Pew Research Center, 2018). 
En este contexto, la enseñanza de la lengua y la literatura en los centros de educación secundaria, tanto en las etapas tanto obligatorias como postobligatorias, necesita en la sociedad de la información apoyarse de manera preferente en la realidad social, cultural y tecnológica de los destinatarios de dicha enseñanza. Nuestra propuesta parte de la atención actual a la comunicación en el curriculum de secundaria de la asignatura de Lengua y Literatura, y la realidad sociocultural referida, para proponer un acercamiento más eficaz a los procesos de lectoescritura en las aulas de ESO y Bachillerato.

139 - Evolución del uso de las redes sociales digitales científicas y la imagen de las facultades de comunicación en Ecuador Ketty Daniela Calva-Cabrera - Universidad Nacional de Loja (Ecuador) - ketty.calva@unl.edu.ec e Idoia Portilla - Universidad de Navarra (España) - iportilla@unav.es

Las redes sociales digitales científicas están constituyéndose como una importante herramienta de divulgación de la ciencia. Al mismo tiempo, estas redes proporcionan métricas alternativas públicas del impacto de los documentos científicos disponibles. Por tanto, el uso de estas plataformas por parte de docentes de una facultad puede influir en la imagen de la misma. En esta investigación se estudia la evolución de las redes sociales digitales científicas en el caso de docentes de las facultades de comunicación de Ecuador, comparando la situación en marzo de 2015 con la de septiembre de 2018. El objetivo es analizar la evolución de la presencia de estos docentes en Academia.edu, ResearchGate.net y Google Académico. Los indicadores utilizados son el número de profesores con perfiles en las redes de estudio, el número de seguidores, su origen, el número de cuentas que siguen, y países a los que pertenecen tales cuentas. Además, se medirá el cambio en el impacto de estas cuentas atendiendo al número de documentos, lecturas y descargas, el índice h y el RG Score. Los resultados de este estudio comparativo muestran mejoras en cuanto al uso y gestión de las redes por parte de los docentes, confirmando que estas nuevas plataformas emergentes están alcanzando mayor relevancia dentro del mundo académico. Además, el estudio por facultades, permitirá 
Comunicación y Música: mensajes, manifestaciones y negocios

observar los cambios que puedan afectar a la imagen de estas organizaciones.

140 - El ensayo documental: El documental subjetivo mirarlo la melancolía y lo abyecto - Luis Deltell - Universidad Complutense de Madrid - ldeltell@ucm.es

Esta comunicación estudia el ensayo audiovisual como una forma de la no ficción y el documental que indaga en lo subjetivo desde la perspectiva de lo melancólico y lo abyecto. El ensayo audiovisual se estudiando como una herramienta para narrar el yo y con frecuencia en el narcisismo, como ya predijo Krauss para el cine experimental y el video-arte. Pero lo cierto es que el cine documental y ensayístico, en especial en España, divaga más hacia lo melancólico (como hace Oskar Alegria, Mercedes Álvarez, Víctor Erice o Samuel Aranda) o por otro lado para mostrar lo abyecto o trágico (como lo usa el colectivo Terrorismo de autor, Virginia García del Pino o algunas obras de León Simiani). Esta comunicación muestra como estas dos tensiones, lo melancólico y lo abyecto se entrecruzan en los proyectos del ensayo audiovisual.

141 - El escándalo de cambridge analytica en la prensa francesa: las consecuencias del panoptismo digital - Camila, Pérez Lagos - Sorbonne Nouvelle Paris 3 CIM ERCOMES perez.lagos.camila@gmail.com

La presente comunicación se inspira de la noción de panoptismo digital (Byung-Chul, 2013), entendido como el fenómeno de vigilancia permanente en internet a través de las huellas que el internauta deja, voluntariamente o no, durante su navegación. La noción se basa en el panopticon de Jeremy Bethman (1780): "figura arquitectónica en la que desde un punto central, una torre, el vigilante puede controlar mientras que los vigilados, alojados en celdas individuales, separadas unas de otras, son vistos sin ver a quien los observa" (Mattelart, 2009. 17). Según Han Byung-Chul (2013), el panopticon de Bethman, mantiene algunas diferencias con el panopticon digital: en el caso de internet los usuarios no ven a su vigilante. Según Tristán Nitot (2016) la eficacia del panoptismo digital, estaría acentuada por la invisibilidad de los 
mecanismos de vigilancia y en algunos casos su perfecta legalidad. Sin embargo, ¿qué ocurre cuando los mecanismos de vigilancia e intromisión en la vida privada de los usuarios de internet y redes sociales salen a la luz publica?

A través de un análisis semio-discursivo (Charaudeau, 1995, 2011) se buscó identificar e interpretar los discursos sobre la vigilancia digital y en particular las consecuencias para los usuarios de internet en el caso del escándalo de Cambridge Analytica. El corpus de estudio estuvo conformado de 130 artículos de la prensa francesa, en particular del periódico "Le Figaro" extraídos de la base de datos FACTIVA. Los artículos tratan el "escándalo" de Cambridge Analytica, desde marzo hasta septiembre 2018. El estudio muestra, la vinculación del "escándalo" con el nuevo reglamento europeo de respeto a los datos personales "RGPD", vehiculando así la idea que "Francia estaría protegida de dichos eventos". Además, se plantea la necesidad "ética" del respeto a la vida privada por parte de las empresas frente al aumento de la desconfianza de parte de los ciudadanos.

142 - Secreto de las comunicaciones y entorno virtual ¿Un derecho constitucional? - Cristina Zoco Zabala - Profesora Contratada Doctora de la Universidad Pública de Navarra cristina.zoco@unavarra.es

En la actualidad, se asiste a una auténtica revolución tecnológica. Tal evolución de las tecnologías de la información y de la comunicación no ha sido expresión, sólo, de novedosos instrumentos de comunicación mediante soporte (chats, videoconferencia, webconferencia); ha repercutido, fundamentalmente, en dispositivos tecnológicos que lo mismo han soportado innovadoras modalidades comunicativas mediante instrumento técnico (correos electrónicos no leídos, chats en curso), que acomodado comunicaciones ya sin soporte (correos electrónicos leídos, chats finalizados), datos personales, informaciones, imágenes y conversaciones directas que por no ser comunicaciones a través de medio técnico no quedan protegidos por las garantías del art. 18.3 CE. La evolución de las tecnologías de la información y de la comunicación ha redundado también en instrumentos técnicos capaces de captar conversaciones directas a larga distancia (drones, micrófonos 
Comunicación y Música: mensajes, manifestaciones y negocios

espía) y conversaciones ambientales con ocasión de la intervención policial de las comunicaciones a través de medio técnico (SITEL o sistema integral de interceptación de las comunicaciones). Un sector doctrinal ha señalado que es preciso crear un derecho constitucional a un entorno virtual que proteja el espacio virtual del individuo frente a intervenciones mediante resolución judicial. En relación con la intervención o grabación de las conversaciones directas, otro sector ha señalado que éstas quedan protegidas por el art. 18.3 CE pues lo que garantiza el secreto de las comunicaciones es el proceso de la comunicación con independencia del medio empleado (soporte técnico) o de que éste exista.

Esta comunicación analiza el secreto protegido por el art. 18.3 CE: las comunicaciones a través de medio técnico. Ello con el pretexto de verificar si la grabación de las conversaciones, o la intervención del dominio virtual quedan protegidos por las garantías del art. 18.3 CE El objeto protegido por el art. 18.3 CE es el proceso de comunicación a través de instrumento técnico, pero no el proceso de grabación de comunicaciones directas o sin soporte. Así mismo, el secreto de las comunicaciones garantiza la opacidad del proceso comunicacional mediante soporte, pero no el proceso virtual potencialmente comunicativo; en tal sentido, se cuestiona el entorno virtual propio como objeto de un derecho no fundamental que hace abstracción de otros derechos fundamentales que resultan del variado contenido virtual que puede ser interceptado (intimidad, protección de datos personales, o secreto de las comunicaciones). También se plantea la dificultad de definir qué sea el espacio virtual propio por contraposición al entorno virtual ajeno, o los límites temporales de la protección de un espacio virtual permanente, aunque el usuario haya apagado el soporte de acceso a tal dominio virtual.

Finalmente, se recomienda valorar si el entorno virtual propio debe ser regulado como derecho fundamental en la Constitución; o bien puede ser manifestación de derechos fundamentales ya regulados en la Norma Fundamental: intimidad, imagen, o protección de datos personales. 
143 - La escritura pedagógica: herramienta para la sistematización y comunicación de experiencias educativas David Moromenacho - Universidad Católica del Ecuador intipakchuri@gmail.com

Las acciones educativas formales en las sociedades modernas mantienen un rasgo vertical. Las metodologías, los programas y procedimientos tienen un orden jerárquico, generalmente establecidos y regulados desde el Estado. Frente a este orden del sistema educativo, las acciones educativas realizadas en el aula por los profesores aparecen como la aplicación final de un proceso establecido y controlado. Si bien, cada vez hay más campo para la innovación desde abajo, es decir desde el aula, aún estas experiencias se mantienen como hechos aislados y no retroalimentan a la estructura educativa. También, la investigación y sistematización de estas experiencias se realizan a partir de agentes externos quienes observan e intervienen en las acciones del profesor. Frente a esta situación, la escritura pedagógica, como género específico para la sistematización de experiencias educativas con finalidad pedagógica, permite a los docentes plasmar su accionar dentro del aula, haciendo un ejercicio de reflexibilidad de sus acciones educativas. La reflexibilidad es el insumo básico para la escritura pedagógica y por extensión para la sistematización de la experiencia educativa. Los textos producidos mediante la escritura pedagógica constituyen una posibilidad de repensar, reestructurar evaluar la estructura educativa y dar voz al profesor quien es, en última instancia, el ejecutor directo de todo proyecto educativo. También, estos textos abren la posibilidad de una colaboración particular entre docentes en la medida que puedan circular en medios accesibles para los profesores.

144 - Secuenciación de las competencias en las asignaturas de Lenguaje Audiovisual y Técnicas de Creación Audiovisual en los grados de comunicación de la UPV/EHU - Estibaliz Alonso UPV/EHU - estibaliz.alonso@ehu.eus y Aintzane Pagadigorria -UPV/EHU - aintzane.pagadigorria@ehu.eus

El objetivo del presente trabajo es presentar los resultados del Proyecto de Innovación Educativa "Adaptación de programas teóricos y diseño e implementación de un programa práctico integral sobre la 
Comunicación y Música: mensajes, manifestaciones y negocios

metodología de aprendizaje basado en proyectos -abpy-, para reforzar la secuencia formativa entre las asignaturas de lenguaje audiovisual y técnicas de creación audiovisual" que consiste en revisar el programa teórico y rediseñar el programa práctico de dos asignaturas básicas de rama y complementarias entre sí que se imparten de manera secuencial en el primer curso de los grados de Periodismo, Comunicación Audiovisual, y Publicidad y Relaciones Públicas: Lenguaje Audiovisual (primer cuatrimestre) y Técnicas de Creación Audiovisual (segundo cuatrimestre).

Se trata, principalmente, de implementar un programa didáctico basado en el modelo IKD (Aprendizaje Cooperativo y Dinámico. Modelo educativo de la UPV/EHU) que adapta el aprendizaje de competencias al proceso formativo secuencial que se desarrolla a través de estas dos asignaturas a lo largo del curso. Dentro de dicha secuenciación se incluye también la participación del alumnado en diferentes festivales audiovisuales impulsando así dinámicas con el entorno profesional y potenciando el trabajo cooperativo y en equipo.

La metodología utilizada en este proyecto consta de dos apartados: el diseño y la implementación de un programa práctico común a Lenguaje Audiovisual y Técnicas de Creación Audiovisual, y la medición de los resultados obtenidos mediante las encuestas realizadas al alumnado y la evaluación de los trabajos por parte del profesorado y de los miembros del jurado del concurso audiovisual. Estos resultados permiten detectar las debilidades y fortalezas de esta implementación, y dan lugar a una nueva propuesta mejorada de cara al siguiente curso.

* 145 - SaludsinBulos, una plataforma que aúna esfuerzos para luchar contra las noticias falsas sobre salud - Ma . Angélica Real Serrano, UC3M angelicarealserrano@yahoo.es y José Luis Terrón Blanco, InCom-UAB joseluis.terron@uab.cat

Introducción: Los medios de comunicación de masas son una de las fuentes preferidas por los ciudadanos para informarse sobre salud. Pero los medios de comunicación pueden ser, a la vez, un instrumento de educación y promoción de la salud y un vehículo para transmitir la medicalización o la pseudociencia y las terapias alternativas, creando 
confusión y malentendidos entre sus destinatarios, una confusión que en numerosas ocasiones responde a intereses de los propios medios o de sus fuentes de información. Ante este hecho han surgido distintas alternativas de fiscalización e información ciudadana.

Objetivo: Conocer la labor que viene desarrollando la plataforma SaludsinBulos, para los que se dará respuestas a las siguientes preguntas: ¿qué entiende por bulo o fake news en el ámbito de la salud?, ¿quiénes la impulsan?, ¿cuáles son sus finalidades?, ¿cómo funciona? y ¿cómo se presenta formalmente?

Metodología: Hablamos por tanto de un estudio de caso. Para la aproximación al mismo partimos, en primer lugar, de una revisión bibliográfica para saber qué es un bulo en el campo de la salud y si existen otras plataformas similares a la estudiada y, a continuación realizamos un análisis formal y de contenido de la plataforma, para acabar con una serie de entrevistas semiestructuradas a Emilio de Benito -redactor de El País y presidente de ANIS-, Carlos Mateos impulsor de la iniciativa aquí tratada- y Lucía Galán -profesional del sector sanitario con gran visibilidad en las redes sociales-.

Resultados: Iniciativas como SaludsinBulos han desmontado bulos en distintos ámbitos de la salud, implicando a distintos agentes que, debido a la información, divulgación y educación que desde este tipo de plataformas se realiza, han empezado a colaborar en la lucha contra información no veraz en el ámbito sanitario.

Conclusión: Se considera fundamental desmentir las noticias falsas cuanto antes mejor, ya que cada vez tienen una mayor capacidad de difusión y de propagación en menos tiempo a través de los medios convencionales y de las redes sociales mediatizadas, y por tanto de hacer daño. 
Comunicación y Música: mensajes, manifestaciones y negocios

146 - El poder de la prescripción en la comunicación estratégica turística: el influencer 2.0. - Alba-María, Martínez-Sala Universidad de Alicante - albamaria.martinez@ua.es; Juan, Monserrat-Gauchi - Universidad de Alicante juan.monserrat@ua.es y Jesús, Segarra-Saavedra- Universidad de Alicante - jesus.segarra@ua.es

El desarrollo de las redes sociales ha propiciado el nacimiento de una nueva figura, clave en las estrategias de comunicación turística: el influencer 2.0 turístico. Su creciente importancia, así como las ventajas que ofrece a los destinos obligan a un replanteamiento de sus estrategias de comunicación En este sentido, se plantea esta investigación que persigue como objetivo principal analizar el alcance y potencial que ofrecen los principales influencers 2.0 turísticos a las organizaciones de marketing de destinos, así como describir su integración en sus respectivas estrategias de comunicación turística. La metodología de carácter descriptivo combina la revisión bibliográfica con un análisis del alcance de los principales influencers 2.0 turísticos en el conjunto de redes sociales (mapa transmedia) y, de forma específica, en Facebook (comunidad y engagement online). En esta red social se evalúa, además, su potencial comunicativo y relacional respecto de una representación de destinos turísticos españoles. Para ello se realiza un análisis de contenido cuantitativo de las publicaciones y de la interacción generada. El estudio se completa con el punto de vista de los responsables de comunicación digital de los destinos analizados. Los resultados confirman la importancia de esta figura, así como su plena implementación en las estrategias de comunicación turística. Del mismo modo, se concluye que su identificación y selección es una tarea compleja que requiere de la consideración de variables cuantitativas y cualitativas. La investigación y sus conclusiones son una contribución al escaso cuerpo teórico sobre esta figura en el sector turístico, necesaria por su importancia e influencia. Los resultados relativos a su alcance y potencial comunicativo y relacional conforman un estudio actualizado imprescindible para su identificación y correcta integración. Así mismo, el proceso metodológico constituye un modelo de selección de influencers 2.0 turísticos de gran utilidad para los responsables de la comunicación turística. 
147 - Confianza y reputación organizacional en tiempos de infoxicación - Stefani del Cisne Paladines Carranza Universidad Técnica Particular de Loja steffycpc_95@hotmail.com y Jenny Jovita Yaguache Quichimbo - Universidad Técnica Particular de Loja jjyaguache@utpl.edu.ec

La confianza y reputación son la clave del éxito o del fracaso de una empresa, es por esto que la gestión de la comunicación en las organizaciones debe estar enfocada a ella, a la construcción de una identidad corporativa fuerte que sea capaz de defenderse ante el actual mundo digital, especialmente en tiempos de infoxicación.

El valor intangible que tiene toda empresa es sin duda la reputación institucional, pues brinda seguridad y confianza a los stakeholders; además, es un proceso que viene de públicos internos y externos, los mismos que la van construyendo conforme a la historia y el compromiso que haya aportado la organización a la sociedad. Trabajar en acciones que fortalezcan la reputación institucional se ha vuelto casi un reto para las empresas que están dentro del mundo digital, debido a que abunda información de todo tipo y que muchas de las veces son replicadas por usuarios o clientes sin importar de donde vengan, si son positivas o negativas, verdaderas o falsas.

El propósito de esta investigación es conocer el criterio que tienen los gestores de comunicación de las diez principales empresas del Ecuador, con mayor facturación, en cuanto a la importancia de gestionar acciones que fortalezcan la confianza y la reputación y cuáles han sido las estrategias de respuesta en momentos en que estos valores intangibles han sido trastocados.

La investigación se realiza a través de metodología cuali y cuantitativa. En la prima fase se aplican entrevistas semiestructuras a los responsables de comunicación de las empresas y en la segunda, se ejecuta un análisis de contenido a las cuentas Facebook y Twitter de las mismas empresas, a fin de identificar si en algún momento fueron objeto de noticias falsas que desestabilizó la información oficial de la organización. 
Comunicación y Música: mensajes, manifestaciones y negocios

148 - Propuesta metodológica para el estudio del control parental sobre las comunicaciones en redes sociales de la Generación Z - Ma del Pilar Antolínez Merchán, Universidad Camilo José Cela, pantolinez@ucjc.edu y Mª Cristina Cañamero Alvarado, Universidad Camilo José Cela, ccanamero@ucjc.edu

Es sabido que una de las grandes preocupaciones de padres y educadores es la sobreexposición de los jóvenes a las redes sociales, y en general a las nuevas tecnologías de la comunicación en las que interviene internet. Se hace necesario, por tanto, la búsqueda por parte de los investigadores sociales de una propuesta metodológica que pueda aportar soluciones a padres y profesionales de la educación respecto a este problema.

La complejidad de este fenómeno, en el que inciden factores socioeconómicos, tecnológicos, pedagógicos, etc, plantea un reto excepcional de cara a su estudio. La comunicación constituye, en este sentido, una propuesta metodológica interdisciplinar de investigación, en la que se incluye una definición precisa de objetivos de estudio, la delimitación de universos de observación según las distintas categorías poblaciones implicadas (jóvenes por grupos y subgrupos generacionales, padres, comunidad educativa), los métodos de observación y recogida de información pertinentes y, por último, las técnicas de análisis (cuantitativas y cualitativas) consideradas más apropiadas al efecto.

149 - La Responsabilidad Social Corporativa y Empresarial.

Perspectiva de la aplicación de Programas de Salud en la Empresa - Milagros Ronco López - milagros.ronco@ehu.eus, Carmen Peñafiel Saiz - carmen.penafiel@ehu.eus, Universidad del País Vasco UPV/EHU - Lázaro Echegaray Eizaguirre lazaro.echegaray@camarabilbaoubs.com y Ana Mata Galíndez ana.mata@camarabilbaoubs.com - Camarabilbao University Business School -

La Responsabilidad Social Empresarial tiene dos enfoques que cada vez convergen más. Por un lado, el enfoque tradicional de la seguridad y salud en lo que se refiere a la protección, seguridad y prevención, que 
pertenece al ámbito legal obligado. Por otro, un enfoque más avanzado que engloba todo lo referente a la promoción de la salud de los trabajadores y que repercute, sin duda, en el ámbito del trabajo dentro de las empresas, como pueden ser las cuestiones organizativas carga/ritmo de trabajo, la conciliación de los horarios o los hábitos personales y sociales de salud entre otros. Este último enfoque supone el paso más avanzado en el desarrollo de la RSE, el que desemboca en la Empresa Saludable. Objetivo. Este estudio se centra en el análisis de las fuentes documentales imprescindibles para llevar a cabo el Proyecto de investigación "Comunicación, Salud y Responsabilidad Social en el tejido empresarial vasco: análisis de los intangibles y del reporte no financiero en la empresa saludable”. Método. Investigación cualitativa de tipo documental que supone la búsqueda, recopilación, valoración e información documental que permita una visión panorámica de las principales publicaciones en torno al objeto de estudio. Resultados. Se incorporan fuentes que contemplan tanto el enfoque legal como el enfoque evolucionado hacia programas integrales de empresa saludable. Su cobertura es tanto nacional como internacional en ambos enfoques. En el primero de los casos, la protección y seguridad en el trabajo parte de las normas de la Organización Internacional del Trabajo (OIT) así como de las normas legales españolas y, en el segundo, de las recomendaciones de diversas organizaciones internacionales como la Organización Mundial de la Salud (OMS) o la Red Europea de Promoción de la Salud en el Trabajo (ENWHP). En todas ellas está incluida España.

150 - Défaire, refaire les représentations: réflexions sur la mise en place d'une méthode collaborative de l'image dans l'analyse de représentations politiques de migrations - María Alcalá Université Paris 8, CEMTI / Labex Arts-H2H

Dans son ouvrage Walkscapes (2013), l'architecte et chercheur Francesco Careri donne aux migrations une place capitale dans l'histoire de l'humanité. À partir de la considération du menhir comme premier objet situé dans l'espace avec des intentions signifiantes, Careri affirme que " c'est probablement le nomadisme, et plus exactement l'errance, qui a donné lieu à l'architecture en faisant émerger la nécessité d'une construction symbolique du paysage » (Careri, 2013: 40). Ce type 
Comunicación y Música: mensajes, manifestaciones y negocios

de discours très valorisant sur les migrations est pourtant minoritaire dans les domaines politiques et médiatiques actuels. Depuis 2015, des «données chiffrées ont été fortement mobilisées pour rendre compte de la "crise des migrants". Pour représenter cette crise comme exceptionnelle, les chiffres ont généralement été diffusées en valeur absolue (plutôt que relative), de manière décontextualisée et partielle» (Casella Colombeau et Clochard, 2017: 30). La panique face à l'arrivée des personnes fuyant le conflit syrien et d'autres conflits de plus longue date n'est que l'exacerbation du «processus d'ethnicisation des rapports sociaux qui est à l'œuvre dans pratiquement toutes les élections depuis la percée du Front national en 1983» (Hargreaves, 2012: 1), ainsi que de l'imposition, depuis les années 1970, de l'immigration comme thème dans les débats politiques, juridiques et médiatiques français (Barats, 2001: 149).

La crispation médiatique avec les migrations passe souvent au travers des images. Taous Dahmani (2017) parle d'une iconographie de l'arrivée, qui réduit le phénomène migratoire à l'entrée dans le territoire étranger, et Marco Binotto (2015) identifie les figures de l'envahisseur, l'alien et le criminel comme métaphores dans la définition médiatique de la migration. L'utilisation de l'image n'est pas anodine, car nous assistons de nos jours à l'amplification de l'importance du visuel dans nos vies. La théoricienne des Visual Culture Studies Gillian Rose constate dans les travaux de plusieurs chercheur-e-s la déclaration du fait «que ce processus a atteint des niveaux sans précédent, de sorte que les occidentaux interagissent désormais avec le monde, principalement grâce à la façon dont nous le voyons» (Rose, 2012: 3). À partir de ces constats, ainsi que de positionnements épistémologiques et éthiques, la présente communication est le résultat d'une expérience de coconstruction d'analyse des images des migrations qui ont été publiées, pendant la campagne présidentielle française de 2017, dans les sites web des candidat-e-s et des partis politiques qui les accompagnaient. Cette analyse collective a été réalisée avec des membres du programme JRS Jeunes de l'association JRS. À partir des outils de la sémiotique (Beyaert-Geslin, 2009 ; Odin, 2011 ; Saemmer et Tréhondart, 2014), des études sur les représentations des rapports sociaux de race et des migrations (Barats, 2001 ; Binotto, 2015 ; Cervulle, 2017 ; Hall 2007 ; 2014 ; Hargreaves, 2015) et des études sur la visibilité et la 
reconnaissance (Honneth, 2013 ; Mubi-Brighenti, 2007), et prenant appui sur ce que Gillian Rose appelle une " méthodologie visuelle critique » (2012 : 17), soit « une approche qui pense le visuel à partir des significations culturelles, pratiques sociales et rapports de pouvoir dans lesquels il est pris », l'analyse des représentations a été complétée par une activité d'action sur les images, où sa manipulation physique (coupage, collage, etc.) par les participant-e-s permettait de les utiliser comme matière première dans la construction des représentation plus adaptées à leurs histoires et leurs désirs. En plus de présenter des conclusions sur l'analyse desdites images, il s'agira dans cette communication de réfléchir aux opportunités et aux difficultés d'une méthode collaborative de l'image, ainsi que du rôle que ce type de outils méthodologiques peut jouer dans l'analyse des représentations politiques et médiatiques et, plus généralement, dans les sciences de l'information et de la communication.

151 - A investigaçao hibrida: pontes e pontos de contato entre as tecnologias sociais e as ciências sociais - Pedro Andrade Universidade do Minho - pjoandrade@gmail.com

A investigação globalizada e transnacional na contemporaneidade requer atividades não apenas científias mas igualmente sociais, que incluam uma articulação estreita (e por vezes uma hibridação), entre diferentes entidades e processos. Por exemplo, entre saberes e culturas, teoria e prática, trabalho individual e de equipa, media clássicos e digitais. Em particular, torna-se urgente um compromisso entre as racionalidades científicas atuais, as sociabilidades dos novos media e as sensibilidades recentes das artes. A presente comunicação pretende apresentar algumas práticas híbridas de organização da pesquisa atual, onde, cada vez mais, as equipas incluem membros de diferentes qualificações e formações, como programadores, designers e investigadores de Ciências Sociais e Humanas. Duas ilustrações breves: a sociabilidade inerente às redes sociais digitais necessita de ser analizada, não apenas na suas componentes tecnológicas, mas também em termos de utilizadores que agem e pensam como audiências e públicos do ciberespaço e do cibertempo. E os projetos aplicando Physical Computing (Arduino, óculos de realidade aumentada), precisam de uma interpretação da comunicação subjacente às culturas 
Comunicación y Música: mensajes, manifestaciones y negocios

digitais que motivam o uso desses aparelhos, em articulação com a aparelhagem urbanística e social ativada pelas culturas urbanas do mundo 'físico' da cidade. Em termos metodológicos, e para a realização prática de tais objetivos no seio da investigação híbrida, existem muitas ferramentas úteis: sofwares de organização da pesquisa, recolha, análise e interpretação de conteúdos e dados, como o NVivo; redes sociais utilizadas como lugares de partilha de conhecimento entre a equipe do projeto e redes globais / locais de investigadores; blogs usados como diário de pesquisa; RSS entendido como um feed de notícias no ciberespaço e uma fonte de jornalismo de investigação e da "investigação jornalizada"; wikis entendidos enquanto redação coletiva de projetos; a curadoria de conteúdos em sites da internet, para a apresentação do work in progress de projetos de investigação.

152 - Comparativo del capital social y simbólico de organizaciones del sector comercio en México y Colombia: un análisis desde la antropología visual - Rebeca Illiana Arévalo Martínez - Universidad Anáhuac México rebeca.arevalo@anahuac.mx; William Tenjo Beltrán Universidad Anáhuac México williamtenjo@outlook.com; Carlos Cienfuegos Alvarado carlos.cienfuegos@anahuac.mx

En los últimos años la economía de México y Colombia está fuertemente determinada por las micro y pequeñas empresas. Particularmente las micro empresas que comercializan alimentos; sumando un total de 975,760 tiendas de abarrotes en México (INEGI, 2015) y 307,000 en Colombia (Dinero, 2014). Estos pequeños comercios se ubican en los barrios de las ciudades capitales, a pesar de la existencia de grandes supermercados y tiendas de conveniencia, son un espacio de reforzamiento cultural y relacional entre el consumidor y quien atiende la tienda (tendero).

El capital social (confianza entre el tendero y sus clientes); el capital cultural (actitudes, valores, aptitudes, capacidades y aprendizaje producto de la interacción); así como el capital simbólico (valor otorgado por acciones de responsabilidad social y reconocimiento entre el tendero y sus clientes); son resultado de la identidad e imagen que refleja tanto el tendero como la tienda. 
Por todo esto, se presenta los resultados de una investigación que tuvo como objetivo analizar la identidad e imagen, capital cultural, social y simbólico de una muestra de tiendas de abarrotes en México y en Colombia, a partir del análisis fotográfico por medio de la antropología visual. La propuesta metodológica para el análisis de las fotografías retoma las teorías de John Collier (1967) y Malcolm Collier (1986) considerando las categorías de comunidad, entorno doméstico y dinámicas sociales, además de analizar las imágenes en cuatro niveles: espacio, acciones, elementos y experiencia, desde una perspectiva de reflexividad donde sea posible descubrir aspectos no visibles de las experiencias y conocimientos (Ibanez, s.f.). Los hallazgos permiten mostrar la pertinencia de la metodología, ponderar la importancia de la identidad e imagen de las tiendas en la construcción de los capitales ya mencionados, así como marcar nuevos horizontes para el uso de la antropología visual en la investigación en comunicación para las organizaciones.

153 - Exploring visual communication in the food porn frame Sebastiano Benasso - sebastiano.benasso@gmail.com, Luca Guzzetti - luca.guzzetti@unige.it, Luisa Stagiluisa.stagi@unige.it-Laboratorio Sociologia Visuale di Genova, Disfor, Università di Genova

In the social media, the representations of self are also constructed by posting pictures. The aesthetics of the selfies, the staging of social life, as well as the representation of the consumption habits draw on shared codes. Subjectivity, indeed, is built thanks to recognisable languages. In this paper we question the possibility to analyse images virally circulating in the social media, construction of hypotheses about their potential categorisation. Starting from a recent experimental research focused on food porn pictures and their relations with the construction of "Italianicity", we will retrace the whole process, from the definition of the leading research questions to their operationalisation and analysis. Specifically, the research will explore the images and discourses circulating around the traditional Italian recipe of "pasta alla carbonara", putting them in relation with the concept of gastronationalism. The quanti-qualitative analysis has been carried out by the 
Comunicación y Música: mensajes, manifestaciones y negocios

MAXQDA 18 software, operating on the first 50 images of pasta alla carbonara mined by the Google images search engine in anonymous browsing mode. The paper will particularly focus on different perspectives for the analysis of such material, sharing insights concerning their strengths and weaknesses.

154 - The use of netnography in design research: A clifford Geerz's perspective - Virginia Borges Kistmann - Programa de Pesquisa e Pós-Graduação em Design da Universidade Federal do Paraná - vkistmann@ufpr.br

Recently, designers and design researchers have introduced new methods to gather consumer's behaviour, following the mediascape expansion (APPADURAI, 1996). As this new approach is faster, costs less, makes easier the access to distant users/consumers and diminishes the interpersonal contact, not always desired, the use of digital/virtual empirical research relying on visual anthropology it is today a frequently used method in design field (LUCCA, 2016). Nevertheless, although these data source in some ways can be seen as a way to enlarge the traditional methods of visual anthropology, it also may reduce the complexity of ethnographic studies, as the new method is mediated by the Internet instead of by filming or using photography to register and further description and discussion about the context in the field.

This has transformed the field research, full of rich elements into a desk research, in which communication is mediated by a digital media. Thus, indeed deeply modifies the way researchers seek and understand consumers demands to define product concepts. For instance, it brings a new set up in which the experience and the interpretation of another reality involves two or more individuals that may not be always real subjects in the mediation. Considering this, this work discusses the implications of this new method in relation to the Geertz's concepts (1989; 1996; 1997; 2005). It seeks to consider how netnography (KOZINETS, 2017) interwove images, texts, social media sites, as well as questionaires and interviews, as information sources to define consumers demands and products concepts (SANTOS, 2018). Some authors have already mentioned critically how these data can be appropriate, analysed, conceptualized and transmitted by designers and 
researchers (ANDERSON, 2018). Further on, one can consider that the use of the Information and Communication Technologies (ICTs) in the new digital ethnographic methods reinforces and broadens the questions posed by Geertz, regarding the study of the other, the different, the diverse. Who am I, the researcher, who are they, the subject? To what extent, the new digital medium interferes with this vision process of the "real"? How does this impermanent culture change, from each other outcomes (the emitters/companies and the recipients/consumers)? What are the differences between the researcher and the researched, from the point of view of a netnographic approach? Considering this pragmatic tool to make assessments about the sensitive field, this work sheds light on the implications connected with the integration of web-based technologies in ethnographic research. It explores these questions by an interpretative approach in a form of an essay, bringing as result highlights to be considered in the adoption of netnography as a methodological resource in the field of design.

155 - Fabricando una portada para el narco. Análisis de portadas de La revista Cromos 1960-2000 a partir de la semiología de los indicios. - Nataly Botero - Universidad de Burgoña - natalybotero@gmail.com y Gilberto Eduardo Gutiérrez - Pontificia Universidad Javeriana gilberto.gutierrez@javeriana.edu.co

Nuestro estudio propone un análisis en diacronía de las portadas de la revista Cromos, la más antigua revista magazine en Colombia. La identidad editorial de Cromos desde el origen estuvo basada en el tratamiento de la actualidad mundana de las elites nacionales e internacionales y una idea de modernización que se expresa en el slogan "la actualidad ilustrada". Nuestro interés se focaliza en particular en la irrupción de un fenómeno transversal: el narcotráfico. La reorganización de la sociedad colombiana en torno a nuevas figuras de caudillos y vasallos (patrones y sicarios), prácticas ilegales, atentados y desapariciones, connivencias con los poderes políticos y relatos sociales en torno al tráfico de drogas contribuyeron a la emergencia de un imaginario "mafioso" (Saenz Rovner, 2001) se hizo visible en las portadas de prensa. Como el conjunto de la prensa colombiana, 
Comunicación y Música: mensajes, manifestaciones y negocios

Cromos fue al mismo tiempo testigo, lugar de co-construcción y reinterpretación de este imaginario emergente, cuya urgencia y gravedad se impuso. El objetivo del estudio es analizar desde la semiología de los indicios (Houdebine, 2009) las evoluciones formales, narrativas y axiológicas de las portadas de Cromos en tiempos de narcotráfico, y también la manera como el encuadre periodístico reinterpretó y mediatizó el imaginario mafioso en sus páginas de cobertura. Como el asunto del crimen, las drogas y la tematización de su consumo y tráfico comenzaron a ganar fuerza a finales de los $60 \mathrm{y}$ luego se extendieron desde los 70 en adelante, se analiza el periodo desde 1960 hasta el año 2000. El corpus total toma las portadas desde el número 2220 de enero de 1960 hasta 4273-74 del 27 de noviembre de 1999 con un total de 2053 ediciones. Basados en ese corpus, se seleccionan aquellas que tematizan el crimen, narcotráfico y que expresan de alguna manera sus impactos en la sociedad colombiana.

* 156 - El estudio mediático de la existencia digital en su imagen icónica - Alberto J. L. Carrillo Canán - BUAP

En 1964 McLuhan dijo que “(...) ningún grupo de sociólogos puede aproximarse a los equipos publicitarios en la consecución y el procesamiento de datos sociales útiles. Los equipos publicitarios tienen anualmente millones para gastar en investigar y comprobar reacciones, y su producto son magníficas acumulaciones de material sobre la experiencia y los sentimientos compartidos de la comunidad entera." McLuhan agregó que "[a]lgún día los historiadores y los arqueólogos descubrirán que los anuncios publicitarios de nuestros días son los reflejos diarios más ricos y confiables que cualquier sociedad dio nunca sobre el rango entero de sus actividades." La publicidad y las noticias constituyen un "mosaico" que ofrece "la imagen corporativa profunda de la comunidad en acción". Por nuestra parte diremos a) que la WEB convirtió en su "contenido" (McLuhan) a los anteriores nuevos medios de comunicación de masas, la fotografía, el periódico, la radio y la TV, b) que la WEB exige la e-presencia institucional - universidades, empresas, alcaldías, equipos deportivos, periódicos, televisoras, partidos políticos, etc., mediante un sitio dedicado, c) que la WEB llevó al desarrollo de las redes sociales Facebook, Whatsaps, Tinder, Tweeter, etc., con lo que la e-presencia individual convertida en e-presencia 
pública también devino una exigencia. Cada sociedad da su "imagen corporativa" cada vez más completa en la WEB. "Comunicar" es estar presente en la WEB; la comunicología devino e-comunicología, con dos ramas principales, 1) la e-iconología, que estudia cualitativamente la e-presencia de instituciones e individuos en la red, y 2) la etraficología, que estudia cuantitativamente la dinámica de dicha presencia. El enfoque específicamente mediático a los objetos de la ecomunicología sigue la tesis de McLuhan de que "el medio es lo que cuenta", porque es él, en este caso la red, con los íconos mediáticos y su dinámica, el que genera patrones cognitivos y conductuales específicos que no son el objeto de la e-comunicología, sino que la transcienden. En esta presentación esbozaremos la naturaleza del estudio mediático de los objetos de la e-comunicología.

157 - Contribution des méthodes visuelles et créatives à une recherche-projet sur le sommeil et la santé mobile-MCF en Sciences de l'Information et de la Communication Université de Nîmes, Laboratoire Projekt EA 7447 mariejulie.catoir@unimes.fr

Inscrite dans les Sciences de l'information et de la Communication (SIC) et le design, cette communication porte sur une expérience de recherche-projet (Findeli, 2003) menée au CHU de Nîmes en 20172018 pour améliorer la prise en charge des troubles du sommeil, en impliquant des patients et professionnels de santé dans la coconception d'un réseau d'acteurs basé sur un service numérique.

L'objectif de cette communication est double: il s'agit de montrer que: $1 /$ les méthodes visuelles et créatives peuvent être porteuses dans le champ de recherche en santé mobile; 2 / le croisement interdisciplinaire entre SIC, design et anthropologie permet de renouveler les recherches en communication. L'analyse réflexive de notre méthode exploratoire servira à expliquer comment les méthodes visuelles s'insèrent dans notre pratique de recherche à différentes phases, avec un focus sur les différents types de supports produits (photo, dessin, story-board, vidéo, prototypes interactifs d'applications mobiles). La communication visera à répondre au questionnement suivant: ¿Comment les méthodes visuelles peuvent-elles contribuer à une 
Comunicación y Música: mensajes, manifestaciones y negocios

recherche-projet en santé mobile, en développant l'appropriation du projet par les parties prenantes? Comment analyser les productions nombreuses récoltées tout au long de la recherche? Quels sont les apports et limites de ces méthodes?

Pour y répondre, la communication se décomposera en trois parties. Il s'agira tout d'abord de présenter la méthodologie de la recherche-projet - en particulier l'innovation sociale par le design (Manzini, 2015 et Tromp, 2011) et les différentes étapes de la recherche-projet (de l'enquête de terrain à la co-conception du service) qui s'appuient sur les méthodes visuelles (Banks, 2001; Gauntlett, 2007; Pink, 2006) et créatives (Dorst, Cross, 2001; Vial, 2014). La deuxième partie se focalisera sur l'analyse des supports de médiation produits, et sur la collaboration entre chercheur en SIC et designers, pour concevoir, animer et analyser des séances basées sur les méthodes visuelles et créatives. Il s'agira ainsi d'analyser à la fois la communication interpersonnelle et la communication médiatisée, et l'articulation entre la médiation, entendue comme le «processus de création du sens qui se réalise grâce à la relation tissée avec un tiers par un dispositif de communication» (Davallon, Flon, 2013: 23) et la médiatisation, définie comme la scénarisation des différents médias et supports tangibles utilisés tout au long du projet. Enfin, la troisième partie portera sur les apports et limites des méthodes visuelles et créatives dans notre recherche-projet.

Trois types de productions seront analysées, qu'elles soient réalisées et/ou co-produites par les participants, les designers et le chercheur en SIC. Il s'agira d'expliquer comment ces supports sont utilisés selon les différentes étapes de la recherche: pour recueillir des données expérientielles et favoriser la prise de parole (observations), stimuler le dialogue interprofessionnel, le travail collaboratif et la créativité des participants (co-conception), et enfin faciliter la compréhension du service envisagé en le traduisant sous forme visuelle, narrative et expérientielle (valorisation). Prolongeant un travail antérieur sur la méthode d'analyse des supports de médiation produits pendant la recherche (Catoir-Brisson, Jankeviviute, 2013), nous proposerons une méthode à la croisée de la sémiotique (Beyaert-Geslin, 2012; Deni, 2014; Floch, 1990) et de l'anthropologie (Winkin, 2001; Rasse, 2008; 
Goffman, 1974, Suchman, 2011) qui pourrait être transposée dans d'autres contextes de recherches en communication que la santé mobile.

158 - Comment échapper à l'imposition de problématique dans l'enquête sociologique par entretiens? Les ressources del video elicitation à partir d'images de fiction - Pascal Cesaro, PRISM, AixMarseille université-CNRS, pascal.cesaro@univ-amu.fr y Pierre Fournier, LAMES, Aix-Marseille université-CNRS, pierre.fournier@univ-amu.fr

Comment éviter au chercheur d'imposer aux enquêtés des questions qu'ils ne se posent pas et de les voir répondre dans des mots qui ne sont pas les leurs? Le problème posé par les auteurs du Métier de sociologue il y a un demi-siècle a longtemps buté sur les défauts de formation des sociologues, les invitant à prendre garde aux questions qu'ils posent, à s'approcher des façons de raisonner des acteurs en situation plutôt que de se contenter de reporter vers les enquêtés les questions qu'eux-mêmes se posent, formulées dans les termes où elles se posent à eux. Le problème bute aussi sur l'envie des enquêtés de répondre à des questions sur à peu près tous les sujets pour ne pas encourir de jugement négatif sur leur capacité d'analyse, et sur la propension qu'ils ont à se référer au débat public tel qu'il est constitué dans ses formes médiatisées pour choisir les mots de leur réponse et s'assurer de sa légitimité dans l'interaction. Surtout quand le débat est fortement polarisé sur un plan moral et politique comme, hier, sur la guerre d'Algérie, la sexualité au temps du sida, aujourd'hui sur l'intégration des immigrés, l'homophobie...). On peut voir cette situation comme une configuration de parole empêchée qui condamne le chercheur à enregistrer des formules dont il ne sait si elles l'éclairent sur ce qui oriente véritablement l'action des enquêtés au-delà de leur permettre de trouver une contenance face à l'enquêteur.

A partir d'une enquête sur ce que signifient venir travailler dans l'industrie nucléaire et vivre à la proximité de ses sites, on souhaite mettre à l'épreuve les ressources qu'apporte au sociologue le recours à l'entretien par video elicitation à partir d'images de fiction pour dépasser certaines difficultés associées au débat très polarisé en France 
Comunicación y Música: mensajes, manifestaciones y negocios

autour du choix du nucléaire comme source d'énergie, qui contraint la forme des discussions sur le nucléaire quelle qu'en soit l'objet. Les pratiques de recherche par photo elicitation à partir de photos de familles ont depuis longtemps prouvé leur fécondité dans l'enquête en sciences sociales. On imagine volontiers qu'il en est de même del video elicitation à partir de films de famille, voire d'instants de vie (de quartier par exemple) captés avec les cameras qui équipent les smartphones. Les chercheurs en sciences sociales ont aussi profité de l'allègement des systèmes d'enregistrement video pour aller filmer eux-mêmes les pratiques des acteurs sociaux (au travail par exemple) et leur proposer de les voir ensuite ensemble pour les commenter, ce qu'on appelle l'autoconfrontation filmique. ¿Que se passe-t-il quand on propose aux enquêtés non pas de se voir eux-mêmes mais de voir et de commenter leurs homologues, captés par le regard d'un reporter ou d'un documentariste? On s'ouvre la possibilité d'exploiter la comparaison des expériences, dont on sait le rôle dans l'analyse en sciences sociales. Mais on risque de buter sur le souci de l'enquêté de ne pas manquer de respect pour le filmeur ni pour les filmés en commentant ce qu'ils donnent à voir et qui n'est peut-être pas en phase avec son expérience. On est donc menacé de retrouver là une forme d'imposition de la part du chercheur dans la façon de problématiser la situation étudiée.

Le recours à l'image de fiction ouvre peut-être une voie alternative pour peu que la réalisation romanesque soit réaliste comme dans le cas du feuilleton télé Les Atomistes de Léonard Keigel (diffusé en févriermars 1968 et présentant une équipe de chercheurs et de techniciens d'un centre nucléaire face à des défis scientifiques et dans des péripéties de travail et de vie) : la fiction invite plus encore que l'image documentaire à la convocation par l'enquêté de son expérience singulière, l'amenant à parler suivant les catégories d'action qui sont les siennes en les comparant à celles que semblent mobiliser les personnages. Sans que cela l'empêche de se démarquer le cas échéant de ce qui lui est raconté puisque la probité du réalisateur n'est pas en causé dans la narration qu'il propose au spectateur de tenir pour vraie par convention le temps de la projection. L'enquêté peut donc commenter tout à loisir aussi bien ce qui fait écho à son expérience dans ce qu'il voit que ce qui s'en écarte. Et le sociologue peut espérer par là échapper aux discours convenus, au recyclage plus ou moins 
conscient de discours prêt-à-penser. Sur ce terrain de la video elicitation, la digitalisation de l'image offre aujourd'hui à la fois de nouvelles sources d'images et facilite leur réemploi pour qu'on puisse interroger à nouveaux frais les conditions de fécondité du dispositif.

159 - El deporte y la "radio televisada" en España: aproximación a las sinergias entre radio, streaming audiovisual y redes sociales - Francisco Javier Herrero Gutiérrez Universidad de Salamanca - javiherrero82@usal.es, Rafael Galán Arribas - Universidad de Salamanca - rgalan@usal.es y Sonia Casillas Martín - Universidad de Salamanca scasillasma@usal.es

Con la llegada de la radio a España durante la segunda década del siglo $\mathrm{XX}$, llegaba la información deportiva. Décadas más tarde, en los años 50 del siglo XX, la radio española acogía el formato "carrusel" a través del que se informaba de todo lo que acontecía en el mundo del deporte en tiempo real, con conexiones in situ, vía corresponsales o enviados especiales. En los años 80 del siglo XX llega a España la radio deportiva nocturna. Información deportiva en la medianoche que enseguida se populariza entre gran parte de los adeptos al deporte.

Desde prácticamente su nacimiento, la importancia de la información deportiva en la radio española es incontestable. Múltiples horas de programación deportiva se reparten entre las parrillas radiofónicas de las principales emisoras de España, respaldadas por amplias audiencias, tal y como refleja el Estudio General de Medios, oleada tras oleada.

A punto de llegar a la tercera década del siglo XXI, mucho ha cambiado en el panorama radiofónico. La radio es mucho más que radio, al menos como la conocíamos hasta ahora; la radio es radio, pero también es "versión web" ... ¿'es "servicios audiovisuales" ?, ¿es "streaming" ?, ¿es "redes sociales"? La radio ya no solo se oye y se escucha; ahora la radio también se ve: la que podemos denominar como "radio televisada". Porque cada vez con más frecuencia las emisoras apuestan no solo por dar información vía audio, sino que el streaming audiovisual está cada vez más presente. A través de esta comunicación se pretende reflexionar sobre las sinergias que actualmente existen entre la radio, 
Comunicación y Música: mensajes, manifestaciones y negocios

los servicios audiovisuales -especialmente el streaming en directo- y las redes sociales en lo que respecta a la información deportiva de las principales emisoras generalistas (Cadena SER, COPE, Onda Cero y RNE) en España.

Finalmente, esta comunicación concluye que en la radio ya no solo se emite información deportiva "radiofónica" al uso, sino que las principales emisoras radiofónicas convergen con redes sociales, canales audiovisuales, etc. Estamos ante la radio que se oye... y se ve. No solo escuchamos una entrevista radiofónica: también vemos al entrevistado y al entrevistador. No solo escuchamos la retransmisión de un partido de fútbol: también vemos al locutor. A partir de pequeños casos, se pretende establecer una reflexión sobre el que sustentar un posterior estudio en el que se realice un amplio trabajo de campo.

* 160 - Pour comprendre les usages et les émotions, traverser l'écran - Ghislaine Chabert - Univ. Savoie Mont Blanc ghislaine.chabert@univ-smb.fr

1826 ou 1827? Nicéphore Niepce obtient, suite à une longue série d'expérimentations, la première photographie reconnue au monde. Cette photographie montre la vue qu'il perçoit de la fenêtre de son atelier à Saint Loup de Varennes. L'image ayant, depuis, fait le tour du monde montre des bâtiments, des toitures, le ciel de la ville, des indices à peine visibles mais dont les formes sont reconnaissables à leurs jeux de lumières et de contrastes. On ne se doute sans doute pas alors du rôle que va jouer cet acte fondateur pour nos relations aux images et pour nos recherches à travers elles. Car en épousant les contours d'une fenêtre, d'un «pré-écran», la photographie se définit depuis dans une perpétuelle navigation entre un dedans et un dehors, qui ouvre un champ infini d'étude des sensorialités et émotions qui y sont attachées.

La relation profondément émotionnelle aux dispositifs est celle qu'on tente de saisir dans nos actuelles recherches sur les usages du digital. Par une mise en images de la recherche communicationnelle et avec des méthodes visuelles adaptées aux différents contextes à l'étude, il devient possible de rendre visible dans leurs infimes détails « des formes reconnaissables » liées aux relations des individus aux écrans, 
aux actions collectives parmi les écrans, aux ambiances perçues, aux corps communiquant... Aussi après une mise au point sur les apports de l'anthropologie visuelle pour l'observation des registres émotionnels tenant aux expériences du digital, nous développerons dans cette communication le cas spécifique des émotions vécues en immersion dans des images de réalité virtuelle (VR). L'objectif étant au final d'expérimenter et de discuter le principe d'une méthodologie d'observation qui «colle» au dispositif lui-même, en traversant l'écran pour entrer dans celui de la VR.

161 - Análisis de la problemática visual entre la imagen icónica y la predicación política-Fernando R. Contreras fmedina@us.es - Universidad de Sevilla y David Montero Sánchez - davidmontero@us.es-Universidad de Bath

EI trabajo que presentamos es una reflexión del empeño filosófico por aportar luz, una nueva terminología y perspectivas al análisis de la iconografía política. Nuestros planteamientos comienzan a partir de la revisión de posiciones en la historia del arte, la semiótica v de la estética filosófica. Las prácticas visuales contemporáneas con una finalidad política plantean nuevas cuestiones en el conocimiento del arte. La reflexión sobre la actividad icónica tiene por objetivo el conocimiento de las imágenes que fundan un colectivo. La política necesita imágenes, las doctrinas políticas originan imágenes, pero tambien las ideas políticas están ubicadas en imágenes. En la argumentación de este trabajo, también hemos considerado necesario introducir la perspectiva epistémica de los estudios visuales que concibe lo visual como una construcción social y cultural. Si las condiciones históricas cambian también los símbolos icónicos. No obviamos que las comunidades aparecen alrededor de estos símbolos que continuamente son revisados para mantener la identidad común. Por tanto, sin descuidar el marco del análisis cultural, exploramos las cualidades estéticas de estas transformaciones continuas en lo visual (transfiguración, apropiación, intervención). Nuestro programa abarca lo visual en general, no distingue entre lo plástico a lo fílmico, o entre las imágenes artísticas o no artísticas, pues se centra en la plusvalía de las imágenes. Desde este punto de vista, ofrecemos la hipótesis de la predicación visual. Con ella describimos la estructura profunda del poder de las imágenes sobre las 
Comunicación y Música: mensajes, manifestaciones y negocios

creeencias de las personas, que va más allá de la comunicación, la persuasión o la significación. La oratoria de lo político visual consiste en la crítica, en el testimonio y en el adoctrinamiento. La práctica del arte orientada a la cuestión de lo colectivo requiere de la reconfiguración de un determinado espacio cuya naturaleza es a la vez material y simbólico. Además de la discusión de estas cuestiones, profundizaremos sobre cómo se modifican las formas ordinarias de la experiencia sensible, transformando al espectador en actor dentro de estos lugares comunes entre lo estético y lo político.

162 - Méthodes visuelles et méthodes documentaire: croisements, résonnances et perspectives - Natacha CYRULNIK, natacha.cyrulnik@univ-amu.fr - MCF HDR AixMarseille Université

¿Les méthodes visuelles dans un registre anthropologique ou sociologique se rapprochent-elles de la méthode pour réaliser un film documentaire? ¿En quoi sont-elles différentes, et en quoi peuvent-elles se nourrir l'une l'autre? Alors que des anthropologues comme Margaret Mead et Gregory Bateson ont refusé la caméra dans un premier temps parce qu'ils avaient peur qu'elle dénature la réalité, ils en sont finalement devenus de véritables promoteurs. Aujourd'hui les documentaristes affirment d'emblée leur point de vue sur une réalité captée (Ghaninejadi Ahari, 2004). Ils partent du principe que le simple fait de poser une caméra face à une situation oblige à assumer une part de subjectivité. Le témoignage se construit alors à partir des interactions humaines entre le filmeur et le filmé (Cyrulnik, 2018) et révèle une réalité qui se base notamment sur ce qui est raconté et la manière de le faire (Genette, 1991). Par ailleurs le documentaire se base sur un contrat tacite et éthique entre le réalisateur et le spectateur, le premier affirmant que ce dont il témoigne est issu de la réalité et le deuxième décidant d'y croire en entrant dans la salle (Lioult, 2004).

Entre objectivité et subjectivité, entre observation et interactions humaines, entre présentation d'une situation et «re»-présentation (Bougnoux, 2006: 53) de celle-ci, des dispositifs (Agamben, 2007) audiovisuels se mettent en place et témoignent de différentes méthodes, pour permettre que le spectateur au final acquiert une 
meilleure connaissance de la situation filmée, souvent dans la logique d'une approche compréhensive (Niney, 2000 et 2002; Paillé et Mucchielli, 2005). Quinze années de films documentaires dans les cités du Sud de la France proposent un appui pour étayer cette réflexion et analyser des méthodes possibles (Cyrulnik, 2008).

A partir d'un positionnement face à une réalité, en passant par une expérience plus ou moins artistique (Dewey, 1915) qui pourrait favoriser une «esthétique relationnelle» (Bourriaud, 2001) en même temps qu'une approche rhétorique (Soulez, 2011), le film anthropologique et/ou documentaire de création prend corps aussi bien en tant qu'objet de recherche qu'en tant qu'outil pour mettre en œuvre une méthode qui suscite l'acquisition d'un savoir.

163 - Dynamiques émotionnelles et qualité de l'expérience vécue: étude l'usage de l'espace de Valence-Arousal par l'outil Spot Your Mood - Charles-Alexandre Delestage - Université Polytechnique Hauts-de-France, Laboratoire DeVisu - EA2445 - charles.alexandre.delestage@univ-poitiers.fr y Willy Yvart Université Polytechnique Hauts-de-France, Laboratoire DeVisu - EA2445 (France) y Université Polytechnique de Mons, Laboratoire TCTS (Belgique) - willy.yvart@neuf.fr

La dimension émotionnelle de l'expérience et sa visualisation est un thème à l'intérêt grandissant dans les études scientifiques. Si les émotions sont souvent étudiées à l'aide de capteurs mesurant l'activité corporelle ou neuronale d'un individu, peu d'outils existent dans un usage strictement qualitatif (Roue des émotions, Self Assessment Manikin (Bradley, Lang 1994), Spot Your Mood (Yvart, Delestage, Leleu-Merviel 2016)). En termes de visualisation des émotions des coparticipants, l'exploitation de ces dispositifs nécessite qu'ils soient dotés d'une visualisation claire et synchronisée avec le contenu étudié afin d'être rendus pertinents. Sur la base de 17 cas cliniques utilisant l'outil Spot Your Mood (SYM), outil déclaratif des émotions en tempsréel basé sur l'espace de Valence-Arousal (Russell 1979; Scherer 2005), cet article exploré les possibilités de SYM quant à la visualisation des données qu'il produit. Les données émotionnelles recueillies sont notamment croisées avec des entretiens semi-dirigés, ainsi qu'une 
Comunicación y Música: mensajes, manifestaciones y negocios

seconde visualisation des vidéogrammes dans les mêmes conditions de visionnage, commentée directement par le coparticipant (contrairement à la méthode en re-situ subjectif de (Schmitt, 2012)). L'analyse des émotions déclarées sur l'outil SYM et des différentes méthodes de verbalisation ont permit l'émergence de corrélation suffisantes pour évaluer la fiabilité des pointages réalisés. Ce faisant, l'identifications de zones sur cet espace, décrivant la qualité de la relation avec un contenu, ainsi que le cheminement émotionnel de l'individu, permet de décrire des dynamiques émotionnelles, ouvrant la voie à une meilleure représentation de l'expérience émotionnelle d'un individu dans une approche qualitative, ou celle d'un groupe de personnes d'un point de vue statistique. Dans un premier temps, la communication présentera les différents outils de récolte de données émotionnelles sur une base déclarative. Puis, dans le contexte de (Mugur-Schächter 2006) et (Varela, Thompson, Rosch 1993), avec le résultat expérimental observé à travers (Delestage 2018), l'article abordera les possibilités de l'outil SYM dans la détermination des dynamiques émotionnelles de l'individu. La validation des résultats obtenus par l'outil SYM seront également particulièrement développés, en décrivant les moyens de triangulation méthodologique employés.

164 - Deslizamientos discursivos entre las series de plataformas web y las series de televisión. Estética, gramática y tránsitos narrativos frente al espejo - Patricia Delponti - Universidad de La Laguna - pdelponti@ull.edu.es y Carmen Rodríguez Wangüemert - Universidad de La Laguna - crodrigu@ull.edu.es

El desarrollo tecnológico y los nuevos hábitos de consumo audiovisual han llevado a las series de ficción televisiva a hacer un cambio trascendental en las formas de construcción del relato. Las estructuras narrativas, la gramática visual y los estilos se renuevan, se miran unos a otros pasando muchas veces de la mostración a la narración. Se producen historias más profundas con mayor desarrollo y continuidad de las tramas y se reinventan los personajes clásicos y transgresores. Las fronteras de la recepción se amplían en multipantallas y las audiencias están cada vez más fragmentadas, interactivas y exigentes. 
El objetivo de este seminario es reflexionar desde un punto de vista académico y con una mirada desde la semiótica, los tránsitos y deslizamientos discursivos que se dan entre el formato tradicional de las series para televisión y las nuevas formas de construcción del sentido que proponen las plataformas web. También exploraremos lo que cuentan, trasmiten, construyen y proponen las series actuales de ficción y a propósito de la serie El Puente (Bron/Bröen) empleada como ejemplo, indagaremos acerca del concepto de calidad y el modelo de sociedad que se muestran en las series de éxito y los valores y disvalores que discurren en la imagen.

165 - Representaciones fotográficas de la sociedad del cansancio y la pobreza - Rogelio Del Prado Flores rogelio.delprado2@anahuac.mx - Universidad Anáhuac México; Luz Zareth Moreno Basurto luzzareth@yahoo.com.mx - Universidad Anáhuac México y Mariana Chávez Castañeda - mchavez.castaneda@gmail.com Universidad Anáhuac México

El objetivo de la propuesta es realizar un análisis hermenéutico analógico de fotografías tomadas por jóvenes estudiantes de la carrera de comunicación y periodismo de tres entidades federativas de México (Estado de México, Morelia y Querétaro) sobre las temáticas la sociedad del cansancio (Byung-Chul, Han) y la pobreza. Se trata de contrastar percepciones, de analizar encuadres y miradas sobre el otro (que parece vivir en cansancio y pobreza). El rostro del otro (E. Lévinas) revela una resistencia a la objetivación, una alteridad que responsabiliza al Yo. sin embargo, el encuadre y la percepción (Mereleau-Ponty) efectuada por jóvenes a través de la fotografía permite analizar la interpretación de lo real (de la fotografía) de manera analógica. La analogía es un modo de conocer por semejanza, punto intermedio entre lo unívoco y el equivocismo (desde la tradición de Aristóteles, santo Tomás de Aquino, M. Beuchot) de lo real (en este caso de la sociedad del cansancio y la pobreza). El estatus epistémico de la fotografía se encuentra situado en un punto intermedio entre el registro como simulacro (J. Baudrillard) y objetivación univocista. El punto teórico sobre la sociedad del cansancio en México es tomado de la filosofía de Byung-Chul, Han, que en contraste con las sociedades 
Comunicación y Música: mensajes, manifestaciones y negocios

opulentas del Atlántico Norte, viven en situación de pobreza y desigualdad extrema. El contexto socioeconómico de México está conformad por $52 \%$ de personas que viven en pobreza, el $10 \%$ vive en pobreza extrema. La desigualdad es muy marcada en la población mexicana. Nos interesa analizar a percepción sociológica de jóvenes que estudian comunicación y periodismo en tres localidades diferentes de México a través de registros fotográficos de encuadre documental, bajo la mirada sociológica de P. Bourdieu y W. Benjamin. Metodológicamente se tomará una muestra de un universo de 270 fotografías para efectuar la hermenéutica analógica de las fotografías, poniendo atención al rostro del Otro, y al encuadre de la percepción de jóvenes con el apoyo de la filosofía y la teoría sociológica antes mencionada.

166 - Capter des interactions Intergénérationnelles avec écran : quels défis technico-méthodologiques? - Christine Develotte ICAR CNRS UMR 5191, cdevelotte@gmail.com; Mabrouka El Hachani - ELICO EA4147 - mabrouka.el-hachani@univlyon3.fr, y Justine Lascar; Cellule Corpus Complexe ICAR CNRS UMR 5191, justine.lascar@ens-lyon.fr

Les recherches menées autour des interactions interpersonnelles ont donné lieu depuis longtemps à des captations vidéo (Cosnier, Kerbrat Orechioni, 1991). La complexité de ces interactions s 'est accrue avec l'apparition de différents artefacts numériques, telles que les tablettes numériques. Dans le cadre du projet ITAC (Interactions InTergénérationnelles Avec éCran) mené en collaboration entre les laboratoires ICAR et Elico de Lyon ainsi que la Bibliothèque Municipale de Lyon (BML), nous avons cherché à documenter des activités ludiques intergénérationnelles face à une table interactive. Après avoir présenté les objectifs de ce projet financé par le Labex Aslan, nous évoquerons notre cadre méthodologique basé sur une approche interdisciplinaire issue d'un côté de l'éthologie compréhensive (Cosnier, Develotte, 2011) et de l'approche qualitative basée sur l'observation directe amenant au suivi des usagers (Vidal 2017) afin de mieux comprendre leur appropriation du numérique. Cette observation directe est appuyée par une collecte de données vidéo constituant des corpus multi-vues. Ainsi, nous nous fonderons 
sur ces corpus de données recueillis en 2017 et 2018 pour chercher à expliciter les différents défis qui se sont posés aux niveaux : organisationnels - éthiques - techniques et méthodologiques (pour le recueil puis le montage des données) Puis les solutions de stockage et de partage qui ont été choisies. Nous chercherons enfin à discuter des différents enjeux que revêtent les différents choix méthodologiques non seulement au niveau de leur exploitation scientifique mais aussi de leur exposition dans des formats scientifiquement légitimés.

167 - First analysis of the organizational culture in Rockwell Collins- EEMSA Mexicali - Gallegos Arredondo Ambar Eugenia - Université Savoie Mont Blanc ambar.gallegosarredondo@gmail.com

The organizational culture inside the company is key to the development of objectives, that's why it is really important to understand what happens from the inside, from the mind of the employees.

The main reason or objective of this study is to know directly from the employees, how they perceive the culture in their organization, which is their opinion on the way the communication it's handled in the same company, if they think something is missing, how they feel the leadership from the managers, also what kind of leadership the manager uses with his staff, besides that, it provides information of how the labor relations are between the members of the company.

To accomplish this was necessary to use the filming as a visual method of observation, some of the principal authors that works the visual methods and the space which I took as reference were De Certeau (1980) and Pink (2007). First they were filmed two different events in the company, one of them as a celebration of the closure of the fiscal year, the other event is the anniversary celebration. As a second part of the filming, during the interviews the persons were filmed, also the leaders in the focus group, this with the objective of analyzing their behavior at the moment they were answering. 
Comunicación y Música: mensajes, manifestaciones y negocios

The principal results obtained after this analysis is that during the observation through film they show that they have a good relation in the company, respect and work as a team, even with the leaders, also that in some situations the hierarchies practically disappear helping the accomplish of objectives.

168 - De l'usage des traces audiovisuelles en contexte d'enquête: ¿de la réminiscence à la reviviscence? - Geoffroy Gawin, LERIA EA 2645, Université d'Angers, geoffroy.gawin@yahoo.fr y Elodie Jarrier, GRANEM EA 7456, Université d'Angers, elodie.jarrier@univ-angers.fr

Ce travail s'inscrit dans un projet de recherche régional visant à proposer une méthodologie d'évaluation des dispositifs numériques de médiation transférable à différentes structures touristiques et culturelles. En mettant en perspective des recherches en sciences de l'information et de la communication (Schmitt et Aubert, 2017 ; Idjéraoui-Ravez, 2008 ; Gawin, 2017), en sciences de gestion (Flacandji, 2015; Jarrier, 2015) et en psychologie cognitive (Tulving, 2002; Conway, 2005 ; Duval et al., 2007), cette contribution vise à prolonger l'approche théorique réflexive de l'usage des traces visuelles (photographiques et vidéographiques) comme outil de remémoration et de verbalisation de l'expérience de visite muséale. Elle apporte un éclairage sur l'articulation entre les notions d'expériences et différentes modalités d'observation.

À ce titre, elle interroge, pour chacune de ces modalités, les variations de la remémoration des visiteurs selon que les entretiens donnent lieu à des réminiscences parcellaires (Wong et Watt, 1991; Rix et Biache, 2004) ou à des reviviscences plus intenses, associées à des moments durant lesquels l'enquêté a le sentiment de revivre un état déjà vécu lors de la visite. Par ailleurs, cette contribution met en évidence des complémentarités entre des données ethnographiques (notes de terrain), photographiques (12 entretiens projectifs à partir d'un album photo) et vidéographiques (entretiens re-situ subjectifs, 6 à partir d'une caméra go pro et 8 à partir de lunettes à eye-tracking), toutes recueillies dans un même musée. Elle pointe les aspects de l'expérience que chaque méthode appréhende plus spécifiquement, et décrit l'influence 
des contextes de visite et d'enquête. Enfin, cette recherche porte un regard critique sur l'opérabilité des concepts décrits en les mettant en perspective avec des modalités de mise en œuvre d'observation à la portée de la plupart des structures culturelles.

169 - Approche de la dimension rituelle des raids de World of Warcraft par l'anthropologie visuelle - GHOUL SAMSON, Jacques. Institut Méditerranéen des Sciences de l'Information et de la Communication, Université de Toulon, France jacques.ghoul-samson@univ-tln.fr

Au cours d'une ethnographie de deux ans interrogeant les dynamiques d'interaction des membres de groupes d'avatars (guildes) du jeu de rôle en ligne massivement multijoueur «World of Warcraft» (WoW), nous avons dû faire face à la nécessité de garder des traces visuelles des moments d'activité les plus intenses, les raids. L'implication cognitive qu'ils exigent est telle que la prise de notes du chercheur en situation d'observation participante devient nécessairement lacunaire (Nardi, 2010; Taylor, 2006). Pour saisir ces périodes d'activité nous avons opté pour la misé en place d'un système de captation vidéo et audio enregistrant l'écran du chercheur et donnant ainsi à voir son avatar à la troisième personne.

La possibilité, proposée par le logiciel d'analyse qualitatif Atlas T.I., de découper plusieurs heures de vidéo en centaines de fragments, isolant une interaction, a mis en relief la richesse de ces enregistrements. Ainsi, au fil des mois, ce qui n'avait été pensé que comme un carnet de terrain s'est révélé être une source de données à part entière dépassant l'unique fonction de rappel de ce qui a été (Barthes, 1980) faisant prendre, de cette manière, un tournant décisivement visuel à notre ethnographie. Le présent article se base sur l'analyse descriptive d'un corpus de 60 vidéos (comptant plus de 150 heures d'enregistrement) captées sur une période de cinq mois et demi au début de l'année 2017.

L'analyse de ces films nous permet de faire émerger la fonction rituelle des raids au sein de WoW comme «des manières d'agir qui ne prennent naissance qu'au sein des groupes assemblés et qui sont destinés à susciter, à entretenir ou à refaire certains états mentaux de ces groupes» (Durkheim, 2014). A travers le prisme de la ritualisation des raids nous 
Comunicación y Música: mensajes, manifestaciones y negocios

interrogerons les rôles des différents participants et leur substituabilité, les rythmes de ces expériences particulières et les dynamiques communicationnelles en œuvre au cours de ces dernières.

* 170 - Ce que filmer les frontières enseigne au chercheur: les migrants entre demande et rejet de la camera - Hlaoua Aziz hlaoua.aziz@yahoo.fr

Cette contribution questionne l'appréhension de l'immigration par l'outil de l'anthropologie filmique en se focalisant sur le phénomène de la mobilité et de la frontière. Depuis début 2015, nous avons eu recours à la caméra sur plusieurs terrains ethnographiques, ce qui permet de dégager des réflexions méthodologiques. L’outil visuel est utilisé afin de comprendre les pratiques des exilés, communément dénommés migrants ou réfugiés dans les médias. Capter en images les mouvements des phénomènes sociaux qui s'organisent autour de la frontière était la première tâche de nos pratiques filmiques, Nous avons choisi de filmer ces exilés et leurs narration de leur migration et de leur expérience de la frontière à Ceuta, Melilla et Calais, des lieux que nous qualifions de «espaces des non-lieux migratoires». L'approche praxéologique que nous préconisons cherche à dégager le sens des pratiques observées. Une telle démarche s'intéresse aux contextes de production de l'action dans un espace et un temps donnés. La forêt, les barrières, les frontières, les zones d'attente, les campements, en tant que lieux de passages de migrants, nous a permis d'observer et capter en images les pratiques de mobilité en action. L'approche appliquée à notre travail consiste à limiter l'analyse de ces pratiques migratoires aux actions observées dans leurs contextes de production.

Retour sur une expérience de terrain: Mon intervention, en tant que chercheur et cameraman sur un documentaire dont l'objectif principal est de privilégier la parole et le point de vue du migrant, portait essentiellement sur la place et l'éthique de la caméra dans un tel projet socio-politique. Cette réflexion, nourrie par de nombreux travaux déjà effectués sur l'utilisation du support caméra dans la démarche sociologique et anthropologique, est née de notre propre expérience sur le terrain, au contact des migrants, et de l'étonnante différence d'appréciation de ce médium selon le pays dans lequel nous nous 
trouvons. En effet, dès notre arrivée à Calais début Mars 2018 (qui, hasard des calendriers, à coïncider avec le début de la distribution de nourriture «assumée» par l'Etat) nous avons immédiatement senti, Laurent (deuxième cameraman) et moi, une certaine méfiance, voire une franche hostilité des migrants, vis à vis de la caméra. Bien que, de part notre démarche et le matériel que nous utilisions, nous ne nous affichions pas comme des journalistes, les migrants refusaient de s'exprimer devant la caméra, même en usant des dispositifs habituels pour garantir l'anonymat. Nous étions surpris, car je savais qu’à l'inverse, lorsque je suis allait filmer les migrants coincés dans les forêts aux abords des frontières espagnoles de Ceuta et Melilla, au nord du Maroc, le dialogue se faisait plus facilement et la confiance s'établissait vite. Il y avait à l'évidence, de leur part, un besoin de raconter, de témoigner, de montrer. Or ce besoin était dû en grande partie au fait que les médias marocains, muselés par le gouvernement, taisaient délibérément le problème migratoire, rendant les migrants «invisibles» aux yeux de l'opinion publique, et permettant aux autorités de leur infliger les pires traitements. La caméra arrivait donc comme une libération de leur parole, un outil audio et visuel idéal pour enfin témoigner de leur situation, espérant ainsi toucher l'opinion publique international. A Calais, en échangeant rapidement avec quelques migrants, nous nous sommes retrouvé face au problème inverse: les migrants sont ici sur-médiatisés. Or loin d'être bénéfique, cela amène de nombreuses dérives, à commencer par le respect de leur anonymat. Venant «volen» quelques images pour leur sujet, les journalistes et les cameraman filment les migrants à distance, sans consentement, et utilisent ensuite ces images comme bon leur semble sans prendre la peine de flouter les visages. Images qui se retrouvent ensuite sur internet via les nombreuses plateformes vidéos à disposition, accessibles n'importe où dans le monde. Et c'est ainsi que certains migrants ont été retrouvés, alors qu'ils cherchaient précisément à fuir leur pays ou leur famille. La confiance entre les migrants et la caméra a donc été «sappé» par le travail journalistique, rendant difficile toute approche immédiate avec la caméra. Toute la difficulté de notre démarche documentaire est donc de trouver la juste place de la caméra afin que celle-ci, au-delà de son rôle de témoin, se mette véritablement au service de la parole des migrants. Comment rétablir la confiance? Que pouvons-nous filmer? Comment adopter le point de vue des 
Comunicación y Música: mensajes, manifestaciones y negocios

migrants? Serait-il intéressant de laisser une caméra aux mains des migrants et de leur permettre de filmer ce qu'ils veulent? C'est un long travail sur le terrain qui nous attend, où plusieurs pistes sont à explorer pour trouver une approche sociologique et documentaire juste, et jusqu'à présent inédite concernant le sujet migratoire.

171 - $360^{\circ}$ de vision: une étude comparative sur l'utilisation de la vidéo traditionnelle et de la vidéo $360^{\circ}$ comme méthode de recherche - Marín, Alba - Université Savoie Mont Blanc Universidad de Sevilla - ylbacm@gmail.com

Le chercheur qui utilise la vidéo traditionnelle doit choisir. Il a à décider ce qui est l'important et où fixer son regard, laissant derrière lui d'autres données qui pourraient sembler intéressantes. Ce «problème» disparaît avec la vidéo $360^{\circ}$, change les dynamiques de narration parce qu'elle oblige à créer une histoire pointée sur l'utilisateur. Nous avons beaucoup outils numériques que nous utilisons pour la création du contenu et l'expérimentation, mais que nous pouvons appliquer aussi pour la recherche. Une possibilité est l'utilisation de forme combinée de formats de vidéo.

Pour le travail de champ nous avons besoin d'une autre approche. La question est: comment utilisons-nous la caméra pour l'observation et la participation? Comment pouvons-nous analyser productivement le film pour nos propos? Qu'est-ce qui peut nous apporter le filmage $360^{\circ}$ ?

La caméra vidéo obtient toute l'information, c'est-à-dire dire que la sélection de l'angle de vision est éliminée. Il y a une limitation de plans et une absence de mouvement. La relation qui s'établit entre une caméra vidéo 360 et le chercheur est complètement différent de la relation qui existe avec une caméra vidéo traditionnelle. Dans ce cas, le dispositif pourrait se considérer comme une étendue du corps qui capte son regard. Le chercher peut décider de fixer la caméra vidéo o le porter pour filmer cela qu'il considère intéressant. Par contra, la vidéo $360^{\circ}$ limite le mouvement et la relation entre ceux-ci est indépendante. N'il n'y a pas une relation entre l'enregistrement et le regard du chercheur. Nous avons utilisé les deux outils dans deux 
études de cas pour vérifier quelles sont ces différences et comment nous pourrions travailler avec la vidéo $360^{\circ}$.

172 - Creating new formats - creating transcultural experiences - Tiécoura N’Daou y Anja Veirman

Our paper will address the aspects of subjectivity and building narratives in the co-creation of audio-visual works during the project, 'Mudcloth, and the making of social and artistic 'fabric'. This project aims to create a deeper understanding of the complex intertwinement between ritual and artistic practices in the making and wearing of mudcloth in the Senufo context of Burkina Faso. The authors aim to document and visualize these practices and interrelationships. As audiovisual makers from different disciplines and cultural backgrounds, this includes questioning conventional representational formats and mechanisms of cultural reproduction and knowledge building. Each from his/her own background and sensitivity; be it as an African artist with a personal visual language or an European scholar with a sensitivity to post-colonial representational issues. This leads to fundamental questions about representation, authorship and [dominant] [visual] canons in the arts and humanities. Furthermore, the conventional division of roles between the 'artist/cinéaste' and the 'anthropologist/scholar' is constantly blurred and influenced by the input of the (Senufo) subjects we work with. We follow the idea that meaning and narratives emerge through the making processes of these textiles on the one hand, and through the making of audiovisual works on the other. The way in which we choose to visualize our subjectivities and methods is made clear during the process of filmmaking, and in correspondence with the interactions of the participating partners. Out of respect for the multifaceted context of Senufo textile practices, we searched for audiovisual formats that correspond with the complexity of the content, the personal intuitions and the cultural concerns of all project participants. Sensitive to our Senufo participants and their symbolic universe, the project was critical to 'flattening' representational formats and instead used layered formats to share anthropological knowledge and create transcultural experiences. 
Comunicación y Música: mensajes, manifestaciones y negocios

The result (for now) is a multi-screen video installation in which several narratives are combined to a layered, visual and sonar fabric. The viewer has to take part in the knowledge creating activity. As filmmakers we don't present a leading narrative, nor do we impose a single or univocal interpretation on our public. The 3-screen installation permanently creates new - combined and layered - images and opens sensuous experiences, imagination and new forms of comprehension by the viewer. Because we want to create a cinematographic, haptic experience we choose not to be literally visible as researchers in the installation view. Our subjectivity as co-creators is manifestly present in many other ways: the profoundly researched ethnographic content and the stylistic choices we make during the shooting and editing process, such as framing, aspects of light and movement, rhythm and composition during the editing and the choice of our format. In this article, we draw a link between these choices and the subjectivities of the filmmakers - artist, anthropologist, and Senufo - and how these are tied to narratives presented to the audience.

173 - The visual representation of the hologram: a comparative approach to its political and social uses - Dr. Jacques Ibanez Bueno - Université Savoie Mont-Blanc - Jacques.IbanezBueno@univ-smb.fr y Dr. Luis Felipe Ramírez Alvarado Universidad Anáhuac México, Campus Norte luis.ramirez@anahuac.mx

Last $28^{\text {th }}$ April 2017 in Grenoble (France), French political leader JeanLuc Mélenchon used a hologram to be represented in front of an audience during a real meeting in Dijon (simultaneous time). It's an opportunity to understand better the modality of this process of communication. One of the research questions is what is the bodily relation between political leader Jean-Luc Mélenchon and his audience? Maybe the political party, La France Insoumise want the holographic representation is like to "become real" but it's an illusion (Tisseron: 2008). The research becomes doing semiotic material like photographies and videos in official websites or social medias. After we want to analyze the interactions of visitors in Grenoble place with modes of expression. All of the above modes are intrinsic to the experience. Kress and Van Leeuwen (2001) see the meaning as being 
socially produced through discourse, production, design and consumption, and "text." In the case of Mélenchon's hologram, the significant potential in the visitors' imagination and hypermodality is clear (Andrieu: 2011), because through holography it is possible: + To perceive the sound of the voice + Body movement, gestures, facial expressions; + Visual elements, such as clothing, colors, dimension; + The 3D image, that is, the feeling of presence; + And the speech, text written previously and spoken. This process is an hypermodal communication. To design a new a specific hologram in relation to the research question was a practical complement to associate theoretical contents about holographic communication. This choice is not to illustrate the research but to include this visual production in a main development of a visual methodology (Pink: 2006) shooting images and sounds for next situations of interactions in front of holograms. This research is also to think and to present characteristics of an innovative, interactive and visual methodology.

174 - El cartel como herramienta de transmisión de información - Noa Real García, Universidad de La Laguna, hello@noareal.com

Esta comunicación surge de una investigación de Tesis Doctoral sobre la herramienta de transmisión de información más utilizada a lo largo de toda la historia, el cartel. Dicha investigación se inició en en el año 2014 para un Trabajo Fin de Grado en Diseño y se ha ido ampliando posteriormente con la realización de un Trabajo Fin de Máster y de diversos artículos para diferentes congresos. Esta investigación ha estado enfocada especialmente en analizar la cartelería de las fiestas turísticas y tradicionales de Canarias, pero en una próxima fase, se pretende comparar con otras regiones, puesto que sus conclusiones se pueden extrapolar a cualquier otra comunidad.

El análisis de los carteles que se está realizando nos está permitiendo recabar una gran cantidad de información sobre sus autores y la repercusión de su trabajo, sobre la visión y la evolución de las fiestas, la manera en la que aparecen reflejadas en los carteles, su finalidad, las técnicas utilizadas para su producción, o cómo se articula el tejido social y cultural en torno a ellos, entre otras muchas cosas. Estos datos 
Comunicación y Música: mensajes, manifestaciones y negocios

recopilados a través de diversos métodos visuales, nos pueden ayudar a comprender mejor las sociedades e identidades y a mejorar determinados aspectos de diseño en cuanto a las propuestas presentadas para que sean la imagen de fiestas, que en muchos de los casos tienen más relevancia al estar Declaradas de Interés Turístico.

175 - Films publicitarios engañosos en la categoría de alimentos: Análisis sociológico - María Antonieta Guadalupe Rebeil Corella - Universidad Anáhuac México arebeil@anahuac.mx, Ricardo Ignacio Prado Hurtado Director General de Servicios Creativos MostroTown Publicidad - rprado@mostrotown.com.mx y Beatriz Adriana Tuxpan Rueda - Universidad Anáhuac México beatriz.tuxpan@anahuac.mx

Una categoría ampliamente extendida en el mundo actual y desde el año 1938 (Estados Unidos de Norteamérica, el Acta de Wheeler-Lee) es la temática de la publicidad engañosa según se expresa en los films publicitarios. Estos mensajes que se difunden a nivel masivo tanto en las salas de cine como en internet y televisión abierta, tienen un impacto en consumidores de niños, jóvenes y adultos.

Desde luego, involucra a prácticamente todos los niveles socioeconómicos específicamente en las zonas urbanas. Esta investigación pretende analizar un conjunto de films publicitarios sobre alimentos que se consumen en México y el mundo entero. En el caso particular de los cereales, estos productos se entienden como uno de los elementos fundamentales en la dieta diaria. Incluso, de acuerdo los organismos públicos orientados a asegurar el balance alimenticio en la sociedad, los considera como el segundo alimento en importancia para la población.

El objetivo de este trabajo es el de analizar los filmes publicitarios de la categoría de alimentos en cuatro niveles básicos de la sociología fílmica: descriptivo general; los estereotipos que se representan; el contexto sociodemográfico; la promesa de estilo de vida; y, el nivel deontológico de los mensajes, con el fin de evidenciar cómo estos contenidos 
publicitarios generan expectativas aspiracionales a los que motiva a sus audiencias.

176 - Visualización de los territorios de la biopiratería de las medicinas tradicionales en YouTube - Luis Torres-Yepez luisyepez13@gmail.com - Université Paris 8 Vincennes - SaintDenis y France Khaldoun Zreik - zreik@univ-paris8.fr Université Paris 8 Vincennes - Saint-Denis, France

La biopirateria es una problemática global que actualmente tiene mucho interés en algunos países y también en instituciones internacionales. El Convenio sobre la Diversidad Biológica (CBD) propone el protocolo de Nagoya, el cual emerge como una alternativa para dar respuestas a la problemática de la biopirateria. Este artículo expone una visualización de los territorios de la biopirateria en la red social Youtube utilizando los métodos digitales. De esta manera, presentaremos una serie de gráficos donde identificamos los productos y actores a partir del análisis y la visualización de los "metadatos" en Youtube.

177 - Research to analyze the documentary films produced by anthropologists and ethnographers about Central Asia - Dr. Elira Turdubaeva - American University of Central Asia eliraturdubayeva@gmail.com

The aim of this research is to analyze the documentary films produced by anthropologists and ethnographers about Central Asia. Documentary films about pre-Soviet and Soviet times, Second World War and after the war will be selected to analysis in terms of the visual anthropology methods usage, representation and ideology. Documentary films by anthropologists and ethnographers studying Central Asia and which are available on open access sources will be chosen for this study. The main research questions of this study are:

1. How ethnographers described experiences of Central Asian people through visuals? 2. How they used visual traces for the description of past lifestyles of Central Asian communities? 3. How they understood the sensory experiences of the Other? 
178 - SORODAS. Pour une méthodologie visuelle à l'oeuvre en recherche création - Carole BRANDON y Marc VEYRAT Laboratoire LLSETI - USMB

Dans quelle mesure faut-il cadrer le protocole de mise en oeuvre des enregistrements afin de pouvoir les exploiter. Dans quelle mesure le contexte de l'expérience influence-il l'enregistrement et les résultats obtenus? L'oeuvre SIRESSES de Carole Brandon en est le parfait exemple.

Prévue pour l'Atelier-Laboratoire IDÉFI-CréaTIC Art[S] Langue[S] \& Patrimoine[S] délocalisé hypothétiquement en 2018 à Mayotte (-! le voyage sera annulé quelques jours avant notre départ! -) ce dispositif hypermédia s'est accompagné d'un long travail de recherche en anthropologie visuelle, mené avec Ghislaine CHABERT et les étudiants... par rapport à ce terrain très particulier qu'est Mayotte.

Comme chacun sait, Mayotte est constitué principalement de deux îles, Grande-Terre et Petite-Terre, appartenant à l'archipel des Comores. Situées près de Madagascar dans le canal du Mozambique et contrairement au reste de l'archipel, sous l'i+M/PULSION des "chatouilleuses "1 — des femmes dont va s'inspirer Carole BRANDON pour SORODAS — qui ont refusé l'indépendance en 1976, ces îles vont devenir en 2011 un département et région d'outremer français puis en 2014 une région ultrapériphérique de l’Union Européenne.

Mais les tensions avec le reste des Comores sont nombreuses, en particulier autour de questions d'immigration. Et ce sont des manifestations violentes, toujours d'actualité, qui ont provoqué l'annulation de notre voyage... 
179 - Comunicación de los códigos deontológicos de las organizaciones del tercer sector de México, Chile, España e Inglaterra - Dra. Rebeca Illiana Arévalo Martínez, Universidad Anáhuac México, rebeca.arevalo@anahuac.mx, Mtro. Carlos Cienfuegos Alvarado, Universidad Anáhuac México, carlos.cienfuegos@anahuac.mx y Mtra. Herlinda Ortiz Rodríguez, Universidad Anáhuac México, adnil94@hotmail.com

Las organizaciones del tercer sector buscan apoyar el desarrollo social de manera altruista a través de acciones a favor de grupos vulnerables. Dichas organizaciones en los últimos años han tomado un papel protagónico dadas las condiciones en las que se encuentra la sociedad, la incapacidad del Estado de cubrir todas las necesidades y la creciente pobreza y falta de oportunidades económicas y de bienestar.

A pesar de que la razón de ser de este tipo de organizaciones está intrínsecamente relacionada con la búsqueda del bien común, es fundamental que su funcionamiento responsable no sea casual, sino que se encuentre fundamentado en códigos deontológicos que marquen puntos de referencia y dirijan sus acciones alineados a principios éticos.

El impacto social que generan con su labor, debe reforzarse con la comunicación clara de su enfoque de responsabilidad social organizacional y de sus principios de actuación con base en la ética. La presente ponencia da cuenta de los principales hallazgos de una investigación que tuvo por objetivo analizar y comparar los códigos deontológicos de una muestra de 40 organizaciones del tercer sector de cuatro países: México, Chile, España e Inglaterra, a fin de identificar la presencia de las siguientes categorías: transparencia, comportamiento ético, medio ambiente y cambio climático, y contribución a la comunidad. Entre los resultados se encontró que las organizaciones europeas, en este caso España e Inglaterra, presentan un mayor avance en la construcción de sus códigos de ética, en comparación con Chile y por supuesto con México, país que presenta un nulo desarrollo en este tema. 
* 180 - La síntesis conceptual en las portadas de libro - Koldo Atxaga Arnedo - Universidad del País Vasco (UPV/EHU) koldo.atxaga@ehu.eus

La portada de un libro se comporta del mismo modo que un anuncio publicitario: debe captar la atención del público, suscitar interés y prometer un contenido atractivo. Se trata de la última oportunidad de la que dispondrá el producto para persuadir al lector potencial. Puede que, incluso, sea la única acción promocional con la que haya entrado en contacto el posible comprador.

Esta oportunidad resulta del todo fugaz. Es necesario captar la atención en el primer instante. Casi paralelamente, la portada debe expresar una promesa respecto al contenido del libro. Una promesa tan seductora como para que el cliente sienta deseos de tomar el libro entre sus manos. A partir de ahí, otros factores determinarán el éxito de la compra: fidelidad hacia el autor/tema, calidad de la edición, sinopsis, reseñas, pasajes leídos aleatoriamente o precio.

La promesa de satisfacción se expresará íntegramente a través del lenguaje visual, mediante la tipografía y la ilustración en la portada. Abogo por una imagen tan sencilla como potente, que emplée una gramática visual muy esquemática pero que suscite asociaciones de profundo calado intelectual y/o emocional. En este sentido, las portadas responden a la definición de cartel publicitario que sostuviera diseñador vanguardista Cassandre.

La creatividad en el diseño de las portadas debe encontrar la manera de expresar poéticamente la esencia del libro. Es aquí donde la síntesis conceptual adquiere relevancia. El mensaje debe guardar fidelidad al contenido, pero no conviene desvelar demasiado explícitamente los hilos argumentales. Evitaremos lo obvio y buscaremos lo sugerido a través de las figuras de retórica visual, estableciendo un juego en el que el lector deberá cerrar el círculo del sentido. 
La ponencia ilustrará las estrategias comunicativas a través de diseños de Daniel Gil, Manuel Estrada, Pablo Amargo, Isidro Ferrer y diseños del propio conferenciante Koldo Atxaga.

* 181 - La cobertura del narcotráfico en países en conflicto: el caso de los periodistas de México - Dra. Elba Díaz Cerveró Universidad Panamericana (México) - eldiazc@up.edu.mx y Dr. Daniel Barredo Ibáñez - Universidad del Rosario (Colombia) daniel.barredo@urosario.edu.co

México es uno de los países más violentos para el ejercicio periodístico, con más de 100 periodistas muertos en las últimas dos décadas. Detrás de estos asesinatos -la mayor parte de ellos, por cierto, todavía impunes-, se encuentran fenómenos como el crimen organizado o la corrupción, así como la falta de presencia estatal en algunas regiones. En este estudio nos centramos en el análisis de un tema relevante en la agenda informativa contemporánea: la cobertura sobre el narcotráfico. Para ello, hemos entrevistado a casi dos docenas de periodistas mexicanos que se desempeñan en los principales medios nacionales de este país. Entre los resultados, evaluaremos aspectos como las diferencias en los tratamientos de este y otros temas; los protocolos de seguridad con que cuentan los profesionales encargados; y cuáles son los subtemas recurrentes en este tipo de cobertura.

182 - El Guardián de la Marca, una figura intangible en la empresa en el siglo Millennial's - Lic. Jefferson José Noble Miranda Msc. - Consultora Branding DirCom jeffmiranda2233@gmail.com

Este trabajo tiene como finalidad presentar a la comunicación como eje transversal en toda empresa, institución u organismo; verla como un intangible y por ende indispensable en el lugar donde se la emplee adecuadamente, dejando de lado el imaginario que el comunicador está sobrevalorada, dimensionado o limitado dentro de los medios masivos. A partir de las necesidades que se van generando en este tiempo millennial's parte la idea de la cátedra de crear nuevos perfiles profesionales que denoten los alcances y universo de un comunicador. El Directorio de Comunicación o bien conocido como DirCom se ha convertido en ese eje transversal que toda empresa necesita pero que 
Comunicación y Música: mensajes, manifestaciones y negocios

no muchos lo saben, un estratega que está siempre atento, desarrolla la habilidad de ser creativo de la comunicación convirtiéndose en foco luz de todo empresa, de ahí que parte la idea de guardián de la marca, teniendo en cuenta que la marca no es simplemente un logo o envoltura, ni algo subyacente, una marca es la identidad, la imagen, el cómo ve o proyecta la gente a una empresa, organización o institución, lo que creen que es.

El estudio se basa en la trascendencia que tiene hoy en día la comunicación empleando una metodología experimental y analítica permitirá ver a la disciplina desde otra perspectiva, donde la innovación y el desarrollo tecnológico promoverá a la actualización y frescura del conocimiento con el autoaprendizaje. La investigación fomenta el aprendizaje, la enseñanza de la comunicación desde el punto de vista empresarial que atienda las demandas o necesidades de la misma, posicionándola en la menta de la gente como base fundamental que permitirá tener mejores resultados y prever posibles riesgos o crisis a futuro convirtiéndose en guardianes protectores de la marca. Porque la estrategia de la comunicación millenial's es llegar a topar emociones de la gente, generando beneficios, más no características.

183 - Las Cofradías como elemento de participación ciudadana.

Estudio de Caso: Cofradías y Hermandades malagueñas, comunicación corporativa y estructura organizacional $-\mathrm{M}^{\mathrm{a}}$ Dolores García Fernández Facultad Ciencias de la Comunicación Universidad de Málaga lolagarcia@uma.es y Esperanza Marín Gallero Universidad de Málaga emaringallero@uma.es

A pesar de tener un peso específico en la construcción de la identidad de parte de la sociedad malagueña, su estructura comunicativa es escasa. Este trabajo pretende profundizar en la cultura corporativa de estas organizaciones y en las herramientas de comunicación externa e interna que utilizan para transmitir su misión y valores a sus públicos internos y externos.

Para ello, se ha realizado un análisis de carácter cualitativo y cuantitativo a través del análisis de las webs a través de ficha de análisis de 
contenido. Se ha recabado información de fuentes primarias a través de un cuestionario a 41 Cofradías y Hermandades de Málaga para conocer el organigrama de las diferentes organizaciones, canales de comunicación formales e informales y utilización de herramientas de comunicación interna y externa y encuesta a los públicos para comprobar si consiguen ser elementos de cohesión y participación ciudadana.

184 - Una aproximación a la importancia del sector de la distribución en la industria cinematográfica: los casos opuestos de Corea del Sur y España - Luis Miguel Machín Martín Universidad de La Laguna - luismachinm@gmail.com

Las industrias cinematográficas de España y Corea del Sur han experimentado, desde principios del siglo XXI situaciones opuestas. Por un lado, la cinematografía española se ha sumido en una indefinición estratégica que afecta a la comercialización de sus películas. La surcoreana, en cambio, ha vivido un crecimiento llamativo en varios aspectos como el número de producciones cinematográficas realizadas anualmente o los ingresos en las taquillas de cine de sus obras realizadas. Este trabajo se centra en el sector de la distribución dentro de las industrias cinematográficas española y surcoreana para hallar, mediante el contraste de los resultados, los elementos clave que las diferencian. Los resultados indican una fuerte oposición entre la industria surcoreana, donde las empresas nacionales controlan el sector, y la española, donde las compañías nacionales están en una posición de desventaja.

185 - Digital gender gap. Evolución de los estudios sobre la disgregación en los espacios digitales - Miriam Suárez-Romero - Contratada Predoctoral FPU. Universidad de Sevilla miriamsuarez@us.es

Múltiples instituciones reclaman desde hace años la necesidad de abordar un problema de desigualdad social invisibilizado: la brecha digital de género, o diferencia en el uso de TIC (Tecnologías de la Información y la Comunicación) entre hombres y mujeres. Si bien algunas iniciativas se centran en los países en vías de desarrollo, donde 
Comunicación y Música: mensajes, manifestaciones y negocios

la desigualdad es mayor (como es el caso de las propuestas provenientes de la Unión Europea o de ONU Mujeres, entre otras), también se pone de manifiesto desde múltiples foros la existencia de esta diferencia en los países desarrollados, donde se detectan nuevas formas de desigualdad social derivadas de los accesos y usos de las nuevas tecnologías. Este estudio ofrece una primera aproximación a la acogida que ha tenido esta problemática en la producción académica internacional. Se ha realizado para ello una revisión bibliográfica de las investigaciones presentes en la plataforma Scopus referidas a la brecha digital de género. Esbozamos así un esquema de su evolución a través de un análisis de contenido de los textos de las dos últimas décadas indexados en la plataforma bajo los criterios seleccionados.

* 186 - Inteligencia Artificial en la gestión de la comunicación: impacto de la robotización en la elaboración de contenidos informativos - Túñez-López, José Miguel. Universidade de Santiago de Compostela miguel.tunez@usc.es y Toural-Bran, Carlos. Universidade de Santiago de Compostela carlos.toural@usc.es

La Inteligencia Artificial (IA) está empezando a ocupar un terreno tradicionalmente dominado por el factor humano en el manejo de relaciones informativas entre las organizaciones, los medios y la sociedad. La aplicación de data mining para generar algoritmos que posibiliten automatizar la gestión y derivarla hacia el trabajo de bots en la elaboración de noticias. La profesión periodística vive momentos convulsos aparentemente ajena a la robotización de las redacciones y de la producción informativa basada en algoritmos.

La ponencia aporta un esquemático mapa mundial de 50 medios, agencias y empresas que recurren a la automatización en la elaboración de información, refleja la percepción de los periodistas sobre la posibilidad de que su actividad se robotice a través de una encuesta a 366 profesionales españoles sobre el impacto de la IA en su profesión y avanza datos comparativos de contenidos creados por robot $y$ noticias sobre el mismo tema redactadas por humanos. 
187 - Las redes sociales en las radio universitarias: caso Ecuador - Ana Magali Culqui Medina - Pontificia Universidad Católica del Ecuador - amculqui1@pucesi.edu.ec; Viviana Galarza Pontificia Universidad Católica del Ecuador vngalarza@pucesi.edu.ec y Remigio Cisneros - Pontificia Universidad Católica del Ecuador - rdcisneros@pucesi.edu.ec

El presente estudio pretende plasmar la pertinencia y eficacia de la comunicación digital de las plataformas web de las radios universitarias en Ecuador a través de sus redes sociales. Para ello, se analizaron las radios universitarias que poseen un sitio en internet. Es necesario recordar que la radio a lo largo de la historia, ha sido un medio de comunicación de fácil acceso, llegando a todas las clases sociales y perdurando a través del tiempo, acoplándose a los cambios que han surgido. Hoy en día, la popularización del internet, obliga a todos y en especial a los medios de comunicación a innovar y adoptar nuevas tecnologías, encontrando en los entornos virtuales muchos beneficios para mejorar los procesos de comunicación. Esta nueva concepción digital busca alcanzar que los medios dejen de ser simples transmisores de información y sean generadores de interacción y cumplan con un elemento fundamental de la comunicación digital, la reticularidad.

188 - Los micro influencers de moda en Instagram. Perfiles no profesionales vs exigencias de regulación - Angela Agulleiro Prats - Universitat Jaume I - angela.agulleiro@alumail.uji.es y Susana Miquel-Segarra - Universitat Jaume I - smiquel@uji.es

El nacimiento del fenómeno influencer, a raíz de la constante y veloz evolución de las nuevas tecnologías y las redes sociales, ha propiciado un cambio en el paradigma de la comunicación de moda en los últimos años. Un nuevo escenario comunicativo 3.0 necesitado de regulación específica, como la aparición del sistema ad hoc 'Patrocinado por' de Instagram. El objetivo de la presente investigación es comprobar de qué forma los micro instagramers de moda en España dan a conocer que una publicación conlleva una contraprestación. Para ello, se ha realizado un análisis de contenido de los 138 posts publicados en octubre de 2018 por un grupo de siete micro influenciadores, que previamente participó en un estudio más amplio a través de encuestas. 
Comunicación y Música: mensajes, manifestaciones y negocios

En concreto, el análisis de las publicaciones de estos micro influencers, que entre todos acumulan una audiencia de 176.427 fanes, demuestra que etiquetan a marcas en la mayoría de sus fotos, aunque resulta imposible identificar si están patrocinadas. A este respecto, tan solo el 1,44\% de las publicaciones analizadas utilizan fórmulas explícitas para tal fin, como el uso de los hashtags \#advertising o \#ad, tal como exige la normativa ya en otros países como EE.UU.

Angela Agulleiro Prats es doctoranda en el programa de Comunicación de la Universitat Jaume I (UJI) de Castellón. Máster en Nuevas Tendencias y Procesos de Innovación en Comunicación (2018) y licenciada en Publicidad y Relaciones Públicas por la UJI (2008), donde obtuvo una beca de estudios a Estados Unidos, cursando un semestre en Oklahoma University (2006). Su trayectoria profesional se enmarcada dentro de medios de comunicación locales, como elPeriódico, Canal 9, Onda Cero o Televisión de Castellón.

Susana Miquel Segarra es Doctora por la Universidad de Alicante con mención internacional (acreditado por la Glasgow Caledonian University). Actualmente es profesora ayudante doctora en el Departamento de Ciencias de la Comunicación y Vicedecana en el Grado de Publicidad y Relaciones Públicas en la Universitat Jaume I de Castellón. Así mismo es investigadora en el grupo ENCOM de esta universidad y colaboradora en el grupo Periodismo, comunicación y poder. Sus investigaciones se centran principalmente en el perfil de los profesionales de la comunicación corporativa y la publicidad, así como en el potencial dialógico y comunicativo de las redes sociales en diferentes ámbitos. Es miembro de la Junta Directiva de la Delegación Comunitat Valenciana y Región de Murcia de la Asociación de Profesionales de Comunicación (DIRCOM). Asociada en AdComunica (Asociación provincial para el desarrollo de la Comunicación en la provincia de Castellón) y miembro del Ilustre Colegio Oficial de Publicitarios y RRPP de la Comunidad Valenciana. 
189 - Estrategia comunicativa para evitar la violencia en estadios del norte de México - M.C. Daniel García Santos - Universidad Autónoma de Nuevo León - dagas07@hotmail.com; M.C. Rómulo Flores de la Rosa - Universidad Autónoma de Nuevo León - floresdelarosa94@gmail.com y Dr. Sergio M. de la Fuente Valdez - Universidad Autónoma de Nuevo León sermanfuen@yahoo.com

A la par de la consolidación del deporte - espectáculo, han surgido diversas manifestaciones culturales las cuales brindan un significado del deporte en las vidas de las personas y la sociedad. Estas manifestaciones han llegado a provocar un impacto social atreves de la participación de las personas en el deporte, así como los valores y normas creadas a partir de los diferentes roles de participación como: directivos, jugadores, trabajadores o espectadores. Una de las principales manifestaciones culturales derivadas del futbol profesional por parte del espectador, es la formación de barras o grupos de animación que apoyan a los clubes deportivos. Estos grupos de animación han establecido una estrecha relación con la identificación del equipo a tal grado que han creado todo un sistema estructural de normas e ideologías para apoyar a sus clubes. Desde el aspecto comunicativo las barras se han apropiado de las redes sociales para dar a conocer su perfil, canticos, así como viajes para apoyar a su equipo.

Los grupos de animación en el estado de Nuevo León tienen una gran relevancia social ya que sus acciones son seguidas por los medios de comunicación masiva debido a que se cuentan con un gran número de programas deportivos tanto en radio, televisión e internet, además de prensa especializada en deportes, puede asegurarse que el futbol es el deporte de mayor difusión en la localidad. Desde esta perspectiva la presente comunicación (1) busca describir la conformación y estructura de los grupos de animación del estado de Nuevo León; (2) identificar lenguaje y manifestaciones agresivas hacia la barra rival y (3) proponer un modelo comunicativo para evitar la violencia entre aficionados al futbol. Esta investigación pretende ser de gran utilidad para el futbol mexicano, ya que se puede extender a otros clubes además de involucrar a la sociedad en general. 
Comunicación y Música: mensajes, manifestaciones y negocios

190 - La homogeneización del mensaje periodísico a partir de los pseudoeventos - Jose Luis Argiñano Errarte joseluis.arguinano@ehu.eus - Universidad del País Vasco Euskal Herriko Unibertsitatea (UPV -EHU)

La sobreinformación, potenciada por el advenimiento de los medios online y la persistencia de los mass-media tradicionales, encuentra un manantial inagotable en los pseudoeventos. Definidos en el año 1961 por Boorstin como falsos eventos, con el objetivo de obtener el reclamo de la prensa, los pseudoeventos miden precisamente su éxito en función del espacio que acaparan en los medios. El ejemplo manifiesto de pseudoevento es, para Boorstin, la rueda de prensa del presidente estadounidense; Roosevelt, en su caso. En la actualidad, estos hechos manufacturados se visualizan en la oleada incesante de tuits de Donald Trump. La información elaborada a partir de pseudoeventos rehúye del periodismo de servicio y se aleja, de esta forma, de los intereses reales de la ciudadanía. Son piezas periodísticas ancladas en el periodismo declarativo. Más importante que el hecho resultan las opiniones en relación a ese mismo hecho. De esta forma, el género noticioso pierde terreno colonizado, de forma camuflada, por la opinión. Esta forma de hacer descuida la variedad temática, concentra la agenda-setting en una suerte de issues escudados en las voces de los poderosos y homogeneiza el manesaje, en la medida que los medios replican los dogmas de la elite.

191 - Valores: una mirada del comportamiento organizacional Nancy Graciela Ulloa-Erazo - nulloa@pucesi.edu.ec - Pontificia Universidad Católica del Ecuador Sede Ibarra y Yalitza T.Ramos Gil-ytramos@pucesi.edu.ec-Pontificia Universidad Católica del Ecuador Sede Ibarra

Hacer una definición de los valores humanos como una realidad intangible en las organizaciones no resulta una tarea sencilla, debido a las múltiples interpretaciones y argumentaciones que le han dado las distintas teorías filosóficas, culturales y sociales, a lo largo de la historia. Esta complejidad aumenta, si se analiza el momento actual, en el que, el individuo y su punto de vista particular, parecen haber adquirido todo el protagonismo, en los ambientes empresariales. Con este 
preámbulo, la presente investigación guarda una fundamentación que perfila una propuesta para repensar el comportamiento organizacional desde una perspectiva humanista, sensible e integral. En principio desde la definición de cultura organizacional se intenta identificar las prácticas de comunicación en la institución, así como la eficacia de la administración del talento humano, los programas de motivación, capacitación, el trabajo en equipo, la toma de decisiones, etc. Así también se estiman las características y conductas de los miembros como los atributos que conducen a la configuración del ambiente organizacional. Es allí donde se origina el interés por analizar en qué medida los valores que comportan las conductas de los integrantes de una institución son argumentos claves para posicionar el buen nombre de la empresa y la permanencia de esta en el mercado.

192 - Los cien primeros días de Manuela Carmena como alcaldesa en $A b c$ - Lara Carrascosa Puertas - Universidad de La Laguna-lcarrasc@ull.edu.es

This research try to analyse texts about Manuela Carmena published in Abc during her first one hundred days as Madrid's mayor. The aims is intend to reveal gender stereotypes and sexism which have featured Carmena as an erratic unprepared woman, albeit she had an elite professional -she was a juzge- and several awards in her career. In order to depict this attributes, I have used codes, grouped in categories, which are useful to figure out that Carmena is showed with negatives leadership characteristics.

193 - El sonido y las voces de la fotografía para narrar la paz Beatriz Múnera Barbosa - UTadeo -

beatrize.munerab@utadeo.edu.co y J. Ignacio Chaves G. Uniminuto - jose.chaves@uniminuto.edu

El mundo cambió cuando el ser humano fue capaz de retener el instante decisivo al plasmarlo en un papel con nitrato de plata. Pero también cuando fue capaz de transmitir sonidos por las ondas del éter. En la fotografía "anidan" voces y sonidos que son transmitidos por la imagen que recoge. Una instantánea que nos muestra un momento detenido en el tiempo y que nos permite viajar por ese tiempo y el 
Comunicación y Música: mensajes, manifestaciones y negocios

espacio hasta "situarnos" físicamente en el lugar y captar lo que rodea ese preciso segundo que queda "vivo" en la fotografía. Inventamos e imaginamos sonidos y voces que "están" en la fotografía y que nos completan lo que el sentido de la vista nos ofrece. También dicen que cada época, cada momento, tiene su propia banda sonora. La banda sonora de nuestra vida.

Esa sonoridad se puede concretar en letras y músicas que le dan "cuerpo" a la sonoridad de nuestros relatos. Si juntamos esas "voces" de las imágenes con los "ecos" de la banda sonora podemos "construir" una sinfonía de fotografías y sonidos que contribuyan a narrar la paz. La apuesta pedagógica es promover esas narrativas de paz a través de la conjunción de la imagen y la música, poniéndoles sonidos a las imágenes para construir un mapa audiovisual de nuestra propuesta individual de paz para conformar un atlas de paz colectivo.

* 194 - El catolicismo y el vampirismo en la literatura y el cine: una comparativa entre La muerta enamorada de Théophile Gautier yThirst de Park Chan-wook - Carlos Javier Eguren Hernández - Universidad de La Laguna - cjeguren@gmail.com y Luis Miguel Machín Martín - Universidad de La Laguna luismachinm@gmail.com

En este trabajo se exploran nuevas representaciones del mito vampírico en el cine partiendo de la comparativa entre la película Thirst (Bakjwi, 2009), del director surcoreano Park Chan-wook, y el relato La muerta enamorada (La morte amoureuse) de 1836 de Théophile Gautier. Tanto el protagonista de Thirst, un sacerdote católico llamado Sanghyun, que se ve transformado en vampiro, como el sacerdote Romualdo del relato La muerta enamorada, se ven tentados por figuras femeninas y ven sus votos sacerdotales comprometidos.

Así pues, en este estudio se aborda un análisis de ambas obras, atendiendo especialmente a la evolución de la temática del vampirismo y a las ideas que han trascendido un relato francés decimonónico hasta una película surcoreana contemporánea... 
195 - Someone else responsibility. The point of view of Italian advertising practitioners about the production gender portrayals - Paola Panarese - University of Rome "La Sapienza" y Juan Carlos Suárez Villegas - University of Seville

As one of the most visible marketing tools, advertising is not new to social controversy and ethical concerns. Despite advertising ethics has been defined as the ultimate oxymoron (Beltramini 2003), the study of ethics of/in advertising is quite ancient and extensive. However, advertising ethics has been studied mainly in a moral- philosophical perspective and from a "macro" viewpoint. Few scholars have examined the ethical practice of advertising professionals (Drumwright \& Murphy, 2004, 2009; Fraedrich, Ferrell, \& Pride, 1989; Moon \& Franke, 2000; Pratt \& James, 1994). Moreover, in spite of persistent criticisms of advertising's treatment of gender (Kilbourne, 1999), few authors have focused their attention on the production process behind the gendered messages (Tuncay Zayer \& Coleman, 2014).

In Italy, in particular, there is a rich literature on gender stereotypes in advertisements, and a recent surge of attention among professionals about the bias in the media representations of women, but there is no study about the production processes or the perceptions of gendered images among practitioners. Thus, the paper focused on the advertising practice as it relates to gender. In order to appreciate the commercial "culture of production" (du Gay, 1997), we studied the production processes that lead to particular gender representations and the manner in which advertising professionals make sense of ethical issues related to gender portrayals within their societal contexts.

In particular, we tried to discover where the ideas for certain gender representations come from, who determines how and what genderbased advertising should be, which are the prevailing cultural norms and practices in the advertising gender representations, what practitioners' perceptions are about how advertising gender portrayals impact male and female audiences, and in what ways ethics inform their creative and strategic choices regarding gender portrayals in advertising. Because the study's aim is to understand practitioners' 
Comunicación y Música: mensajes, manifestaciones y negocios

thinking about the work of advertising in their own terms and to evaluate those thoughts relative to existing theories, a qualitative design was selected. 40 semi-structured in-depth interviews with senior-level agency practitioners were used as the key field method. First results provide evidence for the existence of such autonomous practitioner knowledge schemas. Advertising agency professionals know well the bias of the most common representations of gender in Italian advertising. They recognize the most frequent sex-stereotypes and are critical towards them. In particular, the respondents believe that the gendered images are mainly caused by inexperienced operators or customers. They appreciate the cases of innovative representation of gender identity and strongly believe in the need for professional ethics that protects a more equitable and respectful gender representation. Finally, they are aware of the impact on the public of stereotyped gender portrayals, but they do not believe in the need for more or stricter codes of conduct.

* 196 - La radio como medio educativo en África: análisis de iniciativas - Lis Gaibar García - Universidad Miguel Hernández de Elche-1.gaibar@umh.es

A pesar de la expansión y democratización de las ICT en muchos países de África, la radio continúa siendo el medio de comunicación más empleado por la población para informarse. A principios del siglo XXI se comenzó a popularizar el concepto de "radio comunitaria" en varios países del continente, en la mayoría de ocasiones con fines de desarrollo, pero ya en 1980 se documenta la existencia de radios rurales dedicadas al crecimiento, mejora o participación de la comunidad. En este sentido, la popularidad del soporte radiofónico en los países africanos ha llevado a que organismos tanto nacionales como internacionales hayan elegido éste como el formato más adecuado para difundir mensajes enfocados al desarrollo de las comunidades.

El presente estudio pretende analizar el empleo y la evolución del soporte radiofónico con fines educativos, de paz o de desarrollo en cuatro países de África - República Democrática del Congo, Kenia, Uganda y Ruanda- a través del estudio de diferentes casos, contextualizando el marco mediático e incidiendo en los actores y 
factores que intervienen, el procedimiento de la puesta en marcha de este tipo de emisoras, los contenidos predominantes, la continuidad de las iniciativas y las ventajas y limitaciones que vienen presentando.

197 - La aplicación de mensajería WhatsApp en las estrategias de marketing, comunicación y publicidad de los anunciantes Laura Melendo Rodriguez-Carmona - Universidad Camilo José Cela-1melendo@ucjc.edu y África Presol Herrero Universidad Nebrija - apresol@nebrija.es

En el presente artículo se analizan las posibilidades que ofrece la aplicación de mensajería WhatsApp como herramienta de marketing y soporte publicitario. En los últimos meses la aplicación ha anunciado sus planes de abrir sus puertas a la publicidad con el fin de monetizar su uso. Entre las opciones que se han conocido está la de anuncios en sus estados, que se verán anuncios intercalados entre los mensajes de los contactos, además de su versión de la aplicación para negocios, WhatsApp Business. Por todo ello, se estima oportuno realizar una revisión de las aportaciones de esta aplicación a las estrategias de marketing, campañas de publicidad y comunicación de los anunciantes.

198 - Los cuerpos de agua como procesos de resistencia para la paz - Laura Melina Martínez Páez - UNIMINUTO melymartinezp@gmail.com y Paola Porras Camacho UNIMINUTO - paoporras03@gmail.com

En Colombia, comunidades diversas articulan sus saberes y sentires desde los cuerpos de agua. En el Magdalena Medio, la organización de Pescadores y Acuicultores del Llanito (APALL) lleva más de dos décadas navegando y resistiendo frente a la degradación del ecosistema cenagoso que circunda su corregimiento que, ha sido agravada por el conflicto armado en el país. Durante años, la Ciénaga de El Llanito se convirtió en un punto estratégico para la acción de distintos grupos armados al margen de la ley. Esto configura una relación de poder, dominación y explotación del territorio. Frente a esta mirada, la organización ha generado procesos de resistencia que se manifiestan a través de actos comunicativos que relatan las conexiones profundas y sensibilidades que establecen los pescadores con la ciénaga. En esta 
Comunicación y Música: mensajes, manifestaciones y negocios

medida, la interacción con el territorio no es reducida a reconocerle como un entorno, lugar, o recurso; por el contrario, se le concibe como un otro. Un otro que comparte una conexión y que se consolida como eje estructurante de sus narrativas, colectividades y saberes productivos.

199 - Nuevas fórmulas de aplicación del branded content en microteatro - Pablo Díaz Morilla - EADE University of Wales y Universidad de Málaga- pablodmorilla@uma.es y Andrea Castro Martínez- Universidad de Málaga- andreacastro@uma.es

El branded content es una estrategia publicitaria que ha aumentado notablemente su presencia en los últimos años. Los contenidos promovidos son un recurso empleado por las marcas para destacar en un mercado publicitario altamente saturado en el que los usuarios se han decantado por nuevos formatos que les aporten valor y dejen atrás narrativas propias de la comunicación comercial tradicional. A través de este formato se potencian los beneficios de un producto, los valores asociados a una marca o cualquier otro aspecto o idea que se pretenda destacar, sin que necesariamente se muestre visualmente o se mencione de forma directa a la compañía responsable. Pese a que el branded content puede desarrollarse en cualquier tipo de soporte, fundamentalmente se ha aplicado a medios que trabajan con contenidos audiovisuales. La televisión y las diferentes opciones de comunicación digital online que emplean vídeo son los medios a los que más se recurre para ponerlo en práctica. Sin embargo, la televisión y el vídeo no son los únicos medios capaces de combinar mensajes visuales y textuales. El branded content es una de las nuevas fórmulas publicitarias que se han comenzado a aplicar al teatro con el objetivo de aprovechar sus recursos comunicativos y de brindar un enfoque más experiencial a los contenidos creados por una marca. Este es el caso de Homocrisis, obra de teatro creada para Microteatro por dinero Málaga en 2016. La pieza teatral de formato corto contó con el respaldo de la marca Toshiba, que aportó uno de sus productos de forma que estuviese presente en la escenografía. El objetivo de la acción consistió en vincular la marca con los valores promovidos por el texto de forma que los actores pudieran incluir una alusión directa a ella. 
200 - ¿La precariedad laboral en el periodismo tiene género?: un acercamiento teórico a la situación laboral de la mujer periodista - María José Cantalapiedra - UPV/EHU mariajose.cantalapiedra@ehu.eus, Juan José Gutiérrez, UPV/EHU - juanjose.gutierrez@ehu.eus y Naiara Vink, UPV/EHU - naiara.vink@ehu.eus

La llegada de la mujer a la esfera pública y, por tanto, su acceso al mercado laboral, supuso un avance en el reconocimiento de la igualdad de oportunidades entre hombres y mujeres. En el marco de la feminización del sector periodístico y entendiendo que la igualdad de oportunidades es real y efectiva, ésta no se traduce en una igualdad de reconocimiento que ponga de manifiesto que hombres y mujeres son iguales en salario, condiciones laborales, posibilidades de promoción o acceso a puestos de decisión. El ámbito académico no ha prestado una atención continuada a las condiciones laborales y profesionales de los periodistas. Los trabajos de investigación específicos sobre la situación profesional y laboral del colectivo conforman un corpus escaso sin la necesaria continuidad para establecer cómo han evolucionado esas condiciones. Durante el desarrollo del proyecto Aplicación de la Convergencia Intermedia en la Comunicación Corporativa: Sala de Comunicación Abierta (SCA) se comprobó la existencia de una brecha de género en las rutinas y condiciones laborales. Tras la crisis económica de 2008 han surgido estudios en los que se alerta de la precariedad existente en la profesión y sus efectos en las rutinas de trabajo y la calidad de la información. Sin embargo, la perspectiva de género no se ha incorporado de manera sistemática y no se segregan los datos por sexo para conocer y comparar la situación laboral y profesional de hombres y mujeres. Sin ahondar en las causas, bien es cierto que la cercanía, aún hoy, de la mujer al ámbito de los cuidados podría suponer un obstáculo que impide su avance profesional. El presente trabajo trata de definir una base teórica que pudiera dar respuesta a la pregunta de si el género resulta determinante o no cuando se habla de precariedad laboral en las redacciones de nuestro país. 
Comunicación y Música: mensajes, manifestaciones y negocios

201 - Nuevas maneras de hacer para nuevas formas de ser: la enseñanza al servicio del emprendedor - María José, Sánchez Leyva- Universidad Rey Juan Carlosmariajosefa.sanchez@urjc.es

Creatividad, comunicación y emoción se insertan en la escuela y el discurso sobre la educación como meras afirmaciones de principios junto a ciertos procedimientos metodológicos que los avalarían. Técnicas como la gamificación y el uso de los medios audiovisuales en el aula suponen la mayor parte de las veces meras fórmulas y rituales vacíos que implican la desaparición de la finalidad emancipadora fundamental de la educación. El omnipresente interés de instituciones y empresas por la enseñanza expresa hoy un deseo de configuración de un sujeto flexible que soporte todas las imposiciones de los nuevos requerimientos del mercado laboral. Algo que no puede conseguirse si no es a través de una intervención sobre la propia subjetividad.

El sentido actual de la incorporación de las llamadas TIC y del recurso del audiovisual en las aulas suponen una estrategia interesada que entronca con las necesidades empresariales de búsqueda de trabajadores más adaptados a las nuevas circunstancias impuestas por el neoliberalismo. Estos procesos de subjetivación encuentran en la figura del "emprendedor de sí mismo" su máxima expresión.

La implantación de un modelo educativo/productivo permite observar esta relación entre el perfil del nuevo tipo de sujeto que la ingeniería social está construyendo con éxito y las metodologías docentes, pues se precisan nuevas maneras de hacer para estas nuevas formas de ser que se persiguen.

El procedimiento en enseñanza ha sustituido las finalidades. En este contexto, no sólo resulta pertinente una reflexión sobre los instrumentos didácticos audiovisuales (y los conceptos pedagógicos) sino muy especialmente una interrogación sobre su exacto papel en la práctica docente pues los métodos pedagógicos no pueden ser el eje básico de la formación ya que las técnicas didácticas por sí mismas no garantizan el éxito de la función docente. 
202 - Convergencia laboral y deontológica en los profesionales de TVE - Samuel Toledano - Universidad de La Laguna stoledano@ull.edu.es, José María García de Madariaga Universidad Rey Juan Carlos y María Lamuedra - Universidad de Sevilla

El ente RTVE se ha configurado como uno de los organismos públicos más cuestionados por diversos sectores de la sociedad. Partidos políticos, sindicatos de periodistas, asociaciones, colectivos o sus propios profesionales han elevado la voz ante lo parece ser la crítica más asentada: el uso partidista del ente por parte del gobierno. Entrevistas en profundidad a más de una docena trabajadores del ente con diferentes categorías profesionales y laborales en el ente revelan su concepción, defensa y puesta en práctica de la independencia o la pluralidad informativa. Lo que aparentemente se circunscribe a aspectos deontológicos de una información como servicio público tiene, sin embargo, una estrecha relación con los aspectos laborales. Con diferentes matices, los trabajadores apuntan a una vinculación del consejo de informativos con el comité de empresa o asocian el ejercicio de la independencia o pluralidad a las condiciones laborales, según se desprende del estudio realizado en el marco del proyecto de investigación Dinámicas de Relación Ante el Cambio Social: Contextos, Contenidos, Productores, Público y Produsuarios en las Noticias de TVE e YLE.

203 - Colaboración y comunidad virtual en las prácticas de autogestión en la música independiente de Quito - Andrea Angulo Granda - CIESPAL

La escena musical independiente de Quito atraviesa por un proceso de crecimiento, debido a, entre otros factores, la apropiación de las nuevas tecnologías por parte de los artistas como medio para difundir sus propuestas y crear lazos sociales. La presente ponencia abordará este fenómeno a partir de los casos de Guardarraya, Munn y La Máquina Camaleón, que fueron analizados dentro de la tesis de posgrado Del Escenario al Ciberespacio: colaboración y comunidad digital en las nuevas prácticas de visibilización de tres bandas de música alternativa de Quito en redes sociales, presentada para la obtención del título de 
Comunicación y Música: mensajes, manifestaciones y negocios

Magíster en Estudios de la Cultura de la Universidad Andina Simón Bolívar. En la exposición se trabajará sobre la circulación de contenido cultural a través del trabajo colaborativo y la inteligencia colectiva, por medio de las perspectivas de Pierre Lévy, Howard Rheingold y Henry Jenkins. Además, se dará un breve contexto sobre la situación actual de la escena musical alternativa de Quito. Con este preámbulo se hablará sobre los proyectos que desarrollaron las agrupaciones estudiadas y las estrategias utilizadas en redes sociales para visibilizar sus obras y crear vínculos con otros actores culturales y los públicos. Finalmente se compartirán las conclusiones de la investigación, alrededor del uso de los nuevos medios como canal de socialización para ganar reconocimiento.

204 - Información sobre salud y ficción televisiva - Pablo Díaz Morilla-EADE University of Wales y Universidad de Málagapablodmorilla@uma.es y Andrea Castro Martínez- Universidad de Málaga- andreacastro@uma.es

El interés que muestra la ciudadanía española en temas relacionados con el mundo de la salud y el bienestar se ha visto incrementado de forma notable y ha derivado en la proliferación de informaciones e investigaciones sobre este ámbito. Este interés también se ve reflejado en la parrilla televisiva, no sólo en espacios o programas completos dedicados al mundo de la salud, sino en otro tipo de contenidos. Las series de ficción que se desarrollan en entornos hospitalarios o que tienen relación con el mundo de la salud tienen presencia en la programación desde hace años y acercan información sobre enfermedades, fármacos y tratamientos al público generalista. Es el caso deCentro médico, el formato de docu-ficción emitido por Televisión Española (TVE) que lleva en antena más de tres años y ha superado los 1.000 capítulosen las 10 temporadas que se han emitido hasta octubre de 2018. El programa presenta a través de sus capítulos de 30 minutos casos médicos basados en hechos realesmediante los cuales ofrece información sobre diversas patologías y enseña el protocolo de actuación que se debe seguir en el caso de detectarlas. Se ha convertido en una herramienta para hacer llegar a los espectadores mensajes concretos sobre la práctica médica general y sobre cómo actuar ante diversas situaciones relacionadas con la salud. Es el caso de 
un niño asturiano de 10 años que logró salvar la vida de su padre al practicarle una Reanimación Cardio Pulmonar gracias a lo aprendido a través de la serie. Como complemento a sus capítulos, TVE ha desarrollado la aplicación móvil elaborada por médicos y que ofrece contenidos sobre diversas enfermedades, vida saludable, consejos prácticos y píldoras informativas.

205 - Los medios en tiempos de lobbies antivacunas: análisis de contenidos en prensa nacional - Daniel Catalán-Matamoros, Universidad Carlos III de Madrid, dacatala@hum.uc3m.es y Carmen Peñafiel, Universidad del País Vasco/Euskal Herriko Unibertsitatea, carmen.penafiel@ehu.eus

Introducción. La confianza en vacunas y los niveles de vacunación en la población están disminuyendo en muchos países europeos constituyendo un importante reto actual en salud pública (p.ej. Reino Unido, Italia, Rumanía). Estudios previos han mostrado cómo los medios pueden influir en la concienciación pública y la respuesta a las campañas de vacunación. Objetivo: Por lo tanto, el objetivo de este estudio fue examinar la cobertura periodística de las vacunas para averiguar sus características y posibles efectos en salud pública. Metodología: Mediante la base de datos Mynews se realizó una búsqueda en prensa nacional en España de 2012 a 2017, en la que se identificaron 131 artículos. Resultados: El análisis de contenido reveló que los medios informaron sobre las vacunas significativamente más frecuente en 2015 ( $p=<.001)$ cuando hubo un gran debate sobre las vacunas contra la varicela, la difteria, la tos ferina, el sarampión y la meningitis. La sección "Sociedad" fue la más frecuente, mientras que "noticias" y "reportajes" fueron los géneros periodísticos más usados. El tono positivo y neutro hacia la vacunación aumentaron significativamente $(\mathrm{p}=<.001 \mathrm{y} \mathrm{p}=.001$ respectivamente) durante el período de estudio, mientras que el tono negativo se mantuvo similar $(\mathrm{p}=$.306). Los temas más frecuentes fueron "investigación" y "reticencia a la vacunación", mientras que el framing más común fue "interés humano" y "conflicto". Conclusiones: Los resultados, además de aportar información sobre los principales acontecimientos mediáticos sobre las vacunas, muestran una tendencia positiva hacia la vacunación y la reducción de mensajes alarmistas. 
Comunicación y Música: mensajes, manifestaciones y negocios

206 - El "trap" como representación de una realidad social: estudio de caso de la producción musical del artista Yung Beef - Robles Andreu, Ma Carmen - Universidad Católica San Antonio de Murcia (UCAM) - mcrobles@ucam.edu y Albaladejo Ortega, Sergio - Universidad Católica San Antonio de Murcia (UCAM) - salbadalejo@ucam.edu

El "trap", como fenómeno musical, ha arraigado a pasos agigantados en la escena de lo social en los últimos años. A pesar de estar notablemente presente en webs, wikis, redes sociales, programas televisivos, diarios, revistas y vídeos en plataformas de contenido, resulta, más allá de su etiqueta, un gran desconocido. En la actualidad existen algunas aproximaciones desde la academia, pero se trata de un fenómeno en pleno proceso de definición que exige un estudio próximo y pormenorizado que contribuya a la configuración del imaginario colectivo contemporáneo. Con este propósito, se acomete un estudio de caso de la producción musical del artista granadino Yung Beef, buscando dilucidar, a partir de la revisión bibliográfica y el análisis de contenido de sus obras, el origen y los rasgos definitorios del estilo musical trap, y el modo en que representan aquellas realidades sociales que respaldan sus letras. El trabajo se erige sobre dos hipótesis: (i) que el 'trap', con sus distintos rasgos identitarios, es una derivación del estilo musical 'rap' y, más concretamente, del subgénero conocido como 'gangsta rap', caracterizado por letras violentas y explícitas que reflejan los problemas de los barrios desfavorecidos; y (ii) que la producción musical y audiovisual de los artistas españoles pertenecientes a este estilo se corresponde con la representación que se hace del barrio -the hood- en los temas musicales de rap y trap estadounidense, así como en el modo en que lo ilustran las obras audiovisuales del presente más reciente. La propuesta resulta especialmente pertinente en un momento en que las nuevas plataformas de difusión han conquistado un lugar privilegiado en el ecosistema mediático para hacer llegar a la juventud cada nuevo movimiento de estos artistas, convirtiendo a los jóvenes, no solo en consumidores de estas creaciones sino también en difusores de los mensajes contenidos en ellas. 
207 - La capacitación y el uso de la tecnología dentro de la organización - Gallegos Arredondo, Ambar EugeniaUniversité Savoie Mont Blancambar.gallegosarredondo@gmail.com

La tecnología hoy en día está al alcance de las manos, en las organizaciones se ha convertido en una de las principales herramientas con las que trabajan los empleados, tanto aquellos que están en producción como aquellos que están en el área administrativa. En estas organizaciones es fundamental que los empleados, principalmente los administrativos estén conectados todo el día, pendientes de sus correos electrónicos o de los menajes que reciban en otras aplicaciones. Puesto que gran parte de su comunicación se realiza a través de correo electrónico o mensajes en grupos en los que esté incluidos, es normal que, aunque estén en algún otro evento o en la organización estén siempre pendientes de su celular.

Para el desarrollo de esta investigación se abordan dos partes de la metodología, la primera es de manera cuantitativa en la que se realizó un cuestionario a personal de tres distintas empresas, las preguntas estuvieron enfocadas al uso de la tecnología y a la capacitación. En la metodología cualitativa la población de estudio fue de 7 personas a través de una entrevista y un focus group. Para Cavalcante \& Valentim (2010) la tecnología dentro de la organización está completamente ligada al mismo desarrollo que le de la persona, por lo que en este punto se destaca la relevancia de la capacitación en los empleados.

Y Chouikha (2016), destaca la importancia de que las tecnologías que se utilizan tengan un soporte adecuado que permita a los empleados que desarrollen su trabajo de una manera más efectiva. Como resultado tras el análisis de la metodología se puede destacar que en las organizaciones los empleados reciben una capacitación previa a la utilización de la tecnología, de igual manera si ellos sienten una necesidad de cubrir cierta área de oportunidad se les ofrecen los medios para ello. 
Comunicación y Música: mensajes, manifestaciones y negocios

208 - Incidencia de las redes sociales en la comunicación intrafamiliar - Aydé Elizabeth Velásquez Quintana aydev@yahoo.com

El presente trabajo analiza la realidad de la familia en relación a la incidencia de las redes sociales en la comunicación intrafamiliar, sus usos y apropiaciones, manejo de la comunicación, conflictos, ejercicio del poder e intergeneracionalidad. Para el desarrollo de esta investigación se plantearon objetivos que permitieron identificar las redes sociales más utilizadas y su peso mediacional en las relaciones intrafamiliares, analizar las formas y alcances de la interacción; y evidenciar los problemas comunicacionales que existen en los espacios familiares y las relaciones de poder que pueden ejercerse entre los integrantes de la familia. Esta investigación demuestra que las familias enfrentan una crisis comunicacional en donde el uso de las redes sociales a través del celular es uno de los factores que inciden. Adicionalmente, en los resultados se presentan criterios y testimonios sobre la vivencia comunicacional entre padres e hijos y los conflictos asociados al uso de la tecnología.

209 - Las pantallas y su influencia en la vida cotidiana. Estudio de caso: realizado en la ciudad de Loja - Ecuador. - Hernán Antonio Yaguana Romero -hayaguana@utpl.edu.ec Universidad Técnica Particular de Loja y María Noralma Romero Camacho - mnromero@utpl.edu.ec - Universidad Técnica Particular de Loja

La presente investigación tiene por objeto darnos a conocer, a partir de una perspectiva social, cuáles son las nuevas interacciones que se dan con el uso de las pantallas, desde la representación y accionar de los estudiantes universitarios de los últimos años de carrera. Nuestro recorrido empieza con una conceptualización teórica, destacando la influencia técnico-social que las pantallas están construyendo en nuestro tiempo, y cómo desde esa dualidad edifican nuevas comunidades, donde los individuos alteran sus ritmos y rutinas con otras totalmente nuevas, mezcla de lo real con lo simulado, pero que a la final no se logran distinguir, pues, es tan fuerte la influencia de la una con la otra que no da tiempo a mirar detalles. La metodología aplicada 
combina técnicas cualitativas y cuantitativas, merced a su éxito en investigaciones similares. Con la población, objeto de estudio, se realizaron de 600 encuestas en línea y 50 entrevistas no estructuras, efectuadas durante junio y septiembre del 2018. En la interpretación de resultados combinamos ambas técnicas, buscando los hallazgos que nos permitan entender cuáles son las situaciones, los momentos y circunstancias donde las pantallas ha redefinido nuestro entorno.

210 - La Racionalidad Sustantiva y el racismo en México a través de la acción comunicativa y la ética comparada de los mensajes y memes en tres casos específicos de Facebook y Twitter - Dra. María Antonieta Rebeil Corella - Universidad Anáhuac México - arebeil@anahuac.mx, Dr. Rogelio Del Prado Flores - Universidad Anáhuac México rogelio.delprado2@anahuac.mx, Dr. Raúl Santos Morales Universidad Anáhuac México - raul.santos@anahuac.mx

Facebook y Twitter son redes sociodigitales que provocan la participación de las personas en diferentes niveles como espectadores, participantes, coleccionistas, críticos o creadores, generando ciertos tipos de comunicación que detonan en situaciones de conflicto y crisis. A través de la teoría de la acción comunicativa, se revisaron tres casos diferentes de racismo en México vinculados a las elecciones políticas, a una campaña digital de publicidad y a la migración centroamericana dentro del país, haciendo énfasis en los mensajes y memes de cada caso, donde, además de analizar la acción estratégica, la acción dramatúrgica y la acción comunicativa, se profundiza en la acción regulada de cada caso a través de un análisis de ética comparada, puesto que los componentes cognitivos y expresivos están determinados por estándares y orientaciones valorativas de cada ser humano, de tal manera que es importante descubrir el tipo de ética premoderna, moderna o postmoderna que predomina alrededor del racismo dentro de entornos virtuales como Facebook y Twitter, lo cual, ayudará a describir otra faceta de los usuarios de las redes sociodigitales en México, algo que la mayoría de los estudios de corte cuantitativo dejan de lado: el estado axiológico de las acciones comunicativas de los cibernautas mexicanos ante situaciones socioculturales muy específicas. 
Comunicación y Música: mensajes, manifestaciones y negocios

211 - Creación de experiencias inmersivas de no ficción: El caso de la serie documental Hors-Cadre (2018) - Alba Marín Université Savoie Mont Blanc / Universidad de Sevilla ylbacm@gmail.com

Las producciones documentales digitales contemporáneas se basan en la interactividad del medio y se sirven de multitud de tecnologías no sólo para conformar un relato de la realidad, sino para ofrecer al usuario una experiencia visual. La carrera por la inclusión del usuario ha llevado a los documentalistas a desarrollar narrativas experimentales y espacios compartidos para a ir más allá de la representación y crear experiencias digitales. En este contexto tecnológico nos preguntamos por la influencia de las tecnologías como la realidad virtual o la realidad aumentada sobre la creación de productos audiovisuales de no ficción. ¿Cómo se puede representar la realidad a través de la creación de realidades virtuales? ¿Cómo afecta a la narración? ¿Qué ocurre con el referente real? Pensar en la producción de un documental en la actualidad es diferente a pensarlo en un contexto cinematográfico anterior. La concepción del documental ha cambiado, así como la visualización de las producciones de no ficción.

Presentamos un estudio de caso de la serie Hors-Cadre, una serie de cortometrajes en realidad virtual cuyo objetivo es mostrar en profundidad obras de referencia de importantes pintores suizos. La serie ha sido producida por la RTS (Radio Télèvision Suiza) y la productora DNA Studios. Nuestro objeto de investigación ha sido analizado de manera interdisciplinar partiendo de metodologías insertadas en las ciencias sociales. Concretamente, desde una perspectiva etnográfica y comunicacional con la que nos hemos centrado en dos aspectos principales. Por un lado, el proceso de creación, diseño y tratamiento de la información y, por otro, la experiencia final que se ofrece al usuario. Hemos diseñando una metodología visual compuesta para conocer las formas de representación y creación de cada obra. Por lo tanto, abordamos el estudio de casos desde los métodos visuales y utilizamos la imagen como herramienta de investigación. 
212 - El desafío de sindicatos, partidos políticos y asociaciones profesionales para regular la profesión periodística a partir de la Democracia - Ángela Belmar Talón - Universidad de Extremadura - angelabelmartalon@gmail.com

Desde el punto de vista jurídico, el proceso de profesionalización del periodismo en España se ha enfrentado a diversos problemas a lo largo de su historia. Entre ellos, constituyendo unas trabas que han llegado hasta la actualidad, destacan: la falta de consenso para llegar a una definición de periodista, así como si ésta debe incluir sólo a los periodistas titulados o también a aquéllos que carecen de titulación; la ausencia de un estatuto jurídico propio que regule nítidamente sus derechos y deberes; junto con la carencia de un colegio profesional, con fuerza vinculante, al que se puedan acoger los periodistas y vele por sus intereses.

Desde 1980 hasta 2004 se suceden los intentos por parte de sindicatos, partidos políticos y asociaciones profesionales por sacar adelante una legislación que vertebre la profesión periodística; sin embargo, la única tentativa que entra en vía parlamentaria es la Proposición de Ley del Estatuto del Periodista Profesional de 2004.

Surgida a instancias de Izquierda Unida-Iniciativa Per Catalunya Verds (IU-ICV), esta iniciativa se erige en el proyecto más sólido y con mayor recorrido legislativo. $\mathrm{Y}$ aunque, finalmente termina en una vía muerta por las discrepancias que su discusión suscita, sí se atreve a definir quién es periodista: considera que debe recibir esta calificación aquella persona cuya principal ocupación se centra en la actividad informativa, independientemente de su forma y de la relación laboral que mantenga con la empresa.

Además, rescata una de las medidas de acceso a la profesión del periodo franquista, puesto que el periodista debe acreditar su condición a través de un carné, con la salvedad de que este documento ahora lo otorgaría un Consejo Estatal de la Información o sus equivalentes autonómicos, en vez de la Federación Nacional de Asociaciones de la Prensa (FNAPE). 
Comunicación y Música: mensajes, manifestaciones y negocios

213 - El contenido digital revoluciona la ficción tradicional: hacia nuevos modelos de creación y consumo en la ficción mundial - Finocha Formoso Barro-- Universidade da Coruñam.formoso@udc.es

El contenido digital aumenta en todo el mundo y genera un conflicto de intereses con la televisión lineal porque cada vez se atraen más televidentes a las distintas plataformas y servicios de streaming. La industria había desarrollado su actividad en un entorno estable y controlado donde unos cuantos canales de televisión, luchaban por mantener la atención del espectador. Con la llegada de las nuevas plataformas los usuarios consumen en cualquier dispositivo y en cualquier lugar del mundo. En este entorno, las series son un contenido prioritario por sus posibilidades estratégicas y porque conforman un elemento diferenciador que permite generar marca y exclusividad en torno a una plataforma. Las series digitales originales producidas por las plataformas SVOD Netflix, Amazon, Crackle, Youtube Premium y Facebook Watch compiten con fuerza con los contenidos de los canales de televisión lineal. Las televisiones convencionales han empezado a ver a las nuevas plataformas como aliados naturales para atender demandas y necesidades que los usuarios reclaman. La globalización que conlleva la digitalizacion permite consumir series de ficción de modo inmediato tras su producción y eliminar ventanas de explotación. Por tanto, revisar el contenido y el consumo de las series de ficción creadas por las nuevas plataformas permite reconocer los componentes tecnológicos y el grado de creatividad que incorporan las nuevas plataformas digitales.

214 - Dispositivos móviles y redes sociales: herramientas para el control entre ciudadanos - Alberto Hermida - Universidad de Sevilla - ahermida@us.es y Víctor Hernández-Santaolalla Universidad de Sevilla - vhsantaolalla@us.es

Las redes sociales y los dispositivos móviles son utilizados como herramientas propicias para la vigilancia y el control tanto verticales (de los estamentos de poder a los ciudadanos y a la inversa), como horizontales (entre ciudadanos) en un contexto marcado por la hiperconectividad. Si bien ambas dinámicas parecen haber sido 
asumidas como consustanciales a las nuevas formas de comunicación, es la segunda, la denominada vigilancia horizontal, la que cobra una especial relevancia en la presente comunicación. Consulta de perfiles ajenos, suplantación de perfil social, apropiación indebida de contenido multimedia, etc., son solo algunos ejemplos de las acciones que los usuarios llevan a cabo en la red en entornos familiares, de amistad o de pareja, entre otros. De esta forma, y en consonancia con conceptos como los de "vigilancia lateral" y "vigilancia social", la ponencia propuesta repasa algunas de las prácticas más habituales relacionadas con el espionaje llevadas a cabo por los usuarios sobre otros ciudadanos. Dichas prácticas, no solo llegan a convertirse en claras muestras de invasión de la privacidad, hasta cierto punto normalizadas en la actualidad, sino que también ponen de manifiesto la falta de control sobre el contenido subido a la red; aspectos sobre los que se reflexiona en el presente estudio.

215 - Disrupción en el aula en FP inicial: cómo mejorar las estrategias docentes - Gloria Gil Talavero - Universidad de Salamanca

En lo que respecta a la psicopatología, es cada vez más común encontrar a adolescentes que fracasan académicamente y que presentan trastornos que alteran su comportamiento: dominancia, depresiónansiedad, búsqueda de atención, trastorno por déficit de Atención con Hiperactividad, agresividad-delincuencia, baja empatía y sociabilidad, drogas... Adolescentes que manifiestan un patrón de conducta antisocial, bien cuando existe un deterioro significativo en el funcionamiento diario en casa o en la escuela, o bien cuando las conductas son consideradas incontrolables por familiares y amigos.

En general, se observa que los alumnos de Formación Profesional Inicial, debido a que se encuentran en una situación desfavorable a nivel personal; tienen desequilibrio emocional (baja autoestima), familiarsocial (situaciones conflictivas y desequilibrios) y educativo (poco interés y déficits para la obtención de la mayoría de las competencias clave del sistema educativo español); presentan altos niveles de alteraciones emocionales que se pueden ver agravados en sujetos con alteraciones y problemas conductuales, factores que, en la mayoría de 
Comunicación y Música: mensajes, manifestaciones y negocios

los casos, se traducen en absentismo o un bajo rendimiento académico. ¿Los trastornos conductuales se reflejan en el fracaso académico?

Tras el fracaso académico emanan trastornos que alteran el comportamiento del alumno, acompañado de un desequilibrio emocional y conflicto familiar y social. Por lo que el profesorado se encuentra con el reto de encontrar herramientas lingüísticascomunicativas y de control para hacer frente a situaciones disruptivas en el aula. Ante esta situación, el docente reclama una intervención metodológica en la que se valore el desarrollo de la competencia lingüística-comunicativa desde el fomento de las habilidades emocionales, para mejorar la resolución de problemas. Desde el punto de vista neuropsicológico, se propone un modelo de plan de intervención con el alumnado disruptivo, debido a la posibilidad de obtener una retroalimentación positiva por sus iguales y por otros sectores de la sociedad.

216 - Deporte y comunicación: las primeras huellas del fútbol femenino en Canarias - Laura Esther Castro Hernández Universidad de La Laguna- info@lauracastro.es, Carmen María Rodríguez Wangüemert- Universidad de La Lagunacrodrigu@ull.edu.es.y María Aránzazu Calzadilla MedinaUniversidad de La Laguna - acmedina@ull.edu.es

Los movimientos sociales del siglo XIX marcaron el avance de la mujer y su papel en el mundo del deporte. Detractores y defensores debatieron en los comienzos del siglo XX sobre si el deporte era una actividad recomendable para la salud de las mujeres o no, hasta que, se comenzó a normalizar la práctica de algunas modalidades influenciadas por la corriente deportiva internacional, relacionada con la participación femenina en pruebas como los Juegos Olímpicos y los movimientos feministas nacionales. El fútbol femenino estuvo vetado durante muchos años hasta que, finalmente, comienzan a crearse los primeros equipos de fútbol en los felices años veinte que no tendrían mucha acogida mediática y sí algunas voces opositoras en los medios de comunicación. 
Su normalización no llega hasta terminada la dictadura franquista momento en el que se constituyen los primeros clubs de fútbol femenino influenciados por los ya existentes a nivel nacional como el Bilbao o el FC Barcelona femenino. La investigación ha partido de la revisión bibliográfica y hemerográfica de la prensa especializada y de las noticias deportivas de la época. Asimismo, se han tenido en cuenta otros estudios actuales para centrar una posición desde la historia social del deporte. Esta comunicación recoge los artículos publicados en los periódicos canarios entre los años 1915 y 1950.

217 - El cine como herramienta didáctica para la enseñanza de las matemáticas en el aula de Educación Primaria - Leticia Rodas Alfaya, Rocío Guede-Cid y Ana Isabel Cid-Cid Universidad Rey Juan Carlos, URJC, España leticia.rodas@urjc.es

Flatland, La habitación de Fermat, Moebius, 21 Black Jack, El indomable Will Hunting, La pizarra, Contact, Una mente maravillosa, La soledad de los números primos, Donald en el país de las matemáticas, Descifrando enigmas, La teoría del todo... películas como estas pueden ser una herramienta apropiada para el aprendizaje y la enseñanza de las matemáticas en el aula. Las matemáticas han sido consideradas tradicionalmente como una materia compleja y árida, que exige un elevado nivel de implicación y motivación tanto a estudiantes como a docentes. Resultaría por lo tanto interesante convertir las clases de matemáticas en una experiencia lúdica y atractiva para los estudiantes, que a la vez permita al profesor desarrollar métodos de innovación docente. En este sentido se ha pensado en el cine como elemento acelerador de la enseñanza de las matemáticas. El visionado de películas o de secuencias en el aula aporta frescura y dinamismo a las clases y da lugar a la introducción de distintas situaciones didácticas, incluyendo actividades como interpretación, análisis del contenido o investigación del entorno del filme. Esta comunicación pretende presentar un catálogo de películas que pueden utilizarse como herramienta didáctica para la enseñanza de las matemáticas en los diferentes niveles del sistema educativo. Se propondrán además situaciones didácticas asociadas a cada película, indicando qué temas o 
Comunicación y Música: mensajes, manifestaciones y negocios

conceptos se pueden trabajar con cada una de ellas y a qué tipo de estudiantes va dirigida la actividad.

218 - Comunicación remota en implantes con marcapasos: las experiencias de los usuarios en un hospital noruego - Daniel Catalán-Matamoros, Universidad Carlos III de Madrid, dacatala@hum.uc3m.es y Antonio López-Villegas, Universidad de Tromsø, Noruega, y Hospital de Poniente, Almería, España, antonio.lopez@ephpo.es

Introducción. La comunicación remota con los pacientes es actualmente una práctica frecuente en los servicios sanitarios. Los pacientes con enfermedad cardiovascular están en aumento y la telecardiología se aplica para dar respuesta a esta demanda. Sin embargo, no existen estudios sobre las experiencias de los usuarios en estas nuevas formas de comunicación con el hospital. Objetivo: Analizar las experiencias de los usuarios con marcapasos que siguen un sistema de comunicación remota con el hospital. Metodología: Se crearon dos grupos de usuarios aleatoriamente, uno con el sistema de seguimiento hospitalario y otro con el sistema de tele-monitorización. Se administró el 'Cuestionario genérico de experiencias de pacientes cortos (GSPEQ)' y una encuesta ad hoc construida mediante la 'encuesta de satisfacción en telesalud' y la 'encuesta de costes'. Los datos se recogieron seis meses después del implante de marcapasos en una cohorte de 50 pacientes consecutivos. Finalmente, 24 pacientes se incluyeron en el seguimiento hospitalario, mientras que 25 utilizaron el sistema de tele-monitorización. Resultados: Se observan experiencias positivas y similares en general en ambos grupos. Se encontraron diferencias significativas en GS-PEQ en que en el grupo con la comunicación remota se recibió menos información sobre el diagnóstico $(p=0,046)$. No se encontraron diferencias significativas en otros ítems como 'confianza en los profesionales sanitarios', 'percepción de la adaptación de su tratamiento', 'participación en las decisiones', 'percepción de la organización del hospital', 'espera antes del ingreso', 'beneficio recibido' y 'satisfacción del servicio recibido'. Conclusiones: la comunicación remota con los usuarios con marcapasos fue positiva con experiencias similares a los pacientes en el seguimiento hospitalario. Sin embargo, los usuarios con comunicación 
remota recibieron menos información. En consecuencia, es necesario mejorar la calidad de la información durante el seguimiento remoto de marcapasos.

219 - Comunicación ética de salud - Carlos Cachán-Alcolea Universidad Nebrija ccachan@nebrija.es

La comunicación de salud interesa cada vez más. El ecosistema Salud -cada vez más complejo- suministra acontecimientos mediáticos muy demandados por los ciudadanos. La comunicación es fundamento de las relaciones entre las personas y su actividad intelectual determinada por la relación de los seres humanos con su entorno social en el que se identifica o enfrenta sus posiciones empleando un sistema de signos comunes. Sin comunicación no hay relaciones organizadas entre las personas, grupos o redes sociales (físicas o virtuales). La ética periodística es la ciencia de los deberes y conductas propios de los profesionales de la comunicación. Poner en relación estos tres términos -comunicación, salud, ética periodística-, constituye el núcleo de esta investigación académica e interprofesional.

Como periodista y experto en comunicación científica y de salud, profesor de Ética y deontología de la comunicación e investigador principal del Grupo Nebrija de Periodismo de Análisis y Anticipación (https://www.nebrija.com/investigacion-universidad/grupos/grupoperiodismo.php), nos interesa mucho analizar los aspectos éticos aplicados a la comunicación de salud. Por eso, dentro del Aula NebrijaMSD de Comunicación y Ciencias de la Salud, proyecto competitivo y financiado por MSD España, estamos desarrollando una investigación aplicada a la comunicación ética de salud. Una parte importante de la investigación ha consistido en la realización de una serie de entrevistas cualitativas a periodistas de salud, divulgadores científicos y expertos en comunicación corporativa sobre los "aspectos éticos aplicados a la comunicación de salud". Las entrevistas tuvieron lugar entre enero y octubre de 2018. Con el objetivo de que las respuestas de estos expertos en salud -como fuentes de referencia- puedan ser de utilidad para los profesionales de la comunicación y la medicina, así como a pacientes-receptores. Esta comunicación recoge el resultado del trabajo de campo. 
Comunicación y Música: mensajes, manifestaciones y negocios

220 - Parlar la paz, marcando la diferencia desde las voces de la radio universitaria en Zipaquirá y Sabana Centro - Ariolfo Velasco Quesada - Corporación Universitaria Minuto de Dios UNIMINUTO - avelasco@uniminuto.edu.co

Hablar de paz no resulta fácil, especialmente en un mundo que ha estado enmarcado por la guerra y cuyas naciones, como Colombia, viven de ella para justificar el direccionamiento de recursos. La paz es sinónimo de tranquilidad, estabilidad, equilibrio, armonía, etc., que en términos políticos-sociales, infiere justamente a eso: a lo político, social, económico y religioso. Ahora, hablar de paz a través de la radio universitaria significa construir un diálogo que, llevado a las audiencias, propicie esa construcción desde sí mismos como personas para que redunde en la familia, en el barrio, en los centros educativos y demás entornos locales y regionales. Sistema Voces U Radio es una propuesta universitaria que nace en el programa de Comunicación Social Periodismo de la Corporación Universitaria Minuto de Dios UNIMINUTO, Centro Regional Zipaquirá.

Desde ahí, se realizan una serie de programas producidos y conducidos por sus estudiantes y emitidos por emisoras comunitarias de Zipaquirá y Gachancipá, y vía online por UNIMINUTO Radio Soacha, municipios de Cundimanarca - Colombia. Dentro de sus contenidos se desarrollan temas del orden social, político, cultural, educativo, religioso, medio ambiental y económico, entre otros, en varios formatos radiofónicos, con un lenguaje propio de los jóvenes, manteniendo la esencia misional de la radio: formar, informar y entretener. Con esta ponencia se quiere evidenciar cómo los jóvenes, mediante la radio universitaria, logran establecer esos diálogos que están inmersos en lo que compete a la construcción de paz, pensados para un público que empieza a sentir la posibilidad del fin de un conflicto que ha afectado a varias generaciones por más de 50 años. También, cómo los estudiantes hacen uso de la radio comunitaria como canal de participación para que niños, jóvenes y audiencia en general, sean gestores activos en la construcción de un mejor barrio, una mejor región y un mejor país. 
221 - El uso del aula invertida para la enseñanza de las matemáticas en el aula universitaria - Rocío Guede-Cid, Leticia Rodas Alfaya y Piedad Tolmos Rodríguez-Piñero - Universidad Rey Juan Carlos, URJC, España - rocio.guede@urjc.es

Las publicaciones sobre experiencias de aplicación de aulas invertidas en todos los ámbitos de la docencia se han multiplicado en los últimos años, lo que supone una innegable muestra del interés que despierta esta metodología. La divulgación de resultados del desarrollo docente de los profesores que han aplicado esta metodología son factores que contribuyen día a día a la expansión de su aplicación. En esta propuesta se analiza una experiencia de aula invertida puesta en práctica durante dos cursos académicos en la asignatura "Métodos de Decisión Empresarial" del Grado en Administración y dirección de Empresas de la Universidad Rey Juan Carlos. Los resultados se comparan con los obtenidos en el resto de grupos que siguen metodologías didácticas tradicionales. En un estudio previo se concluyó que existen indicios suficientes de que la clase invertida mejora los resultados académicos. Adicionalmente se detecta que la metodología no funciona igual de bien entre los estudiantes repetidores, aquellos que no cursan la asignatura por primera vez Con este trabajo se plantea un doble objetivo, determinar las causas de la menor implicación de los estudiantes repetidores y averiguar en qué sentido podría modificarse el planteamiento de las clases para mejorar los resultados de aprendizaje de este colectivo.

222 - Storytelling educativo y científico: aplicación de estrategias de guion cinematográfico a las narrativas emergentes - Manuel Gértrudix (Universidad Rey Juan Carlos) manuel.gertrudix@urjc.es, Mario Rajas (Universidad Rey Juan Carlos)-mario.rajas@urjc.es y Miguel Baños (Universidad Rey Juan Carlos)-miguel.banos@urjc.es

Las estrategias y técnicas narrativas se están aplicando en ámbitos profesionales tan dispares como el mundo de la política, la empresa o la medicina. Esta investigación se centra en los procesos de storytelling asociados al campo de la enseñanza universitaria y de la difusión científica. Tanto en los itinerarios formativos presenciales o virtuales, 
Comunicación y Música: mensajes, manifestaciones y negocios

en los métodos de innovación docente (clase invertida, ABP, etc.) o en los canales emergentes de divulgación de la ciencia, la narrativa audiovisual ejerce un papel fundamental de articulación y potenciación de mecanismos eficientes para implicar emocionalmente al espectador, demandar su participación activa y, en definitiva, mejorar su experiencia personal y única de aprendizaje.

Con el objetivo de diseñar un modelo de análisis y creación de contenidos narrativos específicamente educativos y científicos, en este trabajo de investigación se estudian los paradigmas conceptuales de la teoría del guion audiovisual y se reelaboran los procedimientos de escritura de vídeos didácticos con la finalidad de integrar los instrumentos, características y funciones de los relatos televisivos o cinematográficos en la práctica cotidiana de enseñanza-aprendizaje.

Así, por un lado, se analiza la estructura de los materiales didácticos de acuerdo a los objetivos o los resultados esperados y se enumeran las técnicas más importantes del storytelling educativo y científico; por otro, se describe el proceso secuencial de escritura de guion y se adaptan a los formatos más relevantes para la creación de vídeo educativo y científico; por último, se introducen modelos de evaluación y control de los materiales elaborados antes de iniciar el proceso de producción audiovisual de los distintos contenidos. Este artículo, dirigido tanto a docentes como a discentes, pretende ser una muestra de las posibilidades de las técnicas narrativas para enseñar y aprender más rápido y mejor, para aprovechar los recursos que la sociedad digital pone a disposición del conocimiento para que la enseñanza y la ciencia converjan con el entretenimiento y con la industria audiovisual.

223 - Comciencia: contenidos audiovisuales y multimedia para la comunicación científica - Juan Romero-Luis (Universidad Rey Juan Carlos) - juan.romero@urjc.es, Claudia MartínCarnerero (Universidad Rey Juan Carlos) claudia.martin@urjc.es y María Bastida (Universidad Rey Juan Carlos)-maria.bastida@urjc.es

Los productos audiovisuales, multimedia e interactivos tienen un potencial extraordinario para la transmisión del conocimiento 
científico. Solo seremos capaces de llegar al público objetivo si conseguimos construir los relatos de forma adecuada. Cada vez más, en el ámbito educativo, científico y periodístico, vemos cómo se incluyen nuevos formatos audiovisuales que incluyen características como la multimedialidad o la interactividad, para aumentar el tiempo de visualización $y$, por tanto, incrementar la conversión y las posibilidades de transferencia del conocimiento. El grupo de investigación Ciberimaginario trabaja en la innovación de formatos que favorezcan la transferencia del conocimiento a través de productos que puedan ser utilizados en el ámbito generalista, pero también en el ámbito educativo. A través de diferentes canales (redes sociales, YouTube, web social...) se difunden y ponen a disposición los productos al público objetivo.

Este trabajo reflexiona sobre diferentes formatos utilizados para la transferencia del conocimiento científico en sus múltiples formas: "Voces para una comunicación científica eficiente" y "Reflexiones para una comunicación científica eficiente" (vinculada al proyecto 'Escuelas Comciencia'), dos formatos audiovisuales que presentan entrevistas a destacados científicos, profesores y cargos institucionales que comentan aspectos relevantes sobre la comunicación científica; el Motion Graphics como medio para la transferencia de información o conceptos complejos a través de gráficos y animaciones en dos dimensiones; el videoartículo científico (IMV paper) que presenta, a través de un vídeo multimedia interactivo, los resultados iniciales del proyecto 'Escuelas Comciencia'; el blog y sus diferentes formatos y posibilidades para la comunicación científica.

Además, se tratan las principales técnicas de guion, grabación y edición empleadas en la producción de los vídeos, subrayando la importancia de innovar en la creación de formatos audiovisuales para la difusión y la diseminación científicas.

224 - La utilización de modelos gráficos visuales como herramientas de investigación-acción participativa para la formulación de propuestas en Políticas de Diseño - Bernardo Antonio, Candela Sanjuán - Universidad de La Laguna - 
Comunicación y Música: mensajes, manifestaciones y negocios

bcandels@ull.edu.es y Carlos, Jiménez-Martínez - Universidad de La Laguna - carjimen@ull.edu.es

La representación gráfica y la interpretación visual facilitan la comprensión, memorización y comunicación de conceptos complejos y pensamiento abstracto. Permiten así, avanzar también en el desarrollo en torno a dichas ideas. El concepto Sistema Diseño (SD) es un modelo teórico, instrumental y operativo, que facilita la identificación y mapeo de un conjunto de actores y sus interrelaciones alrededor del sector del Diseño que tienen lugar en un territorio, permitiendo diagnosticar su estado de desarrollo para la formulación de políticas públicas de diseño. La complejidad del concepto ha hecho que muchos autores hagan uso de imágenes, representaciones gráficas, o dibujos, para explicar, dar a conocer, o aumentar la comprensión y difusión de sus propuestas de modelo de Sistema Diseño. Esta comunicación pretende, por un lado, exponer los modelos gráficos utilizados para comunicar la complejidad del concepto Sistema Diseño. Por otro, presentar la metodología de investigación utilizada para el desarrollo de talleres de co-creación de propuestas para políticas públicas de diseño con los agentes sociales implicados, en el que destaca el potencial de aplicación de herramientas visuales utilizadas, adaptadas y creadas ad hoc.

225 - La comunicación estratégica para la promoción de la responsabilidad social de las empresas y su repercusión en la marca: caso Ecuacorriente S. A. - Cristina Estefanía Marca Cueva- cris.95tfa@gmail.com, Luis Javier Ontaneda Vivancoluis.j.ontaneda@unl.edu.ec, Mónica Maldonado monica.maldonado@unl.edu.esc y Mónica Hinojosa Becerra Universidad Nacional de Loja (UNL) monica.hinojosa@unl.edu.esc

Las empresas tienen que estar involucradas no solo en su desarrollo como $\mathrm{I}+\mathrm{d}+\mathrm{i}$ sino también en la responsabilidad social con la comunidad en la que se desenvuelven, a través de estrategias de comunicación, que les permitan una mayor clientela, aceptación de stakeholders y mejorar su imagen empresarial. En Ecuador, la responsabilidad social empieza a formar parte de la gestión y estrategias comunicacionales de las empresas. En concreto, la compañía 
internacional Ecuacorriente S.A., ubicado en la parroquia Tundayme, provincia de Zamora Chinchipe, es una de las multinacionales pioneras en desarrollar un proyecto minero a gran escala, dónde, ya en sus inicios, se vislumbra las primeras dificultades con los habitantes del sector, tales como: manifestaciones públicas en contra de la explotación minera, agresiones físicas de los habitantes a los trabajadores y viceversa; desacuerdos entre los pobladores por los desalojos y controversias en defensa del medio ambiente por la contaminación que conlleva la explotación minera. El objetivo de esta investigación es estudiar las estrategias de comunicación que Ecuacorriente S.A ha utilizado para la promoción de su responsabilidad social y repercusión del posicionamiento de su marca de empresa. Para ello, nos pusimos en contacto con los responsables de comunicación y responsabilidad social de la compañía para introducirnos en la multinacional, y mediante la observación participante y otras técnicas de investigación, indagar sobre cómo manejaron sus estrategias de comunicación para promocionar la responsabilidad social de la compañía, y cómo ésta influyó o no, en los habitantes del sector. Entre las conclusiones de este estudio se evidencia que la empresa internacional Ecuacorriente S. A. no ha trabajado con estrategias de comunicación claras para promocionar la responsabilidad social, y se aprecia además que ha existido tergiversación de imágenes e información para influir en los habitantes de la comunidad de forma positiva en beneficio de la multinacional.

226 - El Muro de la Expresión, La Voz del Bolívar - Paula Sandra Bernal Carrera - Universidad Corporación Universitaria Minuto de Dios - paula. bernal@ uniminuto.edu

Bolívar 83 es un barrio ubicado en Zipaquirá, Cundinamarca (Colombia), fundado en la década de 1980 por militantes del movimiento guerrillero M19. Este barrio fue construido por sus pobladores, cuentan sus habitantes que de manera organizada ellos construyeron sus casas, sus calles, etc. Fueron largas jornadas comunitarias en donde tanto mujeres como hombres, hombro a hombro, construyeron y le dieron vida a este emblemático barrio. A pesar de que es considerado como una zona de alto riesgo, sus habitantes siguen luchando día a día por sacarlo adelante y que no sean 
Comunicación y Música: mensajes, manifestaciones y negocios

estigmatizados. Este barrio inicialmente se conformó con desplazados por la violencia provenientes de diversas regiones del país. El Bolívar 83 siempre ha sido considerado como uno de los barrios más peligrosos de Zipaquirá en donde una de las principales problemáticas es la drogadicción, allí viven cultivadores de flores, albañiles y personas muy humildes que luchan día a día por tener una mejor vida. El voluntariado de la Corporación Universitaria Minuto de Dios del Centro Regional Zipaquirá viene trabajando el proyecto El Muro de la Expresión en alianza con la Parroquia Jesús Obrero de esa localidad. Este proyecto busca realizar una transformación social de la comunidad a través del arte, en este caso la pintura y la música. El género musical que más gusta allí es el hip hop, pues a partir de la creación de canciones ellos representan sus sueños y anhelos y uno de estos es la paz y el poder salir de la droga, flagelo al cual ellos se sienten atados. El Muro de la Expresión es un mural que la comunidad está pintando, en donde reflejan sus sueños e ideales y esperan convertir en un reflejo positivo de lo que ellos son y lo que quieren ser.

227 - El ciclo de violencia en tiempos de paz -Sistema de información visual sobre la resiliencia en Bogotá - Valeria Paola Castro Brissolese - valeriap.castrob@utadeo.edu.co, María Paula Riveros Paredes-mariap.riverosp@utadeo.edu.co y Sandra Paola Vargas Jiménez - sandrap.vargasj@utadeo.edu.co Universidad de Bogotá Jorge Tadeo Lozano.

La discriminación y la desinformación son los principales enemigos de la reintegración y la resiliencia de víctimas y victimarios del conflicto armado en Colombia, situación que complica el proceso de paz y promueve nuevos ciclos de violencia. A pesar de que atender esta problemática es apremiante, el desarrollo de estrategias es ineficiente y la disponibilidad de medios de difusión casi inexistente, lo que hace que la búsqueda de alternativas a través del diseño de información sea una necesidad y una oportunidad, al posibilitar herramientas de comunicación y de transformación social. Así, esta investigación se propone acercar a los sectores empresarial, universitario y padres de familia de Bogotá, a la necesidad de integración de los vinculados al conflicto, a través de una estrategia de comunicación visual. Esta investigación aplicada se estableció inicialmente como estudio 
exploratorio de método mixto, cuyo levantamiento de datos e indagación se realizó, en primer lugar, a través de observación participante, entrevistas semiestructuradas y matrices de análisis aplicadas a las actividades de la población objeto de estudio, desmovilizados y afectados por el conflicto vinculados al grupo VICTUS del Centro de Memoria Histórica. Asimismo, a través de una serie de encuestas y entrevistas al grupo de destino de las piezas de comunicación. Los resultados permiten inferir que el desconocimiento es la principal causa de esta problemática y para hacerle frente el propósito fundamental es llevar información objetiva e imparcial a los civiles no afectados, con la idea de que los datos visualizados provoquen la emergencia de un vínculo empático hacia aquellos en proceso de resiliencia. Esta infografía piloto, luego de tres focus groups, evidenció una comprensión más profunda de la situación, la historia y el rol de todos los actores involucrados, generando una actitud diferente frente a esta nueva configuración del tejido social colombiano.

228 - Narrativa de la posmemoria, como desafío que enfrenta el "testigo del testimonio" en el posconflicto - Nyrama Osorio Triana - UNIMINUTO-nosoriotria@uniminuto.edu.co

Esta ponencia es una aproximación al desafío que supone la posmemoria de quiénes en el texto denomino "testigos del testimonio". Se hace imperativo en el escenario del posconflicto colombiano apostarle a la paz, la dificultad se plantea cuándo las generaciones encargadas de construir escenarios venideros hacia la reconciliación, son poseedores de una memoria de la que no fueron testigos, pero que adquieren a través de la mediación de actores encargados de plasmar los relatos de las víctimas a través de narrativas en formatos audiovisuales. El conflicto armado atravesado por Colombia representa un pasado de horror y barbarie, la memoria es y será el mecanismo fehaciente que pugne por devolverle a las víctimas la verdad y a la sociedad su dignidad, es la oportunidad de quiénes vivieron la guerra de alzar su voz a través de testimonios únicos e irrepetibles, pero este panorama plantea un desafío que no podemos ni debemos obviar, y es el futuro de esa memoria, quiénes son y serán esas generaciones portadoras de esa memoria, los otros, que aunque no 
Comunicación y Música: mensajes, manifestaciones y negocios

vivieron el recuerdo sí fueron testigos de ese testimonio, llevándolo y apropiándolo a su propio pasado. Esa memoria mediada, es lo que algunos han denominado posmemoria, pero cuál es el impacto de esta en un escenario de posconflicto como el que atraviesa Colombia, el duelo de una víctima es el mismo del testigo del testimonio, debemos acaso aprender a recordar para no caer en una ideología de odio. Esta apuesta busca reflexionar en torno a cómo se consolidan las formas de ver y representar desde el lugar del testigo del testimonio a través de la obra: "El Testigo: Memorias del conflicto armado colombiano en el lente y la voz de Jesús Abad Colorado".

229 - Mujeres en Avanzada: una cartografía audiovisual de la Red de Mujeres en Avanzada hacia el Poder y la Paz de Ciudad Bolívar - Alejandra Meneses Reyes - alesmi@gmail.com y Juan Pablo Gómez Peña Institución - gomezp.juanp@gmail.com Fundación Artesa y Rutas del Conflicto

Mujeres en Avanzada es un proyecto multimedia de la Fundación Artesa y Rutas del Conflicto que permite conocer la historia de esta Red de Ciudad Bolívar, su configuración en relación con el territorio y sus acciones frente a la violencia contra la mujer. Aún cuando cada una de las 13 organizaciones que componen la Red es diferente y trabaja independientemente, todas se articulan para aprender en la diversidad, compartir en confianza, crecer en experiencia y trabajar por un bien común. La Paz, última palabra del nombre de la Red, hace parte de ese propósito colectivo: construir paz desde y para las comunidades, quienes conviven en territorios tanto marcados por la violencia como transformados a diario por la resistencia de sus lideresas.

El proyecto brinda la oportunidad de comprender el valor de las redes en la construcción de escenarios pacíficos. No se trata de salir del territorio para hallar iniciativas que mitiguen la violencia, sino de "encontrar recursos basados en las relaciones, conectores y espacios sociales dentro del escenario que [tengan] la capacidad de generar procesos de cambio" (Lederach, 2016, p. 162). Tras una reflexión conjunta con las mujeres sobre cómo representar las violencias a las que han estado expuestas y sus formas de resistencia, el cuerpo, el espacio y el tiempo se consideraron como poderosos vehículos para 
narrar. Este artículo analiza los ejercicios cartográficos realizados en el proyecto, que, alimentados de narrativas audiovisuales desde la voz, el rostro y el territorio de las mujeres de Ciudad Bolívar, pueden ser pensados como ventanas para mirar lo que el ojo, a simple vista, no puede. Cartografías colectivas que esperan ser inspiración para resignificar, puerta para el sentimiento e invitación para la acción.

230 - Estereótipos de género e eficácia publicitária em anúncios de revistas urbanas portuguesas - Marlene Loureiro Universidade de Trás-os-Montes e Alto Douro (UTAD), Portugal-mloureiro@utad.pt, Álvaro Cairrão - Instituto Politécnico de Viana do Castelo (IPVC), Portugalacairrao@esce.ipvc.pt y Ariana Meireles- Universidade de Trásos-Montes e Alto Douro (UTAD), Portugal arianadiasmeireles@gmail.com

Os estereótipos de género estão presentes na sociedade em todos os lugares do mundo, mais ou menos demarcados, fazendo também parte da publicidade que vemos todos os dias. Os variados papéis desempenhados pelos dois géneros nos anúncios publicitários são um reflexo da sociedade, realçando as suas principais características, valores e crenças. A nossa questão de investigação é se a utilização de diferentes estereótipos de género influencia a eficácia publicitária de anúncios de revista? Partindo desta questão de investigação, procuramos alcançar os seguintes objetivos: (1) determinar a influência dos diferentes estereótipos de género na eficácia publicitária em anúncios de revista; (2) verificar se os diferentes estereótipos de género em anúncios de revista motivam a compra do produto anunciado em função do género; (3) analisar se os diferentes estereótipos de género em anúncios de revista são manipuladores de opinião. Assim, realizámos um estudo exploratório, dividido em dois momentos. Num primeiro momento, fez-se análise de conteúdo qualitativa de anúncios presentes em revistas urbanas femininas e masculinas portuguesas. Num segundo momento, foi aplicado um inquérito no sentido de analisar a opinião pública sobre a eficácia dos estereótipos de género na publicidade de revistas. A realização deste inquérito partiu das três dimensões do sexo na publicidade (Pereira e Veríssimo, 2008): a perniciosa, em que as pessoas podem sentir que o sexo na publicidade 
Comunicación y Música: mensajes, manifestaciones y negocios

é moralmente pernicioso para quem visualiza a publicidade; Censurável, uma medida geral de reação em que as pessoas consideram que o sexo na publicidade deve ser objeto de censura; manipulador, uma medida onde as pessoas consideram que o sexo na publicidade pode manipular as atitudes das pessoas que a visualizam. Este estudo exploratório aponta que a eficácia da representação da mulher e do homem seguindo papéis estereotipados ainda tem elevada presença em anúncios publicitários. De igual forma, os resultados do nosso inquérito revelam pouca consciencialização das consequências deste tipo de anúncios para a perpetuação dos estereótipos de género.

231 - Nuevas fórmulas para la comunicación institucional: la modularidad como método de elaboración y difusión de la información sanitaria - Aingeru Genaut Arratibel aingeru.genaut@ehu.eus, Sara Loiti Rodríguez sloiti001@ikasle.ehu.eus y María José Cantalapiedra mariajose.cantalapiedra@ehu.eus - Universidad del País Vasco / Euskal Herriko Unibertsitatea.

Un ordenador es en esencia una máquina de cálculo numérico: compila, computa, almacena y organiza el contenido mediante bases de datos. Es precisamente esta forma de trabajo la que posibilita el desarrollo de las tres características más destacadas de la comunicación a través de las nuevas tecnologías: el hipertexto, la interactividad y la multimedialidad. Las bases de datos pasan en muchos casos desapercibidas para el usuario, pero se encuentran presentes en prácticamente todo el proceso de la comunicación asistida por ordenador; desde la recopilación de datos hasta la difusión del contenido, pasando por la edición, la redacción y el diseño. Sin embargo, la forma en la que el ser humano acostumbra a comunicarse tiende a ser, en última instancia, lineal, y aunque el ordenador nos ha permitido crear nuevos flujos y formas de comunicación, la inercia cultural y las rutinas profesionales generan notables puntos de fricción entre la narración tradicional -ordenada y lineal-y la lógica de las bases de datos -desordenada y no lineal-.

El presente artículo pretende demostrar que, basándose en las aportaciones teóricas acerca de la teoría de la comunicación, es posible 
trasladar la modularidad connatural de las nuevas tecnologías a todas las fases de la creación de un servicio de comunicación, si se cumplen ciertas condiciones. Para ello se ha llevado a cabo un experimento empírico para hallar la forma de elaborar múltiples piezas informativas -animaciones por ordenador- mediante la combinación de secuencias animadas más pequeñas, capaz de ser integrado en las rutinas profesionales de un servicio de comunicación institucional concretamente, en el Servicio de Salud de Salud Vasco-Osakidetza-, e identificar los recursos, las formas, los problemas y las ventajas de esta rutina de trabajo.

232 - El phubbing y su incidencia en la comunicación interpersonal - María Elizabeth Granda Sánchez, Ana Magali Culqui, Ericka Hidalgo-megranda@pucesi.edu.ec, amculqui1@pucesi.edu.ec, ericalis_13@hotmail.com - Grupo de Investigación Medios, Tecnologías Aplicadas y Comunicación (METACOM), Pontificia Universidad Católica del Ecuador Sede Ibarra, Ecuador, 100112, Imbabura, Ecuador, Grupo de Investigación Medios, Tecnologías Aplicadas y Comunicación (METACOM), Pontificia Universidad Católica del Ecuador Sede Ibarra, Ecuador, 100112, Imbabura, Ecuador, Gobierno Autónomo Descentralizado Municipal San Miguel de Ibarra, Ecuador, 100150, Imbabura, Ecuador.

La investigación tiene por finalidad presentar un análisis referencial sobre la incidencia del phubbing, permitiendo identificar las causas y efectos del apego desmedido de las personas hacia los móviles, pues, este mal hábito desarrollado por las nuevas generaciones se ha convertido en una problemática social que no distingue situación económica, género ni edad y ha trascendido de manera negativa y significativa en el desarrollo de las habilidades sociales, limitando cada vez más la interacción persona a persona. Estos datos obtenidos durante la etapa de recolección de la información, a través de la entrevista y la encuesta, permitieron establecer las consecuencias de este mal que está afectando al mundo, convirtiéndose en un agente distractor, generador de ansiedad, sedentarismo y sobre todo que afecta notablemente el auto concepto, al facilitar en los jóvenes la construcción de una realidad ajena, con la finalidad de ser aceptados 
Comunicación y Música: mensajes, manifestaciones y negocios

por otros, evidenciando así, cómo este fenómeno mediático está perjudicando a la sociedad.

233 - Estrategias de comunicación para colectivizar nuevos imaginarios sobre el cuidado a la Madre Tierra: el caso del asentamiento sustentable Proyecto Gaia - María Victoria de la Morena García- Corporación Universitaria Minuto de Diosviquimo@yahoo.es

La presente ponencia tiene como finalidad principal reflexionar sobre las estrategias de comunicación puestas en juego en la villa ecológica Proyecto Gaia, un asentamiento sustentable del departamento de Boyacá, Colombia, para contribuir a la transformación de los imaginarios sociales que desde el sistema capitalista neoliberal se han construido e impuesto en torno a la visión de calidad de vida y a la comprensión del desarrollo. Este cambio de paradigma e imaginarios sobre nuestra manera de ser, estar y hacer en el mundo como colectividad es cada vez más urgente para poder abordar la crisis civilizatoria actual, cuya base se sostiene sobre la manera como hemos concebido la relación entre el ser humano y la Naturaleza, y por tanto, cómo se integra lo ambiental en las conceptualizaciones de desarrollo. Se compartirán algunos de los resultados finales más relevantes de la investigación producto de la tesis de la Maestría en Comunicación, Desarrollo y Cambio Social de la Universidad Minuto de Dios, que fue finalizada en septiembre de 2017. A este respecto Proyecto Gaia contribuye tanto a la construcción de sentidos colectivos alrededor del cuidado a la Madre Tierra como a la movilización ciudadana para transitar de la ciudad al campo, a través de estrategias de comunicación como la educomunicación, la movilización social y el mercadeo social y el uso de una diversidad de acciones y herramientas de comunicación que han sido teorizadas por reconocidos comunicólogos latinoamericanos. Para la consecución de dichos resultados se realizó un estudio de caso de Proyecto Gaia, siendo las técnicas de investigación utilizadas 10 entrevistas en profundidad a diversos actores vinculados con la villa, un diario de campo resultado de los 35 días de estancia en la misma, dos talleres grupales con sus habitantes relativos a la memoria colectiva y el mapa de los grupos de interés de 
la villa y recolección documental variada (documentos, web, redes sociales, fotografías, etc.).

234 - Propuesta para el análisis de la comunicación online del sector de la moda española desde el punto de vista de la triangulación metodológica - F. J. Cristòfol - ESIC, Business \& Marketing School - fjcristofol@esic.edu, Jesús Segarra-Saavedra - Universidad de Alicante - jesus.segarra@ua.es y Carmen Cristófol-Rodríguez - Universidad de Málaga - carcrir@uma.es

La comunicación online en el sector de la moda es un elemento básico en la gestión de la comunicación corporativa. Por ello, el propósito de la presente comunicación es realizar una propuesta metodológica para el estudio de la comunicación online en las páginas corporativas verificadas en Facebook de las marcas de moda españolas Zara y Mango. Dicha propuesta se basa en un triple trabajo metodológico mediante el análisis de caso y de contenido, las entrevistas en profundidad a profesionales de la moda relacionados con las marcas anteriormente citadas y el método Delphi circulado entre profesionales de la comunicación de moda y académicos.

235 - Periodismo narrativo vs. Periodismo literario. Comparación entre el nuevo nuevo periodismo iberoamericano y norteamericano en la era digital. - Alba Sabaté Gauxachs, albasg@blanquerna.url.edu, Josep Lluís Micó Sanz joseplluisms@blanquerna.url.edu, Míriam Díez Bosch miriamdb@blanquerna.url.edu- Universitat Ramon Llull

Contar la realidad con las herramientas de la literatura (Palau y Cuartero; 2018; Herrscher, 2012; Schudson, 2003). Este es el objetivo del periodismo narrativo o periodismo literario (Marsh, 2010), un género que antepone la profundidad, el reporteo y la calidad literaria a la inmediatez, brevedad y sencillez que requiere el mundo digital (Albalad, 2018). Rompiendo las normas del periodismo digital, ¿cómo se presenta y desarrolla el periodismo narrativo en la red? ¿cuáles son sus principales retos? ¿cómo adaptan los periodistas sus rutinas a este periodismo slow en un entorno fast? Estas son las preguntas que la presente investigación pretende responder. El objetivo es desvelar 
Comunicación y Música: mensajes, manifestaciones y negocios

cuáles son los desafíos a los que se enfrenta el periodismo narrativo y los periodistas narrativos en el entorno digital y descubrir qué diferencias y semejanzas existen entre los medios y profesionales que lo ejercen en Iberoamérica (Angulo; 2013; Herrscher, 2012) y los que lo practican en Estados Unidos (Boynton, 2012). La metodología utilizada es la entrevista en profundidad (Voutsina, 2018; Johnson, 2002), realizada a 35 periodistas narrativos y expertos, y el análisis de contenido (Van Dijk, 2013), llevado a cabo en 45 artículos de las tres revistas que integran la muestra seleccionada: Jot Down, Gatopardo y The New Yorker. El estudio se desarrolla sobre tres campos teóricos: periodismo narrativo, con autores como Wolfe (1973), Sims (1996) o Herrscher (2012) y periodismo digital, con firmas como Domingo y Heinonen (2008) o Rost (2006).

236 - Diversidad sexual en la educación primaria y secundaria en México. Resistencias y heterosexismo en el Frente Nacional por la Familia - Luis Alfonso Guadarrama Rico- Universidad Autónoma del Estado de México- lagrico@famecom.org-

Mediante el hashtag \#DefendemosLaFamilia, la Asociación Civil «Frente Nacional por la Familia», surgida en el año 2016 a raíz de la iniciativa sobre Matrimonio Igualitario, enviada por el presidente Enrique Peña Nieto al Poder Legislativo, ejerció presión para que -apoyada por otras organizaciones y grupos conservadores-- dicha propuesta no avanzara; asunto que, en efecto, no prosperó pues tal iniciativa presidencial fue declarada improcedente en noviembre de ese mismo año. Al poco tiempo, la misma Asociación Civil dirigió sus esfuerzos para expresar su oposición al contenido de varios libros de texto, dirigidos a los niveles de preescolar, primaria y secundaria, por considerarlos inapropiados, cargados de la «ideología de género», promotores de la homosexualidad y, desde una óptica heteronormativa, desvinculaban el sexo biológico del género hombre o mujer. En la ponencia se analiza la estrategia argumentativa operada por el Frente Nacional por la Familia, misma que fue difundida en una de sus secciones:

http://frentenacional.mx/wpcontent/uploads/2016/11/Análisis-libros-de-texto.pdf de su sitio oficial: http:/ / frentenacional.mx, con el propósito de sumar adeptos digitales a su esquema ideológico-interpretativo, basado en una óptica 
heterosexista. En el trabajo, interesó dar cuenta tanto de la estrategia, es decir, qué mensajes de los libros de textos de educación básica fueron seleccionados, para qué tratamiento «argumentativo» y, cómo trataron de vincular su visión heteronormativa con las posibles preocupaciones de otros padres o madres de familia de ópticas similares.

237 - Estudio comparativo del tratamiento de la medicina de precisión por parte la prensa de medicina de Colombia, España y Estados Unidos - Carlos A. Gutierrez MD, MPH, Candidato PhD Incom UAB; Jose Luis Terron, PhD Incom UAB

Antecedentes: Estudios anteriores (Marcon,2018; Schafer, 2011; Myers, 2016; Weishaar, 2016; Ashfin, 2015) han demostrado la importancia de los medios masivos en la comunicación de temas relacionados con la salud, incluyendo la educación general de la población, la aceptación o rechazo de nuevas tecnologías, y una influencia importante en las decisiones de salud pública y cobertura de salud de cada Sociedad. Durante la última década la medicina ha dado pasos adelantados en el entendimiento del genoma humano y la asociación de anomalías de este con múltiples enfermedades. Nuevos retos y fronteras en la definición del concepto de la salud y la enfermedad han sido abiertos, incluyendo nuevas posibilidades de prevención, diagnostico temprano y tratamientos personalizados con potencial de manejo o curación de enfermedades consideradas de alta mortalidad hasta hace poco. Nuestra hipótesis es que los medios de comunicación en - Colombia, España y Los Estados Unidos - han venido cubriendo los avances relacionados con medicina de precisión destacando sus beneficios y considerando los retos relacionados con los altos costos de las nuevas terapias, pero que existen importantes diferencias entre la información comunicada en los 3 países. Metodología: Mediante un análisis de contenidos revisamos los artículos publicados entre enero de 2005 y junio de 2018 en 3 de los principales medios de los países estudiados, por lo que se consideran las plataformas digitales de El Tiempo (Colombia), El País (España) y The New York Times (Estados Unidos). Las piezas informativas fueron analizadas de acuerdo al género narrativo, perspectivas planteadas, tecnologías destacadas, referencia a instituciones de 
Comunicación y Música: mensajes, manifestaciones y negocios

investigación, líderes de opinión, y fuentes de información primaria. Esta comunicación forma parte de una investigación más amplia en la que también se incluye metodologías y técnicas cualitativas para profundizar en los enfoques informativos que aparecen en las piezas analizadas y sus razones de ser. Resultados: Encontramos que los tres diarios incluidos han venido comunicando sobre temas relacionados de medicina de precisión o personalizada durante los años a estudio. El País $(n=1,432)$ refleja el mayor número de publicaciones, seguido por The New York Times $(n=398)$ y El Tiempo ( $n=227)$. Los tres medios destacan los beneficios ofrecidos por las nuevas terapias (El País 95\%, New York Times 82\%, El Tiempo 90\%) mientras expresan preocupación por los retos de economía en salud que la adopción de las nuevas tecnologías implican y en particular manifiestan la necesidad de equidad y no discriminación en el acceso de la población a los avances de la ciencia. El cáncer representa el conjunto de enfermedades mayormente destacadas en los 3 medios, seguido de las enfermedades raras y las condiciones neurológicas de tipo degenerativo. El New York Times refleja un mayor número de géneros narrativos utilizados, incluyendo columnas de opinión, reportajes de casos de pacientes, entrevista a expertos en salud y economía, y columnas de debate de consideraciones a favor y en contra de los avances de la ciencia. Igualmente, sus publicaciones reflejan un amplio número de instituciones y expertos consultados o coautores de las opiniones expresadas y son mencionadas un gran número de instituciones de investigación de toda la nación. El País refleja un uso principalmente de reportajes y entrevistas, y un segundo nivel de expertos consultados, destacándose fuentes e instituciones ubicadas en Madrid, Barcelona y Valencia. El Tiempo refleja un menor número de artículos, predominando artículos breves que proceden de agencias informativas internacionales.

238 - Innovar en el periodismo como antídoto ante las fake news - Luis-Mario Valarezo-Cambizaca, Claudia RodríguezHidalgo

En los últimos años las fake news han acaparado la atención de millones de personas en todo mundo, llegando incluso a ocupar un mayor espacio que las noticias que se publican como resultado de las 
rutinas productivas de medios de comunicación y periodistas, generando con ello efectos perniciosos en la sociedad. En este contexto, la investigación pretende determinar por un lado el impacto de las fake news en las personas, y por otro las oportunidades del periodismo para hacer frente a este fenómeno, utilizando como primer recurso la innovación. El estudio es de carácter descriptivo y se realiza en torno a 14 sitios identificados por Fundamedios como difusores de fake news en Ecuador, en el periodo comprendido entre agosto y octubre de 2018. Se aplicó una metodología mixta en la que se combinó un análisis de contenido y entrevistas a expertos, así como el análisis cuantitativo de los 14 sitios. Entre los resultados más relevantes se evidenció que los sitios que difunden las fake news en Ecuador se identifican como páginas de parodia, sátira, broma o política, más no como medios de comunicación. A pesar de ello sus publicaciones ganan visibilidad y credibilidad entre los usuarios quienes carecen de las competencias que les permitan diferenciarlos. Si bien las fake news constituyen un peligro para el periodismo, éste tiene la oportunidad de recuperar la atención del público, que se ha volcado a las redes sociales en búsqueda de información gratuita, a través de la innovación de sus rutinas productivas y de la generación de contenidos que se identifiquen con los usuarios, lo que a la larga derivará en modelos de negocio de gran relevancia y en la mejora del tratamiento informativo.

239 - Incremento de la visibilidad e impacto positivo de las firmas de moda en la comunicación de su sostenibilidad - Dra. Dña. María Luisa Notario Rocha, Centro Universitario San Isidoro,lnotario@centosanisidoro.es

La comunicación de una transparente gestión de la sostenibilidad se ha convertido en una de las oportunidades de mercado para las firmas de moda. En 2017, el 33\% de los consumidores optó por comprar marcas que consideró que hacían un bien social o medioambiental (Accenture, 2017) y el $22 \%$ afirmó que escogía sólo aquellas que acreditaban con certificaciones sostenibles el abastecimiento, los materiales y las prácticas laborales. Esta tendencia del consumidor del siglo XXI refleja el especial interés de las empresas de moda a la difusión de sus prácticas sostenibles. Hipótesis: demostrar el incremento de la visibilidad e impacto positivo en su comunicación por parte de las firmas de moda 
Comunicación y Música: mensajes, manifestaciones y negocios

sostenible españolas. Objetivos: - Definir el concepto de desarrollo sostenible, en base a una serie de índices (igualdad social, estabilidad medioambiental, viabilidad económica) a partir de una serie de indicadores de medición de los índices. -Analizar la comunicación acerca de gestión de la sostenibilidad y su nivel de desarrollo realizada por 24 pymes de moda española consideradas sostenibles y las firmas Inditex y Mango. - Identificar la adopción de un enfoque holístico sobre la sostenibilidad en las firmas de moda analizadas. Metodología: Esta investigación de carácter explicativo pretende descubrir las causas que explican el impacto positivo de la difusión de la sostenibilidad promovida por las firmas de moda. Para ello se hace necesario establecer si existe una relación entre las dos variables y cual es la fuerza de esa relación. Se aplicarán diferentes modelos de explicación introduciendo variables independientes cambiantes que influyan sobre la dependiente y la independiente (o explicativa) que interesa. Resultados: Definir los indicadores que influyen positivamente en la comunicación de las marcas de moda sostenible.

240 - TJTool del diario Público.es, una oportunidad para mejorar la docencia de las asignaturas de redacción de Periodismo - María José Cantalapiedra González mariajose.cantalapiedra@ehu.eus, Iker Merchán Mota iker.merchan@ehu.eus, María Ruiz - maria.ruiz@ehu.eus, Maialen Goirizelaia - maialen.goirizelaia.ehu.eus, Asier Rufo asier.rufo@ehu.eus y Tania Arriaga - tania.arriaga@ehu.eus Universidad del País Vasco

El diario Público ha puesto en marcha una herramienta que mide y muestra la trazabilidad de las informaciones: Transparent Journalism Tool (TJTool). Este sistema otorga una nota del 0 al 100 a cada artículo informativo en función de su grado de cumplimiento de 8 variables sobre su trazabilidad (que no su calidad). Dentro de estas variables está el número y tipo de fuentes utilizadas, la fecha de publicación, dónde está firmada la información o quién es su autor o autora. Así, de la misma forma en que en la industria alimentaria se puede investigar una toxiinfección para encontrar el origen de la misma, una lectora o lector puede diseccionar cómo se ha elaborado una información para hallar dónde se ha producido la desinformación. Este proyecto se ha 
desarrollado gracias al apoyo de Google a través de su iniciativa Digital News Innovation Fund y ofrece una oportunidad a la docencia del Periodismo para estandarizar los criterios exigibles al alumnado a la hora de elaborar sus prácticas. Las responsables de TJTool -Luisa Cabello, 'product manager' de la aplicación y Virginia Pérez Alonso, codirectora de Público- solicitaron al grupo consolidado de investigación Bitartez ayuda para dar a conocer la iniciativa entre la comunidad académica y profesional del País Vasco. El trabajo en común iniciado abre una puerta al estudio de las rutinas periodísticas que analiza el proyecto SCA financiado por el Ministerio de Ciencia e Innovación. La colaboración desde la universidad puede abrir esta herramienta a otros idiomas además del español como el inglés o el euskera y aportar casuísticas que sean útiles para su desarrollo antes de su implantación en otros medios de comunicación. El objetivo es que trascienda de su lugar de nacimiento -el diario Público- y se convierta en un estándar internacional con el que la ciudadanía pueda contar para combatir la desinformación.

241 - La mujer en las tiras cómicas de Zakilixut (1977). Análisis discursivo de la figura de la mujer y del feminismo en las tiras cómicas de Antton Olariaga - Aitor Castañeda - Universidad del País Vasco / Euskal Herriko Unibertsitatea (EHU) aitor.castaneda@ehu.eus

Cuando el dibujante vasco Antton Olariaga creó al personaje Zakilixut para el periódico local Egin en 1977, su humor obsceno resultó rompedor en el feminismo que empezaba a reivindicarse en las calles del España y particularmente del País Vasco. Se analizan aquí las tiras cómicas de dicho personaje durante el 77 , referente humorístico de la prensa de la región desde entonces hasta nuestros días, a través del análisis del discurso, siendo objeto de estudio la figura significativa de la mujer que él recrea. Se concluye de manera general que Zakilixut parte de la feminización discursiva de su tierra, donde desde un planteamiento emergente y rompedor de mitos, infiere una tierra vasca que al igual que la mujer, lucha por sus derechos, otorgándole así a esa tierra un género femenino y posicionándose el autor a favor tanto de los nuevos planteamientos feministas como de la liberación y autonomía del pueblo vasco. 
Comunicación y Música: mensajes, manifestaciones y negocios

242 - Concepto y ejercicio de ciudadanía en la Educación Secundaria y mexicana - Josué Castro Puga, Gabriel Gil Talavero y Gloria Gil Talavero - Universidad de Salamanca

El paradigma de clásico de la ciudadanía moderna plantea a ésta como un estatus jurídico de pertenencia a una comunidad política, a un Estado. Es un estatus que se da a los nacionales que cumplan con ciertas características (y que cumplan con ciertas obligaciones), y les otorga una serie de derechos. Desde un punto de vista de un análisis sociológico es conceptualizada por Marshall (1950). Sin embargo, más allá de este paradigma de la ciudadanía como estatus de pertenencia a una comunidad nacional-política, la idea de ciudadanía posee también dimensiones meta-jurídicas, que la plantean como un hacer, que la vinculan con una serie de comportamientos de los individuos en todos los ámbitos de la vida social dentro del contexto de una sociedad democrática. A partir de la idea de que el aprendizaje de la vida democrática es un proceso educativo que implica el aprendizaje del civismo, el respeto por las normas públicas y el cómo convertirse en un ciudadano activo (Puig et. al., 2011), es fundamental conocer cuáles son las ideas de los jóvenes en torno a qué es la ciudadanía y sobretodo, acerca de qué implica ser un ciudadano o una ciudadana. Es a partir del conocimiento real de las ideas de los jóvenes al respecto, que se podrán delinear estrategias para una educación en la ciudadanía democrática que busque potenciar una manera activa y comprometida de ejercerla, en oposición a una pasiva, que espere que sean las autoridades las que resuelvan los problemas sociales. En el presente trabajo presenta los resultados de un ejercicio de investigación de corte descriptivo exploratorio con respecto a la materia señalada con una población de alumnos de una escuela secundaria privada en el estado de Querétaro, en México.

243 - Las Redes Sociales, la Enseñanza y la Construcción de Identidades en el alumnado - David Caldevilla DomínguezUniversidad Complutense de Madrid (UCM)davidcaldevilla@ccinf.ucm.es y Almudena Barrientos Báez (Centro Iriarte-Universidad de La Laguna) almudenabarrientos@iriarteuniversidad.es 
El impacto de las Redes Sociales en el panorama audiovisual y mediático actual alcanzado hace ya tiempo la magnitud necesaria como para considerarlo, incluso académicamente, como un elemento definitorio de la comunicación contemporánea. Con millones de usuarios, cabe plantearse de qué forma las Redes Sociales actúan como agentes uniformadoras y canonizadoras de pensamientos y comportamientos, de prácticas y costumbres, de gustos artísticos y, por qué no, de sentimientos religiosos e ideologías políticas. El objeto de esta ponencia es analizar el papel que cumplen la Enseñanza y las Redes Sociales en la construcción de identidades, tanto en la configuración de características personales como en la creación de colectivos a través de la Red. Se parte de una hipótesis de trabajo basada en la aplicación de las Redes Sociales a la enseñanza superior, desarrollada en un momento crítico en la formación de la identidad personal como la adolescencia aunque se imbrica con la propia de la sociedad-. Para ello se realizará una profundización historiográfica, buscando las fuentes sociológicas que influyen en la construcción de la identidad personal a través de la comunicación.

244 - Análisis de la gestión de comunicación interna en las organizaciones de Loja-Ecuador - Fernando Mora Universidad Técnica Particular de Loja (Ecuador) ferchomora1995@gmail.com y Laura Sánchez - Universidad técnica Particular de Loja (Ecuador) - lesanchezc@hotmail.com

La presente investigación busca conocer la gestión de comunicación interna que realizan las empresas e instituciones de Loja en Ecuador. La Titulación de Relaciones Públicas de la Universidad Técnica Particular de Loja trabajó con 21 estudiantes, con quienes, a través de la observación directa y entrevistas a los responsables de comunicación o Dircom, se obtuvo datos importantes que revelan la realidad de esta disciplina en el día a día de la labor administrativa. Se han realizado varias investigaciones en Ecuador para determinar el uso de herramientas y canales para llegar a los públicos internos, sin embargo, no significa que se esté dando la atención que se debe a la comunicación interna para desarrollar sentido de pertenencia y compromiso en los colaboradores. Se levantó información de las estrategias y tácticas usadas en la gestión de comunicación interna de 
Comunicación y Música: mensajes, manifestaciones y negocios

14 empresas e instituciones con diversas actividades económicas, seis de las cuales son de carácter público y ocho del privado. En las organizaciones es primordial el uso de herramientas para gestionar la comunicación con su público interno, puesto que desarrollan capacidades de diálogo, de discusión y debate, de interacción y comunicación y, en general de información. Entre los canales más usados están el correo electrónico, el teléfono y las reuniones. Además, el tipo de comunicación que prevalece es el formal, puesto que la propia organización la establece, siguiendo los niveles jerárquicos y el orden establecido.

245 - Modelo educomunicativo para la inclusión escolar de estudiantes en condición del espectro autista en el nivel universitario. - Sonia Esquivel Ochotorena, Doctorante de Comunicación e Innovación Educativa de la Facultad de Ciencias de la Comunicación de la Universidad Autónoma de Nuevo León, correo: sony_esq@hotmail.com y Julieta Flores Michel, Asesora de tesis, Facultad de Ciencias de la Comunicación de la Universidad Autónoma de Nuevo León, correo: julietaflores@hotmail.com

Actualmente en México la matrícula de estudiantes con trastornos del espectro autista (TEA) está aumentando sensiblemente en el nivel básico, debido en gran parte a la implementación del Nuevo Modelo Educativo del Gobierno Federal, el cual tiene como uno de sus ejes principales a la inclusión. Por lo tanto, se espera que vaya en aumento la inclusión de estos estudiantes en los siguientes niveles como mediosuperior e incluso superior. La inclusión educativa de los estudiantes con TEA en nivel superior debe de ser de manera integral, esto es desde el trámite de inscripción a la universidad hasta la incorporación a sus clases, sin dejar atrás la convivencia que tendrá con docentes y compañeros en el transcurso de su estancia. En este proceso educativo intervienen diferentes áreas y departamentos como: admisiones, servicios escolares, coordinación académica, cuerpo docente hasta llegar al grupo de alumnos que convivirán con el estudiante con TEA todos los días. Con esta investigación se busca crear un modelo educomunicativo que involucre a todas las áreas principales de la 
universidad para poder mejorar la inclusión de los estudiantes con TEA.

246 - Social Media y su necesidad para el manejo de la reputación de las marcas en el Ecuador - Msc. Gabriela García Moreno - Universidad UTE - jgarcia@ute.edu.ec - Quito, Ecuador y Msc. Darío Ron - Unir - dron@gsg.com.ec - Quito Ecuador

La comunicación se mueve a un ritmo muy vertiginoso, la presencia de la tecnología y los altos índices de penetración de internet en los hogares ecuatorianos, obligan a estar conectados con las nuevas tendencias comunicacionales, más aún ahora con las nuevas generaciones como los denominados "milenials", "centenials" y los que aún están por descubrirse. La sociedad vive una realidad que es marcada por la adaptación de la forma en cómo se genera el proceso de comunicación para emitir mensajes o la eficacia que se pretende conseguir al transmitirlos. El facilitar los lazos de contacto o mejorar los tiempos de respuesta en la transmisión de información permite la llegada del Social Media es decir sitios específicos en los cuales la información puede llegar a ser pública o privada pero orientada a un enfoque social en el cual se comparte contenidos. Su uso se masifica cada vez más gracias a los smarthphones, a la aparición de aplicaciones que facilitan el acceso, interés y compartición de información, a la aparición de redes sociales que permiten estar cada vez más cerca de los otros y conocer más de la cibersociedad. Las marcas necesitan comunicarse con esta nueva sociedad invlucrada al ciber espacio, para lograr llegar a formar parte de su vida, es así como el término publicidad digital ahora es el más utilizado en el mundo ya que ha pasado a formar parte de una de las formas de comunicación socialmente más aceptadas y multitarget.

247 - Las Relaciones Públicas Internacionales en la movilidad académica - Dra. Yolanda López- Lara - Universidad Autónoma de Nuevo León yolandalopezlara_uanl@hotmail.com yolanda.lopezlr@uanl.edu.mx, M.C. Francisco Gerardo Valdez Rincón- Universidad Autónoma de Nuevo León 
Comunicación y Música: mensajes, manifestaciones y negocios

francisco.valdezr@uanl.mx pacovaldez68@hotmail.com y Lic.

Daniel García Santos- Universidad Autónoma de Nuevo León-

Dagas07@hotmail.com

A través del tiempo, las distancias se han hecho más pequeñas conforme se crean planes de acción de diferente índole para vincular a las personas y las organizaciones. Las instituciones de educación superior (IES), no se han quedado atrás para fortalecer y ampliar la formación de sus estudiantes, han creado estrategias académicas sustentadas en las Relaciones Públicas a nivel nacional e internacional, facilitando la vinculación y acompañamiento de sus alumnos en el transcurso del proceso de movilidad académica. La Universidad Autónoma de Nuevo León (UANL), se ha aplicado en gestionar convenios con múltiples instituciones educativas y por ello, la Coordinación de Intercambió Académico de la Facultad de Ciencias de la Comunicación, decidió realizar un estudio que determine la incidencia de los programas de relaciones públicas en la formación académica de los estudiantes a nivel internacional con una retrospectiva de cinco años a 2018. El estudio es de corte cualitativo con un alcance descriptivo y un diseño metodológico de estudio de caso intrínseco, donde su premisa evidencie que: el modelo bidireccional de las relaciones públicas gestionado entre instituciones de educación superior a nivel internacional, potencia el éxito de los programas enfocados en la movilidad académica de la UANL. Las técnicas de recolección de datos seleccionadas fueron: revisión de documentos institucionales, realización de matrices de información de diez semestres, consulta de fuentes de primera y segunda mano, además de entrevistas estructuradas con los sujetos interesados en realizar un intercambio académico. Los hallazgos más importantes muestran las relaciones públicas internacionales que se han gestionado con las universidades receptoras de los países de España, Chile, Perú, Argentina, Colombia, así como el impacto en la formación académica en las unidades de aprendizaje cursadas en esas instituciones entre otros datos. Keywords: Relaciones Públicas; Intercambio académico; Internacionalización; Comunicación Organizacional; formación académica. 
248 - Los Códigos de Ética en la Prensa Regiomontana y de la Ciudad de México - Sergio Manuel de la Fuente Valdez.Universidad Autónoma de Nuevo León sermanfuen@yahoo.com, Yolanda López Lara.-Universidad Autónoma de Nuevo León yolandalopezlara_uanl@hotmail.com y Daniel García Santos. Universidad Autónoma de Nuevo León dagas07@hotmail.com

Fue realizada una investigación cuantitativa, descriptiva, no experimental y exploratoria, relacionada con los códigos de ética, en los principales periódicos de Monterrey, Nuevo León y la Ciudad de México. El universo: los diarios regiomontanos y capitalinos. La muestra son aquéllos que cuentan con un código de ética y la selección de la muestra son los diarios que más completo y extenso tienen su código de ética. El objetivo general: valorar la moral, la ética, los valores universales y generales presentes en los lineamientos de cada código objeto de estudio. Objetivos Específicos: cuantificar el total de lineamentos generales de cada código; determinar el lenguaje utilizado (tipo, estilo y tono) intuir la presencia de la moral y la ética en los lineamientos; detectar los valores universales y generales en los lineamientos establecidos; localizar las semejanzas y diferencias entre los códigos de ética analizados. El instrumento de medición: el análisis de contenido para el cual se elaboró un manual de contenido, estructurado en categorías y subcategorías. Principales hallazgos: la cantidad de lineamientos de cada código de ética analizado oscila entre ocho y doce. El lenguaje utilizado es coloquial, con rasgos de culto. El estilo es el periodístico y pedagógico. El tono es persuasivo, sutil, amable y convincente. Existe la presencia implícita y explícita de la moral y la ética profesional, en cuanto a las buenas conductas y continuidad de las buenas costumbres, buenos comportamientos en el quehacer periodístico y en la toma de decisiones. Los valores universales presentes en los códigos de ética: la paz, la justicia, democracia, solidaridad, igualdad, principalmente. Los valores generales localizados: responsabilidad, honestidad, prudencia, disciplina, entre otros. Son muchas las semejanzas localizadas entre los códigos de ética analizados y muy pocas las diferencias, tanto en los códigos de ética de los diarios regiomontanos, como en los periódicos capitalinos. 
Comunicación y Música: mensajes, manifestaciones y negocios

249 - Colaboración y comunidad virtual en las prácticas de autogestión en la música independiente de Quito - Andrea Angulo Granda - CIESPAL

La escena musical independiente de Quito atraviesa por un proceso de crecimiento, debido a, entre otros factores, la apropiación de las nuevas tecnologías por parte de los artistas como medio para difundir sus propuestas y crear lazos sociales. La presente ponencia abordará este fenómeno a partir de los casos de Guardarraya, Munn y La Máquina Camaleón, que fueron analizados dentro de la tesis de posgrado Del Escenario al Ciberespacio: colaboración y comunidad digital en las nuevas prácticas de visibilización de tres bandas de música alternativa de Quito en redes sociales, presentada para la obtención del título de Magíster en Estudios de la Cultura de la Universidad Andina Simón Bolívar. En la exposición se trabajará sobre la circulación de contenido cultural a través del trabajo colaborativo y la inteligencia colectiva, por medio de las perspectivas de Pierre Lévy, Howard Rheingold y Henry Jenkins. Además, se dará un breve contexto sobre la situación actual de la escena musical alternativa de Quito. Con este preámbulo se hablará sobre los proyectos que desarrollaron las agrupaciones estudiadas y las estrategias utilizadas en redes sociales para visibilizar sus obras y crear vínculos con otros actores culturales y los públicos. Finalmente se compartirán las conclusiones de la investigación, alrededor del uso de los nuevos medios como canal de socialización para ganar reconocimiento.

250 - Las webs de los Ayuntamientos en Aragón: propuestas para la mejora de la calidad y la transparencia en la información y comunicación municipal - Nerea Vadillo Bengoa-Universidad San Jorge-nvadillo@usj.es; Lucas Morales Domínguez Universidad de La Laguna (Tenerife)lucasmoralesdominguez@gmail.com; Alfonso Boullón Sabínalfonsoboullon@escueladeartetenerife.es

El objetivo de esta comunicación es presentar un informe que refleje con exactitud la forma en la que los consistorios aragoneses han adoptado la legislación vigente en España en materia de transparencia, y cómo éstos suelen informar a su ciudadanía de todos aquellos 
indicadores considerados esenciales para mejorar la calidad democrática y la promoción de un modelo de gobierno abierto, que garantice una nueva relación entre las Administraciones Públicas aragonesas y los ciudadanos. Así, en este trabajo mostramos los resultados obtenidos de la tercera ola de evaluaciones de los 731 municipios aragoneses, realizada entre octubre de 2016 y junio de 2017 , a la luz de los cuales, proponemos una seria de propuestas de mejora. La metodología empleada para el desarrollo de esta investigación es la del proyecto Mapa Infoparticipa (http://mapainfoparticipa.com/ index/home/). De carácter cuantitativo, se centra en el análisis de 52 indicadores repartidos en 2 grupos y 5 sub-grupos. El primer grupo sobre "Transparencia de la Corporación" está compuesto por tres cuestiones: quiénes son los representantes políticos, cómo gestionan los recursos colectivos y cómo se gestionan los recursos económicos: presupuestos, salarios, contrataciones, subvenciones. El segundo grupo, "Información para la Participación", responde a dos interrogantes: Qué información proporcionan sobre el municipio y la gestión de los recursos colectivos y qué herramientas se ofrecen para la participación ciudadana.

251 - Sitios web y las redes sociales como plataformas de comunicación corporativa de las agencias de comunicación de Colombia - Vanessa Karina Duque Rengel - Universidad Técnica Particular de Loja - vkduque@utpl.edu.ec y Ulianova Elizabeth Espinosa Jiménez - Universidad Técnica Particular de Loja - ulianova_1995@hotmail.es

Los medios sociales y plataformas web han permitido principalmente a las empresas posicionar su marca y tener un acercamiento e interacción con sus públicos a través de la generación y publicación de contenidos como: noticias, imágenes, vídeos, etc., estos son segmentados para que cada stakeholder pueda acceder a la información de su interés. Partiendo de la importancia de la gestión de estas herramientas digitales, nace esta investigación, cuyo fin fue el análisis de las redes sociales y portales web de las agencias de comunicación de Colombia. Para su estudio se seleccionó una muestra de 10 agencias distribuidas en todo el país. Se aplicó una metodología de enfoque mixto, es decir se utilizó técnicas cualitativas (observación y 
Comunicación y Música: mensajes, manifestaciones y negocios

documentación para la creación de base de datos de dichas empresas) y cuantitativas (se desarrolló y aplicó una ficha de investigación, en el caso de los portales web; y la herramienta en línea Fanpage Karma, en el caso de las redes sociales institucionales). En el estudio se analizó como es la comunicación en los sitios web y medios sociales de las Agencias, las herramientas digitales tanto internas como externas, con qué redes cuenta, la comunicación estratégica, cultura corporativa y posicionamiento web. Como resultado se obtuvieron datos de gran relevancia para visibilizar el estado actual de las Agencias de Comunicación y Marketing del país de estudio, que su mayoría poseen páginas web y redes sociales, mientras que unas pocas se manejan con el sitio web principal de la organización con sede en otro país; en lo que respecta a las redes sociales la mayoría de las empresas tienen sus cuentas activas en Facebook (100\%), Twitter (100\%), Instagram (70\%) y YouTube $(90 \%)$, en esta última no existen muchas publicaciones y las ya existentes tienen el mismo contenido publicado en las otras redes.

252 - Impacto de la crisis estructural de la inversión publicitaria en la televisión convencional - Eva Sánchez-Amboage Universidad de A Coruña, España eva.sanchez.amboage@udc.es; Matías Membiela-Pollán Universidad de A Coruña, España - matias.membiela@udc.es; Valentín-Alejandro Martínez-Fernández - Universidad de A Coruña, España - valentin.martinez@udc.es y Óscar Juanatey Boga - Universidad de A Coruña, España oscar.juanatey@udc.es

Introducción. La inversión publicitaria, en el mercado mediático español, muestra preocupantes síntomas de una desaceleración. En el caso de la televisión, el hecho de que desde 1993 no haya dejado de ostentar el liderazgo la convierte en un medio referente para poder identificar tendencias. Objetivo y metodología. Este trabajo efectúa un análisis descriptivo de la inversión publicitaria en televisión; para ello se han manejado los datos correspondientes a los informes anuales de Infoadex, con un marco temporal específico correspondiente a la última década, pero con una mirada retrospectiva situada en los últimos veinticuatro años. Resultados. Se advierte un significativo cambio de comportamiento de los anunciantes en el destino de sus inversiones, 
cuyas razones no estriban únicamente en el impacto de las tecnologías en el consumo de productos informativos y de entretenimiento audiovisual. Discusión y conclusiones. El medio, en términos generales, se encuentra sumido en un importante proceso de transformación y muestra una tendencia poco halagüeña sin que se haya encontrado un nuevo modelo de negocio orientado a situarse nuevamente en el foco de atención del anunciante.

253 - La moda en la política española durante la campaña para las elecciones al Parlamento de Andalucía de 2018 - Ruth Gómez de Travesedo Rojas, Universidad de Málaga ruthgtr@uma.es; Marta Gil Ramírez, Universidad de Málaga martagr@uma.es

La presente investigación pretende responder al interrogante, tradicionalmente formulado en el imaginario colectivo de la sociedad, de si la forma de vestir de los distintos políticos que nos representan expresa valores ideológicos. Para ello se ha analizado, durante la primera semana de la campaña, la vestimenta de los cuatro candidatos a presidir la Junta de Andalucía en los comicios del 2 de diciembre; con el objeto de poder establecer si existe una tendencia o patrón que vincule la indumentaria empleada por los representantes públicos con una determinada ideología, ya sea de derechas o de izquierdas. La metodología empleada ha sido el análisis de contenido, a través de una imagen de cada uno de los cuatro representantes políticos desde el 16 al 22 de noviembre. En total 28 imágenes en las que se analizan variables como el color de la ropa, uso de chaqueta o corbata, estilismos serios o informales, entre otros aspectos.

254 - Activismo feminista contra el acoso sexual callejero:

nuevas tecnologías y estrategias digitales para el empoderamiento de las mujeres - Irene Liberia Vayá Universidad de Sevilla - iliberia@us.es

El acoso sexual callejero es una forma de violencia contra las mujeres que ayuda a perpetuar el sistema desigual de poder propio de las sociedades patriarcales. En los últimos años esta estrategia de dominación masculina se ha convertido en objeto de importantes 
Comunicación y Música: mensajes, manifestaciones y negocios

debates sociales, mediáticos, políticos y también jurídicos, llegándose a aprobar en varios países -Bélgica, Portugal, Perú, Chile...- leyes para perseguir y sancionar como delitos penales las diferentes formas de acoso sexual en el espacio público. Los avances legislativos en esta materia, pero también la implementación de otra clase de iniciativas políticas e institucionales como la creación de Observatorios contra el acoso en las calles, son fruto de la lucha permanente de los movimientos feministas contra estos tipos de violencia. Así, el feminismo ha logrado incluso someter a escrutinio público supuestas "tradiciones" o "prácticas culturales" tan arraigadas como el piropo. Entre las estrategias político-culturales que mujeres individuales y colectivos activistas han venido desarrollando para combatir el acoso sexual callejero, se encuentra especialmente el uso de dispositivos móviles, medios digitales y redes sociales con distintos objetivos. En primer lugar, la documentación y denuncia pública de situaciones concretas de acoso; en segundo término, el afrontamiento directo de los agresores, y por último, la contribución a la toma de conciencia colectiva mediante la difusión de los ataques y eventualmente de las respuestas por parte de las víctimas. Partiendo de esta realidad, el presente trabajo realiza un estudio exploratorio de las estrategias feministas de empoderamiento tecnológico contra el acoso callejero. Para ello, se lleva a cabo un análisis textual crítico de un conjunto de casos que conforman una muestra de tipo teórico, y que permiten abordar las principales herramientas y tácticas empleadas por el activismo feminista para visibilizar la envergadura real de este problema social y coadyuvar a su erradicación.

255 - El impacto ejercido por la publicidad de las marcas de lujo en los hábitos de consumo de los lectores de la revista Vogue Sergio Luque - Universidad Europea Miguel de Cervantes sluque@uemc.es

Las revistas de moda son una muestra del Periodismo Especializado, dedicando secciones no solo a la producción periodística, sino a mostrar páginas de publicidad relacionadas con productos de moda y lujo, a su vez, asociados a grandes holdings empresariales como LVMH y Kering. La investigación analiza la influencia que ejerce la publicidad de las marcas de lujo pertenecientes al grupo LVMH y Kering en los 
comportamientos de consumo de los lectores de la revista Vogue. Para ello se han analizado 12 números editados entre julio 2017 y julio de 2018, período que comprende la presentación de las nuevas colecciones de otoño-invierno (septiembre 2017) y de primaveraverano (febrero 2018). La elección de la revista Vogue no es casual ya que es la primera revista especializada en moda y tendencias femeninas más leída en España, según datos facilitados por el EGM en el último estudio realizado en mayo de 2018. La metodología de investigación basada en el análisis de contenido y el cruce de variables SPSS analiza aspectos como el número de veces que la revista muestra la publicidad de las mismas empresas, la visibilidad de ciertas firmas frente a otras, además de medir la forma de consumir productos de lujo entre los lectores de Vogue en relación a la publicidad. Como parte de resultados se confirma que el impacto ejercido por la publicidad de marcas de lujo entre los lectores de Vogue no es completo, sino que resulta compartido por otros estímulos causados por empresas de moda ajenas a la industria del lujo. 
Comunicación y Música: mensajes, manifestaciones y negocios
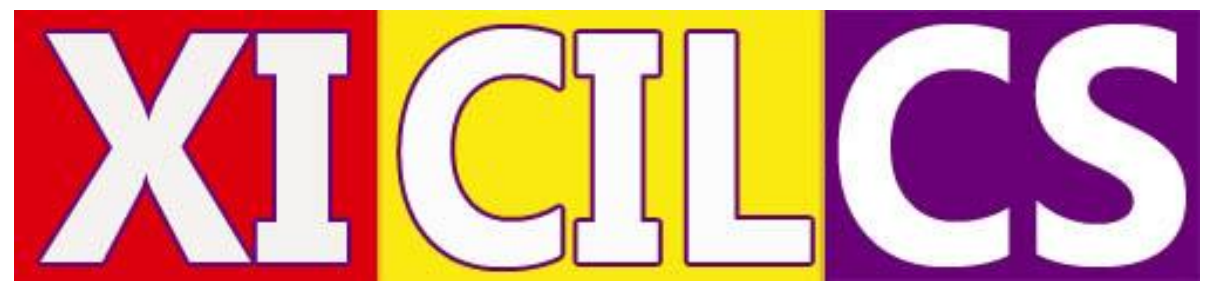

\section{9 - XI Congreso Internacional Latina de Comunicación Social XI CIL CS}

\section{Previsión de fechas:}

Primeros días del mes de diciembre de 2019:

Adelanto de fechas

Lunes, 2 de diciembre

Martes, 3

Miércoles, 4

Jueves, 5 de diciembre

Toda la información estará desde enero de 2018 en esta url: http://www.revistalatinacs.org/19SLCS/2019_convocatoria_11_ congreso.html

Nota: este libro recoge todos los resúmenes recibidos hasta el momento de su cierre. Los recibidos después aparecen en la web del congreso

Edita: Sociedad Latina de Comunicación Social - La Laguna, Tenerife.

\section{Editores:}

Francisco Javier Herrero

Milena Trenta

(Coord.)

(Coord.)

Vanessa Rodríguez Breijo

Ciro Hernández

Alberto Ardèvol Abreu

Samuel Toledano Buendía 


\section{Libro colectivo del $10^{\circ}$ Congreso Internacional Latina de Comunicación Social}

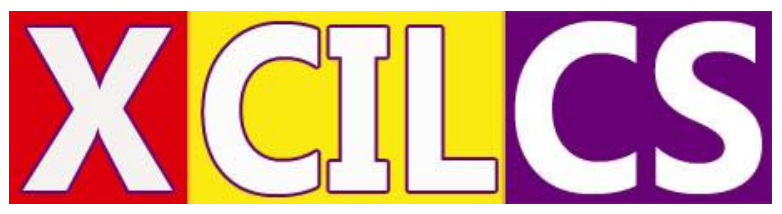

El CD adjunto contiene el libro colectivo originado en el $9^{\circ}$ Congreso Internacional Latina de Comunicación Social, celebrado en la Facultad de Ciencias Políticas, Sociales y de la Comunicación de la Universidad de La Laguna (Tenerife, Canarias; España) en diciembre de 2018.

Todos los trabajos contemplados en ese libro colectivo han sido previamente sometidos a evaluación por los moderadores de las correspondientes mesas de debate donde se presentaron.

Se trata del mismo documento que igualmente aparece en el sitio web: http://www.revistalatinacs.org/18SLCS/cac145.html

El disco está provisto de un pequeño programa de autoarranque: al ser introducido en la disquetera se abre por defecto la página http://www.revistalatinacs.org/18SLCS/libro-colectivo.html

En algunos sistemas puede que no funcione el autoarranque: en esos casos, una vez abierto el disco, hágase doble clic en el fichero http://www.revistalatinacs.org/18SLCS/libro-colectivo.html

Para localizar a un autor, hay que utilizar la herramienta "Buscar en esta página”. Ese $\mathrm{CD}$, como obra colectiva, dispone de los siguientes registros, impresos en su carátula:

ISBN: 978-84-16458-94-3 y D.L.: TF- 800-2018

DOI: $10.4185 /$ CAC145 